\title{
GARDEN-MAKING
}

\section{L.H. BAlLEY}

THE GARDEN-CRAFT SERIES 
WWRARP

OF THE

UNIVERSITY

cLIFORNI

\section{LAMDSCAPE ARCH}




$$
=
$$

Presening por Waiten C. Gition Architoof 


\section{The Garden= $\mathbb{C r a f t}$ Setieg}

EDITED BY L. H. BAILEY

\section{GARDEN-MAKING}


. The 


\title{
GARDEN - MAKING
}

\author{
SUGGESTIONS FOR THE \\ Utilizing of Home Grounds
}

L. H. BAILEY

Aided by L. R. TAFT, Professor of Horticulture in the Agricultural College of Michigan; F. A. WAUGH, Professor of Horticulture in the University of Vermont; and ERNEST WALKER, Assistant in Horticulture and Entomology in Clemson College, South Carolina

HIFTH EDITION, REVISED

\author{
Newo 19ork \\ THE MACMILLAN COMPANY \\ LONDON: MACMILLAN \& CO., LTD \\ 1901 \\ All rights reserved
}




\section{LANDSCAPE ARCH}

Coprizight, 1898,

By L. H. BAILEY

SAt up and electrotyped January, 1898

Reprinted May 1898, January, 1899

February and December, 1901

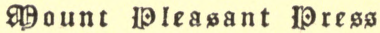

J. Horace McFarland CoMpany

HARRISBURG. PENNSYLVANIA 


\section{$\$ 393$

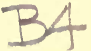 \\ OUTLINE
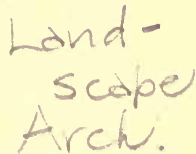

SECTION I

PAGES

$1-119$

Gentral Advice .

The mental ideal, 1- $\bar{i}$. Preparation of the land, $7-37$ (the saving of moisture, $\tau$; preparing the undersoil, 12; preparation of the surface, 18; tools for weeding and subsequent tillage, 24). Sowing and planting, 37-58 (sowing the seed, 37; transplanting young seedlings, 38 ; transplanting established plants and seeds, 44). Winter protection of plants, 58-67. The forcing of plants, 67-88 (coldframes, 71; hotbeds, 75). Insects and diseases, 88-103. Protecting plants from animals, 103-108. Keeping records of the plantation, 109-114. Enriching the land 114-119.

\section{SECTION II}

The Plan of the Pllace

The picture in the landscape, 121-158 (containing a free sketch of what a picture is and how it may be obtained, contrasts of massed and scattered plantings, discussions of flower-beds, borders, types of bushes for lawn effects, weeping and odd trees, the use of poplars and willows, and the fundamentals of landscape gardening). Various specific examples, 158-176 (containing plans of yards and lawns). How to make the improvements, 177-210 (discusses grading, terraces, banks, sunken fences, filling about trees, walks and drives, curbs, suburban streets, edges of walks and drives, materials for walks and drives, etc.; making the plan, 195; making a lawn, 199). 


\section{SECTION III}

Planting the Orankntal Grotend

Choosing the plants, 211-220. List of ornamental plants which are hardy in Central Michigan, 220240. Plants for floral effects (by Ernest Walker), 241-301, containing: (1) Remarks on flower-beds, 241; (2) Carpet-bedding, 243; (3) Edgings and mass-beds, 251; (4) Annuals, 255; (5) Bulbous and tuberous plants, 267; (6) Hardy herbaceous perennials, 278; (7) Hardy climbing plants, 291; (8) The rose, 294.

\section{SECTION IV}

The Frute Plantation

The arrangement of the fruit-garden, 302-305. Advice upon the growing of fruit (by Professor Taft), 305-34 7 , containing: (1) Northern orehard fruits (the apple, 308, the pear, 313 , the plum, 317 , the peach, 319 , apricots and necturines, 323 , the cherry, 323); (2) Sub-tropical fruits (the orange, 325 , the olive, 329 , the pineapple, 330 , banana, 330, fig, 331); (3) The grape, 332; (4) Small-fruits (red and black raspberries 336 ; blackberries and dewberries, 339 ; currants, 340 ; gooseberries, 342 ; strawberries, 343 ).

\section{SECTION V}

The Vegetable Garden.

Plans for the kitchen-garden, 348-352. The vegetable garden (by Professor Waugh), 353-385, containing: (1) Root crops and tubers (beet, carrot, parsnip, potato, etc.), 353; (2) Alliaceous group (onions, etc.), 360 ; (3) Leguminous group (beans and peas), 361 ; (4) Brassicaceous group (cabbage, kale, etc.), 364 ; (5) Solanaceous group (tomatoes, egg-plant, 
etc.), 369 ;

(6) Cucurbitaceous group (cucumber, PAGES melon, squash, etc.), 373; (7) Salad plants and potherbs (lèttuce, cress, endive, spinach, etc.), 376 ; (8) Miscellaneous vegetables (celery, asparagus, sweet corn, etc.), 380; (9) Sweet herbs, 385.

\section{SECTION VI}

Seasonal Reminders $386-411$

General remarks, 386-389. Calendars for the North (by T. Greiner), 389-401. Calendars for the South (by H. W. Smith and F. H. Burnette), 402-411

INDEX ........ 413-417 


$$
\text { - }
$$




\section{GARDEN-MAKING}

\section{Section I}

\section{GENERAL ADVICE}

Every family can have a garden. If there is not a foot of land, there are porches or windows. Wherever there is sunlight, plants may be made to grow; and one plant in a tin-can may be a more helpful and inspiring garden to some mind than a whole acre of lawn and flowers may be to another. The satisfaction of a garden does not depend upon the area, nor, happily, upon the cost or rarity of the plants. It depends upon the temper of the person. One must first seek to love plants and nature, and then to cultivate that happy peace of mind which is satisfied with little. $\mathrm{He}$ will be happier if he has no rigid and arbitrary ideals, for gardens are coquettish, particularly with the novice. If plants grow and thrive, he should be happy; and if the plants which thrive chance not to be the ones which he planted, they are plants nevertheless, and nature is satisfied with them. We are apt to covet the things 
which we cannot have; but we are happier when we love the things which grow because they must. A patch of lusty pigweeds, growing and crowding in luxuriant abandon, may be a better and more worthy object of affection than a bed of coleuses in which every spark of life and spirit and individuality has been sheared out and suppressed. The man who worries morning and night about the dandelions in the lawn will find great relief in loving the dandelions. Each blossom is worth more than a gold coin, as it shimmers in the exuberant sunlight of the growing spring, and attracts the bees to its bosom. Little children love the dandelions: why may not we? Love the things nearest at hand; and love intensely. If I were to write a motto over the gate of a garden, I should choose the remark which Socrates made as he saw the luxuries in the market, "How much there is in the world that I do not want!"

I verily believe that this paragraph which I have just written is worth more than all the advice with which I intend to cram the succeeding pages, notwithstanding the fact that I have most assiduously extracted this advice from various worthy but, happily, long-forgotten authors. Happiness is a quality of a person, not of a plant or a garden; and the anticipation of joy in the writing of a book may be the reason why so many books on garden-making have been writ- 
ten. Of course, all these books have been good and useful. It would be ungrateful, at the least, for the present writer to say otherwise; but books grow old, and the advice becomes too familiar. The sentences need to be transposed and the order of the chapters varied, now and then, or interest lags. Or, to speak plainly, a new book of advice upon handicraft is needed in every decade. There has been a long and worthy procession of these handbooks,-Gardiner \& Hepburn, M'Mahon, Cobbett-original, pungent, ubiquitous Cobbett!-Fessenden, Bridgeman, Sayers, Buist, and a dozen more, each one a little richer because the others had been written. But even the fact that these books pass into oblivion does not deter another hand from making still another venture!

I expect, then, that every person who reads this book will make a garden, or will try to make one; but if only tares grow where roses are desired, I must remind the reader that at the outset I advised pigweeds. The book, therefore, will suit everybody, - the experienced gardener, because it will be an echo of what he already knows; and the novice, because it will apply as well to a garden of burdocks as of onions.

A garden is the personal part of an estate, that area which is most intimately associated with the private life of the home. Originally, the garden was the area inside the enclosure or lines of forti- 
fication, in distinction to the unprotected area or fields which lay beyond; and this latter area was the particular domain of agriculture. This book understands the garden to be that part of the premises which is devoted to ornament, and to the growing of vegetables and fruits either for the home consumption or for market. The garden is, therefore, an ill-defined demesne; but the reader must not make the mistake of defining it by dimensions, for one may have a garden in a flower-pot or on a thousand acres. In other words, this book believes that every bit of land which is not used for buildings, walks, drives and fences, should be planted. What we shall plant, - whether sward, lilacs, thistles, cabbages, pears, chrysanthemums or tomatoes,-we shall talk about as we proceed.

The only way to keep land perfectly unproductive is to keep it moving. The moment the owner lets it alone, the planting has begun. In my own garden, this first planting is of pigweeds. These are usually followed, the next year, by ragweeds, then by docks and thistles, with here and there a start of clover and grass; and it all ends in June-grass and dandelions. Nature does not allow the land to remain bare and idle. Even the bank where plaster and lath were dumped two years ago is now luxuriant with burdocks and sweet clover; and yet people who pass that dump every day say that they can 
grow nothing in their own yard because the soil is so poor! Yet, I venture that those same persons furnish most of the pigweed seed which I use on my garden.

The lesson is that there is no soil,-where a house would be built,-so poor that something cannot be grown. If burdocks will grow, something else will grow; or if nothing else will

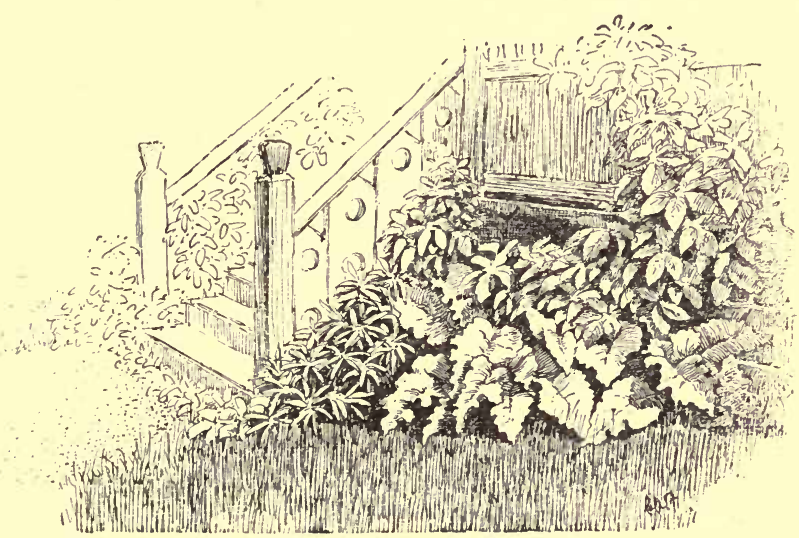

1. The ornamental burdock.

grow, then I prefer burdocks to sand and rubbish. The burdock is one of the most striking and decorative of plants, and a good piece of it against a building or on a rough bank is just as useful as some plant which costs money and is difficult to grow. I had a good clump of it under my study window, and it was a great comfort, but the man would persist in eutting it down when 
he mowed the lawn. When I remonstrated, he declared that it was nothing but burdock; but I insisted that, so far from being burdock, it was really Lappa major, since which time the plant has enjoyed his utmost respect. And I find that most of my friends reserve their appreciation of a plant until they have learned its name and connections.

The dump-heap which I mentioned has a surface area of nearly one-hundred and fifty square feet, and I find that it has grown over two hundred good plants of one kind or another this year. This is more than my gardener accomplished on an equal area, with manure and water and a man to help. The difference was that the plants on the dump wanted to grow, and the imported plants in the garden did not want to grow. It was the difference between a willing horse and a balky one. If a person wants to show his skill, he may choose the balky plant: but if he wants fun and comfort in gardening, he had better choose the willing one.

I have never been able to find out when the burdocks and mustard were planted on the dump; and I am sure that they were never hoed or watered. Nature practices a wonderfully rigid economy. For nearly half the summer she even refused rain to the plants, but still they thrived; yet I staid home from a vacation one summer that I might keep my plants from dying. I have 
since learned that if the plants in my borders cannot take care of themselves for a few weeks, they are little comfort to me.

\section{PREPARATION OF THE LAND}

Having now discussed the most essential elements of gardening, we may give our attention to such minor features as the preparation of the land, fertilizing, and the details of planting. Almost any land contains enough food for the growing of good crops, but the food elements may be chemically unavailable, or there may be insufficient water to dissolve them. It is too long a story to explain the philosophy of tillage at this place, and the reader who desires to make excursious into this delightful subject should consult King on "The Soil" and Roberts on "The Fertility of the Land." The reader must accept the bare statement that tilling the land makes it productive.

The SAving of yoISTURE.-Proper preparation and tillage also put the land in such condition that it holds the water of rainfall. Land which is very hard and compact may shed the rainfall, particularly if it is sloping and if the surface is bare of vegetation. If the hard-pan is near the surface, the land cannot hold much water, and any ordinary rainfall may fill it so full that it overflows, or puddles stand on the surface. Upon land which is in good tilth, the water of rainfall sinks away, 
and is not visible as free water. As soon as the moisture begins to depart from the superincumbent atmosphere, evaporation begins from the surface of the land. Any body which is interposed between the land and the air checks this evaporation: this is why there is moisture underneath a board. It is impracticable, however, to floor over the garden with boards, but any covering will have the same effect, but in different degree. A covering of sawdust or leaves or dry ashes_will prevent the loss of moisture. So will a covering of dry earth. Now, inasmuch as the land is already covered with earth, it only remains to loosen up a layer or stratum on top in order to secure our mulch.

All this is only a roundabout way of saying that frequent shallow surface tillage conserves moisture. The comparatively dry and loose mulch breaks up the eapillary connection between the surface soil and the under soil, and while the mulch itself may be useless as a foraging ground for roots, it more than pays its keep by its preventing of the loss of moisture; and its own soluble plantfoods are washed down into the lower soil by the rains. As often as the surface becomes compact, the mulch should be renewed or repaired by the use of the rake or cultivator or harrow. People are deceived by supposing that so long as the surface remains moist, the land is in the best possible condition; but a moist surface only means that water is rapidly passing off into the 
atmosphere. A dry surface means that little evaporation is taking place. A finely raked bed is dry on top; but the footprints of the cat remain moist for days, for the animal packed the

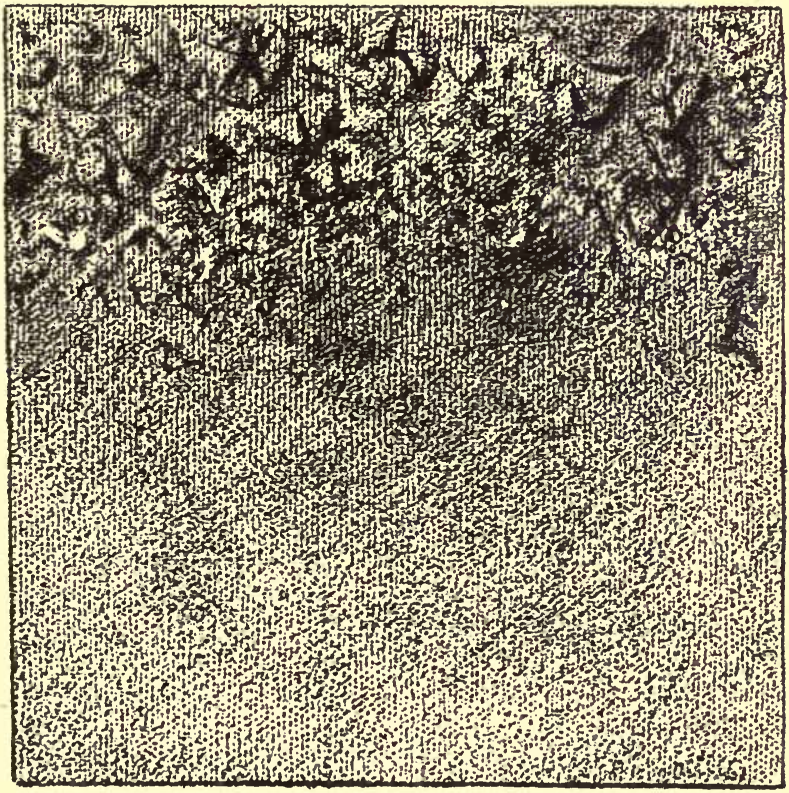

2. Ideal preparation of land.

soil wherever it stepped and a capillary connection was established with the water reservoir beneath. Gardeners advise firming the earth over newly planted seeds to hasten germination. This is essential in dry times; but what we gain 
in hastening germination we lose in the more rapid evaporation of moisture. The lesson is that we should loosen the soil as soon as the seeds have germinated, to reduce the evaporation to the minimum. Large seeds, as beans and peas, can be planted deep and have the earth firmed about them, and then the rake may be applied to the surface to stop the rise of moisture before it reaches the air.

The illustrations, adapted from Roberts' "Fertility," show good and poor preparation of the land. Fig. 2 is a section of land twelve inches deep. The under soil has been finely broken and pulverized and then compacted. It is mellow but firm, and is an excellent water reservoir. Three inches of the surface is a mulch of loose and dry earth. Fig. 3 shows an earth-mulch, but it is too shallow; and the under soil is so open and cloddy that the water runs through it.

This subject of the conservation of moisture is so important that I wish to present it in various ways. The following extract, although written for children ("A Children's Garden"), may still further explain the matter: "I wonder if you have a watering-pot? If you have, put it where you cannot find it, for we are going to water this garden with a rake! We want you to learn, in this little garden, the first great lesson in farming, -how to save the water in the soil. If you learn that much this summer, you will know more than 
many old farmers do. You know that the soil is moist in the spring when you plant the seeds. Where does this moisture go? It dries up, - goes off into the air. If we could cover the soil

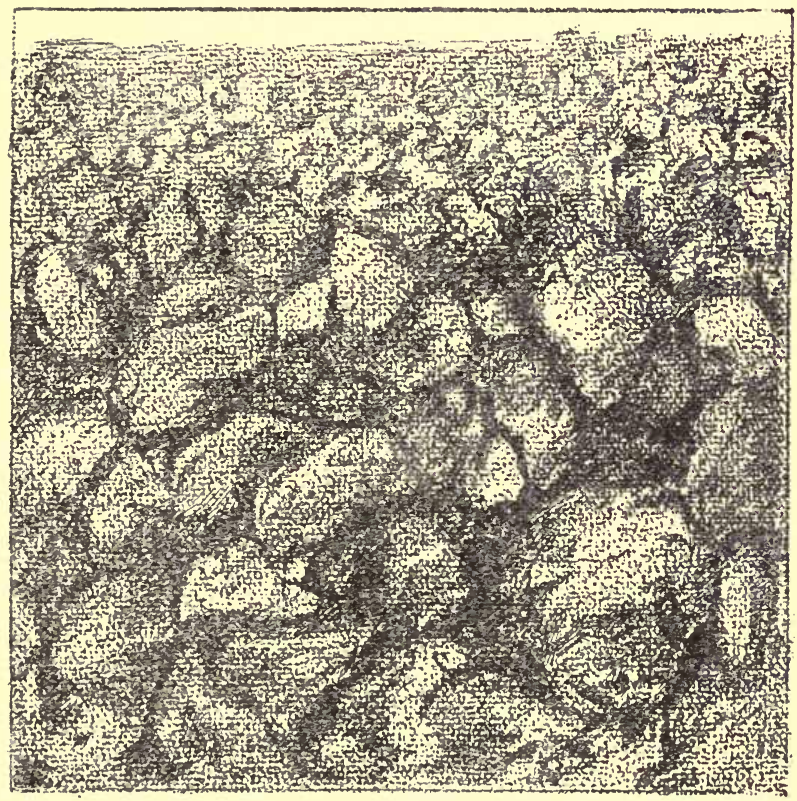

3. Slovenly preparation of land.

with something, we should prevent the moisture from drying up. Let us cover it with a layer of loose, dry earth! We will make this covering •by raking the bed every few days,-once every week anyway, and oftener than that if the top of the 
soil becomes hard and crusty, as it does after a rain. Instead of pouring water on the bed, therefore, we will keep the moisture in the bed. If, however, the soil becomes so dry in spite of you that the plants do not thrive, then water the bed. Do not sprinkle it, but water it. Wet it clear through at evening. Then in the morning, when the surface begins to dry, begin the raking again to keep the water from getting away. Sprinkling the plants every day or two is one of the surest ways of spoiling them."

Preparing THE UNDER-SOIL.-The first step in the preparation of land, after it has been thoroughly cleared and subdued of forest or previous vegetation, is to attend to the drainage. All land which is springy, low and "sour," or which holds the water in puddles for a day or two following heavy rains, should be thoroughly underdrained. Draining also improves the physical condition of the soil, even when the land does not need ditching for the removal of superfluous water. In hard lands, it lowers the water-table, or tends to loosen and aërate the soil to a greater depth, and thereby enables it to hold more water without injury to plants. Drainage is particularly useful in dry but hard garden lands, because these lands are often in sod or permanently planted, and the soil cannot be broken up by deep tillage. Tile drainage is permanent subsoiling.

In most regions, well baked cylindrical tiles 
make the best and most permanent drains. The ditches should not be less than two and one-half feet deep, and three or three and one-half feet is a better depth. In most garden areas, drains may be laid with profit as often as every thirty feet. Give all drains a good and continuous fall. For single drains, and for laterals not over four hundred or five hundred feet long, a two and onehalf inch tile is sufficient, unless much water must be carried from swales or springs. In stony countries, flat stones may be used in place of tiles, and persons who are skillful in laying them make drains as good and permanent as those constructed of tiles. The

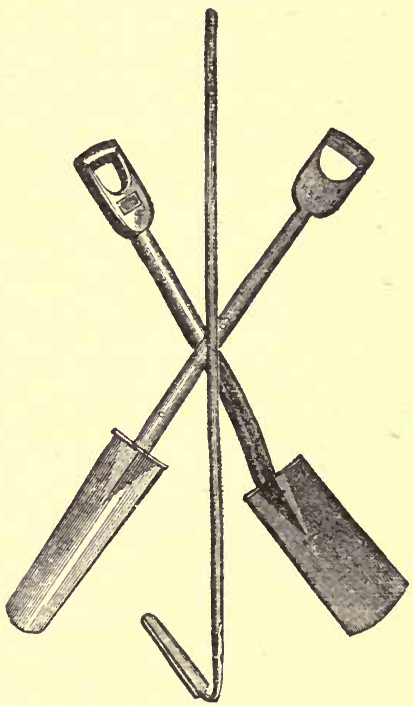

4. Ditching tools.

tiles or stones are covered with sods, straw or paper, and the earth is then filled in. This temporary cover keeps the loose dirt out of thetiles, and by the time it is rotted the earth has settled into place.

In small places, ditching must ordinarily be done wholly with hand tools. A common spade 
and pick are the implements usually employed, although a spade with a long handle and narrow blade, as shown in Fig. 4, is very useful for excavating the bottom of the ditch. In most cases, much time and muscle are wasted in the use of the pick. If the digging is properly done, a spade can be used to cut the soil, even in fairly hard clay land, with no great difficulty. The essential

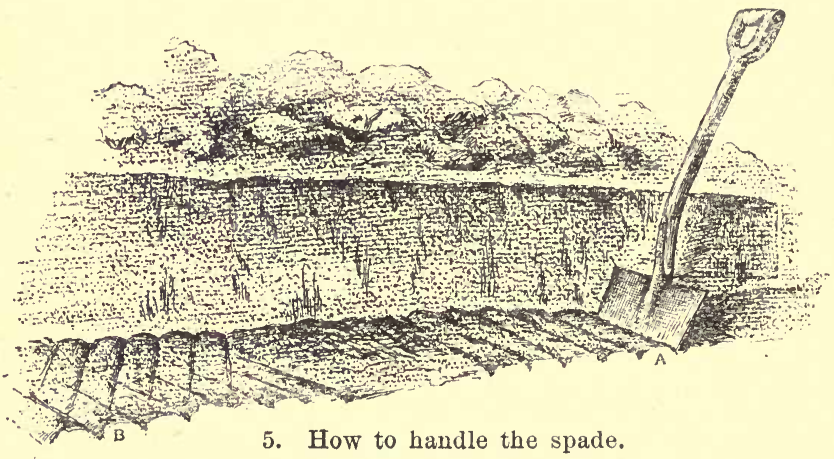

point in the easy use of the spade is to so manage that one edge of the spade always cuts a free or exposed surface. The illustration (Fig. 5) will explain the method. When the operator endeavors to cut the soil in the method shown at $A$, he is obliged to break both surfaces at every thrust of the tool; but when he cuts the slice diagonally, first throwing his spade to the right and then to the left, as shown at $\mathrm{B}$, he cuts only one surface. and is able to make progress without the expendi- 
ture of useless effort. These remarks will apply, with almost equal force, to any spading of the land.

- In large areas, horses may be used to facilitate the work of ditching. There are ditching plows, which, however, need not be discussed here; but three or four furrows can be thrown, out in either direction with an ordinarily strong plow, and a sub-soil plow can be run behind to break up the hard-pan, and this may reduce the labor of digging as much as one-half. When the excavating
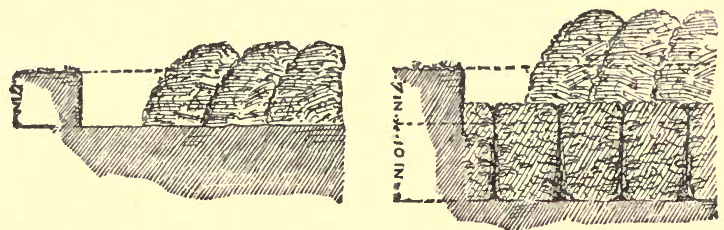

6. Trenching with a spade.

is completed, the bottom of the ditch is evened up - by means of a line or level, and the bed for the tiles is prepared by the use of a goose-neck scoop, shown in Fig. 4. It is very important that the outlets of drains be kept free of weeds and litter. If the outlet is built up with mason work, so as to hold the end of the tile intact, very much will be added to the permanency of the drain.

Although under-draining is the most important means of increasing the depth of the soil, it is not always practicable to lay drains through garden lands, either because the lands are already 
planted or built upon, or because suitable outlets can not be found. In such cases, recourse is had to very deep preparation of the land, either every year or every two or three years. In small garden areas, this deep preparation will ordinarily be done by trenching with a spade. This operation of trenching consists in breaking up the earth two spades deep. Fig. 6 explains the operation. The section at the left shows a single spading, the

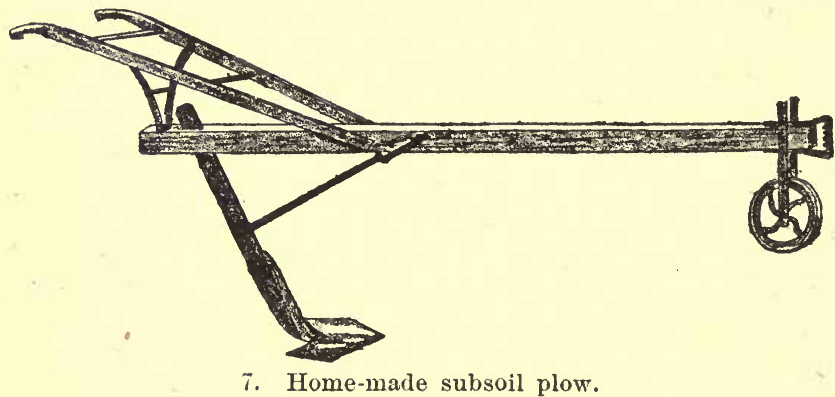

earth being thrown over to the right, leaving the subsoil exposed the whole width of the bed. The section at the right shows a similar operation, so far as the surface spading is concerned, but the subsoil has also been cut as fast as it has been exposed. This under soil is not thrown out upon the surface, and usually it is not inverted; but a spadeful is lifted and then allowed to drop so that it is thoroughly broken and pulverized in the manipulation. In all lands which have a hard 
and high subsoil, it is almost essential to practice trenching if the best results are to be obtained; and this is especially true when deep-rooted plants, like beets, parsnips and other root-crops, are desired.

In places which ean be entered with the plow, deep and heavy plowing to the depth of seven to ten inches may be desirable upon hard lands, especially if such lands cannot be plowed very

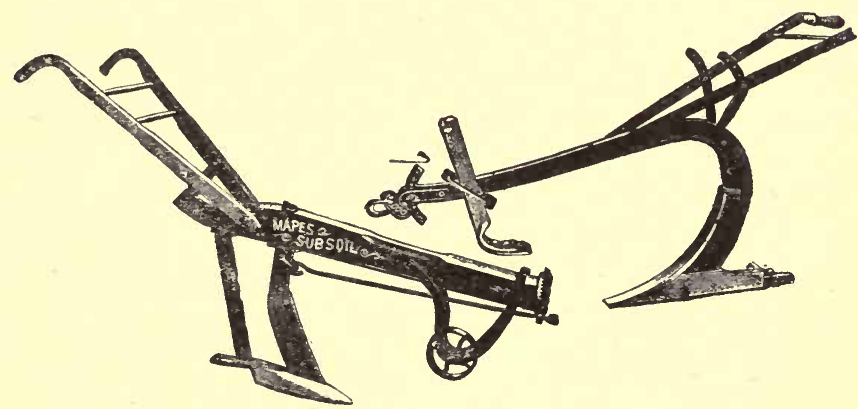

8. Types of subsoil plows.

often; and the depth of the pulverization is often extended by means of the subsoil plow. This subsoil plow does not turn a furrow, but a second team draws the implement behind the ordinary plow, and the bottom of the furrow is loosened and broken. Fig. 7 shows a home-made subsoil plow, and Fig. 8 two types of commercial tools. It must be remembered that it is the hardest lands which need subsoiling, and that, therefore, the subsoil plow should be exceedingly 
strong. Fig. 9 shows various types of model surface plows. The one shown at the upper lefthand is considered by Roberts, in his "Fertility of the Land," to be the ideal general-purpose plow, as respects shape and method of construction.

Preparation of the SURFace.-Every pains should be taken to prevent the surface of the land from becoming crusty or baked, for we have al-

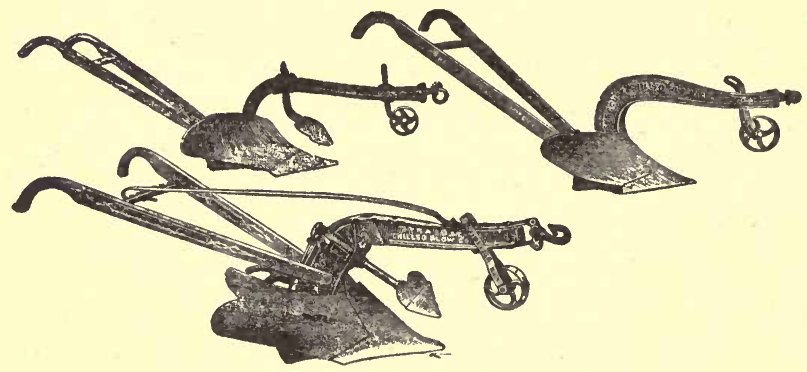

9. Types of model plows.

ready found that the hard surface establishes a capillary connection with the moist soil beneath, and is a means of passing off the water into the atmosphere. Loose and mellow soil also has more free plant-food, and provides the most congenial conditions for the growth of plants. If the soil is a stiff clay, it is often advisable to plow it or dig it in the fall, allowing it to lie rough and loose all winter, so that the weathering may pulverize and slake it. If the clay is very 
tenacious, it may be necessary to throw leafmold or litter over the surface before the spading is done, to prevent the soil from running together or cementing before spring. With mellow and loamy lands, however, it is ordinarily best to leave the preparation of the surface until spring.

In the preparation of the surface, the ordinary hand tools, or spades and shovels, may be used. If, however, the soil is mellow, a fork is a better tool than a spade, from the fact that it does not slice the soil, but tends to break it up into smaller and more irregular masses. The ordinary spading-fork, with strong, flat tines, is a most serviceable tool; but a good spading-fork may be made from an old mauure fork by cutting down the tines, as shown in Fig. 10. It is essential that the soil should not be sticky when it is prepared, as it is likely to become hard and baked and the physical condition greatly injured. However, land which is too wet for the reception of seeds may still be thrown up loose with a spade or

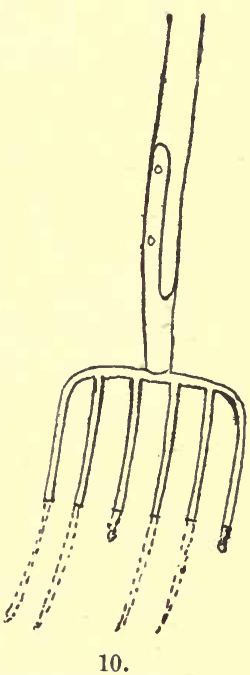

Improvised fork. fork and allowed to dry, and after two or three days the surface preparation may be completed with the use of the hoe and the rake. In ordi- 
nary soils, the hoe is the tool to follow the spading-fork or the spade, but for the final preparation of the surface a steel garden-rake is the ideal tool.

In areas which are large enough to admit horse tools, the land can be fitted more economically by means of the various types of harrows and cultivators which are to be had of any dealer in agricultural implements. The type of machine which is to be used must be determined wholly

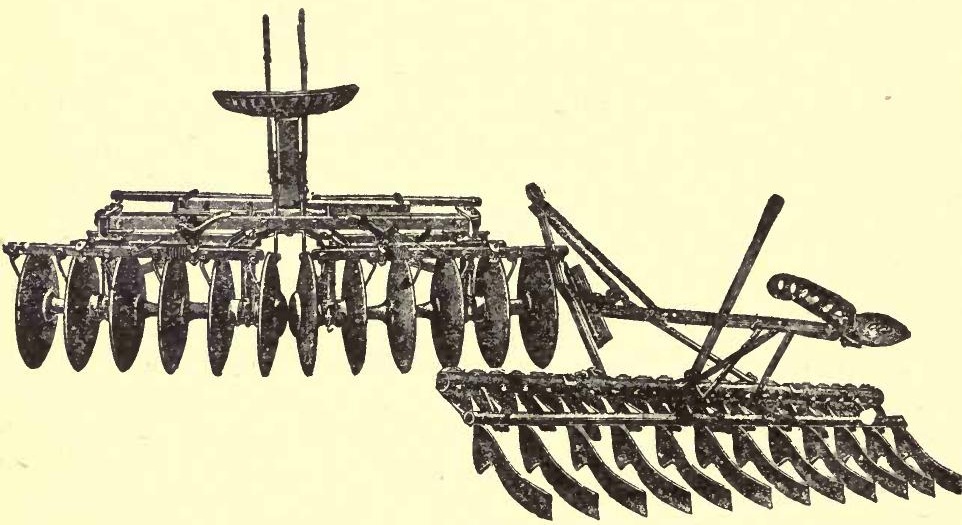

11. Disc and Acme harrows, for the first working of hard or cloddy land.

by the eharacter of the land and the purposes for which it is to be fitted. Land which is hard and clodidy may be reduced by the use of the dise or Acme harrows, shown in Fig. 11, but lands which are friable and mellow may not need such heavy 
and vigorous tools. Upon these mellower lands, the spring-tooth harrow, types of which are shown in Fig. 12, may follow the plow. Upon very hard lands, these spring-tooth harrows may follow the

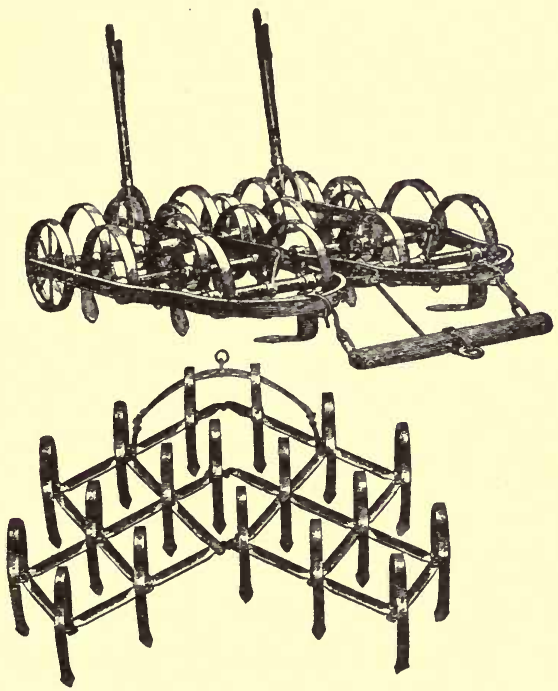

12. Spring-tooth harrows, for working hard or mediumhard lands, and to follow the disc or Acme.

disc and Acme types. The final preparation of the land is accomplished by light implements of the pattern shown in Fig. 13. These spike-tooth smoothing-harrows do for the field what the handrake does for the garden-bed. If it is desired to put a very fine finish upon the surface of the ground by means of horse tools, implements like 
the Breed or Wiard weeder may be used. These are constructed upon the principle of a springtooth horse hay-rake, and are most excellent, not only for fitting loose land for ordinary seeding, but also for subsequent tillage.

In areas which cannot be entered with a team, various one-horse implements may be used to do the work which is done by heavier tools in the field. The spring-tooth cultivator, shown at the right in Fig. 14, may do the kind of work which

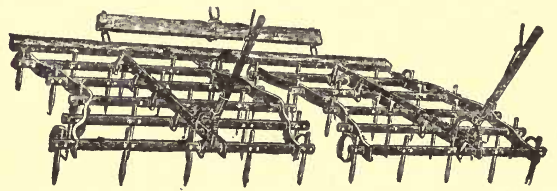

13. Spike-tooth harrow, for the final fitting of the land.

the spring-tooth harrows are expected to do upon larger areas; and various adjustable spike-tooth cultivators, two of which are shown in Fig. 14, are useful for putting a finish upon the land. These tools are also available for the tilling of the land when the crops are growing. The spring-tooth cultivator is a most useful tool for cultivating raspberries and strawberries, and other large-area crops.

For still smaller areas, in which horses cannot be used and which are still too large for tilling wholly by means of hoes and rakes, various types of wheel-hoes may be used. These implements 
are now made in great variety of patterns, to suit any taste and almost any kind of tillage. For the best results, it is essential that the wheel should be large and with a broad tire, that it may override obstacles. Fig. 15 shows an excellent type of wheel-hoe with five blades,

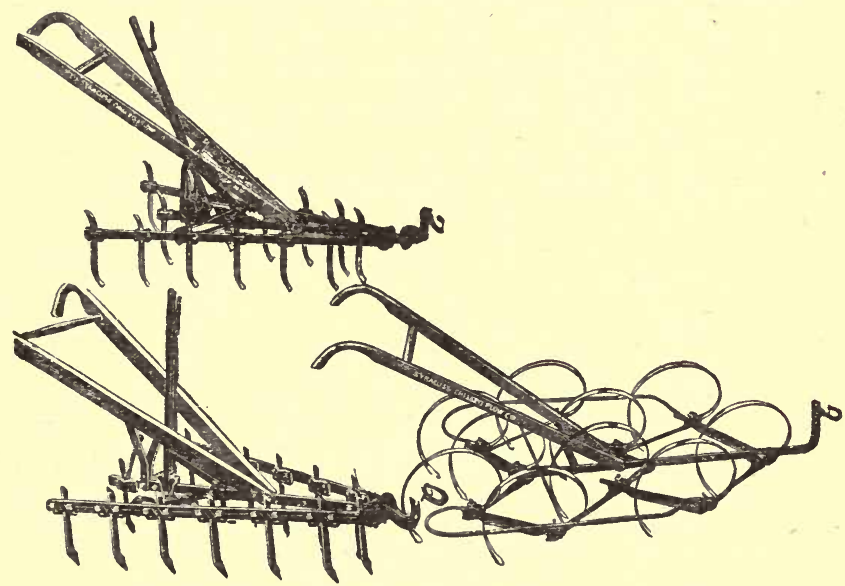

14. Spike-tooth and spring-tooth cultivators, to be used where harrows cannot be employed.

and Fig. 16 shows one with a single blade and which may be used in very narrow rows. Twowheeled hoes are often used, particularly when it is necessary to have the implement very steady, and they may be used to straddle the rows of low plants. Many of these wheel-hoes are provided with various types of blades, so that the implement may be adjusted to many kinds of 
work. Nearly all the weeding of beds of onions and like plants can be done by means of these wheel-hoes, if the ground is well prepared in the beginning; but it must be remembered that they are of comparatively small use in very hard and cloddy and stony lands.

TOOLS FOR WEEDING AND SUBSEQUENT TILLAGE.-Any of the cultivators and wheel-hoes are as useful for the crop as for the land, but there

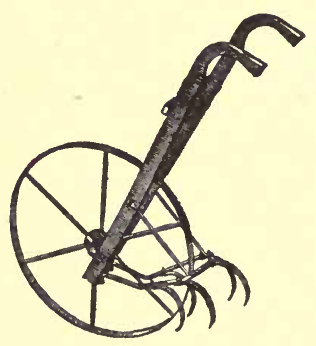

15. Good type of wheel-hoe.

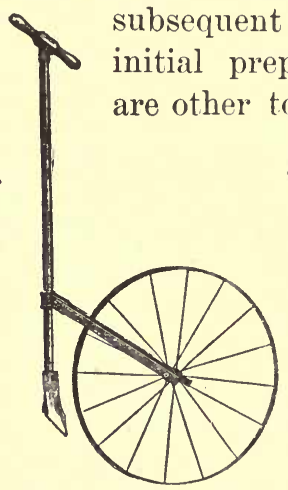

16. A single-blade wheel-hoe.

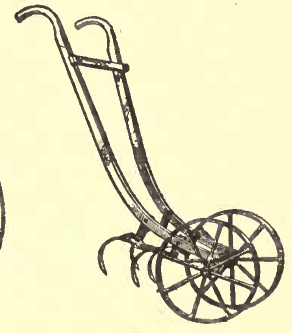

17. Double wheelhoe, useful in straddling the row.

greatly facilitate the keeping of the plantation in order. The common rectangular-bladed hoe is so thoroughly established in the popular mind that it is very difficult to introduce new patterns, even though they may be intrinsically superior. As a general-purpose tool, it is no doubt true that a common hoe is better than any of its 
modifications, but there are various patterns of hoe-blades which are greatly superior for special uses. The great width of the common blade does not allow of its being used in very narrow rows or very close to delicate plants, and it does not allow of the deep stirring of the soil in narrow spaces. It is also difficult to enter hard ground with such a broad face. Various pointed blades have been introduced from time to time, and al-

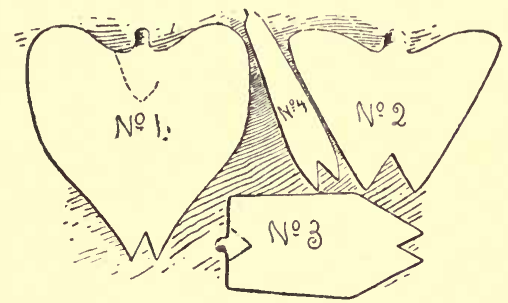

18. Double-pointed hoes.

most any of them have distinct merit. Some persons prefer two points to the hoe, as shown in Marvin's blades, in Fig. 18. Persons who followed the entertaining writings of Mr. A. B. Tarryer (a pseudonym for a well-known experimenter) in "American Garden," a few years back, will recall the great variety of implements which he advised for the purpose of extirpating his hereditary foes, the weeds. A variety of these blades and tools is shown in Figs. 19 and 20. Mr. Tarryer contends that the wheel-hoe is much too clumsy an affair to allow of the pursuit of an individ- 
ual weed. While the operator is busy adjusting his machine and manipulating it about the corners of the garden, the quack-grass has escaped
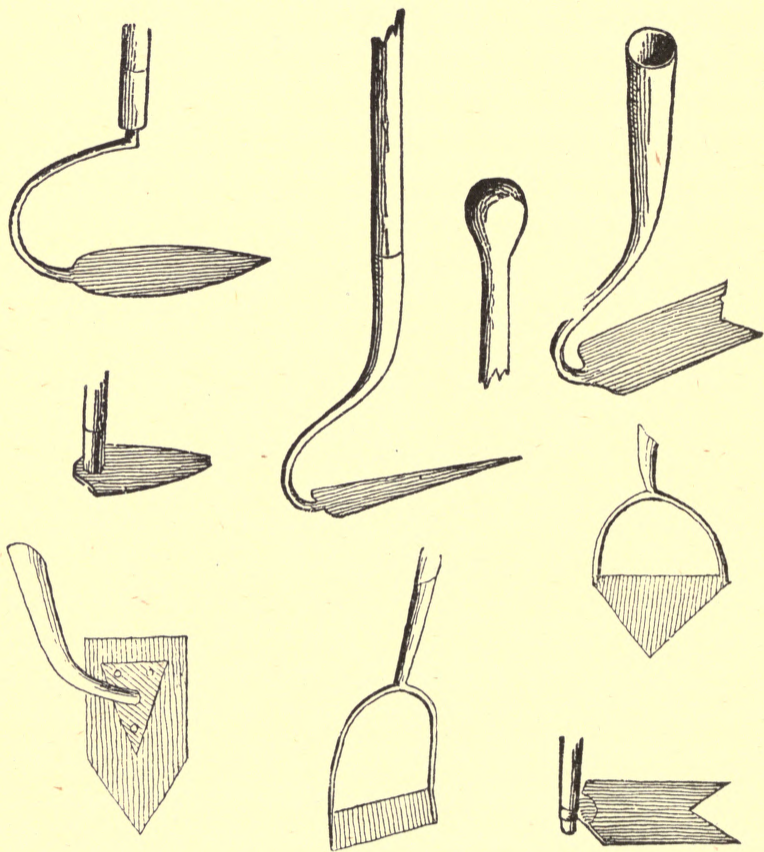

19. Some of the Tarryer hoes.

over the fence or has gone to seed at the other end of the plantation. Upon this point Mr. Tarryer pronounces as follows:

"Scores of times during the season, the ten or 


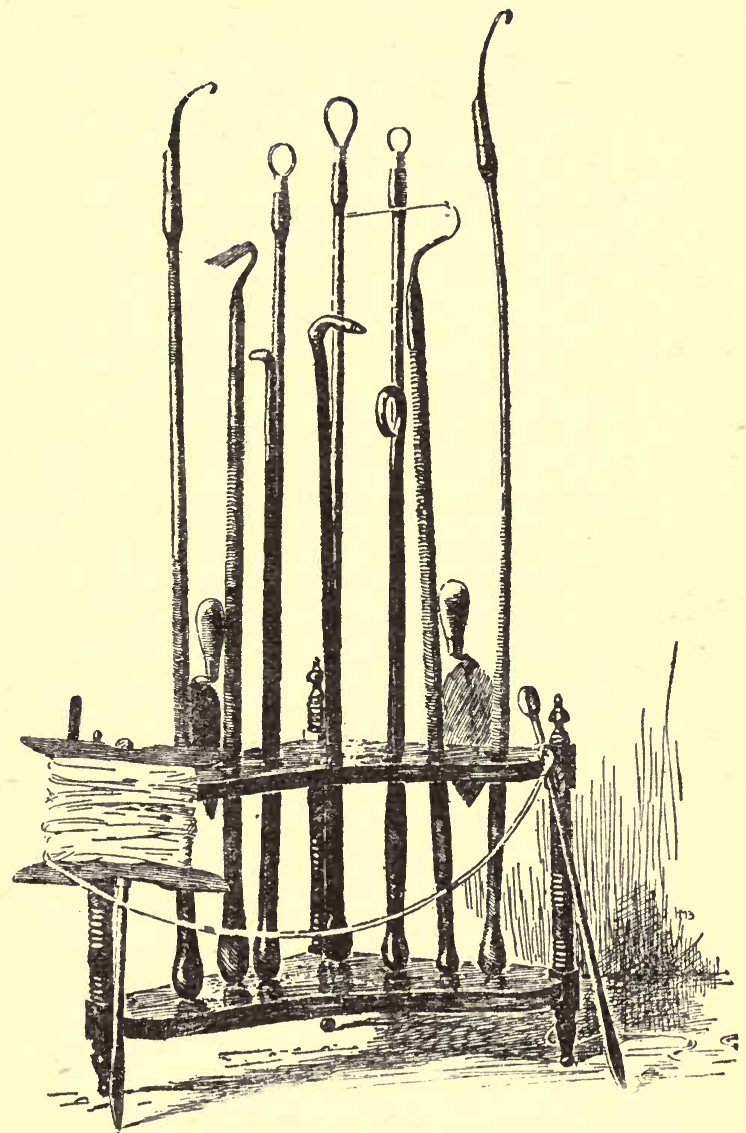

20. A stack of gardening weapons, comprising some of Tarryer's weeding spuds and thimbles. 
fifteen minutes one has to enjoy in the flower, fruit and vegetable garden-and that would suffice for the needful weeding with the hoes we are celebrating-would be lost in harnessing horses or adjusting and oiling squeaky wheel-hoes, even if everybody had them. The 'Garden' is not big enough, nor my patience long enough, to give more than an inkling of the unspeakable merits of these weapons of society and civilization. When Mrs. Tarryer was showing twelve or fifteen acres of garden with never a weed to be seen, she valued her dozen or more of these light implements at five or ten dollars daily; whether they were in actual use or adorning the front hall, like a hunter's or angler's furniture, made no difference. But where are these millennial tools made and sold? Nowhere. They are as unknown as the Bible was in the dark ages, and we must give a few hints towards manufacturing them.

"First, about the handles. The ordinary dealer" or workman may say these knobs can be formed on any handles by winding them with leather; but just fancy a young maiden setting up her hoe meditatively and resting her hands and chin upon an old leather knob to reflect upon something that has been said to her in the garden, and we shall perceive that a knob by some other name would smell far sweeter. Moreover, trees grow large enough at the butt to furnish all the knobs we 
want-even for broom-sticks-though sawyers, turners, dealers and the public seem not to be aware of it; yet it must be confessed we are so far gone in depravity that there will be trouble in getting those handles. *****

"In a broadcast prayer of this public nature, absolute specifications would not be polite. Black walnut and butternut are fragrant as well as beautiful timber. Cherry is stiff, heavy, durable, and, like maple, takes a slippery

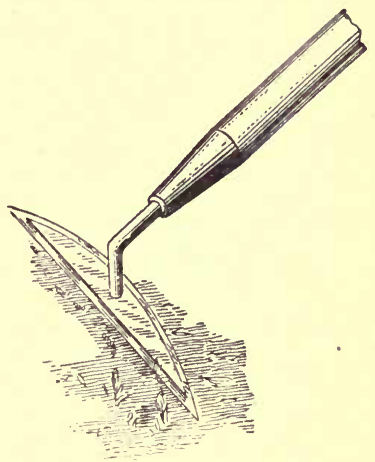

21. A scarifier. polish. For fine, light handles, that the palm will stick to, butt cuts of poplar or cottonwood cannot be excelled, yet straight-grained ash will bear more careless usage. "The handles of Mrs. Tarryer's hoes

22. Home-made scarifier.

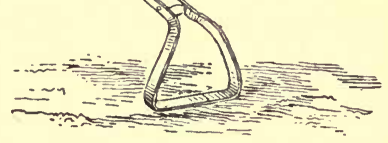

are never perfectly straight. All the bayonet class bend downward in use half an inch or 
more; all the thrust-hoe handles bend up in a regular curve (like a fiddle-bow turned over)

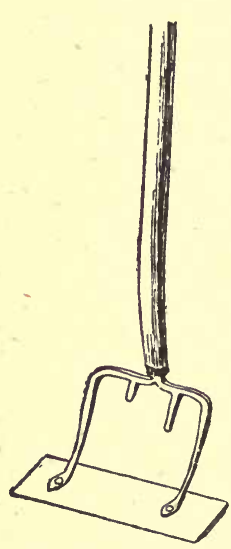

23. Home-made two or three inches. Unless they are hung right, these hoes are very awkward things. When perfectly fit for one, they may not fit anotherthat is, a tall, keen-sighted person cannot use the hoe that is just fit for a very short one. $* *$ Curves in the handles throw centers of gravity where they belong. Good timber generally warps in a handle scarifier or scraper. about right, only

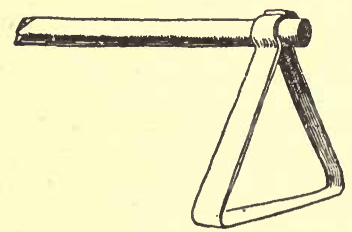

25. Home-made hand weeder.

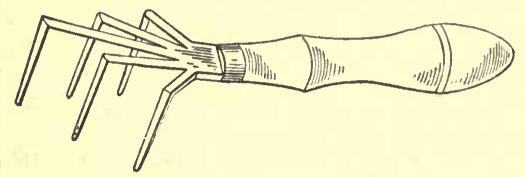

26. Finger-weeder. implement - mak- 24. One ers and babes in of the best weeding may not hand-weedknow when it is made fast right side up in the hoe.

"There are plenty of thrust - hoes in market, such as they are. Some have malleable iron sockets and bows -heavier to the 
buyer and cheaper to the dealer-instead of wroughtiron and steel, such as is required for true worth."

For many purposes, tools which scrape or scarify the surface are preferable to hoes which dig up the ground. Weeds may be kept down by cutting them off, as in walks and often
in flower-beds, rather than by rooting
them out. Fig. 21 shows such a tool,

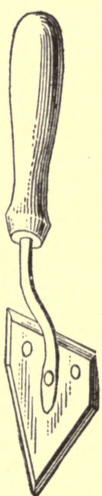

28. Improvised trowel.

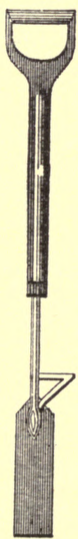

29. Weedspud.

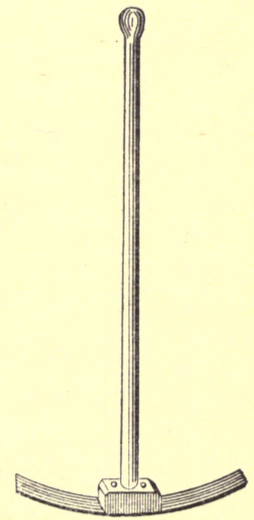

30. Weed-cutter.
27. Long handled trowel.

and a home-made implement answering the same purpose is illustrated in Fig. 22. This latter tool is easily made from strong band-iron. Another type is suggested in Fig. 23, which represents a slicing-hoe made by fastening a sheet of metal to the tines of a broken fork. 
For small beds of flowers or vegetables, handweeders of various patterns are essential to easy (1) and efficient work. One of the best patterns, with long and short handles, is shown in Fig. 24. Another style, which may be made at home of hoop-iron, is drawn in Fig. 25. A finger-weeder is shown in Fig. 26. Many patterns of hand-weeders are in the market, and other forms will suggest themselves to the operator.

Small hand-tools for digging, as trowels, dibbers and spuds, may be had of dealers. In buying a trowel it is economy to pay an extra price and secure a steel blade with a strong shank which runs through the entire length of the handle. One of these tools will last several years and may be used in hard soil, but the cheap trowels are generally hardly worth the buying. One of the steel imple-

31. Weed-cutter. ments may be 32. Hand-roller. secured to a

long handle; or the blade of a broken trowel may be utilized in the same way (Fig. 27). A very good trowel may also be made from a discarded 
blade of a mowing-machine (Fig. 28), and it answers the purpose of a hand-weeder in many places.

Weed-spuds are shown in Figs. 29, 30, 31.

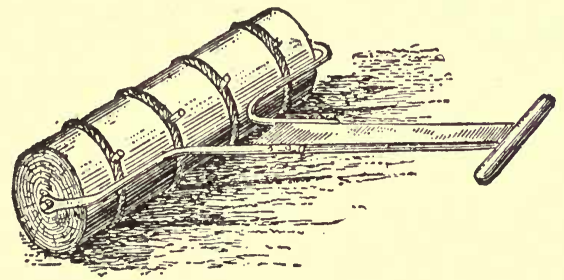

33. Roller and marker.

The first is particularly serviceable in cutting docks and other strong weeds from lawns and

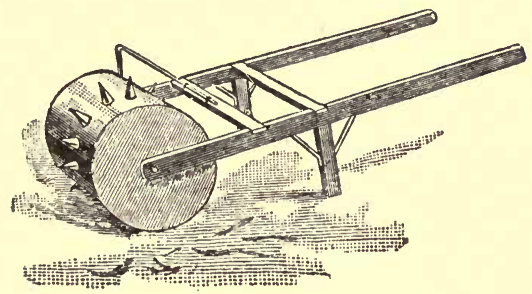

34. Roller and marker.

pastures. It is provided with a brace to allow it to be thrust into the ground with the foot.

It is often essential that the land be compacted after it has been spaded or hoed, and some kind 
of hand-roller is then useful. Very efficient iron rollers are in the market, but a good one

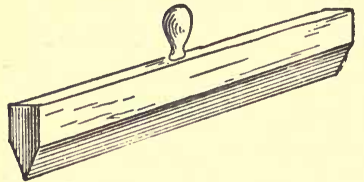

35. Marking-stick. can be made from a hard chestnut or oak log, as shown in Fig. 32. It, should be remembered that when the surface is hard and compact, water escapes from it rapidly, and plants may suffer for moisture upon arrival of warm weather. The roller is useful in two ways-to compact the under-surface, in which

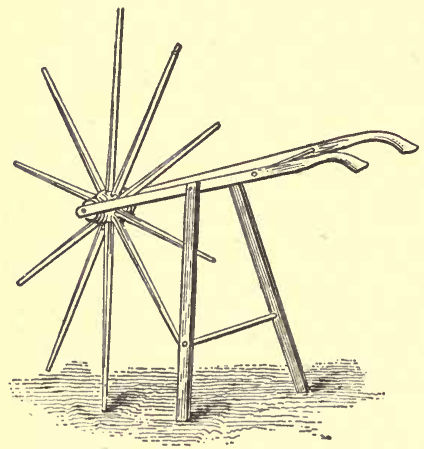

36. Tool for spacing out plants.

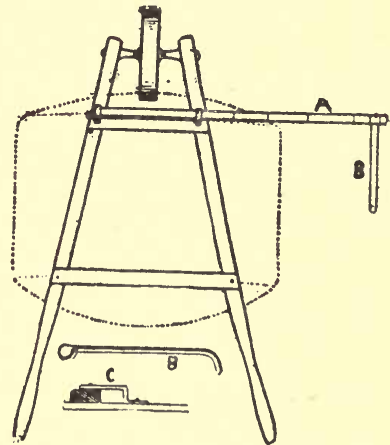

37. Barrow rigged with a marker.

case the surface should be again loosened as soon as the rolling is done; and to firm the earth about seeds (page 10) or the roots of newly-set plants. 
A marker may often be combined with the roller to good advantage, as in Fig. 33. Ropes

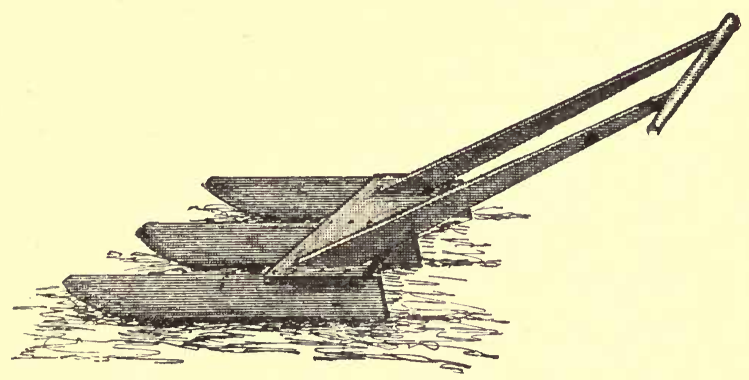

38. Hand sled-marker.

are secured about the cylinder at proper intervals, and these mark the rows. Knots may be

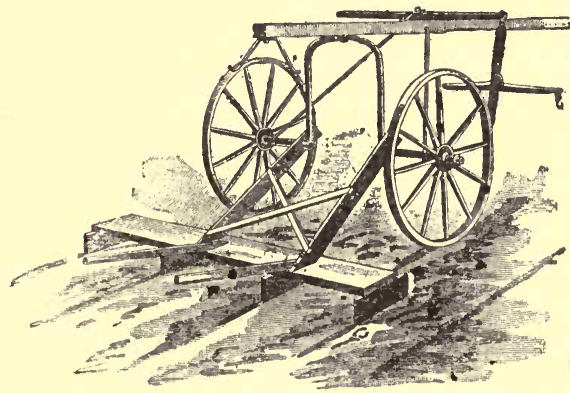

39. Trailing sled-marker.

placed in the ropes to indicate the places where plants are to be set or seeds dropped. An extension of the same idea is seen in Fig. 34, which 
shows iron or wooden pegs that make holes in which very small plants may be set. An L-shaped rod projects at one side to mark the place of the next row.

In most instances, the best and most expeditious method of marking out the garden is by

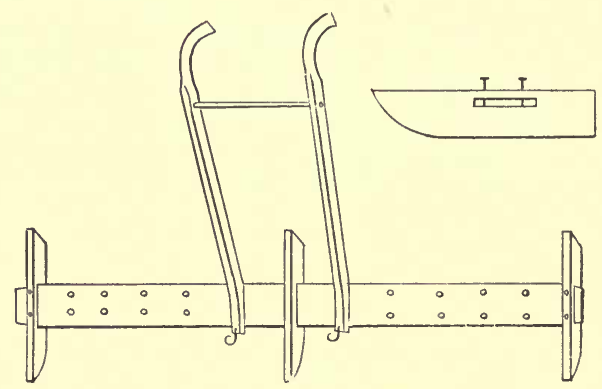

40. Adjustable sled-marker.

the use of the garden line, which is secured to a reel (Fig. 20), but various other devices are often useful. For very small beds, drills or furrows may be made by a simple marking-stick (Fig. 35). A handy marker is shown in Fig. 36. A marker ean be rigged to a wheel-barrow, as in Fig. 37. A rod is secured underneath the front truss, and from its end an adjustable trailer, B, is hung. The wheel of the barrow marks the row, and the trailer indicates the place of the next row, thereby keeping the rows parallel. A hand sled-marker is shown in.Fig. 38, and a similar device may be secured to the frame of a 
sulky cultivator (Fig. 39) or other wheel tool. A good adjustable sled-marker is outlined in Fig. 40.

\section{SOWING AND PLANTING.}

SowIng THE SEED.-The sled-markers open a furrow of sufficient depth for the planting of most seeds. If marker furrows are not available, a furrow may be opened with a hoe for such deepplanted seeds as peas and sweet-peas, or by a trowel or end of a rake-stale for smaller seeds. Plant when the ground is moist, if possible, and preferably just before a rain, if the soil is of such character that it will not bake. For shallow-planted seeds, firm the earth above them by walking over the row or by patting it down with a hoe. Care should be exercised not to sow very small and slow-germinating seeds, as celery, carrot, onion, in poorly prepared soil or in land which bakes. With such seeds it is well to sow seeds of radish or turnip, for these germinate quickly and break the crust, and also mark the row so that tillage may be begun before the regular-crop seeds are up.

Land may be prevented from baking over the seeds by scattering a very thin layer of fine litter, as chaff, or of sifted moss or mold, over the row. A board is sometimes laid on the row to retain the moisture, but it must be lifted gradually just as soon as the plants begin to 
break the ground, or the plants will be greatly injured. Wherever practicable, seed-beds of celery and other slow-germinating seeds should be shaded. If the beds are watered, be careful that the soil is not packed by the force of the water or baked by the sun. In thickly sown seedbeds, thin or transplant the plants as soon as they have made their first true leaves.

For most home-grounds, seeds may be sown by hand, but for large areas of one crop, one of the many kinds of seed-sowers may be used. The particular methods of sowing seeds are specified under the discussions of the different plants, if any other than ordinary treatment is required. The depth at which seeds are to be sown varies with the kind, the soil and its preparation, the season, and whether they are planted in the open or in the house. In boxes and under glass, it is a good rule that the seed be sown to a depth equal to twice its own diameter, but deeper sowing is usually necessary out of doors, particularly in hot and dry weather. More specific remarks upon propagation by seed and otherwise may be found in "The Nursery-Book."

Transplanting young seedlings.-In the transplanting of cabbages, tomatoes, flowers, and all plants which are recently started from seeds, it is important that the ground be thoroughly fined and compacted. Plants usually live better if transplanted into ground which has been freshly 
turned. If possible, transplant in cloudy or rainy weather, particularly if late in the season. Firm the earth snugly about the roots with the hands or feet, in order to bring up the soil moisture; but it is generally best to rake the surface in order to

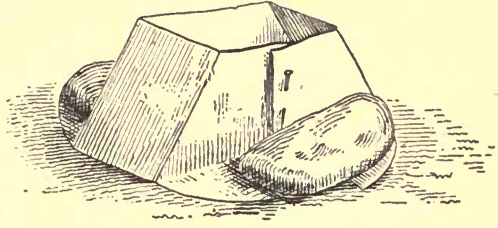

41. Paper screen for newly transplanted plants. establish the earth-mulch, unless the plants are so small that their roots cannot reach through the mulch.

In order to reduce the evaporation from the

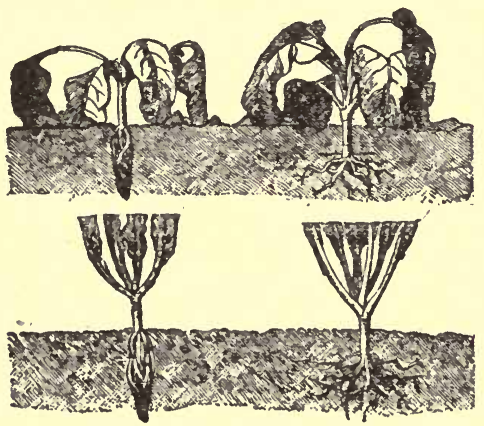

42. Shearing of plants when transplanting.

plant, shingles may be stuck into the ground so as to shade the plant; or a screen may be improvised with pieces of paper (Fig. 41), tin cans, 
inverted flower-pots, coverings of brush, or other means. It is nearly always advisable to remove some of the foliage, particularly if the plant has several leaves and if it has not been grown in a pot, and also if the transplanting is done in

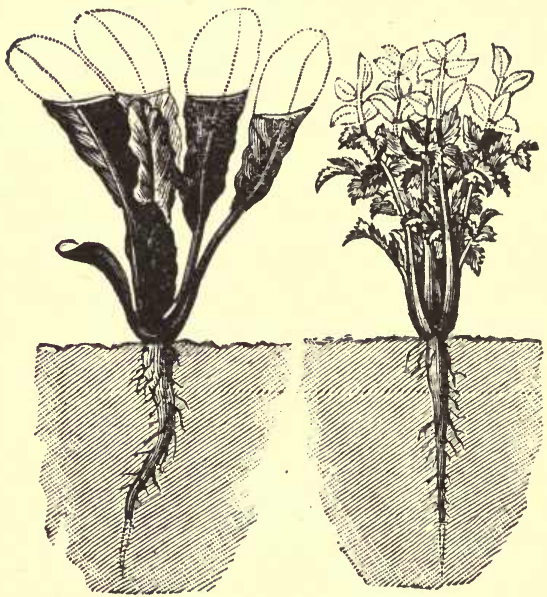

43. Cutting back or shearing the plants.

warm weather. Fig. 42 shows a good treatment for transplanted plants. With the foliage all left on, the plants are likely to behave as in the upper row, but with most of it cut off, as in the lower row, there is little wilting, and new leaves soon start. Fig. 43 also shows what part of the leaves may be cut off on transplanting. If the 
soil is freshly turned and the transplanting is well done, it rarely will be necessary to water the plants; but if watering is necessary, it should

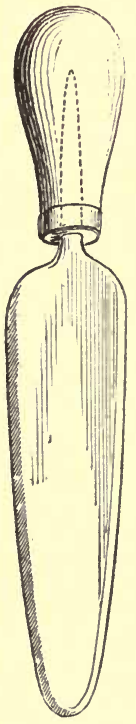

44. A serviceable dibber.

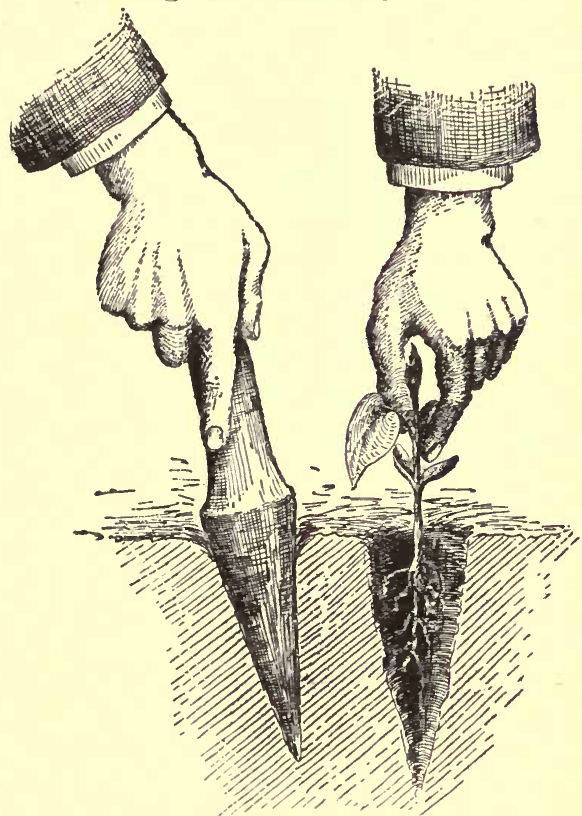

45. Transplanting by means of a dibber.

be done at nightfall, and the surface should be loosened the next morning, or as soon as it becomes dry.

In the transplanting of young plants, some kind of a dibber should be used to make the holes. 
Dibbers make holes without removing any of the earth. A good form of dibber is shown in Fig. 44, which is like a Many persons prefer conical dibber, like 45. For hard soils strong dibber may which has a rightserve as a handle. softened by slipping
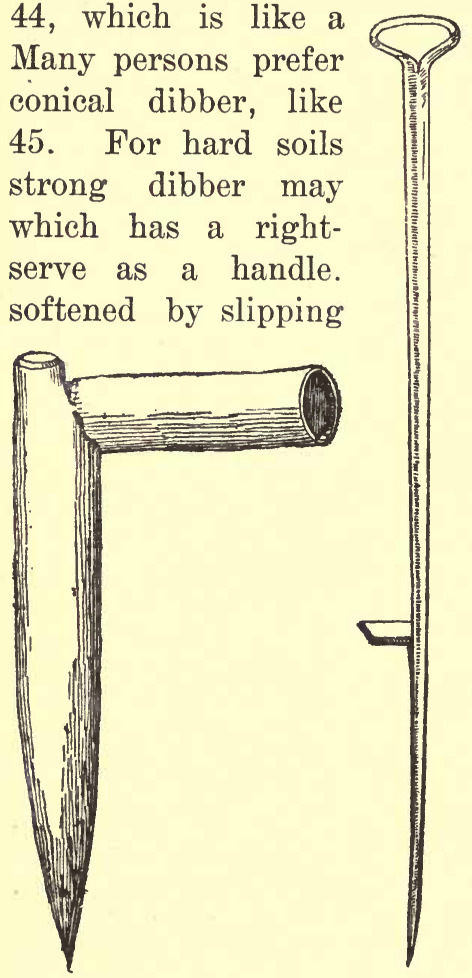

46. A home-made and padded dibber.
47. Dibber and crow-bar combined. flat or plane trowel. a cylindrical and that shown in Fig. and larger plants, a be made from a limb angled branch to This handle may be a piece of rubber

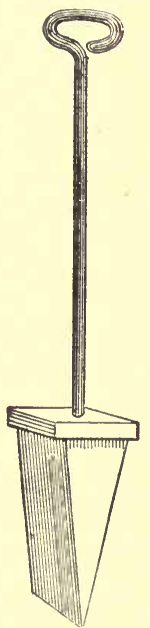

48. Strawberry planter.

hose on it (Fig. 46). A long iron dibber, which may also be used as a crow-bar, is shown in 
Fig. 47. In transplanting with the dibber, a hole is first made by a thrust of the tool, and the earth is then pressed against the root by

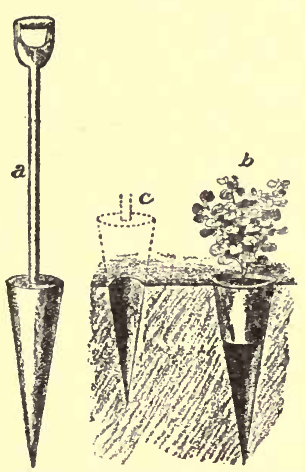

49. Plunging pots.

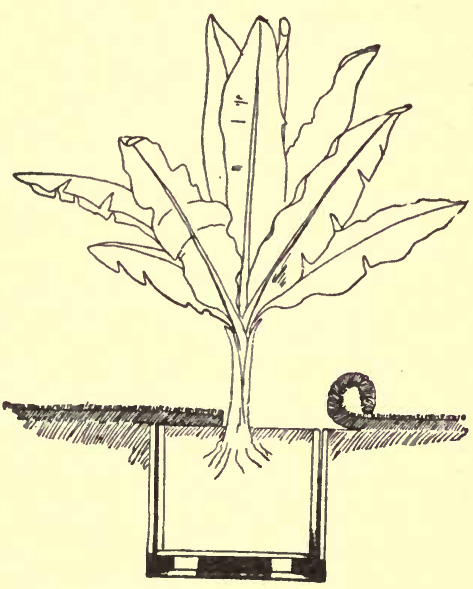

50. Setting large tub-plants in the lawn.

means of the foot, hand, or the dibber itself (as in Fig. 45). The hole is not filled by putting in dirt at the top.

For large plants, a broader dibber may be used. An implement like that shown in Fig. 48 is useful for setting strawberries and other plants with large roots. It is made of two-inch plank, with a block on top to act as foot-rest and to prevent the blade from going too deep. In order to provide space for the foot and to easily direct the 
thrust, the handle may be placed at one side of the middle. For plunging pots, a dibber like that shown in Fig. 49 is useful, particularly when the soil is so hard that a long-pointed tool is necessary. The bottom of the hole may be filled with earth before the pot is inserted; but it is often advisable to leave the vacant space below (as in $b$ ) to provide drainage, to keep the plant from rooting, and to prevent earth-worms from entering the hole in the bottom of the pot. For smaller pots, the tool may be inserted a less depth (as at $c$ ).

Transplanting established Plants and TREES.-In setting potted plants out of doors, it is nearly always advisable to plunge them,that is, to set the pots into the earth,- - unless the place is very wet. The pots are then watered by the rainfall, and demand little care. If the plants are to be returned to the house in the fall, they should not be allowed to root through the hole in the pot, and the rooting may be prevented by turning the pot around every few days. Large decorative plants may be made to look as if growing naturally in the lawn by sinking the pot or box just below the surface level and rolling the sod over it, as suggested in Fig. 50. A space around and below the tub may be provided to insure drainage.

For the shifting of very large tub-plants, a box or tub with moveable sides, as in Fig. 51, 
is handy and efficient. The plant-box recommended to parties who grew plants for exhibition at the World's Fair is shown in Fig. 52. It is made of strong boards or planks. At A is shown the inside of one of two opposite sections or sides, four feet wide at top, three feet wide at bottom and three feet high. The cleats are twoby-four scantlings, through which holes are bored to admit the bolts with which the box is to be held together. $\mathrm{B}$ is an outside view of one of the alternating sections, three feet four inches wide at top, two feet four inches at bottom, and three feet deep. A one-by-six strip is nailed through the center to give strength. $\mathrm{C}$ is an end view of $A$, showing the bolts and also a two-by-four

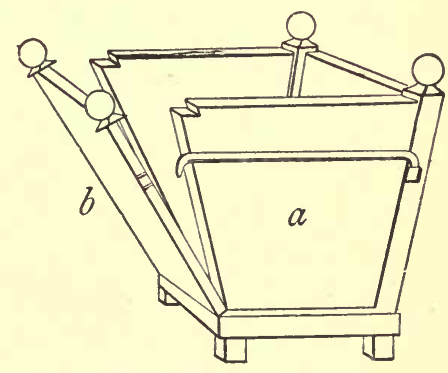

51. Plant-box with a moveable side. cleat to which the bottom is to be nailed. This box was used mostly for transporting large growing stock to the exposition, the stock having been dug from the open and the box secured around the ball of earth.

Very large trees can often be moved with safety. It is essential that the transplanting be done when the trees are perfectly dormant,- -winter being preferable, - that a large mass of earth and 
roots be taken with the tree, and that the top be vigorously cut back. Large trees are often moved in winter upon a stone-boat, by securing a large ball of earth frozen about the roots. This frozen ball is secured by digging about the
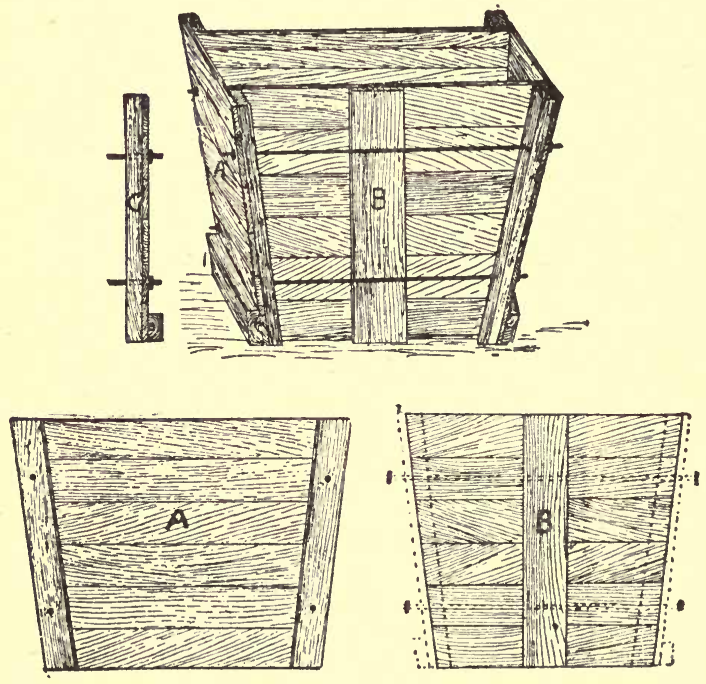

52. Box for transporting large transplanted stock.

tree for several days in succession, so that the freezing progresses with the excavation. A good device for moving such trees is shown in Fig. 53. The trunk of the tree is securely wrapped with burlaps or other soft material, and a ring or chain is then secured about it. A long pole, 
$b$, is run over the truck of a wagon and the end of it is secured to the chain or ring upon the tree. This pole is a lever for raising the tree out of the ground. A team is hitched to $a$, and a man holds the pole $b$.

The following more explicit directions for moving large trees are by Edward Hicks, who has had much experience in the business, and who made this report to the press a few years ago: "In moving large trees, say those ten to twelve inches in diameter and twenty-five to thirty feet high, it is well to prepare them by trimming and cutting or sawing off the roots at a proper distance from the trunks, say six to eight feet, in June. The cut roots heal over and send out fibrous roots, which should not be injured more than is necessary in moving the trees next fall or spring. Young, thrifty maples and elms, originally from the nursery, do not need such preparation nearly as much as other and older trees. In moving a tree, we begin by digging a wide trench six to eight feet from it, leaving all possible roots fast to it. By digging under the tree in the wide trench, and working the soil out of the roots by means of round or dull-pointed sticks, the soil falls into the cavity made under the tree. Three or four men in as many hours could get so much of the soil away from the roots that it would be safe to attach a rope and tackle to the upper part of the trunk 
and to some adjoining post or tree for the purpose of pulling the tree over. A good quantity of bagging must be put around the tree under the rope to prevent injury, and care should be taken that the pulling of the rope does not split off or break a limb. A

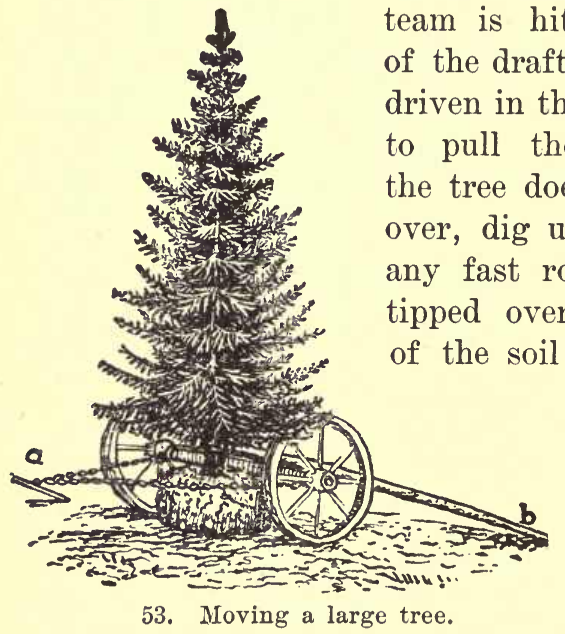

53. Moving a large tree. team is hitched to the end of the draft rope, and slowly driven in the proper direction to pull the tree over. If tree does not readily tip over, dig under and cut off any fast root. While it is tipped over, work out more with the sticks.

Now pass a large rope, double, around a few large roots close to the tree, leaving the ends of the rope turned up by the trunk to be used in lifting the tree at the proper time. Tip the tree in the opposite direction and put another large rope around the large roots close to the trunk; remove more soil and see that no roots are fast to the ground. Four guy-ropes attached to the upper parts of the tree, as shown in the cut (Fig. 54), should be put on properly and used to prevent 
the tree from tipping over too far as well as to keep it upright. A good deal of the soil can be put back in the hole without covering the roots, to get it out of the way of the machine. The latter can now be placed about the tree by removing the front part, fastened by four bolts, placing the frame with the hind

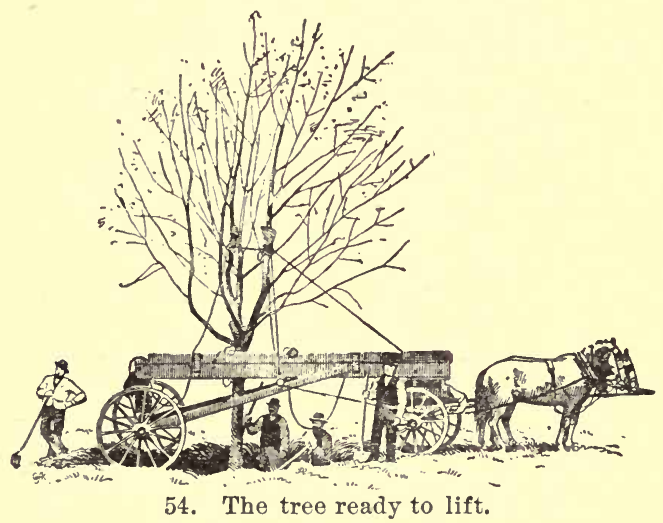

wheels around the tree and replacing the front parts. Two timbers, three-by-nine inches, and twenty feet long, are now placed on the ground under the hind wheels, and in front of them, parallel to each other, for the purpose of keeping the hind wheels up out of the big hole when drawing the tree away; and they are also used while backing the hind wheels across the new hole in which the tree is to be planted. 
The machine (Figs. 54, 55) consists of a hind axle twelve feet long, and broad-tired wheels. The frame is made of spruce three-by-eight inches and twenty feet long. The braces are three-by-five inches and ten feet long, and upright three-by-nine inches and three feet high;

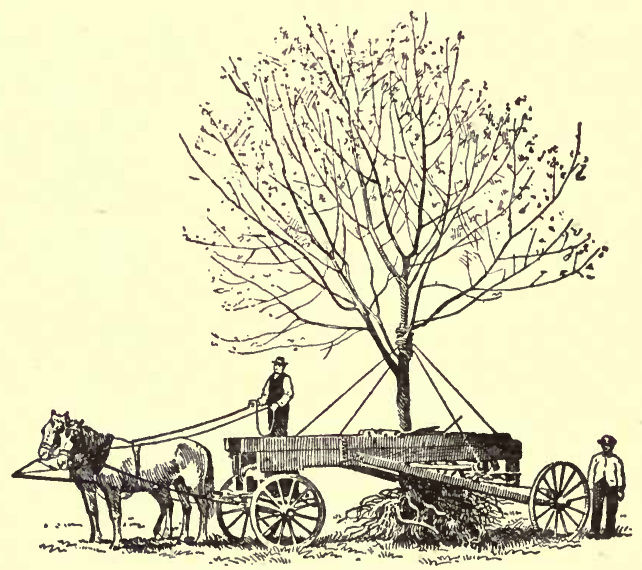

55. The tree ready to move.

these are bolted to the hind axle and main frame. The front axle has a set of blocks bolted together and of sufficient height to support the front end of the frame. Into the top timbers, three-by-six inches, hollows are cut at the proper distances to receive the ends of two locust rollers. A windlass or winch is put at each end of the frame, by which trees can easily and steadily be lifted and lowered, the large double ropes pass- 
ing over the rollers to the windlasses. A locust boom is put across the machine ander the frame and above the braces; iron pins hold it in place. The side guy-ropes are made fast to the ends of this boom. The other guy-ropes are made fast to the front and rear parts of the machine. Four rope loops are made fast inside of the frame, and are so placed that by passing a rope around the trunk of the tree and through the loops two or three times, a rope ring is made around the tree that will keep the trunk in the middle of the frame and not allow it to hit either the edges or the rollers-a very necessary safeguard. As the tree is slowly lifted by the windlasses, the guyropes are loosened, as needed. The tree will pass obstructions, such as trees by the roadside, but in doing so it is better to lean the tree backward. When the tree has arrived at its new place, the two timbers are placed along the opposite edges of the hole so that the hind wheels can be backed over it. The tree is then lowered to the proper depth, and made plumb by the guy-ropes, and good, mellow soil is thrown in and packed well into all the cavities under the roots. When the hole is half filled, several barrels of water should be poured in; this will wash the soil into the cavities under the center of the tree much better. When the water has settled away, fill in and pack the soil till the hole is little more than full. Leave a depression, 
so that all the rain that may fall will be retained. The tree should now be judiciously trimmed and the machine removed. Five men can take up, move and plant a tree in a day, if the distance

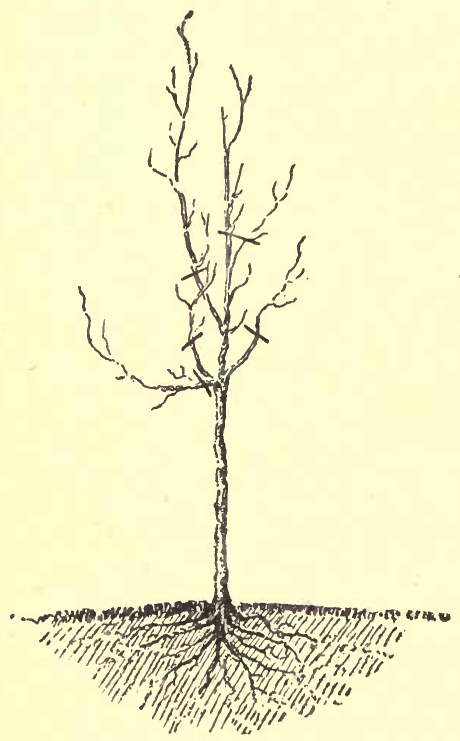

56. Tree well planted.

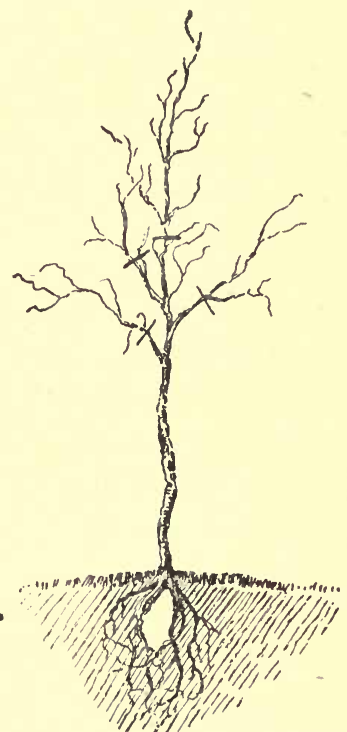

57. Tree not well planted.

is short and the digging not too hard. The tree should be properly wired to stakes to prevent the wind from blowing it over. The front part of the machine is a part of our platform spring market-wagon, while the hind wheels are from a wood-axle wagon. A tree ten inches in diame- 
ter, with some dirt adhering to its roots, will weigh a ton or more."

In the planting of any tree or bush, the roots should be cut back beyond all breaks and serious bruises, and the earth should be thoroughly filled in and firmed about them, as in Fig. 56. No

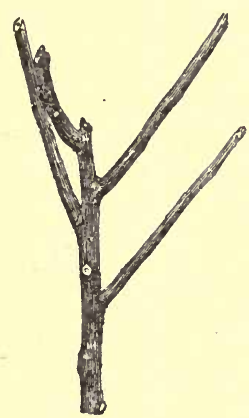

58. Pruned tree. implement is so good as the fingers for working the soil ábout the roots. If the tree has many roots, work it up and down slightly several times during the filling of the hole, to settle the earth in place.

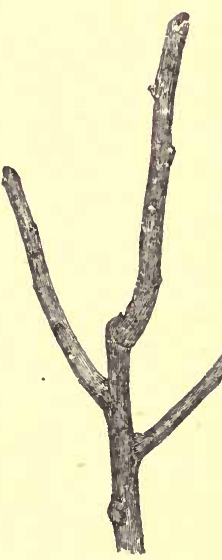

59. Pruned tree.

When the earth is thrown in carelessly, the roots are jammed together, and often an empty place is left beneath the crown, as in Fig. 57, which causes the roots to dry out.

The marks upon the tops of these trees in Figs. 56 and 57 show where the branches should be eut off. See also Fig. 66. Figs. 58 and 59 show the tops of trees after pruning. Strong, branchy trees, as apples, pears and ornamental trees, are usually headed back in this way, upon planting. If the tree has one straight leader and many or 
several slender branches (Fig. 60), it is usually pruned as in Fig. 61, each branch being cut back
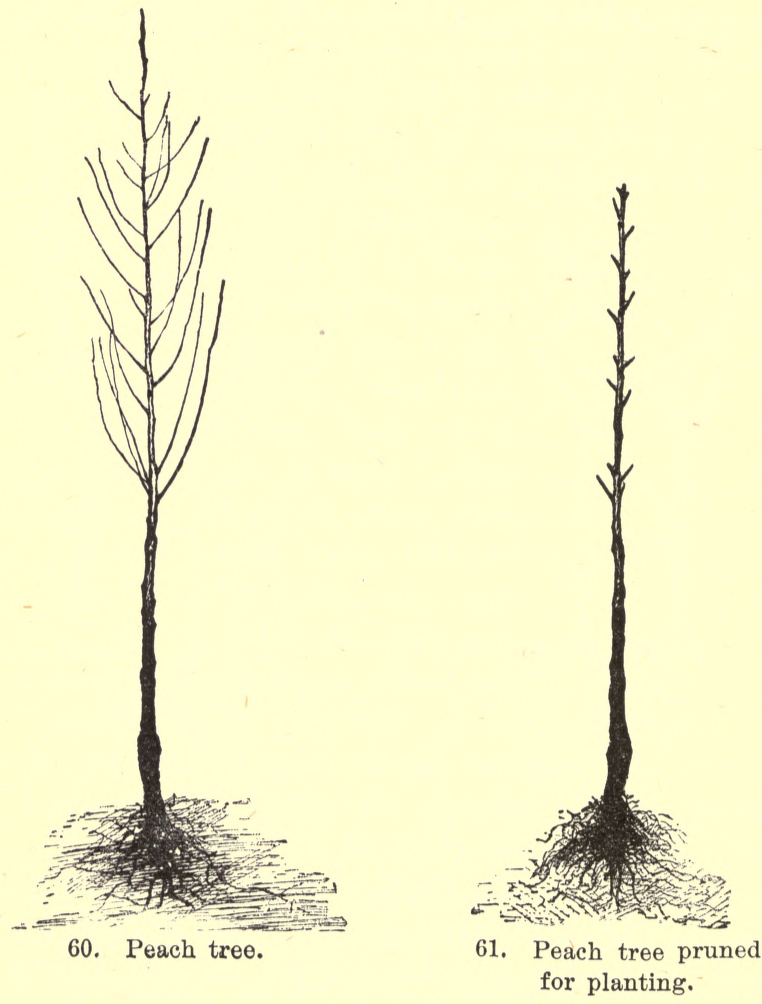

to one or two buds. If there are no branches, or very few of them,-in which case there will be good buds upon the main stem,-the leader 
may be cut back a third or half its length, to a mere whip. Ornamental ${ }_{1}^{7}$ bushes with long tops are usually cut back a third or a half when set, as shown in Fig. 150. Full discussions of both pruning and training may be found in "The Pruning-Book."

In general, it is best to set all hardy plants in the fall, particularly if the soil is fairly dry and the exposure is not too bleak. To this class belong most of the fruit trees and ornamental trees and shrubs; also hardy herbs, like columbines, peonies, lilies, bleeding-hearts, and the like. They should be planted as soon as they are thoroughly mature, so that the leaves begin to fall naturally. If any leaves remain upon the tree or bush at planting time, strip them off, unless the plant is an evergreen. It is generally best not to cut back fall-planted trees to the full extent desired, but to shorten them in threefourths of the required amount in the fall, and take off the remaining fourth in the spring, so that no dead or dry tips are left upon the plant. Evergreens, as pines and spruces, are not headedin much, and usually not at all. All tender and very small plants should be set in the spring, in which case very early planting is desirable.

In well-compacted land, trees and shrubs should be set at about the same depth as they stood in the nursery, but if the land has been deeply trenched or if it is loose from other causes, the 
plants should be set deeper, because the earth will probably settle. The hole should be filled with fine surface earth. It is generally not ad-

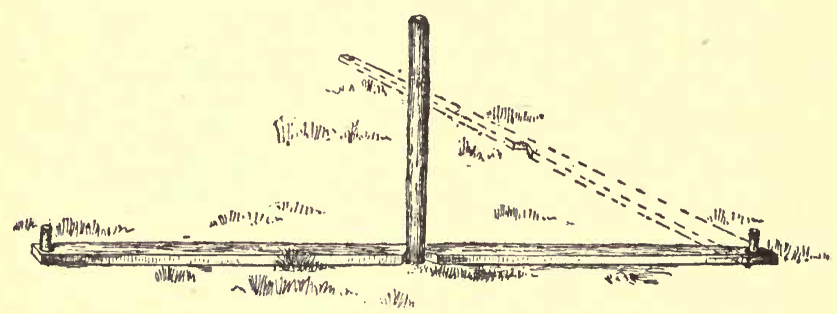

62. Planting-board.

visable to place manure in the hole, but if it is used it should be of small amount and very thoroughly mixed with the earth, else it will cause the soil to dry out. In lawns and other places where surface tillage cannot be given, a light mulch of litter or manure may be placed about

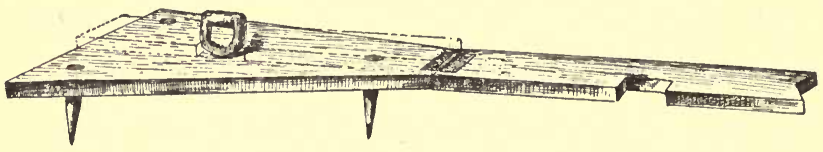

63. Device for locating the tree.

the plants; but the earth-mulch (page 8), when it can be secured, is much the best conserver of moisture.

In order to set trees in rows, it is necessary to use a garden line (Fig. 20), or to mark out the ground with some of the devices already described (Figs. 33-40); or in large areas, the place may be 
staked out.* There are various devices for locating the place of the stake after the stake has been removed and the hole dug. One of the simplest and best is shown in Fig. 62. It is a simple narrow and thin board with a notch in the center and

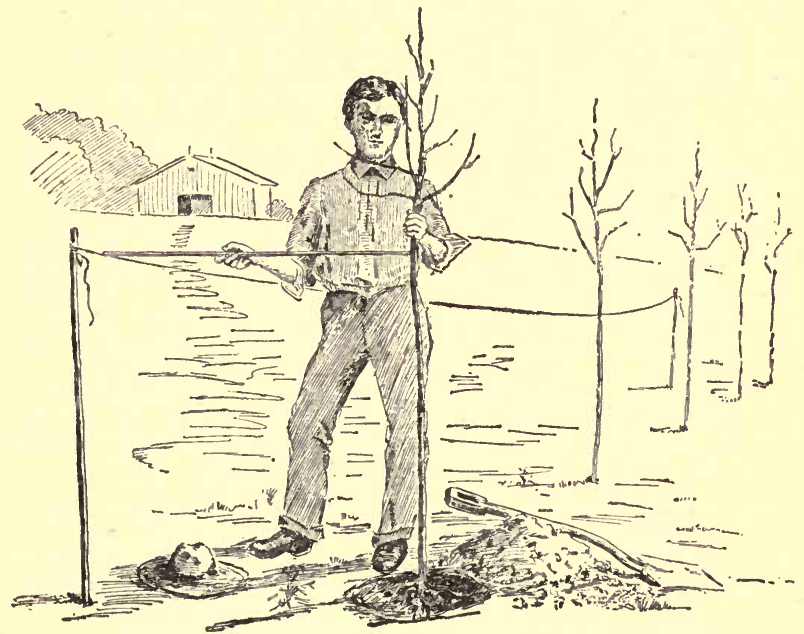

64. Setting trees to a line.

a peg in either end, one of the pegs being stationary. The implement is so placed that the notch meets the stake; then one end of it is thrown out of the way until the hole is dug. When the implement is brought again to its original position, the notch marks the place of the

*Very full directions for laying out orchards are given in "Principles of Fruit-Growing." 
stake and the tree. Fig. 63 is a device with a lid, in the end of which is a notch to mark the place of the stake. This lid is thrown back, as shown by the dotted lines, when the hole is being dug. Fig. 64 shows a method of bringing trees in row by measuring from a line.

\section{WINTER PROTECTION OF PLANTS.}

If the ground is not ready for planting in the fall, or if it is desired to delay until spring, the trees or bushes may be heeled-in, as illustrated in Fig. 65. The roots are laid in a furrow or trench, and are covered with well-firmed earth. Straw or manure may be thrown over the earth to still further protect the roots, but if it is thrown over the tops mice may be attracted by it and the trees

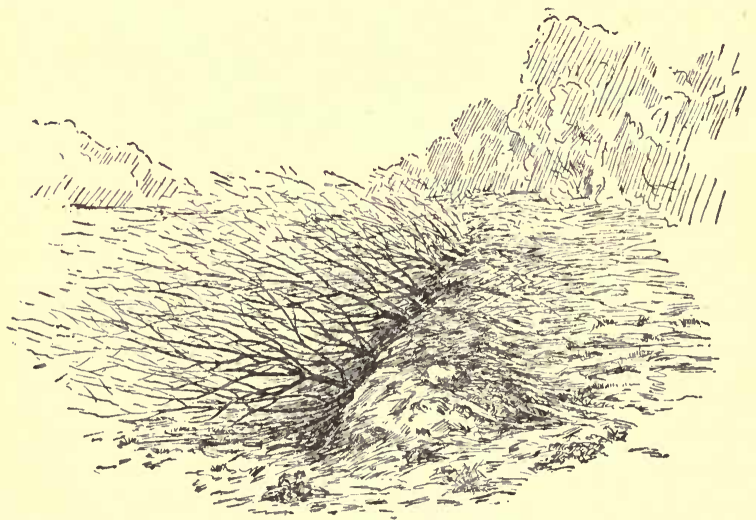

65. Trees heeled-in for the winter. 
be girdled. Tender trees or bushes may be lightly covered to the tips with earth. Plants should be heeled-in only in loose, warm, loamy or sandy soil and in a well-drained place.

Fall-planted trees should generally be mounded up, sometimes even as high as shown in Fig. 66. This hilling holds the tree in position, carries off the water, prevents too deep freezing, and holds the earth from heaving. The mound is taken away in the spring. It is sometimes advisable to mound up established trees in the fall, but on well-drained land the 66. Tree earthed practice is not usually necessary.

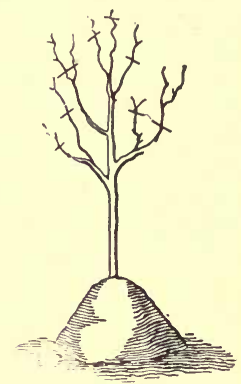

up for winter. In hilling trees, pains should be taken not to leave deep holes, from which the earth was dug, close to the tree, for water collects in them.

It is always advisable to mulch plants which are set in the fall. Any loose and dry material-as straw, manure, leaves, leaf-mold, litter from yards and stables, pine boughs-may be used for this purpose. Very strong or compact manures, as that in which there is little straw or litter, should be avoided. The ground may be covered to a depth of five or six inches, or even a foot or more if the material is loose. Avoid throwing strong manure directly upon the crown of the plants, especially of herbs, for the materials which leach 
from the manure sometimes injure the crown buds and the roots.

This protection may also be given to established plants, particularly to those which, like roses and herbaceous plants, are expected to give a profusion of bloom the following year. This mulch affords not only winter protection, but is an efficient means of fertilizing the land. A large part of the plant-food materials have leached out of the mulch by spring, and have become incorporated in the soil, where the plant makes ready use of them. Mulches also serve a most useful purpose in preventing the ground from packing and baking from the weight of snows and rains, and the cementing action of too much water in the surface soil. In the spring, the coarser parts of the mulch may be removed, and the finer parts spaded or hoed into the ground.

Tender bushes and small trees may be wrapped up with straw, hay, burlaps, or pieces of matting or carpet. Even rather large trees, like bearing peach trees, are often baled up in this way, or sometimes with corn fodder, although the results in the protection of fruit buds are not often very satisfactory. It is important that no grain is left in the baling material, else mice may be attracted to it. It should be known, too, that the object in tying up or baling plants is not so much to protect from direct cold as to mitigate the effects of alternate freezing and thawing, and to protect 
from drying winds. Plants may be wrapped so thick and tight as to injure them. Be sure that no water stands about the roots of tender trees, and cover the surrounding ground with a heavy mulch of leaves or straw. The labor of protecting large plants is often great and the results uncertain, and in most eases it is a question if more satisfaction could not be obtained by growing only hardy trees and shrubs.

The objection to covering tender woody plants cannot be urged with equal force against tender

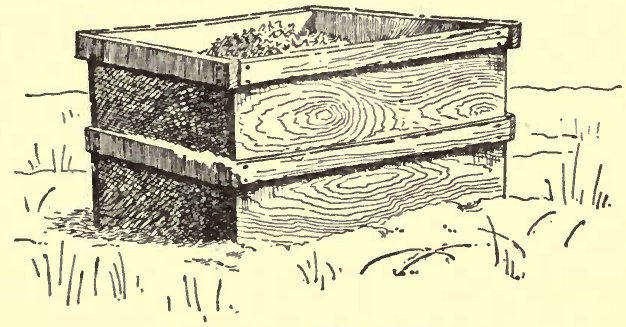

67. Covering plants with a box.

herbs or very low bushes, for these are protected with ease. Even the ordinary mulch may afford sufficient protection; and if the tops kill back, the plant quickly renews itself from the base, and in many plants, - as in most hybrid perpetual roses,the best bloom is upon these new growths of the season. Old boxes or barrels may be used to protect tender low plants (Figs. 67, 68). The box is filled with leaves or dry straw, and either left 
open on top or covered with boards, boughs or even with burlaps (Fig. 68).

The tops of plants may be laid down for the winter. Fig. 69 shows a method of laying down blackberries, as practiced in the Hudson River Valley. The plants were tied to a trellis, as the method is in that country, two wires $(a, b)$ having been run upon either side of the row. The posts are hinged on a pivot to a short post $(c)$, and are

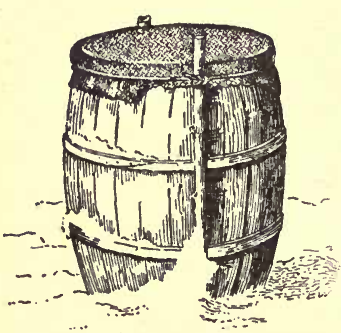

68. Protecting plants with a barrel.

held in position by a brace (d). The entire trellis is then laid down upon the approach of winter, as shown in the illustration. The blackberry tops are so strong that they hold the wires up from the ground, even when the trellis is laid down. To hold the wires close to the earth, stakes are thrust over them in a slanting position, as shown at $n n$. The snow which drifts through the plants ordinarily affords sufficient protection for plants which are as hardy as grapes and berries. In fact, the plants may be uninjured even without cover, since, in their prostrate position, they escape the cold and drying winds.

In severe climates, or in the case of tender plants, the tops should be covered with straw, boughs or litter, as recommended for regular 
mulch-covers. Sometimes a V-shaped trough made from two boards is placed over the stems of long or vine-like plants which have been laid down. All plants with slender or more or less pliant stems can be laid down with ease. With

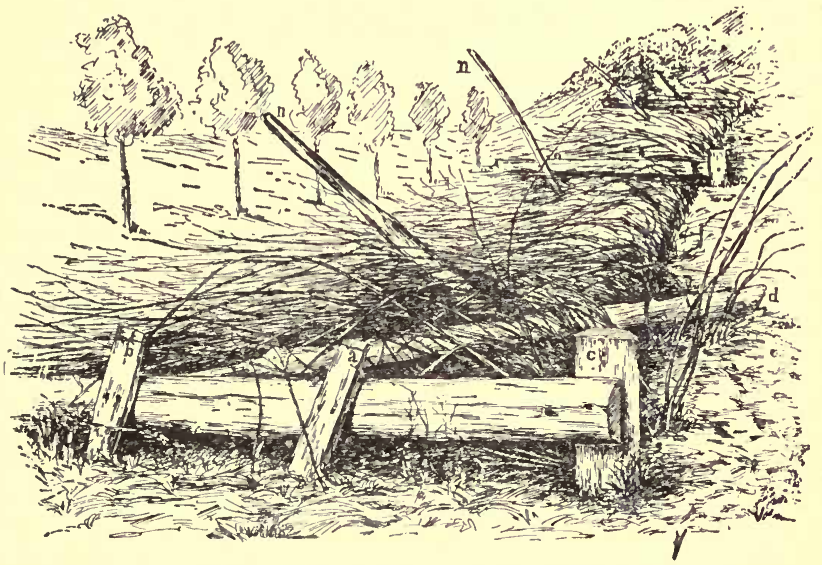

69. Laying down trellis-grown blackberries.

such protection, figs can be grown in the northern states. Peach and other fruit trees may be so trained as to be tipped over and covered. For an account of the method, see "Principles of FruitGrowing."

Laid-down plants are often injured by the retention of the covering too late in the spring. The ground warms up early, and may start the buds on parts of the buried plants, and these tender buds may be broken when the plants are raised, 
or injured by sun, wind or frost. The plants should be raised while the wood and buds are still hard and dormant.

Inasmuch as dark colors absorb heat, and light colors reflect it, Whitten, of the Missouri Experiment Station (Bulletin 38), was led to try the effects of whitewashing peach trees for the purpose of preventing the premature swelling of the buds. The results were marked and satisfactory. The following quotations explain the method and results: "The expense of whitening is not great. A common lime whitewash was at first used, but it washed off badly during rainy weather. Finally a whitewash of lime, with one-fifth skim milk added to the water, was tried with much more satisfactory results. About one pound of salt was also dissolved in each bucketful of the whitewash. Four applications of this wash, applied during the winter and spring, are sufficient to keep the peach trees thoroughly whitened. The first whitening should be done early in winter, shortly before Christmas. The wash may be sprayed on with almost any kind of a spray pump. We found the Bordeaux nozzle to be satisfactory, as a solid stream could readily be turned on if the lime clogged the nozzle. The whitening should be repeated as often as the lime is washed off by rains. A good wash, however, will adhere well for weeks. The trees need two sprayings to begin with, just as wood needs two coats of paint in 
order to cover it well. Two subsequent sprayings are sufficient. The whitewash should be made as thick as can be sprayed through a Bordeaux nozzle. We used a small bucket spray pump, and applied about one-half a bucketful to a tree at each spraying. The time required to apply the whitewash will vary from five to ten minutes, according to the kind of pump and to the size of the trees. The more trees that are sprayed, the cheaper it can be done per tree. Altogether, the cost need not exceed ten cents per tree for the winter."

Following is a summary of the results:

"In this latitude, winter-killing of the fruitbuds of the peach is usually due to the unfavorable effects of freezing after they have been stimulated into growth by warm weather, during winter or early spring.

"This early swelling and growth of the buds is due to the warmth they receive, is practically independent of root action, and may take place on warm, sunny days in winter, while the roots are frozen and dormant.

"Peach fruit-buds may safely endure a temperature of ten or twenty degrees below zero, provided they mature well in autumn, are entirely dormant, and the cold comes on gradually.

"Zero weather may kill fruit-buds that have swollen during previous warm days, or that were not properly ripened in autumn. 
"Shading or whitening peach trees to prevent their absorbing heat on sunny days, opposes growth of the buds and is, consequently, a protective measure.

"Shading the trees with board sheds enabled peach buds to survive the winter uninjured, when eighty per cent of unprotected buds were killed. Trees protected in this way blossomed later, remained in bloom longer, set more fruit in proportion to the number of apparently perfect flowers, and held their fruit better than any other trees on the station grounds. This is the most effective means of winter protection tried at the station, but it is probably too expensive for commercial orchards.

"Whitening the twigs and buds by spraying them with whitewash is, on account of its cheapness and beneficial effects, the most promising method of winter protection tried at this station.

"Whitened buds remained practically dormant until April, when unprotected buds swelled perceptibly during warm days late in February and early in March. Whitened buds blossomed three to six days later than unprotected buds. Eighty per cent of whitened buds passed the winter safely, when only twenty per cent of unwhitened buds passed the winter unharmed.

"Thermometers covered with purple material registered, during bright, sunny weather, from ten to over twenty degrees .higher than thermometers 
covered with white material of similar texture, thus indicating that whitened peach twigs might be expected to absorb much less heat than those that were not whitened."

\section{THE FORCING OF PLANTS}

There are three general means of forcing plants ahead of their season in the early spring-by means of hand boxes and forcing-hills, by coldframes, and by hotbeds.

The forcing-hill is an arrangement by means of which a single plant or a single hill of plants may be forced where it permanently stands. This type of forcing may be applied to perennial plants, as rhubarb and asparagus, or to annuals, as melons and cucumbers. Fig. 70 illustrates a common method of hastening the growth of rhubarb in the spring. A box made with four removable sides, two of which are shown in end section in the figure, is placed around the plant

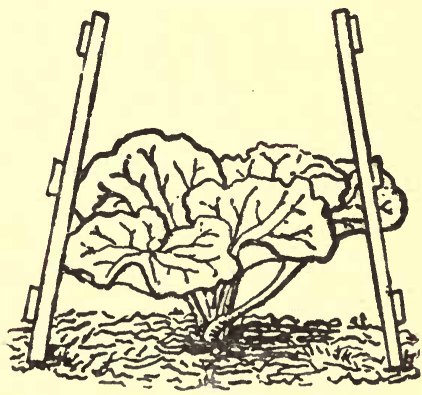

70. Forcing of rhubarb. in the fall. The inside of the box is filled with straw or litter, and the outside is banked thoroughly with any refuse, to prevent the ground from freezing. When it is desired to start the piants, the covering is removed from both the inside and 
outside of the box, and hot manure is piled around the box to its top. If the weather is still cold, dry light leaves or straw may be placed inside the box, or a pane or sash of glass may be placed on top of the box, to answer the purpose of a coldframe. Rhubarb, asparagus, sea-kale and similar plants may be advanced from two to four weeks by means of this method of forcing. Some gardeners use old barrels or half-barrels in place of

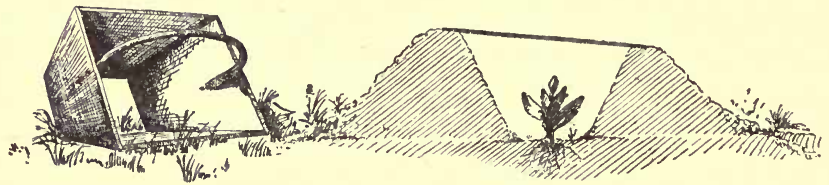

71. Forcing-hill.

the box. The box, however, is better and handier, and the sides can be stored for future use.

Plants which require a long season in which to mature, and which do not transplant readily, as melons and cucumbers, may be planted in forcinghills in the field. One of these hills is shown in Fig. 71. The frame or mold is shown at the left. This mold is a box with flaring sides and no top or bottom, and provided with a handle. This frame is placed with the small end down at the point where the seeds are to be rlanted, and the earth is hilled up about it and firmly packed with the feet. The mold is then withdrawn, and a pane of glass is laid upon the top of the mound 
to concentrate the sun's rays, and to prevent the bank from washing down with the rains. A clod of earth or a stone may be placed upon the pane to hold it down. This type of forcing-hill is not much used, because the bank of earth is apt to wash away, and heavy rain coming up when the glass is off will fill the hill with water and drown the plant. However, it can be used to very good advantage in cases where the gardener can give it close attention.

A forcing-hill is sometimes made by digging a hole in the ground and planting the seeds in the

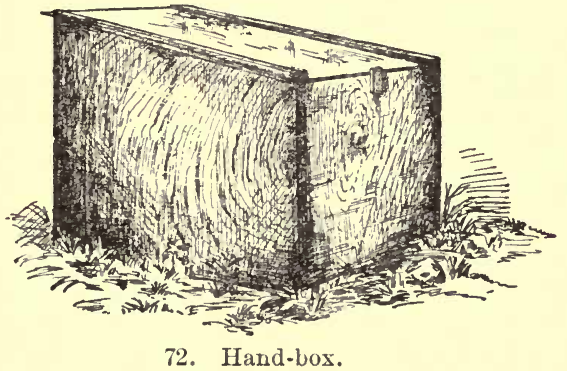

bottom of it, placing the pane of glass upon a slight ridge or mound which is made upon the surface of the ground. This method is less desirable than the other, because the seeds are placed in the poorest and coldest soil, and the hole is very apt to fill with water in the early days of spring.

An excellent type of forcing-hill is made by the 
use of the hand-box, as shown in Fig. 72. This is a rectangular box, without top or bottom, and a pane of glass is slipped into a groove at the top. It is really a miniature coldframe. The earth is banked up slightly about the box, in order to hold it against winds and to prevent the water from running into it. If these boxes are made of good lumber and painted, they will last for many years. Any size of glass may be used which is desired, but a ten-by-twelve pane is as good as any for general purposes.

After the plants are thoroughly established in these forcing-hills, and the weather is settled, the protection is wholly removed, and the plants grow normally in the open.

A very good temporary protection may be given to tender plants by using four panes of glass, as explained in Fig. 73, the two inner panes being held together at the top by a block of wood through which four nails are driven. Plants are more likely to burn in these glass frames than in the handboxes, and such frames

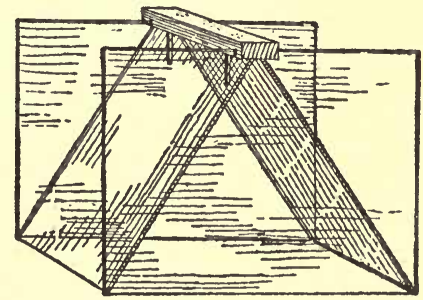

73. Panes of glass used for a forcing-hill. are not so well adapted to the protection of plants in very early spring; but they are often useful for special purposes. 
In all forcing-hills, as in coldframes and hotbeds, it is exceedingly important that the plants receive plenty of air upon bright days. Plants which are kept too close become weak or "drawn," and lose the ability to withstand changes of weather when the protection is removed. Even though the wind is cold and raw, the plants inside the frames will ordinarily not suffer if the glass is taken off when the sun is shining.

Coldframes.-A coldframe is nothing more than an enlarged hand-box; that is, instead of protecting but a single plant or a single hill with a single pane of glass, it is covered with sash, and is large enough to accommodate many plants. There are three general purposes for which a coldframe is used: For the starting of plants early in spring; for receiving partially hardened plants which have been started earlier in hotbeds and forcing-houses; for wintering young cabbages, lettuce and other hardy plants which are sown in the fall.

Coldframes are ordinarily placed near the buildings, and the plants are transplanted into the field when settled weather comes. Sometimes, however, they are made directly in the field where the plants are fo remain, and the frames, and not the plants, are removed. When used for this latter purpose, the frames are made very cheap by running two rows of parallel planks through the field at a distance apart of six feet. The 
plank upon the north is ordinarily ten to twelve inches wide, and that upon the south eight to ten inches. These planks are held in place by stakes, and the sashes are laid A lettuce, and the like, are then sown beneath the sash, and $\int_{1}$ when settled weather arrives the sash and planks are removed and the plants are growing naturally in the field. Half-hardy plants, like those men-

\section{Coldframe} against a building. tioned, may be started fully two or three weeks in advance of

the normal season by this means.

One of the simplest types of coldframes is shown in Fig. 74, which is a lean-to against the foundation of a house. A sill is run just above the surface of the ground, and the sashes, shown at $D$, are laid upon rafters which run from this sill to the sill of the house, A. If this frame is upon the south side of the building, plants may be started even as early as a month before the opening of the season. Such lean-to frames are sometimes made against greenhouses or warm cellars, and heat is supplied to them by the opening of a door in the wall, as at B. In frames which are in 
such sunny positions as these, it is exceedingly important that care be taken to remove the sash, or at least to give ample ventilation, upon all sunny days.

A different type of lean-to structure is shown in Fig. 75. This may be either a temporary or permanent building, and it is generally used for

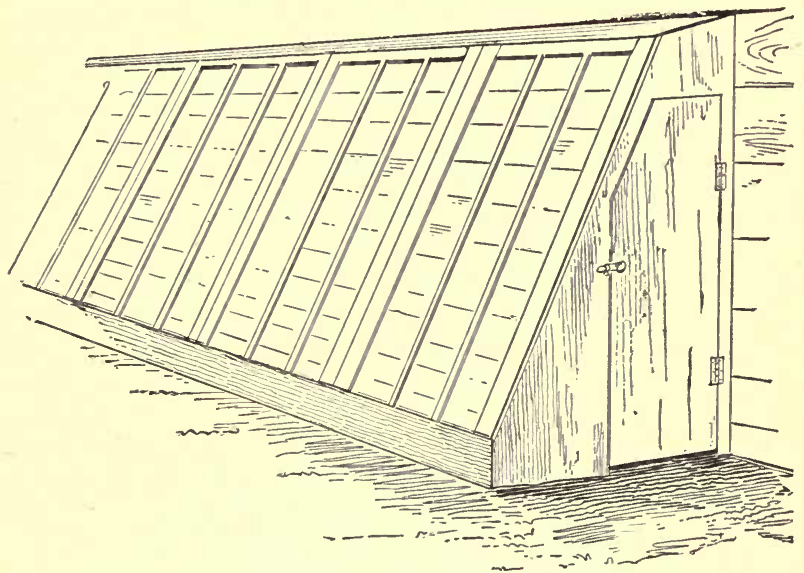

75. Coldframe, or weather screen, against a building.

the protection of half-hardy plants which are grown in pots and tubs. It may be used, however, for the purpose of forwarding pot-plants early in the spring and for the protection of peaches, grapes, oranges or other fruits in tubs or boxes. If it is desired to simply protect the plants through the winter, it is best to have the structure upon the 
north side of the building, in order that the sun may not force the plants into activity.

The common type of coldframe is shown in Fig. 76. It is twelve feet long and six feet wide, and is covered with four three-by-six sash. It is made of ordinary lumber loosely nailed together. If one expects to use coldframes or hotbeds every year, however, it is advisable to make the frames of two-inch stuff, well painted, and to join the parts by bolts and tenons, so that they may be taken apart and stored until needed for the next year's crop. Fig. 77 suggests a method of making the frames so that they may be taken apart.

It is always advisable to place coldframes and hotbeds in a protected place, and especially to protect them from cold north winds. Buildings afford excellent protection, but the sun is sometimes too hot upon the south side of large and

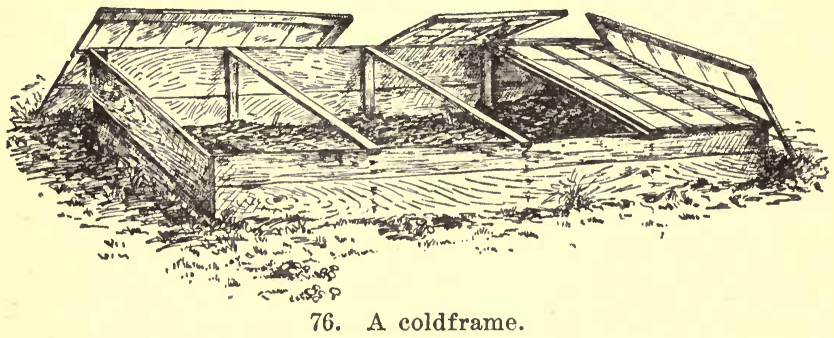

light-colored buildings. One of the best means of protection is to plant a hedge of evergreens, as shown in Fig. 78. It is always desirable, also, to 
place all the coldframes and hotbeds close together, for the purpose of economizing time and labor.

Various small and portable coldframes may be used about the garden for the protection of tender plants or to start them early in the spring. Pansies, daisies and border carnations, for example, may be brought on very early by setting such frames over them or by planting them under the frames in the fall. These frames may be of any size desired, and the sash may be either re-

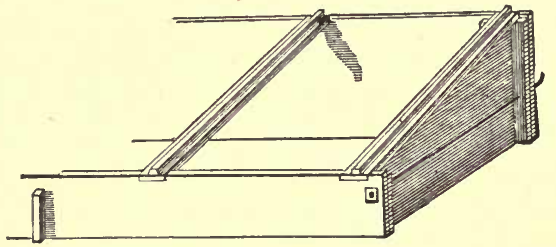

77. A method of making a frame.

movable, or, in case of small frames, they may be hinged at the top, Figs. 79-82 illustrate various types of handy frames.

Hotbeds.-A hotbed differs from a coldframe in having artificial bottom heat. This heat is ordinarily supplied by means of fermenting manure, but it may be obtained from other fermenting material, as tan-bark or leaves, or from artificial heat, as flues, steam pipes or water pipes. The hotbed is used for the very early starting of plants, and when the plants have outgrown the bed, or have become too thick, they are trans- 
planted into cooler hotbeds or into coldframes. There are many crops, however, which are carried

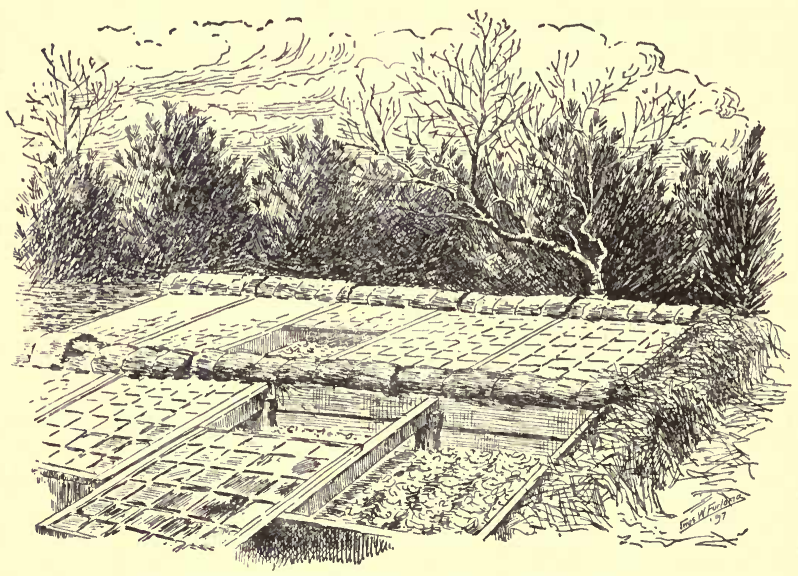

78. Coldframe against $\mathbf{a}$ hedge, and protected by straw mats.

to full maturity in the hotbed itself, as radishes and lettuce. The date at which the hotbed may be started with safety depends almost entirely upon the means at command of heating it and upon the skill of the operator. In the northern states, where outdoor gardening does not begin until the first or the last of May, hotbeds are sometimes started as early as January; but they are ordinarily delayed until early in March.

The heat for hotbeds is commonly supplied by the fermentation of horse manure. It is important that the manure be as uniform as possible 
in composition and texture, that it come from highly-fed horses, and is practically of the same age. The best results are generally obtained from manure from livery stables, from which it can be obtained in large quantities in a short space of time. Perhaps as much as one-half of the whole

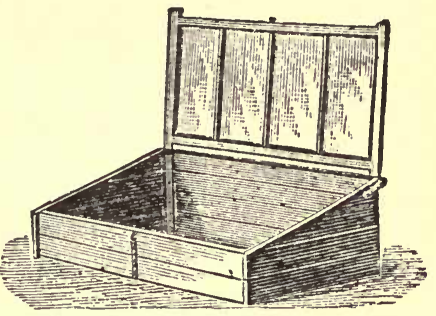

79. Portable coldframe. material should be of litter or straw which has been used in the bedding. The manure is piled in a long and shallow square-topped pile, not

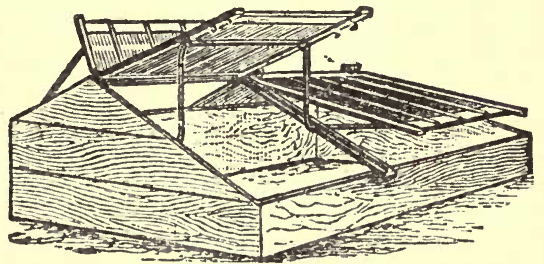

80. Portable coldframe.

more than four or six feet high as a rule, and is then allowed to ferment. Better results are generally obtained if the manure is piled under cover. If the weather is cold and fermentation does not start readily, wetting the pile with hot water may start it. The first fermentation is nearly always irregular; that is, it begins unequally in several places in the pile. In order to make the fermen- 
tation uniform, the pile must be turned occasionally, taking care to break up all hard lumps

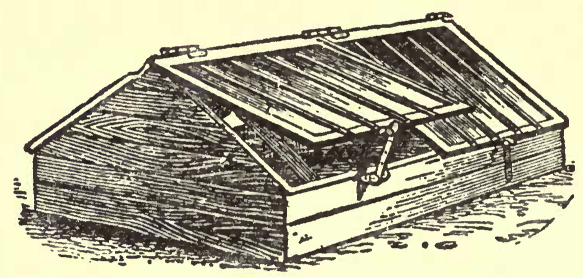

81. Portable coldframe.

and to distribute the hot manure throughout the mass. It is sometimes necessary to turn the pile five or six times before it is finally used, although half this number of turnings is ordinarily sufficient. When the pile is steaming uniformly throughout, it is placed in the hotbed, and is

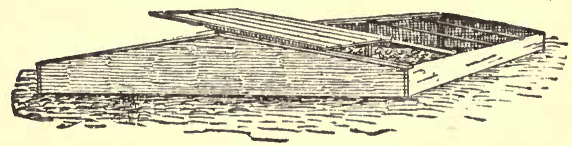

82. Small coldframe.

covered with the earth in which the plants are to be grown.

Hotbed frames are sometimes set on top of the pile of fermenting manure, as shown in Fig. 83. The manure should extend for some distance beyond the edges of the frame; otherwise the frame will become too cold about the outside, and the plants will suffer. It is preferable, however, 
to have a pit beneath the frame in which the manure is placed. If the bed is to be started in midwinter or very early in the spring, it is advisable to make this pit in the fall and to fill it with straw or other litter to prevent the earth from freezing deep. When it is time to make the bed, the litter is thrown out, and the ground is warm and ready to receive the fermenting manure. The pit should be a foot wider upon either

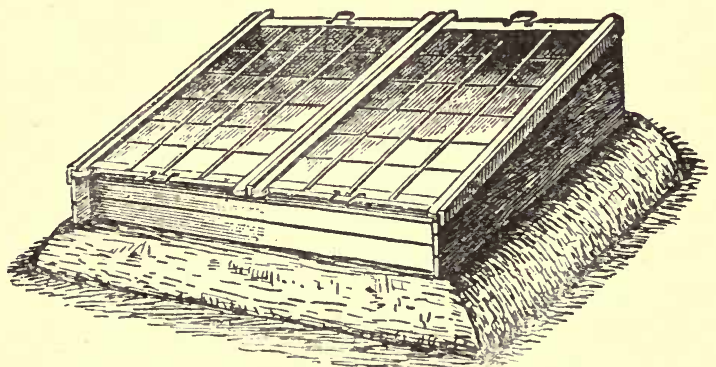

83. Hotbed with manure on top of the ground.

side than the width of the frame. Fig. 84 is a cross-section of such a hotbed pit. Upon the ground a layer of an inch or two of any coarse material is placed to keep the manure off the cold earth. Upon this, from twelve to thirty inchés of manure is placed. Above the manure is a thin layer of leaf-mold or some porous material, which will serve as a distributor of the heat, and above this is four or five inches of soft garden loam, in which the plants are to be grown. 
It is advisable to place the manure in the pit in layers, each stratum to be thoroughly trodden down before another one is put in. These layers should be from four to eight inches in thickness. By this means the mass is easily made uniform in consistency. Manure which has too much straw for the best results, and which will therefore soon part with its heat, will spring up quickly when

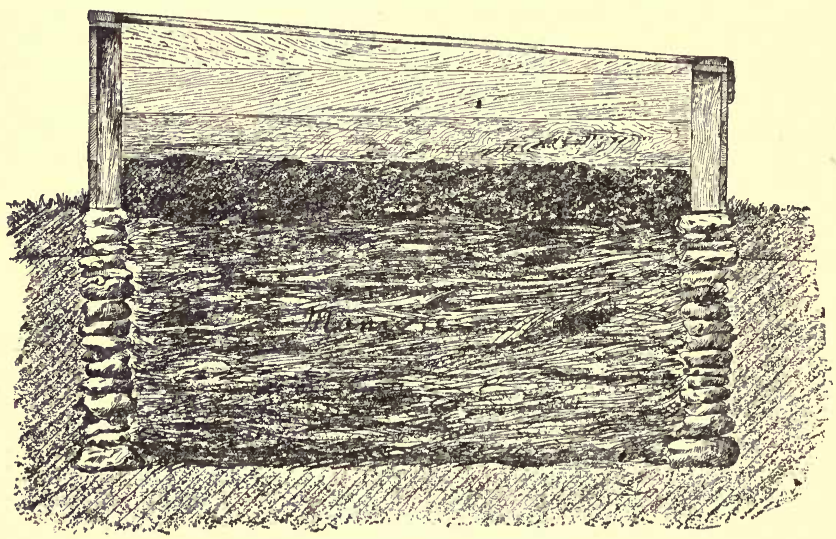

84. Section of a hotbed.

the pressure of the feet is removed. Manure which has too little straw, and which therefore will not heat well or will spend its heat quickly, will pack down into a soggy mass underneath the feet. When the manure has sufficient litter, it will give a springy feeling to the feet as a person walks over it, but will not fluff up when the 
pressure is removed. The amount of manure which is to be used will depend upon its quality, and also upon the season in which the hotbed is made. The earlier the bed is made, the larger should be the quantity of manure. Hotbeds which are supposed to hold for two months should have about two feet of manure, as a rule.

The manure will ordinarily heat very vigorously for a few days after it is placed in the bed. A soil thermometer should be thrust through the earth down to the manure, and the frame kept

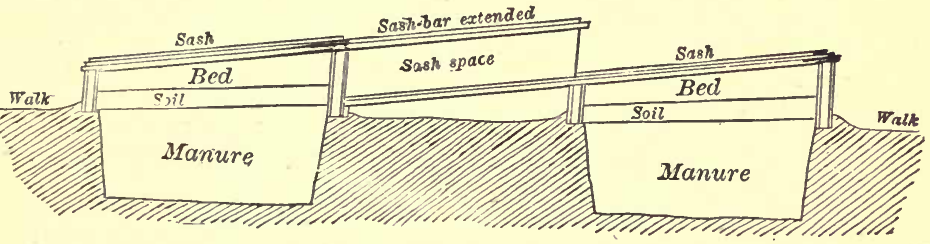

85. Parallel runs of hotbeds with racks for holding sashes.

tightly closed. When the temperature is passing below $90^{\circ}$, seeds of the warm plants, like tomatoes, may be sown, and when it passes below $80^{\circ}$ or $70^{\circ}$ the seeds of cooler plants may be sown.

If hotbeds are to be used every year, permanent pits should be provided for them. Pits are made from two to three feet deep, preferably the former depth, and are walled up with stone or brick. It is important that they be given good drainage from below. In the summer-time, after the sash are stripped, the old beds may be used 
for the growing of various delicate crops, like melons or half-hardy flowers. In this position, the plants can be protected in the fall. As already suggested, the pits should be cleaned out in the fall and filled with litter to facilitate the work of: making the new bed in the winter or spring.

Various modifications of the common type of hotbed will suggest themselves to the operator. The frames should ordinarily run in parallel rows,

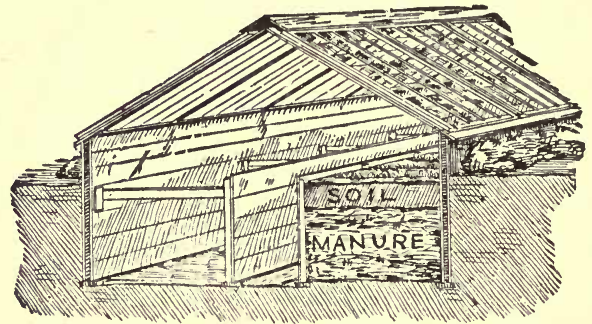

86. Manure-heated forcing-house.

so that a man walking between them ean attend to the ventilation of two rows of sash at once. Fig. 85 shows a different arrangement. There are two parallel runs, with walks upon the outside, and between them are racks to receive the sash from the adjacent frames. The sash from the left-hand bed are run to the right, and those from the right-hand bed are run to the left. Rumning upon racks, the operator does not need to handle them, and the breakage of glass is therefore less; but this system is little used because of the diff- 
culty of reaching the farther side of the bed from the single walk.

If the hotbed were high enough and broad enough to allow a man to work inside, we should have a forcing-house. Such a structure is shown in Fig. 86, upon one side of which the manure and soil are already in place. These manureheated houses are often very efficient, and are a good make-shift until such time as the party can afford to put in flue or pipe heat.

Hotbeds may be heated by means of steam or hot water. They can be piped from the heater in a dwellinghouse or greenhouse. Fig. 87 shows a hotbed with two pipes, in the positions 7,7 . below the bed. The soil is shown at 4 , and the plants (which,

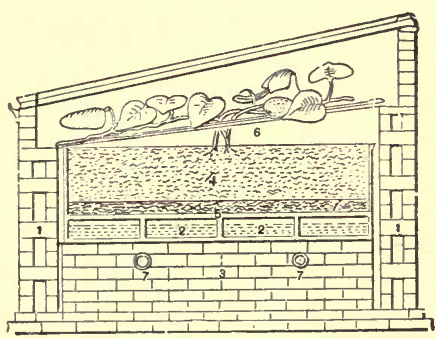

87. Pipe-heated hotbed. in this case, are vines) are growing upon a rack, at 6. There are doors in the end of the house, shown at 2,2, which may be used for ventilation or for admitting air underneath the beds. The pipes should not be surrounded by earth, but should run through a free air space.

It would scarcely pay to put in a hot water or steam heater for the express purpose of heating hotbeds, for if such an expense were incurred, it 
would be better to make a forcing-house. Hotbeds may be heated, however, with hot air flues with very good results. A home-made brick furnace may be constructed in a pit at one end of the run and underneath a shed, and the smoke and hot air, instead of being carried directly upwards, is carried through a slightly rising horizontal pipe which runs underneath the beds. For some distance from the furnace, this flue may be made of brick or unvitrified sewer pipe, but stovepipe may be used for the greater part of the run. The chimney is ordinarily at the farther end of the run of beds. It should be high, in order to secure a good draft. If the run of beds is long, there should be a rise in the underlying pipe of at least one foot in twenty-five. The greater the rise in this pipe, the more perfect will be the draft. If the runs are not too long, the underlying pipe may return underneath the beds and enter a chimney directly over the back end of the furnace, and such a chimney, being warmed from the furnace, will ordinarily have an excellent draft. The underlying pipe should occupy a free space or pit beneath the beds, and whenever it lies near to the floor of the bed or is very hot, it should be covered with asbestos cloth. While such flueheated hotbeds may be eminently successful, it may nevertheless be said, as a general statement, that whenever such trouble and expense are incurred it is better to make a forcing-house. Full direc- 
tions for the making and management of forcinghouses may be found in Taft's "Greenhouse Construction" and in Bailey's "Forcing-Book."

Close attention is required in the management of hotbeds, to insure that they do not become too hot when the sun comes out suddenly, and to give plenty of fresh air. Ventilation is usually effected by raising the sash at the upper end and letting it rest upon a block. Whenever the temperature is above freezing point, it is generally advisable to take the sash off part way, as shown in the central portions of Fig. 78, or even to strip it off entirely, as shown in Fig. 76. Care should be taken not to water the plants at nightfall, especially in dull and cold weather, but to give them water in the morning, when the sun will soon bring the temperature up to its normal state.

The most satisfactory material for use in hotbed and coldframe sash is double-thick, second-quality glass; and panes which are twelve inches wide are ordinarily wide enough, and suffer comparatively little in breakage. For coldframes, however, various oiled papers and water-proof eloths may be used, especially for plants which are started little in advance of the opening of the season. When these materials are used, it is not necessary to have expensive sash, but rectangular frames are made from strips of pine seven-eighths inch thick and two and one-half inches wide, halved together at the corners and each corner 
reinforced by a square carriage-corner, such as is used by carriage-makers to secure the corners of buggy boxes. These corners can be bought by the pound at hardware stores.

Some protection, other than the glass, must be given to hotbeds. They need covering on every cold night, and sometimes during the entire day in very severe weather. Very good material for covering the sash is matting, such as is used for carpeting floors. Old pieces of carpet may also be used. Various hotbed mattings are sold by dealers in gardeners' supplies. Gardeners often make mats of rye straw. Such mats are thick and durable, and are rolled up in the morning, as shown in Fig. 78. There are various methods of making these straw mats, but Fig. 88 illustrates one of the best. A frame is made after the manner of a saw-horse, with a double top, and tarred or marline twine is used for securing the strands of straw. It is customary to use six runs of this warp. Twelve spools of string are provided, six hanging upon either side. Some persons wind the cord upon two twenty-penny nails, as shown in the figure, these nails being held together at one end by wire which is secured in notches filed into them. The other ends of the spikes are free, and allow the string to be caught between them, thus preventing the balls from unwinding as they hang upon the frame. Two wisps of straight rye straw are secured and laid upon the frame, with 
the butt ends outward and the heads overlapping. Two opposite spools are then brought up and a hard knot is tied at each point. The projecting butts of the straw are then cut off with a hatchet, and the mat is allowed to drop through to receive the next pair of wisps. In making these mats,

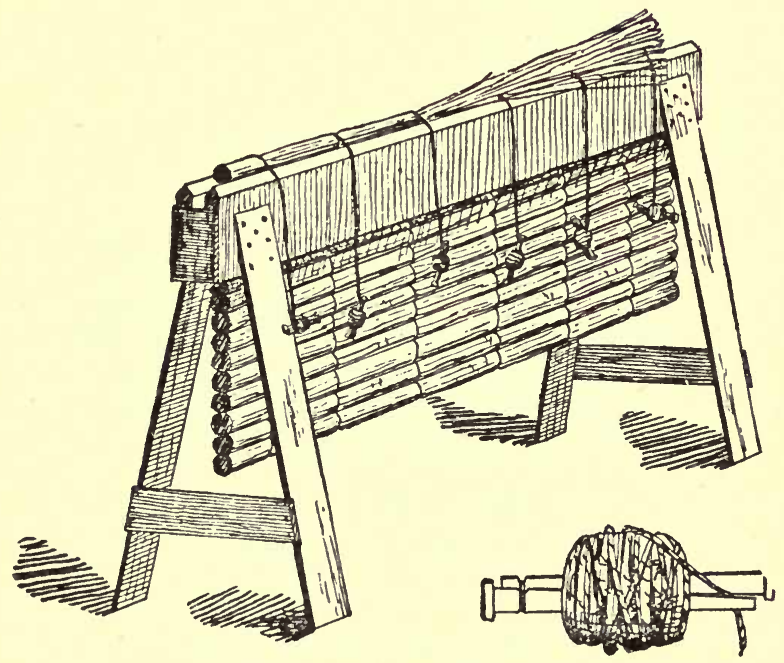

88. Making straw mats.

it is essential that the rye contains no ripe grain; otherwise it attracts the mice. It is best to grow rye for this especial purpose, and to cut it before the grain is in the milk, so that the straw does not need to be threshed.

In addition to these coverings of straw or mat- 
ting, it is sometimes necessary to provide board shutters to protect the beds, especially if the plants are started very early in the season. These shutters are made of half-inch or five-eighths inch pine lumber, and are the same size as the sashthree by six feet. They may be placed upon the sash underneath the matting, or they may be used above the matting. In some cases they are used without any matting.

In the growing of plants in hotbeds, every effort should be made to prevent the plants from growing spindling, or becoming "drawn." To make stocky plants, it is necessary to give room to each plant, to be sure that the distance from the plants to the glass is not great, not to provide too much water in dull and cold weather, and especially to give abundance of air.

\section{INSECTS AND DISEASES}

The insects and diseases which attack garden plants are legion; and yet, for the most part, they are not very difficult to combat if one is timely and thorough in his operations. These difficulties may be divided into three great categories: the injuries wrought by insects; the injuries of parasitic fungi; the various types of so-called constitutional diseases, many of which are caused by germs or microbes.

Insect injuries are easily recognized. The diseases caused by parasitic fungi are usually desig- 
nated by distinct marks or spots upon the leaves or stems, and the gradual weakening or death of the part; and, in many cases, the leaves drop bodily. For the most part, these spots upon the leaves or stems develop sooner or later a mildewlike or rusty appearance, which is due to the development of the spores or fruiting bodies. Fig. 89 illustrates the ravages of one of the parasitic

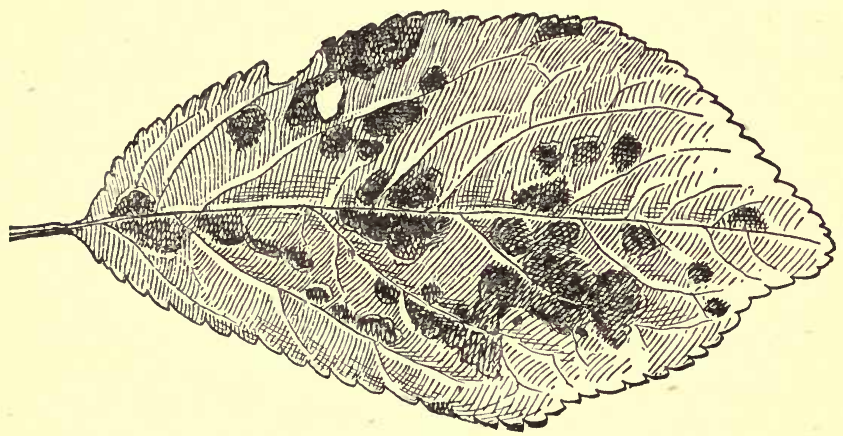

89. Work of shot-hole fungus of plum.

fungi, the shot-hole fungus of the plum. Each spot upon the leaf probably represents a distinct attack of the fungus, and in this particular disease these injured parts of tissue are liable to fall out, leaving holes in the leaf. Plum leaves which are attacked early in the season by this disease usually drop prematurely; but sometimes the leaves persist, being riddled by holes at the close of the season. Fig. 90 is the rust of the holly- 
hock. In this case the pustules of the fungus are very definite upon the under side of the leaf, and each pustule, as in the case of the plum disease, may represent a distinct attack of fungus.

The constitutional and bacterial diseases usually affect the whole plant, or at least large portions of

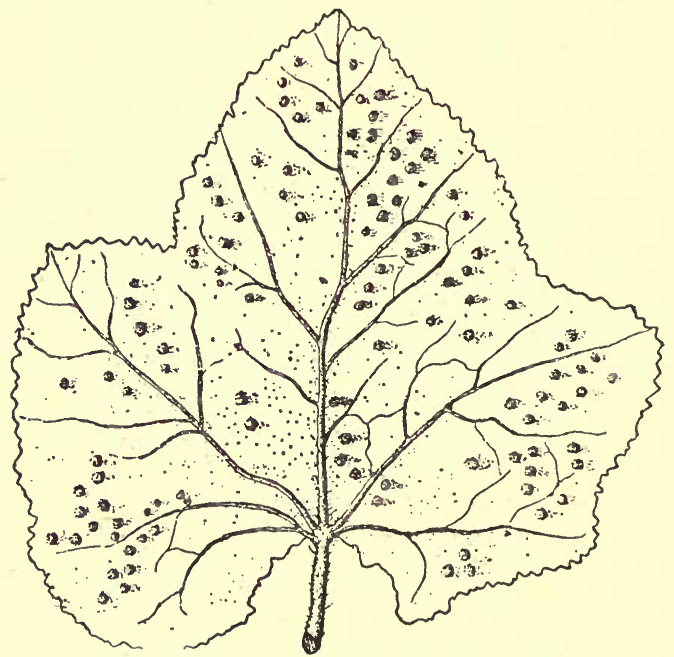

90. Hollyhock rust. Under side of leaf.

it; and the seat of attack is commonly not so much in the individual leaves as in the stems, the sources of food supply being thereby cut off from the foliage. The symptoms of this class of diseases are general weakening of plant when the disease affects the plant as a whole or when it attacks large branches; or sometimes the leaves shrivel 
and die about the edges or in large irregular discolored spots, but without the distinct pustular marks of the parasitic fungi. There is a general tendency for the foliage upon plants affected with such diseases to shrivel and to hang upon the stem for a time. One of the best illustrations of this type of disease is the pear-blight.

Still another class of diseases is characterized by galls upon the roots. The galls upon greenhouse plants, and upon outdoor plants in the southern states, are usually caused by a true worm or nematode, and the only complete remedy for these is to freeze the soil. In glass houses there need be no injury from these galls if the gardener is careful to use no soil except that which has been thoroughly frozen. Nematode galls are not known to occur permanently in the northern states where the ground freezes deep. There is another type of root-gall, however, illustrated in Fig. 91, which is coming to be common throughout the northern states, and the cause of which is unknown. It is probable that this disease propagates itself in the stock, even if the galls are all removed before the plant is set, although this point is not yet thoroughly determined. It is supposed by many careful observers, also, that land in which rootgalls have been produced is unsafe for the setting of plants which are subject to the injury. The best advice which can now be given in regard to this difficulty is to set no plants which have galls 


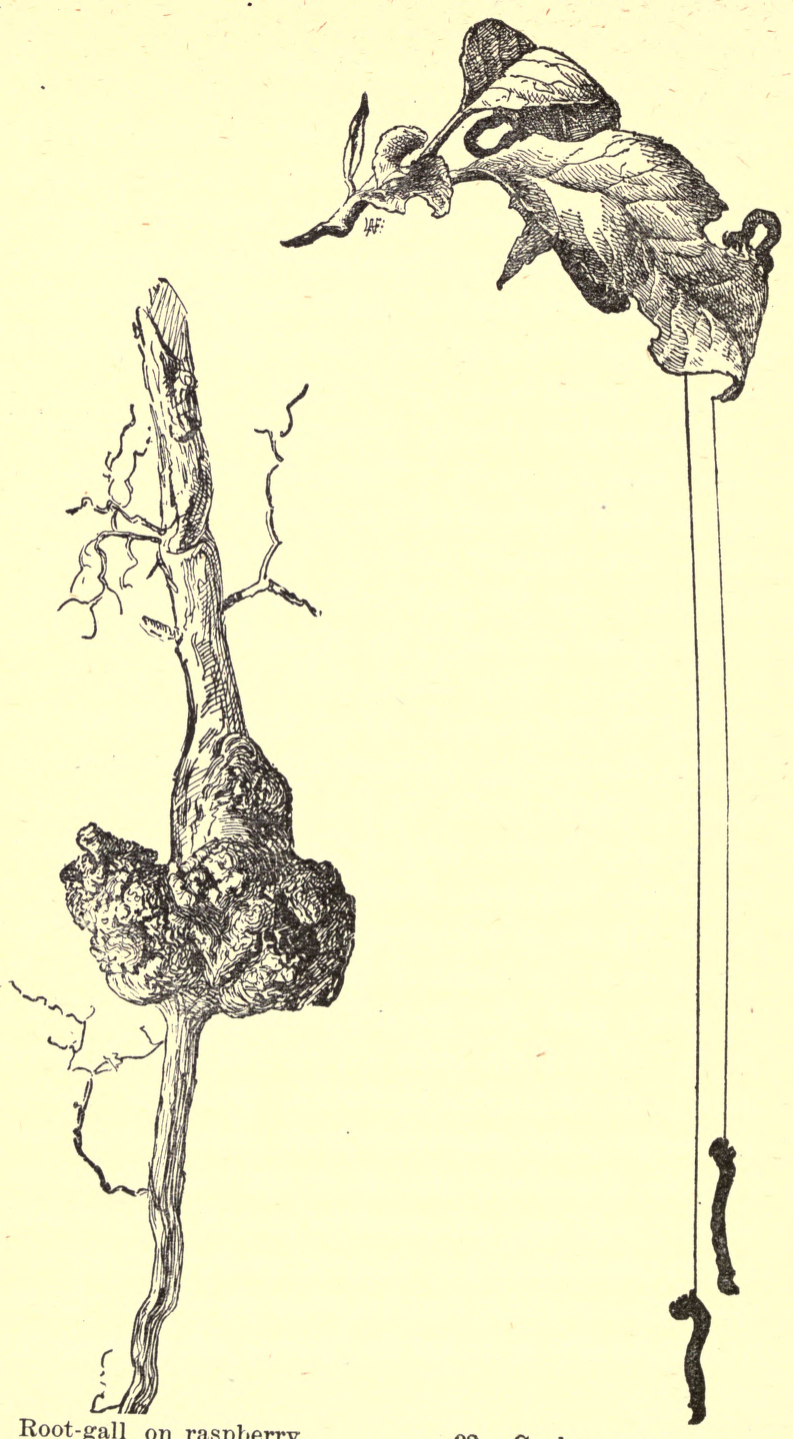

91. Root-gall on rasplerry.

92. Canker-worm 
on them, and to devote land in which galls have been found to some annual crop for three or four

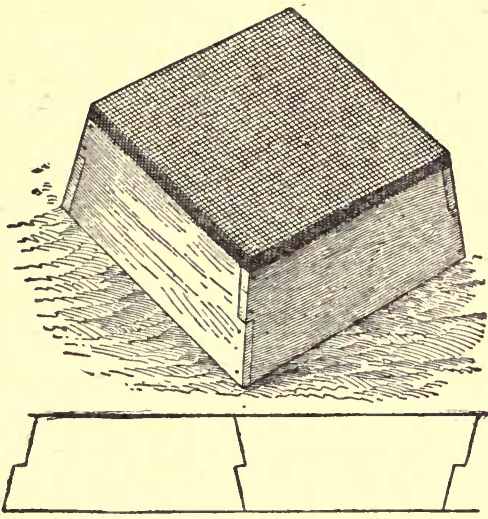

93. Box for protecting plants from insects. years, until the germs of the disease may be sup-

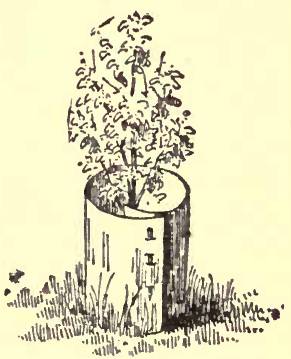

94. Protecting from cut-worms.

posed to be eliminated. These galls are common upon woody plants, especially raspberries and blackberries and the fruit trees.

Of obvious insect injuries, there are two general types,-those wrought by insects which bite or chew their food, as the ordinary beetles and worms, and those wrought by insects which puncture the surface of the plant and derive their food by suction, as scale-insects and plant-lice. The canker-worm (Fig. 92) is a notable example of the former class, and all these insects are readily dispatched by the application of poison to the foliage. It is apparent, however, that insects which suck the juice of the plant are not poisoned 
by any liquid which may be applied to the surface. They may be killed by various materials which act upon them externally, as the soap washes, kerosene emulsions, and the like.

The first and best means of averting trouble from insects and fungi is to prevent their attacks. It is often advisable to plant only those species or varieties which are least subject to serious injury. If a garden is kept clean of rubbish and all places in which the insects can hibernate and the fungi ean propagate, very much will be accomplished towards keeping the plantation in health. All fallen leaves from plants which have been attacked by fungi should be raked up and burned, and in the fall all diseased wood should be cut out and destroyed. In the case of small plants which are attacked by large insects, hand-picking is the most efficient means of riddance. There are also various ways of protecting the plants from the attacks of insects. One of the best is to cover the plants with fine mosquito-netting or to grow them in hand frames, or to use a wire-covered box like that shown in Fig. 93. In growing plants under such covers, care must be taken that the plants are not kept too close or confined; and in cases in which the insects hibernate in the soil, these boxes, by keeping the soil warm, may cause the insects to hatch all the sooner. In most cases, however, these covers are very efficient, especially for keeping the striped bugs off young plants of melons and 
cucumbers. Cut-worms may be kept away from plants by placing sheets of tin or of heavy glazed paper about the stem of the plant, as shown in Fig. 94. Climbing cut-worms are kept off young
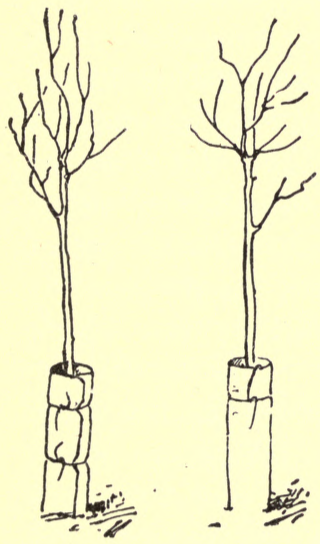

95. Protecting trees from cut-worms.

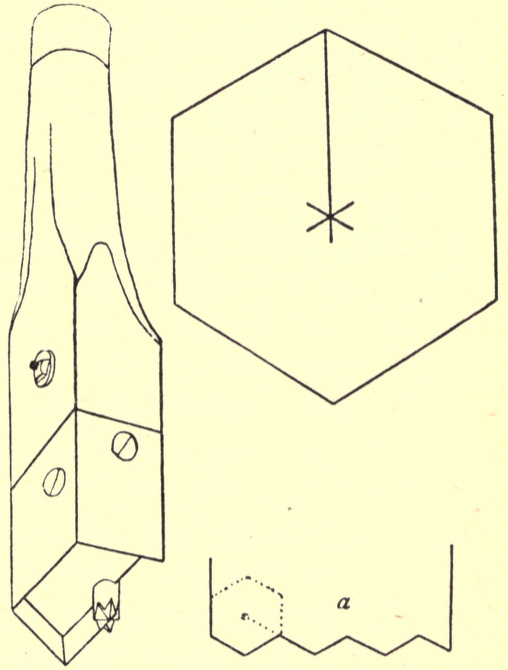

96. Showing methods of cutting paper to protect plants from maggots.

trees by the means as shown in Fig. 95; or a roll of cotton may be placed about the trunk of the tree, a string being tied upon the lower edge of the roll and the upper edge of the cotton turned down like the top of a boot. The insects cannot crawl over this obstruction. 
The maggots which attack the roots of cabbages and cauliflowers may be kept from the plant by pieces of tarred paper, which are placed close about the stem upon the surface of the ground. Fig. 96 illustrates a hexagon of paper, and also shows a tool which is used for cutting it. This means of preventing the attacks of the cabbage maggot is described in detail by Professor Goff :

"The cards are cut in a hexagonal form, in order to better economize the material, and a thinner grade of tarred paper than the ordinary roofing felt is used, as it is not only cheaper, but being more flexible, the cards made from it are more readily placed about the plant without being torn. The blade of the tool, which should be made by an expert blacksmith, is formed from a band of steel, bent in the form of a half hexagon, and then taking an acute angle, reaches nearly to the center, as shown in Fig. 96. The part making the star-shaped eut is formed from a separate piece of steel, so attached to the handle as to make a close joint with the blade. The latter is beveled from the outside all around, so that by removing the part making the star-shaped cut, the edge may be ground on a grindstone. It is important that the angles in the blade be made perfect, and that its outline represents an exact half hexagon. To use the tool, place the tarred paper on the 
end of a section of a log or piece of timber and first cut the lower edge into notches, as indicated at $a$, Fig. 96, using only one angle of the tool. Then commence at the left side, and place the blade as indicated by the dotted lines, and strike at the end of the handle with a light mallet, and a complete card is made. Continue in this manner across the paper. The first cut of every alternate course will make an imperfect card, and the last cut in any course may be imperfect, but the other cuts will make perfect cards if the tool is correctly made, and properly used. The cards should be placed about the plants at the time of transplanting. To place the card bend it slightly, to open the slit, then slip it on to the center, the stem entering the slit, after which spread the card out flat, and press the points formed by the star-shaped cut snugly around the stem."

An efficient means of destroying insects in glass houses is by fumigating with various kinds of smoke or vapors. The best material to use for general purposes is some form of tobacco or tobaceo compounds. The old method of fumigating with tobaceo is to slowly burn slightly dampened tobacco stems in a kettle or scuttle, allowing the house to be filled with the pungent smoke. Lately, however, a fluid extract of tobaceo has been brought into use, which is evaporated in the house by dropping red-hot iron into 
the liquid, and which is very destructive to insect life while it does not injure the plants. Fumigation may be practiced even in hotbeds and coldframes, as shown in Fig. 97, which illustrates a

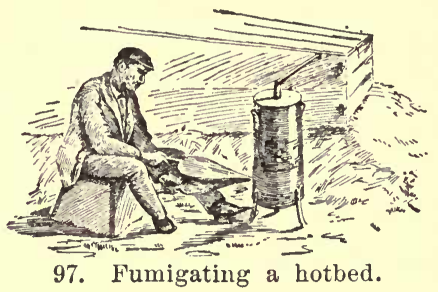

fumigater with the outlet pipe running into the frame and with draft supplied by means of a hand bellows.

The most efficient means of destroying insects and fungi, however, is by the use of various sprays. The two general types of insecticides have already been mentioned-those which kill by poisoning, and those which kill by destroying the body of the insect. Of the former, there are three materials in common use-Paris green, London purple and hellebore.* Of the latter,

*Paris Green.-Paris green, 1 pound; water, 200-300 gallons. If this mixture is to be used upon peach trees, 1 pound of quicklime should be added. Repeated applications will injure most foliage, unless lime is added. Paris green and Bordeaux mixture can be applied together with perfect safety. Use at the rate of 4 ounces of the arsenites to 50 gallons of the mixture. The action of neither is weakened, and the Paris green loses all caustic properties. For insects which chew.

LONDON PURPLE.-This is used in the same proportion as Paris green, but as it is more caustic it should be applied with two or three times its weight of lime, or with the Bordeaux mixture. The composition of Lon- 
the kerosene emulsion* is the most generally used. Sprays for fungi depend for their efficiency upon some form of copper or sulfur, or both. For surface mildews, as cucumber mildew, dusting flowers of sulfur upon the foliage is ample protection. In most cases, however, it is necessary to apply the materials in liquid form, because they can be more thoroughly and economically distributed, and they adhere to the foliage better. The best general fungicide is the Bordeaux mixture ${ }^{\dagger}$ It is generally, however, not advisable to

don purple is exceedingly variable, and unless good reasons exist for supposing that it contains as much arsenic as Paris green, use the latter poison. Do not use London purple on peach or plum trees unless considerable lime is added. For insects which chew.

Hellebore.-Fresh white hellebore, 1 ounce; water, 3 gallons. Apply when thoroughly mixed. This poison is not so energetic as the arsenites, and may be used a short time before thé sprayed portions are harvested. For insects which chew.

*Kerosene Emulsion.-Hard soap, 1/2 pound; boiling water, 1 gallon; kerosene, 2 gallons. Dissolve the soap in the water, add the kerosene, and churn with a pump for 5 to 10 minutes. Dilute 10 to 25 times before applying. Use strong emulsion, diluted four times in winter, for all scale insects. For insects which suck, as plant-lice, mealy bugs, red spider, thrips, bark-lice or scale. Cabbage-worms, currant-worms, and all insects which have soft bodies, can also be successfully treated.

†Bordeaux Mixture.-Copper sulfate, 6 pounds; quicklime, 4 pounds; water, 40 to 50 gallons. Dissolve the copper sulfate by putting it in a bag of coarse cloth and hanging this in a ressel holding at least four gallons, so that it is just covered by the water. Use an earthen or wooden vessel. Slake the lime in an equal amount of water. Then mix the two and add enough water to make 40 gallons. It is then ready for immediate use, but will keep for some tiine. If the mixture is to be used on peach foliage, it is advisable to add an extra pound of lime to the above formula. When applied to such plants as carnations or cabbages, it will adhere better if a pound of hard soap is dissolved in hot water and added to the mixture. For rots, molds, mildews, and all fungous diseases. 
use the Bordeaux mixture upon ornamental plants, because it discolors the foliage and makes the plants look very untidy. In such cases it is best to use the ammoniacal copper solution, ${ }^{*}$ which leaves no stain upon the plant. In all spraying operations, it is especially important that the applications be made the very moment the insect or disease is discovered, or in the case of fungous diseases, if one is expecting an attack, it is well to make an application of Bordeaux mixture even before the disease appears. When the fungus once gets inside the plant tissue it is almost impossible to destroy it, inasmuch as fungicides act upon these deep-seated fungi very largely by preventing their fruiting and their further spread on the surface of the leaf. For ordinary conditions, from two to four sprayings are necessary to dispatch the enemy.

Persons who desire to post themselves thoroughly on spraying should procure Lodeman's "Spraying of Plants," and then consult the recent bulletins of the experiment stations. Spraying in relation to fruit-culture is discussed at some length in "Principles of Fruit-Growing."

There are many kinds of machines and devices for the application of sprays to plants. For

\footnotetext{
*ammoniacal Copper Carbonate.-Copper carbonate, 1 ounce; ammonia, 1 volume $26^{\circ}$ Beaumé, $7 / 8$ volumes water (enough to dissolve the copper); water, 9 gallons. The copper carbonate is best dissolved in large bottles, where it will keep indefinitely, and it should be diluted with water as required. For the same purposes as Bordeaux mixture.
} 
houses and a few individual specimens, the spray nay be applied with a whisk, or with a common garden syringe. If one has fifty or a hundred plants to treat, however, it is best to have some kind of bucket pump like those shown in Fig. 98. Upon a lawn or in a small garden, a tank upon wheels (Figs. 99, 100, 101) is handy and efficient. In such cases, or even for larger areas, some of the knapsack pumps (Fig. 102) are very desirable. These machines are always serviceable, because the operator stands so near to his work; but they carry a comparatively small amount of liquid and do not throw it rapidly, and they are, therefore, expensive when much work is to be done. Yet, in ordinary home grounds, the knapsack pump is

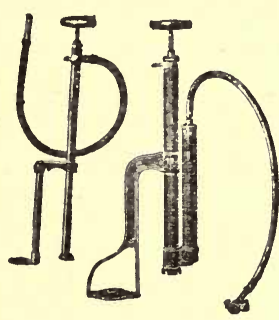

98. Bucket pumps.

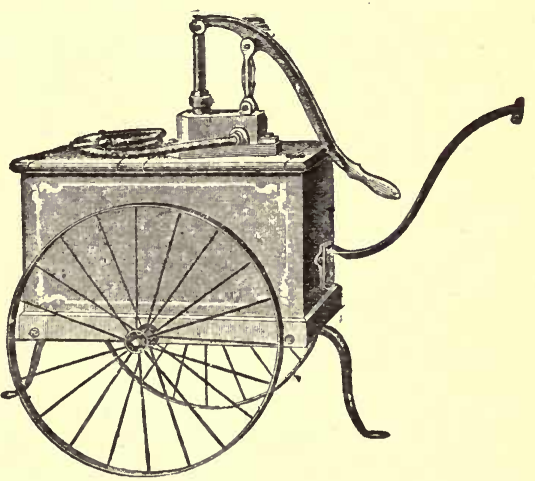

99. A handy garden sprayer.

one of the most efficient and practicable of all the spraying devices. For large areas, as for orchards and fields, a barrel pump mounted upon a wagon 
or a stone-boat is best. Common types of barrel pumps are shown in Fig. 103. There are many patterns of spraying machines, and the intending

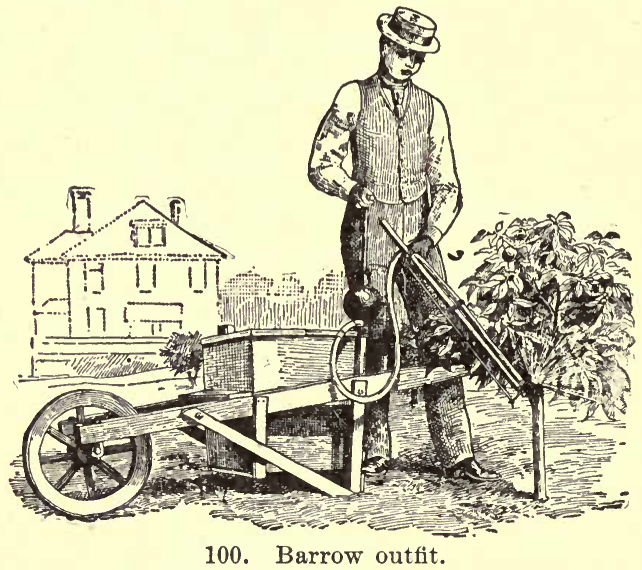

purchaser should send for catalogues to the various manufacturers. The addresses may be found in the advertising pages of rural papers.

As to nozzles for spraying, it may be said that there is no one pattern which is best for all purposes. For work at short range, some of the nozzles of the Cyclone type, as shown in Fig. 104, are to be recommended; but for longer range and for high trees, and especially for barrel pumps, a nozzle which throws more liquid is desirable. One of the best of these is shown in Fig. 105, but nearly every manufacturer of pumps has some 
particular type of nozzle which he sells with his machinery.

\section{PROTECTING PLANTS FROM ANIMALS}

Along roadsides and other exposed places it is often necessary to protect newly set trees from horses and the encroachment of vehicles. There are various kinds of tree guards. The best types are those which are more or less open, so as to allow the free passage of air, and which are far enough removed from the body of the tree that the trunk may expand without difficulty. If the tree guards are very tight they may shade the trunk so much that the tree may suffer when the guard is removed. It is important that the guard does not fill with litter in which insects may harbor. As soon as the tree is old enough to escape injury, the guards should be removed. A very good guard, made of laths held together with three strips of band-iron, and

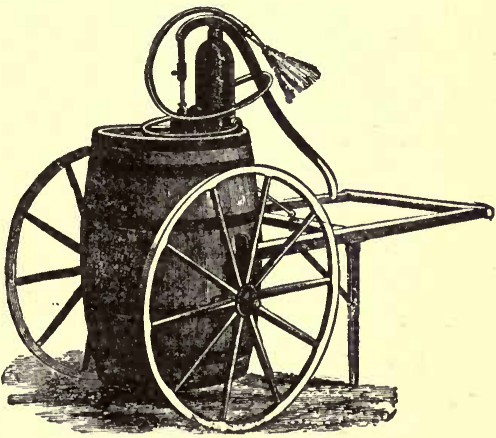

101. Portable barrel outfit. secured to iron posts, is shown in Fig. 106. Fig. 107 shows a guard made by winding fencing wire upon three posts or stakes. When there is likely to be danger from too great shading of 
the trunk, this latter form of guard is one of the best.

Of course hitching posts should be provided, wherever horses are to stand, to obviate the temp-

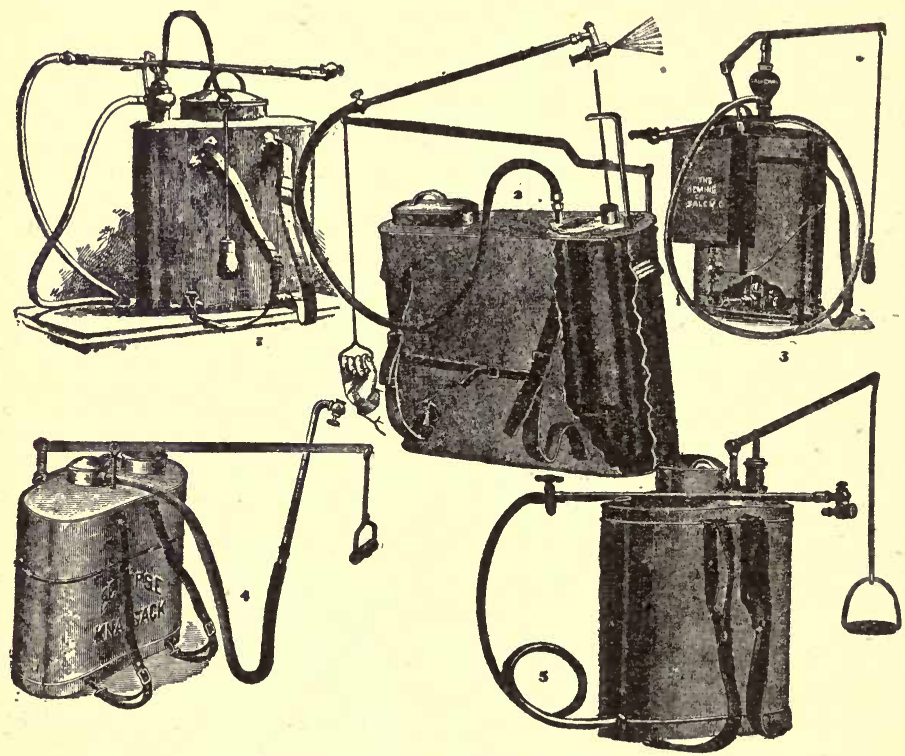

102. Knapsack pumps.-1, Galloway knapsack; 2, Garfield; 3, Deming kerosene emulsion knapsack; 4, Eclipse; 5, Excelsior.

tation of hitching to trees. Fig. 108, however, shows a very good device when a hitching post is not wanted. A strong stick, four or five feet long, is secured to the tree by a staple and at the lower end of the stick is a short chain with a snap 
in the end. The snap is secured to the bridle, and the horse is not able to reach the tree.

Trees and bushes are often seriously injured by the gnawing of mice and rabbits. The best pre-

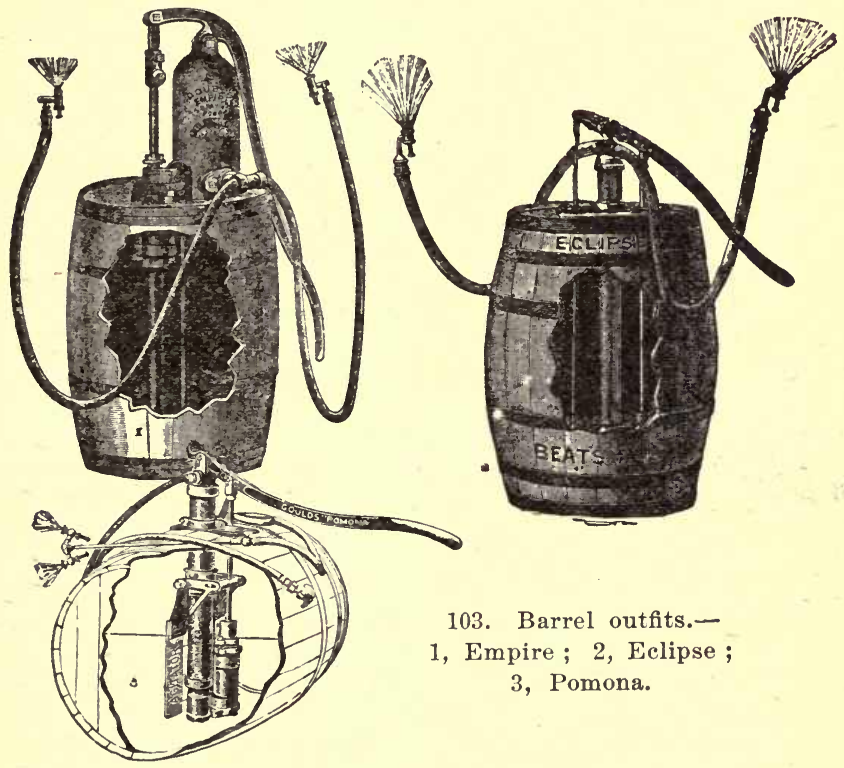

ventive is not to have the vermin. If there are no places in which rabbits and mice can burrow and breed, there will be little difficulty. At the approach of winter, if mice are feared, the dry litter should be removed from about the bases of the trees, or it should be packed down very firm, so that the mice cannot nest in it. If the rodents 
are very abundant, it may be advisable to wrap fine wire netting about the base of the tree. Various washes may be put upon the tree to keep rabbits away, a number of which may be found in the "Horticulturist's Rule-Book." A boy who is fond of trapping or hunting will ordinarily solve the rabbit difficulty. Rags tied upon sticks which are placed at intervals about the plantation will often frighten rabbits away.

Trees which are girdled by mice should be wrapped up as soon as discovered, so that the

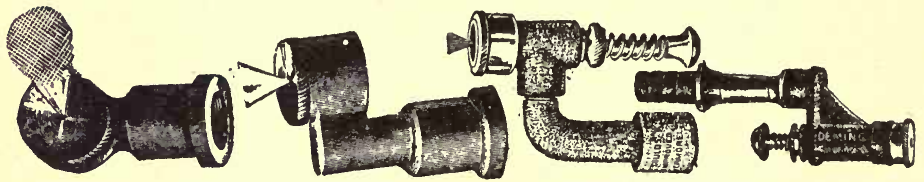

104. Cyclone and Vermorel nozzles.

wood shall not become too dry. When warm weather approaches, shave off the edges of the girdle so that the healing tissue may grow freely, smear the whole surface with grafting-wax, or with clay, and bind the whole wound with strong cloths. Even though the tree is completely girdled for a distance of three or four inches, it may generally be saved by this treatment, unless the injury extends into the wood. The sap from the roots rises through the soft wood and not between the bark and the wood, as commonly supposed. When this sap has reached the foliage, it is elaborated and changed into plant-food, and this food 


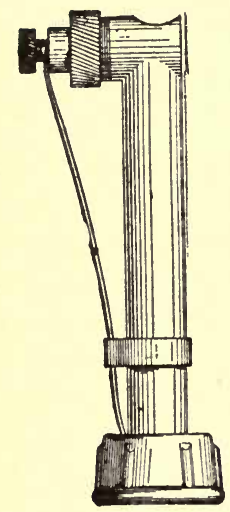

105. MeGowen nozzle.

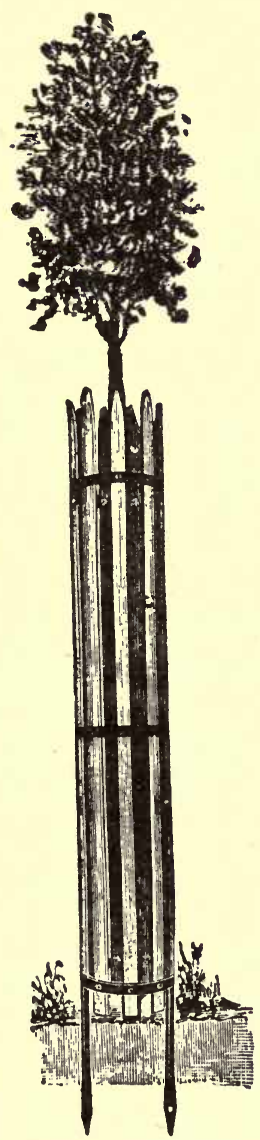

106. Lath tree guard.

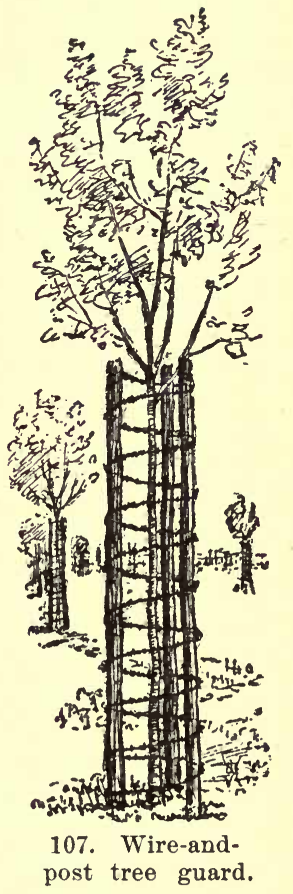


is distributed throughout the plant, the path of transfer being in the inner layers of bark. This food material, being distributed back to the girdle, will generally heal over the wound if the wood is not allowed to become dry. In some cases, however, it is necessary to join the bark above and

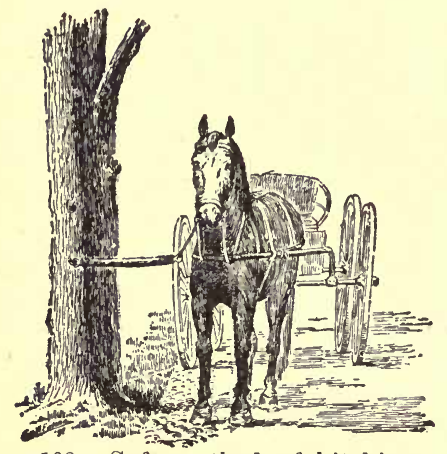

108. Safe method of hitching a horse to a tree.

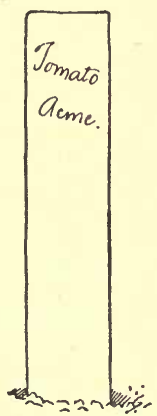

109. Common stake label.

below the girdle by means of cions, which are whittled to a wedge-shape on either end, and inserted underneath the two edges of the bark. The ends of the cions and the edges of the wound are held by a bandage of cloth, and the whole work is protected by melted grafting-wax poured upon it.* See "Pruning-Book" for details.

\footnotetext{
*A good grafting-wax is made as follows : Into a kettle place one part by weight of tallow, two parts of beeswax, four parts of rosin. When completely melted, pour into a tub or pail of cold water, then work it with the hands (which should be greased) until it develops a grain and becomes the color of taffy candy. The whole question of the propagation of plants is discussed in "The Nursery-Book."
} 


\section{KEEPING RECORDS OF THE PLANTATION}

If one has a large and valuable collection of fruit or ornamental plants, it is desirable that he have some permanent record of them. The most satisfactory method is to label the plants, and then to make a chart or map upon which the various plants are indicated in their proper posi-

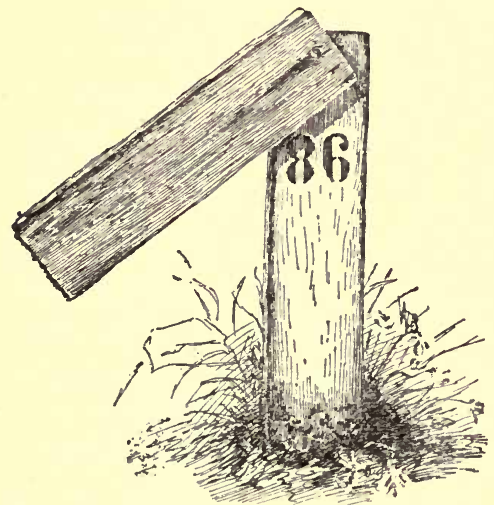

110. A good stake label.

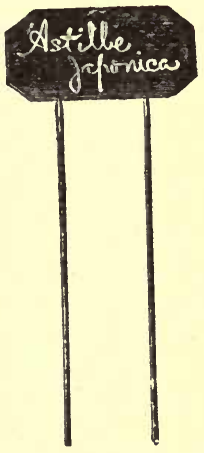

111. Metal stake label.

tions. The labels are always liable to be lost and to become illegible, and they are often misplaced by careless workmen or mischievous boys.

For vegetables, annuals and other temporary plants, the best labels are simple stakes, like that shown in Fig. 109. Garden stakes may be bought of label manufacturers, a foot long, an inch wide and three-eighths inch thick, for from three to five 
dollars a thousand. These take a soft pencil very readily, and if the labels are pulled up in the fall, and stored in a dry place, they will last two
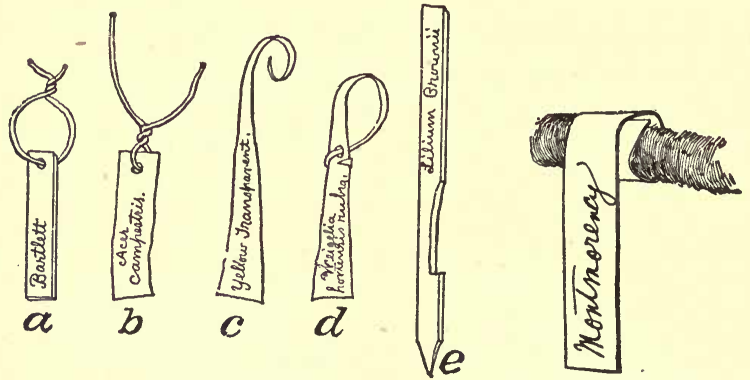

112. Zinc tallies.

113. Common zine tally.

or three years. For more permanent herbaceous plants, as rhubarb and asparagus, or even for bushes, a stake which is sawed from clear pine or cypress, eighteen inches long, three inches wide and an inch or more thick, affords a most excellent label. The lower end of the stake is sawed to a point, and is dipped in coal tar or creosote, or other preservative. The top of the stake is painted white, and the legend is written with a large and soft pencil. When the writing becomes illegible or the stake is needed for other plants, a shaving is taken off the face of the label with a plane, a fresh coat of paint added, and the label is as good as ever. These labels are strong enough to withstand shocks from whiffletrees and tools, and should last ten years. 
Whenever a legend is written with a lead pencil, it is advisable to use the pencil when the paint (which should be white lead) is still fresh or soft. Fig. 110 shows a very good device for preserving the writing upon the face of the label. A block of wood is secured to the label by means of a screw, covering the legend completely and protecting it from the weather.

If more ornamental stake labels are desired, there are various types which can be bought in the market, or one can be made after the fashion of Fig. 111. This is a zinc plate, which can be

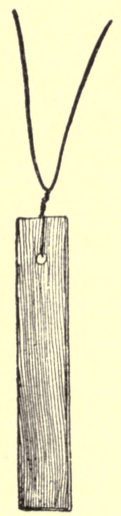

114. Nurseryman's wooden label.

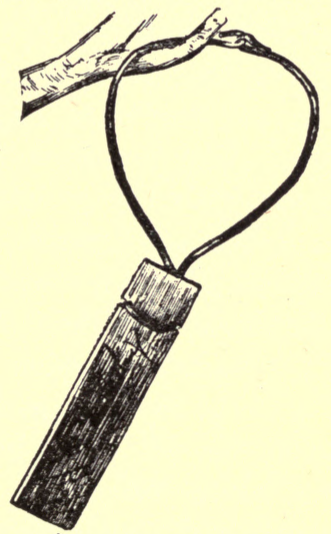

115. Cornell tree label.

painted black and the name written with white paint. Many persons, however, prefer to paint the zinc white, and write or stamp the label with 
black ink or black type. Two strong wire legs are soldered to the label, and these prevent it from turning around. These labels are, of course, much more expensive than the ordinary stake labels, and are usually not so satisfactory.

For labeling trees, various kinds of zinc tallies are in common use, as shown in Figs: 112 and 113. Fresh zinc takes a lead pencil readily, and the writing often becomes more legible as it becomes older, and it will generally last three or four years. These labels are attached either by wires, as $a, b$, Fig. 112, or they are wound about the limb as shown in $c, d$ and $e$, in Fig. 112. The type of zinc label most in use is a simple strip of zinc, as shown in Fig. 113, wrapped about the limb. The metal is so flexible that it expands readily with the growth of the limb. While these zinc labels are durable, they are very inconspicuous because of their neutral color, and it is often difficult to find them in dense masses of foliage. The common wooden label of the nurserymen (Fig. 114) is perhaps as useful as any for general purposes. If the label has had a light coat of thin white lead, and the legend has been made with a soft lead pencil, the writing should be legible for four or five years. Fig. 115 shows another type of label which is more durable, since the wire is stiff and large, and is secured around the limb by means of pincers. The large loop allows the limb to expand, and the stiff wire 
prevents the misplacing of the label by winds and workmen. The tally itself is what is known as the package label of the nurserymen, being six inches long, one and one-fourth inches wide, and costing (painted) less than one and one-half dollars a thousand. The legend is made with a lead

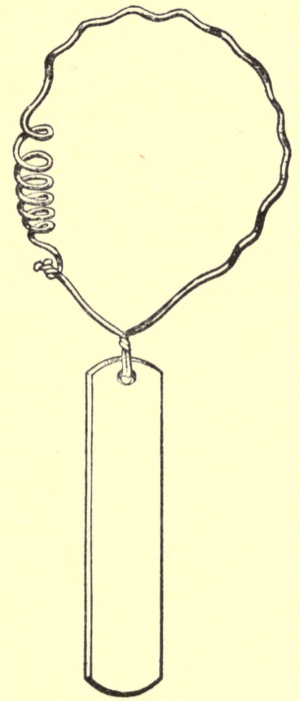

116. Serviceable tree label.

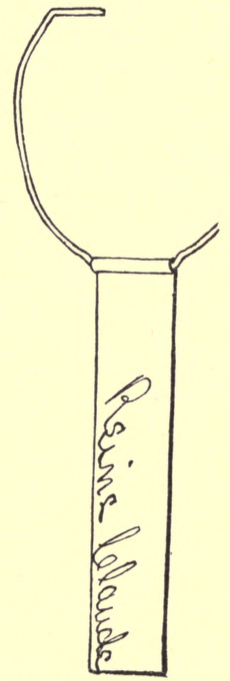

117. Zine tree label.

pencil when the paint is fresh, and sometimes the label is dipped in thin white lead after the writing is made, so that the paint covers the writing with a very thin protecting coat. A similar label is shown in Fig. 116, which has a large wire loop, with a coil to allow the expansion of the limb. 
The tallies of this type of label are often made of glass or porcelain with the name indelibly printed in them. Fig. 117 shows a zinc tally, which is secured to the tree by means of a sharp and pointed wire which is driven into the wood. Some prefer to have two arms to this wire, driving one point upon either side of the tree. If galvanized wire is used, these labels will last for many years.

It is very important, when adjusting labels to trees, to be sure that the wire is not twisted tight

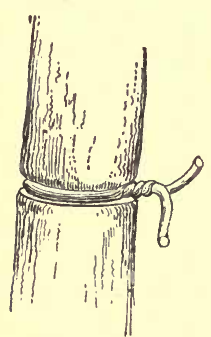

118. Stem against the wood. Fig. 118 shows the injury which is likely to result from label wires. When a tree is constricted or girdled, it is very liable to be broken off by winds. It should be a rule to attach the label to a limb of minor importance, so that if the wire should injure the part, the loss will not girdled by the be serious. When the label, Fig. label wire.

114 , is applied, only the tips of the wire should be twisted together, leaving a large loop for the expansion of the limb.

\section{ENRICHING THE LAND.}

There are two coördinate problems concerned in the fertilizing of the land: the direct addition of plant-food, and the improvement of the physical texture of the soil. The latter office is often the 
more important. Lands which, on the one hand, are very hard and solid, with a tendency to bake, and, upon the other, those which are loose and leachy, are very greatly benefited by the addition of organic matter. When this organic matter, as animal and plant remains, decays and becomes thoroughly incorporated with the soil, it forms what is called humus. The addition of this humus to the land makes it mellow, friable, retentive of moisture, and promotes the general chemical activities of the soil. It also puts the soil in the best physical condition for the comfort and well-being of the plants. Very many of the lands which are said to be exhausted of plantfood still contain enough potash, phosphoric acid and lime, and other fertilizing elements, to raise good crops; but they have been greatly injured in their physical texture by long-continued cropping, injudicious tillage, and the withholding of vegetable matter. A part of the marked results which are obtained from the plowing under of clover is due to the mere addition of vegetable matter to the soil, wholly aside from the addition of fertilizing material; and this is emphatically true of clover because its deep-growing roots penetrate and break up the subsoil. Muck and leaf-mold are often very useful in ameliorating either very hard or very loose lands. Excellent humous material may be constantly at hand if the leaves, garden refuse and some of the manure 
be piled and composted. If the pile is turned several times a year, the material becomes fine and uniform in texture.

The various questions associated with the fertilizing of the land are too large to be considered in detail here. Persons who desire to familiarize themselves with the subject should consult Roberts" "Fertility of the Land" and King's "Soil:" and if it is desired to make application of the knowledge directly to the growing of fruit, they should consult Bailey's "Principles of FruitGrowing."

It may be said, however, that, as a rule, most lands contain all the elements of plant-food in sufficient quantities except potash, phosphoric acid and nitrogen. In many cases, lime is very beneficial to land, usually because it corrects acidity of the soil and has a mechanical effect in pulverizing and floceulating clay and in cementing sands, rather than in the direct addition of plant-food. The chief sources of commercial potash are muriate of potash, sulfate of potash and wood ashes. For general purposes, the muriate of potash is now recommended, because it is comparatively cheap and the composition is uniform. A normal application of muriate of potash is from two hundred to three hundred pounds to the acre; but on some garden lands, where the greatest results are demanded, sometimes as much as twice this application may be made. Phosphoric acid is got 
in dissolved South Carolina and Florida rock and in various bone preparations. These materials are applied at the rate of two hundred to four hundred pounds to the acre. Commercial nitrogen is chiefly obtained in the form of animal refuse, as blood and tankage, and in nitrate of soda. It is more likely to be lost by leaching through the land than the mineral substances are, especially if the land lacks humus. Nitrate of soda is very soluble, and should be applied in small quantities at intervals. Nitrogen, being the element which is mostly conducive to vegetative growth, tends to delay the season of maturity if applied late in the season. One hundred to three hundred pounds of nitrate of soda may be applied to the acre, but it is ordinarily better to make two or three applications at intervals of three to six weeks. Fertilizing materials may be applied either in fall or spring; but in the ease of nitrate of soda, it is usually better not to apply in the fall unless the land has plenty of humus to prevent leaching, or on plants which start very early in the spring. The material is sown broadcast, or it may be scattered lightly in furrows underneath the seeds, and then covered with dirt. If sown broadcast, it may be applied either after the seeds are sown or before. It is usually better to apply it before, for although the rains carry it down, nevertheless the upward movement of water during the dry weather of the summer tends to bring it 
back to the surface. It is important that large lumps of fertilizer, especially muriate of potash and nitrate of soda, do not fall near the crowns of the plants; otherwise the plants may be seriously injured. It is a general principle, also, that it is better to apply sparingly of fertilizers and liberally of tillage. The tendency is to make fertilizers do penance for the sins of neglect, but the results do not often meet one's expectations.

If one has only a small garden or a home yard, it will ordinarily not pay him to buy the chemicals separately, as recommended above, but he can buy some complete fertilizer which is sold under a trademark or brand, and which has a guaranteed analysis. If one is raising plants chiefly for their foliage, as rhubarb and ornamental bushes, he should select a fertilizer comparatively rich in nitrogen; but if he desires chiefly fruit and flowers, the mineral elements, as potash, and phosphoric acid, should be high. If one uses the chemicals, it is not necessary that they be mixed before application; in fact, it is usually better not to mix them, because some plants and some soils need more of one element than of another. Just what materials, and how much, different soils and plants require, must be determined by the grower himself by observation and experiment, but the above hints may suggest the problems to be considered.

Muriate of potash costs forty dollars and up- 
wards per ton, sulfate about forty-eight dollars, dissolved boneblack about twenty-four dollars, ground bone about thirty dollars, kainit about thirteen dollars, and nitrate of soda about two and one-fourth cents per pound. These prices vary, of course, with the composition or mechanical condition of the materials. The average composition of unleached wood ashes in the market is about as follows: Potash, 5.25 per cent; phosphoric acid, 1.70 per cent; lime, 34 per cent; magnesia, 3.40 per cent. The average composition of kainit is 13.54 per cent potash, 1.15 per cent lime. The composition of sylvinit (which is said to be known as sulfate of potash in some quarters) is about 16 per cent of potash, in the form of both muriate and sulfate, mostly the former. The fact that the soil itself is the greatest storehouse of plant-food is shown by the following average of thirty-five analyses of the total content of the first eight inches of surface soils, per acre: 3,521 pounds of nitrogen, 4,400 pounds of phosphoric acid, 19,836 pounds of potash. Much of this is unavailable, but the good tillage and green manuring which have been recommended tend to unlock it. 


\section{SECTION II}

\section{THE PLAN OF THE PLACE}

One cannot expect satisfaction in the planting and developing of a home area unless he has a definite conception of what is to be done. This necessarily follows, since the pleasure which one derives from any enterprise depends chiefly upon the definiteness of his ideals and upon his ability to develop them. The home-maker should develop his plan before he attempts to develop his place. He should determine the locations of the leading features of the place, and the relative importance to be given to the various parts of it, as of the landscape parts, the ornamental areas, the vegetable garden and the fruit plantations. The details of the planting, however, may be determined as the place develops: it is only the structural features and purposes of the place which need to be determined beforehand. The incidental modifications which can be made in the planting from time to time keep the interest alive, and allow the planter to gratify his desire to experiment with new plants and new methods. The following discussions may aid the enquirer in formulating a conception of a home plot. If it 
should happen that any person has read the author's bulletins on "Suggestions for the Planting of Shrubbery," "China Asters," and "Cultivated Poplars," he may recognize some of the sentences in the following pages.

\section{THE PICTURE IN THE LANDSCAPE}

The trouble with home grounds is not so much that there is too little planting of trees and shrubs as that this planting is meaningless. Every yard should be a picture. That is, the area should be set off from every other area, and it should have such a character that the observer catches its entire effect and purpose without stopping to analyze its parts. The yard should be one thing, one area, with every feature contributing its part to one strong and homogeneous effect.

These remarks will become concrete if the reader turns his eye to Figs 119 and 120. The former represents the common type of planting of front yards. The bushes and trees are scattered promiscuously over the area. Such a yard has no purpose, no central idea. It shows plainly that the planter had no constructive conception, no grasp of any design, and no appreciation of the fundamental elements of the beauty of landscape. Its only merit is the fact that trees and shrubs have been planted; and this, to most minds, comprises the essence and sum of the orna- 
mentation of grounds. Every tree and bush is an individual, alone, unattended, disconnected

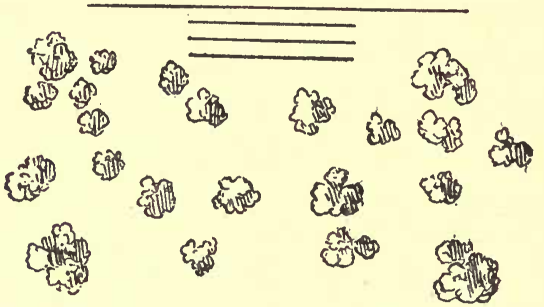

119. The common or nursery way of planting.

from its environments, and therefore meaningless. Such a yard is only a nursery.

The other plan (Fig. 120) is a picture. The eye catches its meaning at once. The central idea/ is the residence, with a warm and open greensward in front of it. The same trees and bushes which were scattered haphazard over Fig. 119 are massed into a framework to give effectiveness to the picture of home and comfort. This style of planting makes a landscape, even though the area be no larger than a parlor. The other style is simply a collection of curious plants. The one has an instant and abiding pictorial effect, which is restful and satisfying: the observer exclaims, "What a beautiful home this is !" The other piques one's curiosity, obscures the residence, divides and distracts the attention: the observer exclaims, "What excellent lilac bushes are these!"

The following sketch, which the author made 
in a periodical ("Science", Nov. 17, 1893) as a comment upon a discussion of the "picture in the landscape", will still further explain the subject under consideration :

"The inquiry in a recent issue, into the causes of the unlike impressions which one receives from a given landscape and from a painting of it, seems to me to explain the subject admirably. The correspondent supposes that the reason why the picture appeals to us more than the landscape does is because the picture is condensed, and the mind becomes acquainted with its entire purpose at once, while the landscape is so broad that the individual objects at first fix the attention, and it is only by a process of synthesis that the unity of the landscape finally becomes apparent. This is admirably illustrated in photographs. One of the first surprises which I experienced when I be-

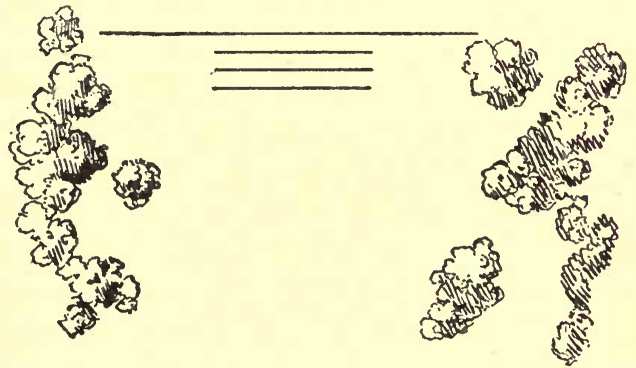

120. The proper or pictorial type of planting.

gan the use of the camera was the discovery that very tame scenes become interesting and often 
even spirited in the photograph. But there is something more than mere condensation in this vitalizing and beautifying effect of the photograph or the painting. Individual objects are so much reduced that they no longer appeal to us as distinct subjects, and however uncouth they may be in the reality, they make no impression in the picture. The thin and sere sward may appear rather like a closely shaven lawn or a new-mown meadow. And again, the picture sets a limit to the scene; it frames it, and thereby cuts off all extraneous and confusing or irrelevant landscapes.

"All these remarks are enforced in the æsthetics of landscape gardening. It is the artist's one desire to make pictures in the landscape. This is done in two ways,-by the form of plantations and by the use of vistas. He will throw his plan-l tations into such positions that open and yet more or less confined areas of greensward are presented to the observer at various points. This glade-like opening is nearly or quite devoid of small or individual objects, which always destroy the unity of such areas and are meaningless in themselves. The two sketches illustrate my mes ling. The first one (Fig. 119) is a fair diagram of the average front-yard. It is full of individual trees and bushes, or groups, and the eye is carrled from object to object, while the entire yard makes no quick appeal to the mind. One is pleased only with the kinds of plants which he sees. The 
second sketeh (Fig. 120) presents a definite area at once to the observer, and the individual plants are of minor importance. Here is a landscapea picture; there is a nursery.

"A vista is a narrow opening or view between plantations to a distant landscape. It cuts up the broad horizon into portions which are readily cognizable. It frames portions of the country-side. The verdurous sides of the planting are the sides of the frame; the foreground is the bottom, and the sky is the top."

If the reader catches the full meaning of these contrasts, he has aequired the first and most important conception in landscape gardening. The conception will grow upon him day by day; and if he is of an observing turn of mind, he will find that this simple lesson will revolutionize his habit of thought respecting the planting of grounds and the beauty of landscapes. He will see that a bush or flower-bed which is no part of any general purpose or design-that is, which does not colltribute to the making of a picture-might better never have been planted. For myself, I had rather have a bare and open pasture than such a yard as that shown in Fig. 119, even though it contained the ehoicest plants of every land. The pasture would at least be plain and restful and unpretentious. It would be nature-like and sweet. But the yard would be full of effort and fidget. 


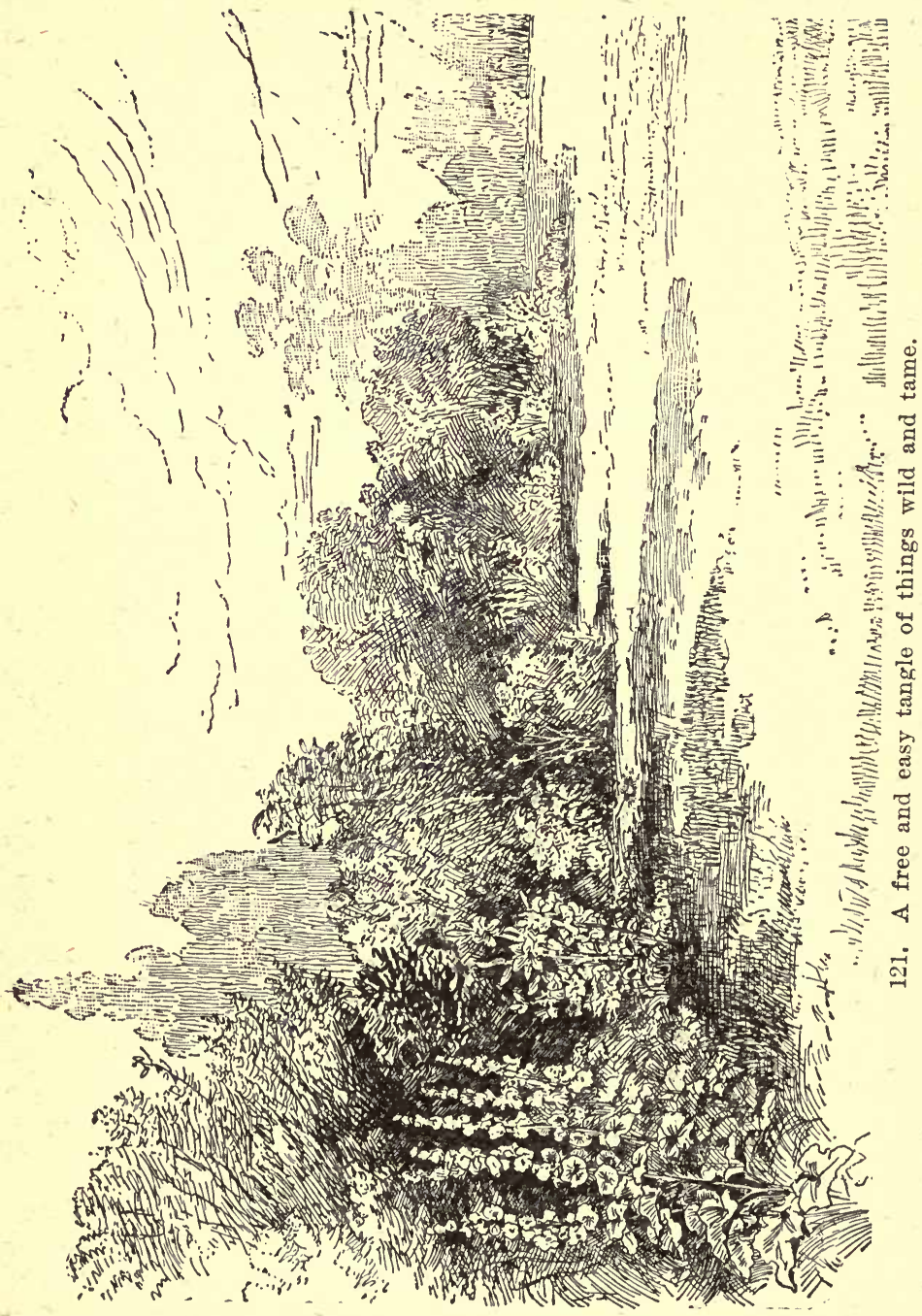


Reduced to a single expression, all this means that the greatest artistic value in planting lies in the effect of the mass, and not in the individual plant. A mass has the greater value because it presents a much greater range and variety of rorms, colors, shades and textures, because it has sufficient extent or dimensions to add structural character to a place, and because its features are so continuous and so well blended that the mind is not distracted by incidental and irrelevant

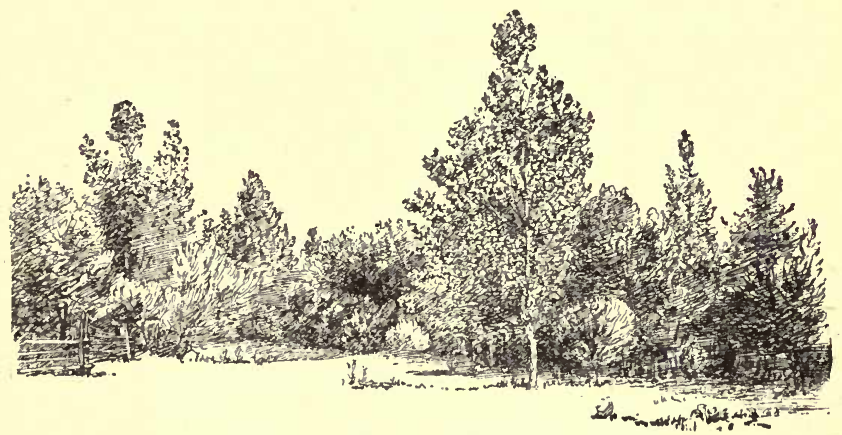

122. A nature-planted tangle.

ideas. A couple of pictures will admirably illustrate all this. Figs. 121, 122 are pictures of natural copses. The former stretches across a vale, and makes a lawn of the bit of meadow which lies in front of it. The landscape has become so small and so well defined by this bank of verdure that it has a familiar and personal feeling. The great, bare, open meadows are too ill- 
defined and too extended to give any domestic air; but here is a portion of the meadow set off into an area which one can compass with his affections.

These masses in Figs. 121, 122, have their own intrinsic merits, as well as their office in defining a bit of nature. One is attracted by the carelessness of arrangement, the irregularity of sky-line; the bold bays and promontories, and the infinite play of light and shade. The observer is interested in each because it has character, or features which no other mass in all the world possesses. He knows that the birds build their nests in the tangle, and the rabbits find it a happy covert.

Now let the reader turn to Fig. 123, which is a picture of an "improved" city yard. Here there is no structural strength to the planting, no defining of the area, no continuous flow of the form and color. Every bush is what every other one is or may be, and there are hundreds like them in the same town. The birds shum them. Only the bugs find any happiness in them. The place has no fundamental design or idea, no lawn upon which a picture can be constructed.

The motive which shears the trees also razes the copse, in order that the gardener or "improver" may show his art. Compare Figs. 124 and 125. Many persons seem to fear that they 


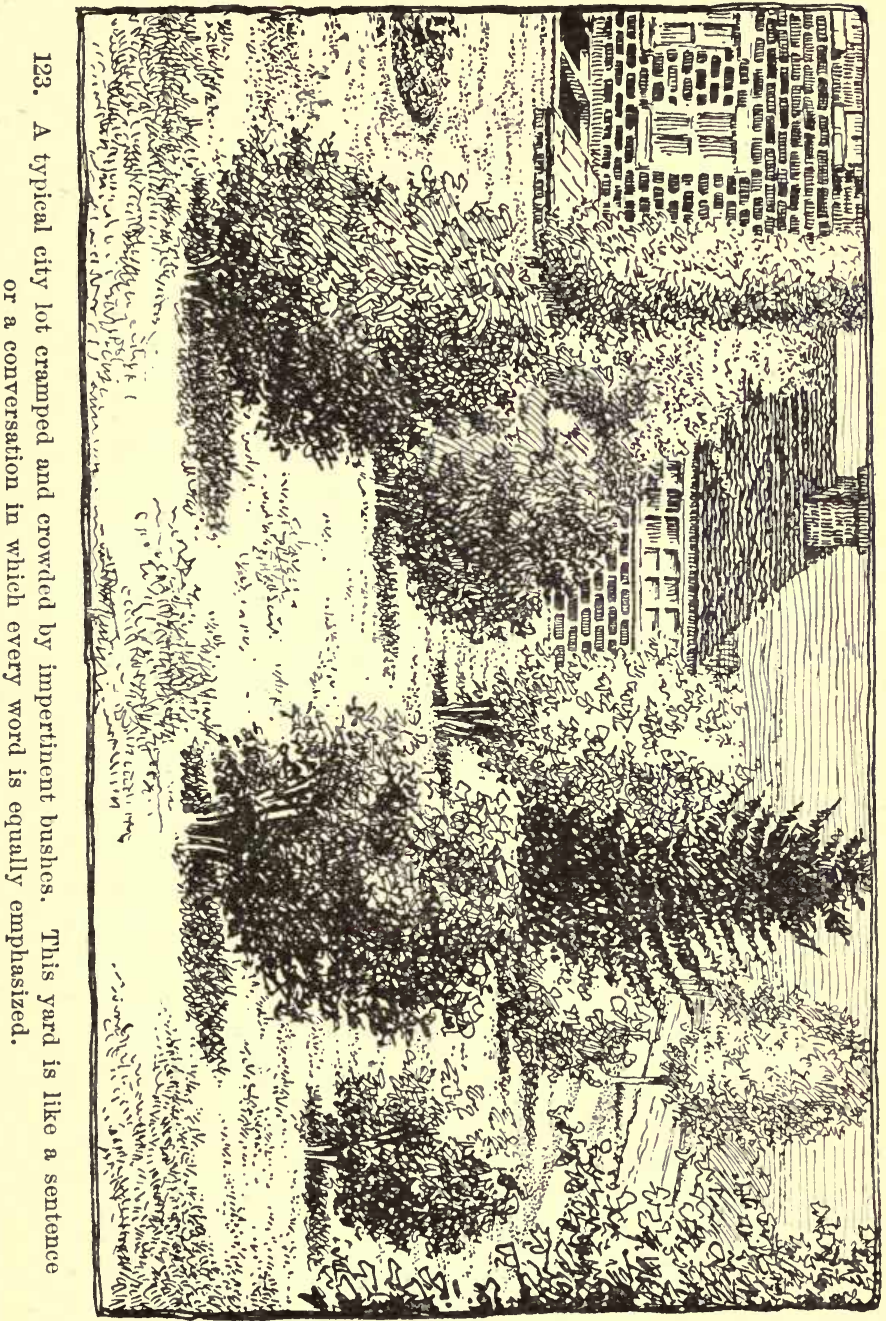


will never be known to the world unless they expend a great amount of muscle or do something

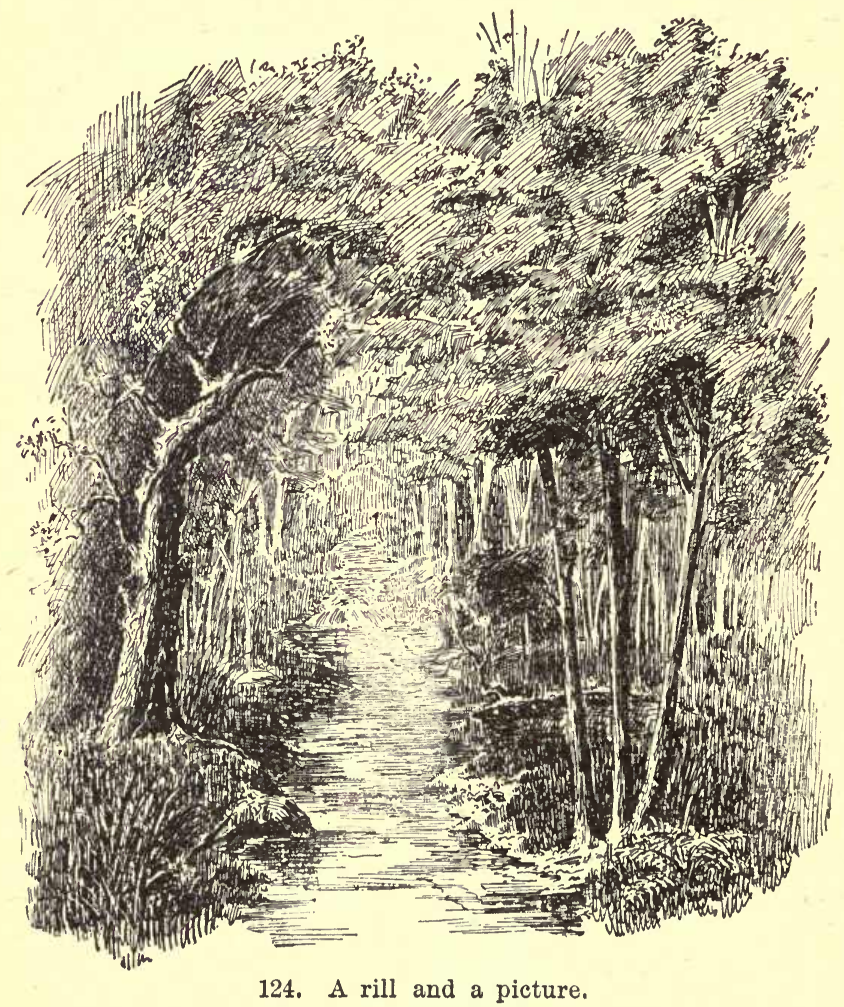

emphatic or spectacular; and their fears are usually well founded.

If a landscape is a picture, it must have a 
canvas. This canvas is the greensward. Upon this, the artist paints with tree and bush and flower, as the painter does upon his canvas with brush and pigments. The opportunity for artistic composition and design is nowhere so great as in the landscape garden, because no other art has

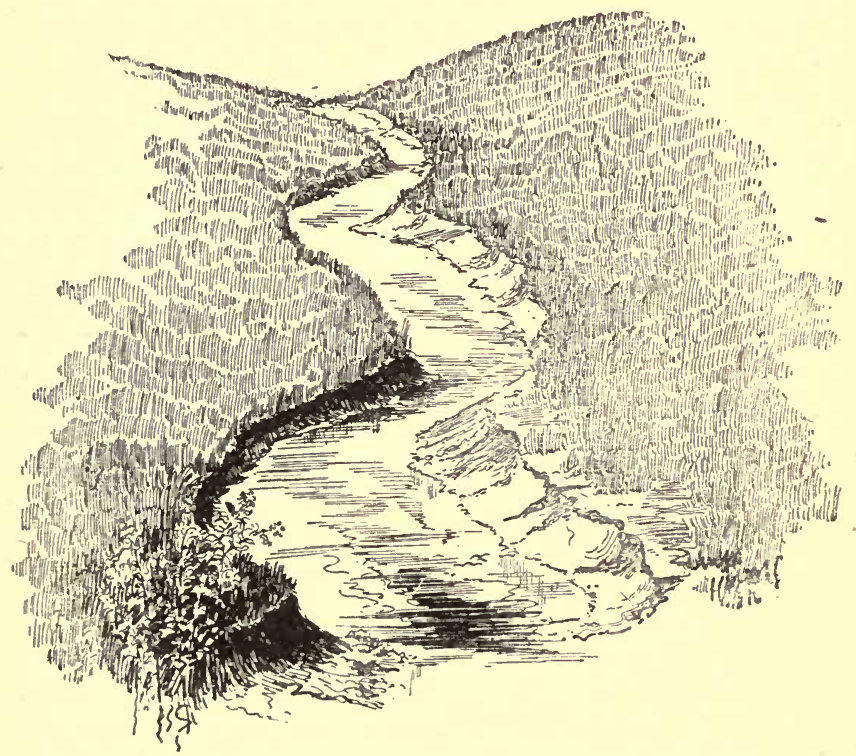

125. The same rill "improved." From an actual example.

such a limitless field for the expression of its emotions. It is not strange, if this be true, that there have been few great landscape gardeners, and that, falling short of art, the landscape gar- 
dener too often works in the sphere of the artisan. There can be no rules for landscape gardening, any more than there can be for painting or sculpture. The operator may be taught how to hold the brush or strike the chisel or plant the tree, but he remains an operator; the art is intellectual and emotional, and will not confine itself in precepts.

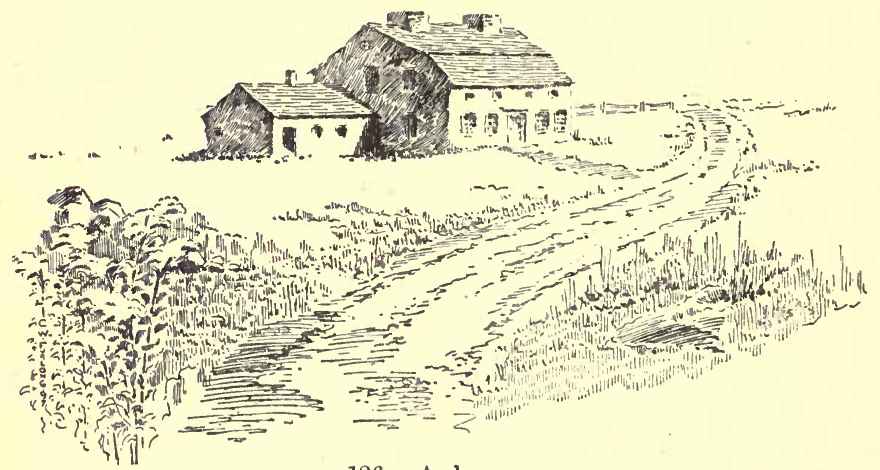

126. A house.

The making of a good and spacious lawn, then, is the very first practical consideration in a landscape garden. This provided, the gardener conceives what is the dominant and central feature in the place, and then throws the entire premises into subordination with this feature. In home grounds this central feature is the house. To scatter trees and bushes over the area defeats the fundamental purpose of the place,-the pur- 
pose to make every part of the grounds lead up to the home and to accentuate its homelikeness. Keep the center of the place open. Plant the borders. Avoid all disconnected, cheap, patchy, and curious effects.

If the lawn then, is the canvas, the house is

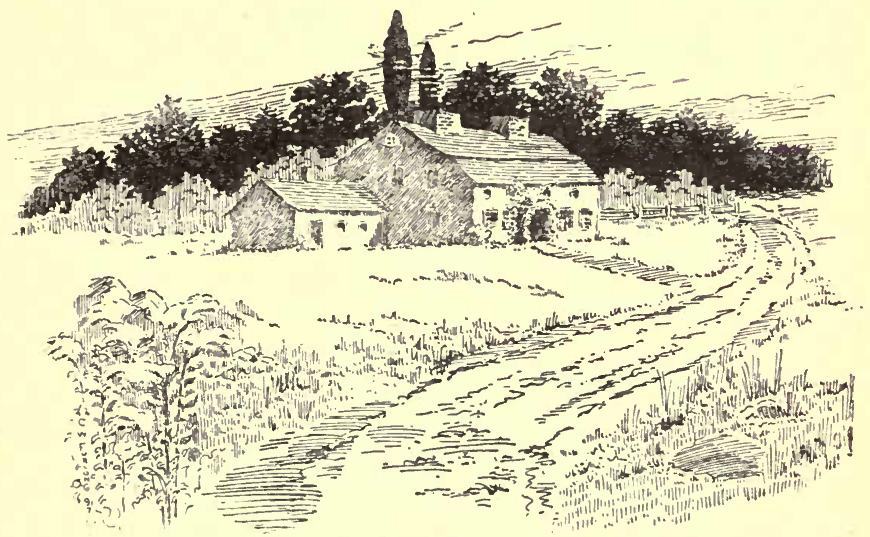

127. A home.

the central object in the picture. All the planting should be subordinate and accessory to it. This central object should itself be defined by a background. A house which stands on a bare plain or hill is a part of the universe, not a part of a home. Recall the cozy little farmhouse which is backed by a rood or an orchard; then compare some pretentious structure which stands apart from all planting. Or observe the warmth and 
homelikeness which the background gives to Fig. 127. Yet how many are the farmhouses which stand as stark and cold against the sky as if they were competing with the moon! We would not believe it possible for a man to live in a house

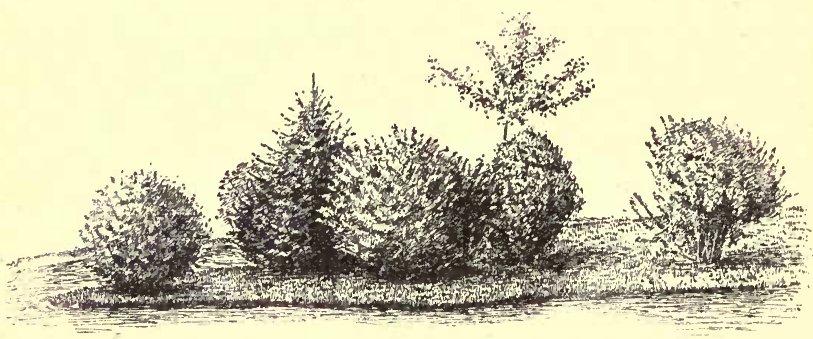

128. Well planned but poorly executed.

twenty-five years and not, by accident, allow some tree to grow, were it not that it is so !

It is not enough that trees and bushes be planted in masses. They must be kept in masses by letting them grow freely in a natural manner. The pruning-knife is the most inveterate enemy of shrubbery. Pictures 128 and 129 illustrate what I mean. The former represents a good group of bushes so far as arrangement is concerned, but it has been ruined by the shears. The attention of the observer is instantly arrested by the individual bushes. Instead of one free and expressive object, there are several stiff and expressionless ones. If the observer stops to consider his own thoughts when he comes upon such 
a collection, he will likely find himself counting the bushes; or, at least, he will be making mental comparisons of the various bushes, and wondering why they are not all sheared to be exactly alike. Fig. 129 shows how the same "artist" has treated two deutzias and a juniper. Much the same effect could have been secured, and with much less trouble, by laying two flour bar-

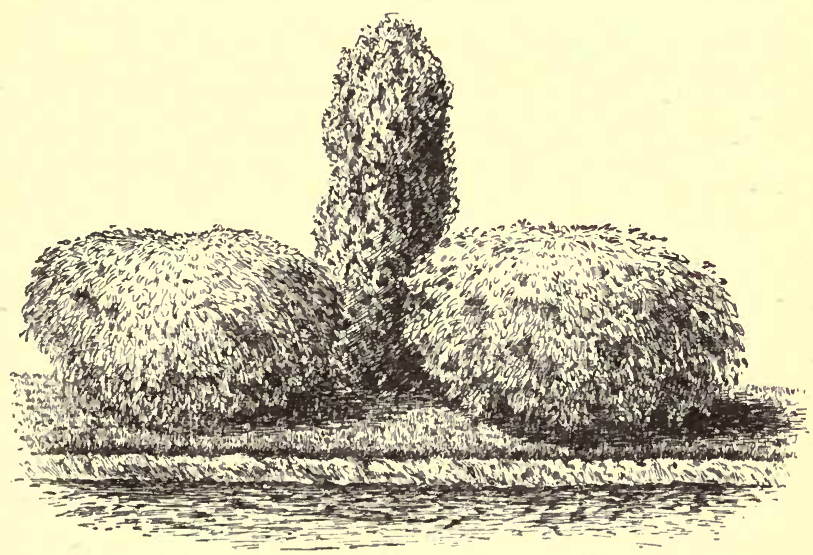

129. The three guardsmen.

rels end to end and standing a third one between them.

I must hasten to say that I have not the slightest objection to the shearing of trees. The only trouble is in calling the practice art, and in putting the trees where people must see them. If the operator simply calls the business shear- 
ing, and puts the things where he and others who like them may see them, objection could not be raised. Some persons like painted stones, others like iron bulldogs in the front yard and the word "welcome" worked into the door-mat, and others like barbered trees. So long as these likes are purely personal, it would seem to be better taste to put such curiosities in the back yard, where the owner may admire them without molestation.

I do not mean to discourage the use of flowers and bright foliage and striking forms of vegetation; but these things are never primary considerations in a good place. The structural elements of the place are designed first. The flanking and bordering masses are then planted. Finally, the flowers and accessories are put in, in just the same way that a house is painted after it is built. Flowers appear to best advantage when seen against a background of foliage, and they are then, also, an integral part of the picture. The flower garden, as such, should be at the rear or side of a place, the same as all other strictly personal appurtenances are; but flowers and bright leaves may be freely scattered along the borders and near the foliage masses.

The use of flower-beds is so commonly misunderstood that I must expatiate upon the fact, even at the risk of putting my reader to sleep. It is commonly assumed that many people have no 
love or appreciation of flowers, but it is probably nearer to the truth to say that no person is wholly lacking in this respect. Even those persons who declare that they care nothing for flowers, are generally deceived by their dislike of flower-beds and the conventional methods of flower-growing. I know many people who stoutly deny any liking for flowers, but who, nevertheless, are rejoiced with the blossoming of the orchards and the purple bloom of the clover fields. The fault is not so much with the persons themselves as with the methods of growing and displaying the flowers.

The greatest fault with our flower-growing is the stinginess of it. We grow our flowers as if they were the choicest rarities, to be coddled in a hotbed or under a bell-jar, and then to be exhibited as single specimens in some little pinched and ridiculous hole cut in the turf, or perched upon an ant-hill which some gardener has laboriously heaped upon a lawn. Nature, on the other hand, grows her flowers in the most luxurious abandon, and one can pick an armful without offense. She grows her flowers in earnest, as a man grows a crop of corn. One can revel in the color and the fragrance, and be satisfied.

The next fault with our flower-growing is the flower-bed. Nature has no time to make flowerbeds; she is busy growing flowers. And, then, if she were given to flower-beds, the whole effect would be lost, for she could no longer be 
luxurious and wanton, and if a flower were picked her whole scheme might be upset. Imagine a geranium-bed or a coleus-bed, with its wonderful "design," set out into a wood or in a free and open landscape! Even the birds would laugh at it!

What I want to say is that we should grow flowers when we make a flower-garden. Have

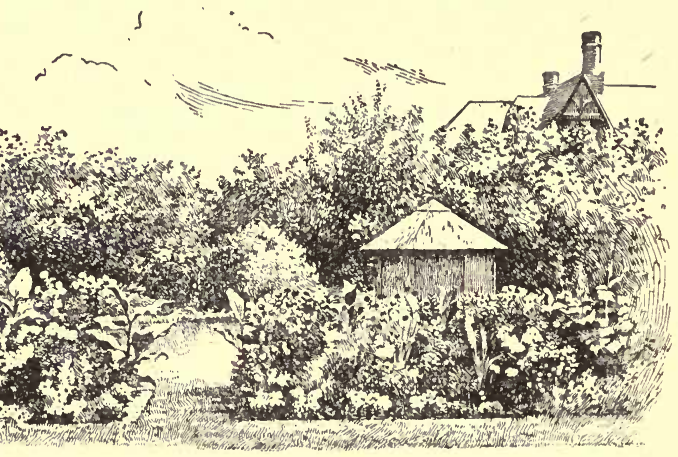

130. The flower-garden is by itself, and at one side or in the rear of the place.

enough of them to make it worth the effort. I sympathize with the man who likes sunflowers. There is enough of them to be worth looking at. They fill the eye. Now show this man ten square feet of pinks, or asters, or daisies, all growing free and easy, and he will tell you that he likes them. All this has a particular application to the farmer. He grows potatoes and buckwheat and 
weeds by the acre: two or three unhappy pinks or geraniums are not enough to make an impression.

I suppose that everyone feels that the greatest charm of any landscape in the north is the greensward. It is the eanvas upon which every artistplanter attempts to make a picture. But imagine a painter putting a glowing bed of coleuses on his canvas for a center-piece! The fact is, the easiest way to spoil a good lawn is to put a flowerbed in it; and the most effective way in which to show off flowers to the least advantage is to plant them in a bed in the greensward. Flowers need a background. We do not hang our pictures on fence-posts. If flowers are to be grown on a

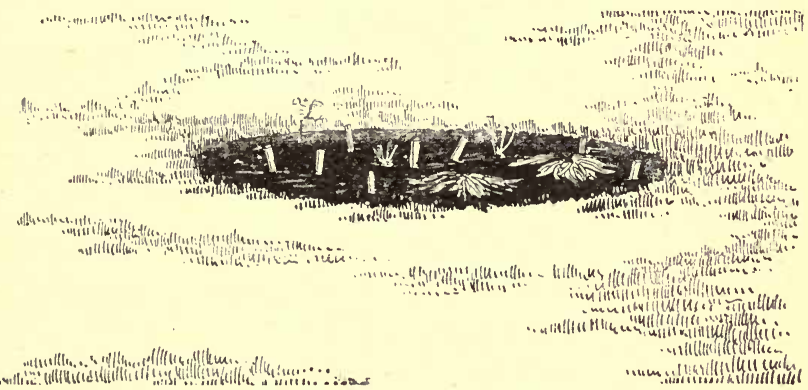

131. A hole in the ground. In July, August and September it was a carpet-bed.

lawn, let them be of the hardy kind, which can be naturalized in the sod and which grow freely in the tall unmown grass. Lawns, upon their part, 
should be large, free and generous, but the more they are cut up and worried with trivial effects the smaller and meaner they look.

But if we consider these lawn flower-beds wholly apart from their surroundings, we must

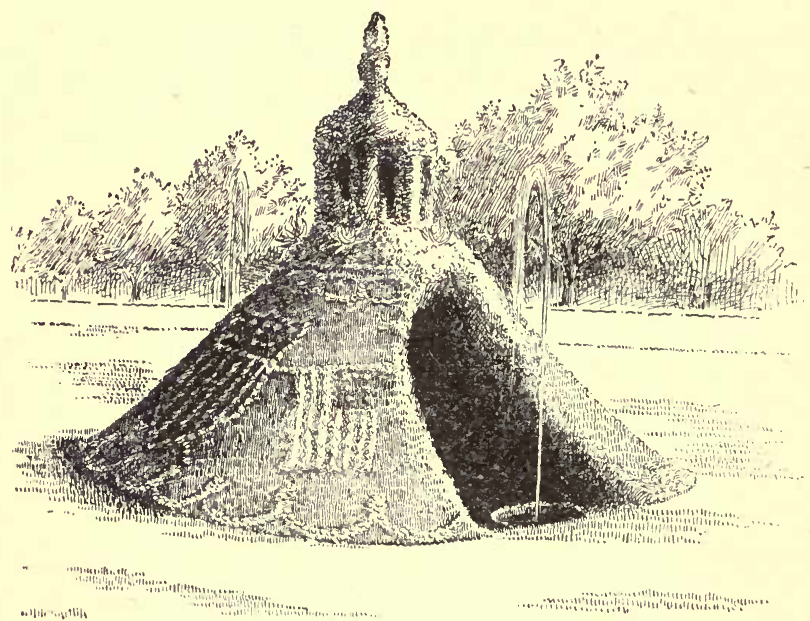

132. Worth paying admittance to see!

admit that they are at best unsatisfactory. It generally amounts to this, that we have four months of sparse and downeast vegetation, one month of limp and frost-bitten plants, and seven months of bare earth or mud. I am not now opposing the carpet-beds which professional gardeners make in parks and other museums. I like museums, and some of the carpet beds and set pieces are "fearfully and wonderfully made" (see 
Fig. 132). I an directing my remarks to those humble home-made flower-beds which are so common in lawns of country and eity homes alike. These beds are eut from the good fresh

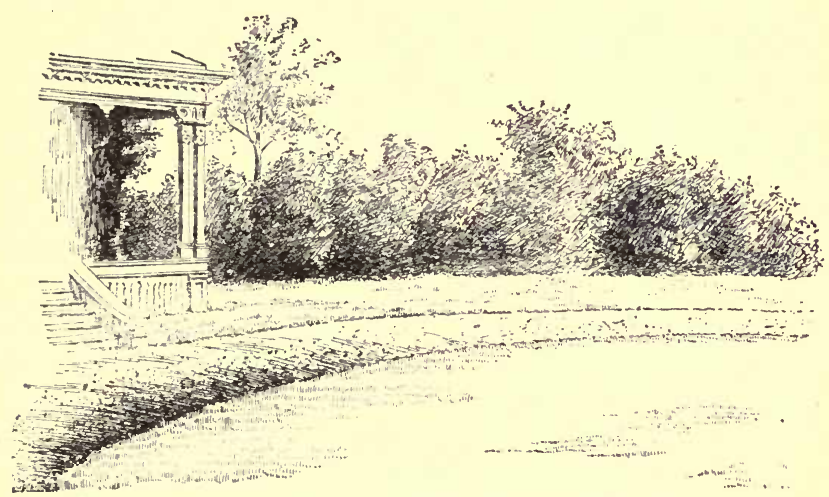

133. A heavy border which shuts out a bleak field. In front of this border is an ideal place for flowers.

turf, often in the most fantastic designs, and are filled with such plants as the women of the place may be able to carry over in cellars or in the window. The plants themselves may look very well in pots, but when they are turned out of doors they have a sorry time for a month adapting themselves to the sun and winds, and it is generally well on towards midsummer before they begin to cover the earth. During all these weeks they have demanded more time and labor than would have been needed to care for a plan. tation of much greater size, and which would 
have given flowers every day from the time the birds began to nest in the spring until the last robin had flown in November.

I wish that instead of saying flower-bed we might say flower-border. Any good place, as I have said, should have its center open. The sides may be more or less confined by plantings of shrubs and trees and many kinds of herbs. This border-planting sets bounds to the place, and makes it one's own. The person lives inside his place, not on it. $\mathrm{He}$ is not cramped and jostled by things scattered all over the place, with no purpose or meaning. Along the borders, against groups, often by the corners of the residence or in front of porches, - these are places for flowers. When planting, do not aim at designs or effects: just have lots of flowers, a variety of them, growing luxuriantly, as if they could not help it. Ten flowers against a background are more effective than a hundred in the ojutin yard.

I have asked a professional artist, Mr. Mathews, to draw me the kind of a flower-bed that he likes. It is shown in Fig. 134. It is a border,-a strip of land two or three feet wide along a fence. This is the place where pigweeds usually grow. Here he has planted marigolds, gladiolus, goldenrod, wild asters, China asters, and-best of allhollyhocks. Any one would like that flower-garden. It has some of that local and indefinable charm which always attaches to an "old-fashioned 


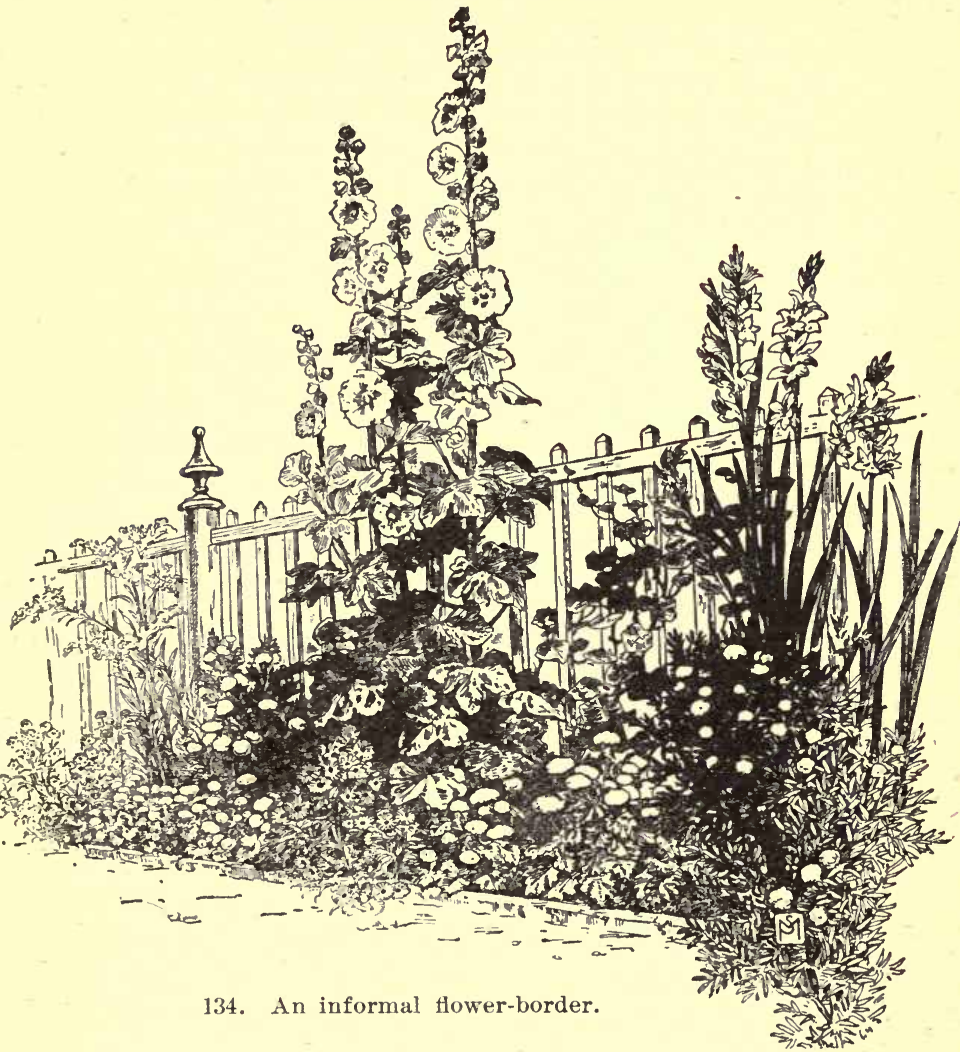

garden," with its exuberant tangle of form and color. Every yard has some such strip of land along a rear walk or fence or against a building. It is the easiest thing to plant it,-ever so much easier than digging the hideous geranium bed into the center of an inoffensive lawn. 
Speaking of the old-fashioned garden reminds me of one of William Falconer's excellent paragraphs ("Gardening," November 15, 1897, p. 75): "We tried it in Schenley Park this year. We needed a handy dumping ground, and hit on the head of a deep ravine between two woods; into it we dumped hundreds upon hundreds of wagon loads of rock and clay, filling it near to the top, then surfaced it with good soil. Here we planted some shrubs, and broadeast among them set out scarlet poppies, eschscholtzias, dwarf nasturtiums, snapdragons, pausies, marigolds, and all manner of hardy herbaceous plants, having enough of each sort to make a mass of its kind and color, and the effect was fine. In the middle was a plantation of hundreds of clumps of Japan and German irises interplanted, thence succeeded by thousands of gladioli, and banded with montbretias, from which we had flowers till frost. The steep face of this hill was graded a little and a series of winding stone steps set into it, making the descent into the hollow quite easy; the stones were the rough, uneven slabs secured in blasting the rocks when grading in other parts of the park, and both along outer edges of the steps and the sides of the upper walk a wide belt of moss pink was planted; and the banks all about were planted with shrubs, vines, wild roses, columbines and other plants. More cameras and kodaks were levelled by visitors at this piece of gardening than 
at any other spot in the park, and still we had acres of painted summer beds."

There is no prescribed rule as to what one should put into these informal flower-borders. Put in them the plants you like. Perhaps the greater part of them should be perennials, which come up of themselves every spring, and which are hardy and reliable. Wild flowers are particularly effective. Everyone knows that many of the native herbs of woods and glades are more attractive than some of the most prized garden flowers. The greater part of these native flowers grow readily in cultivation, sometimes even in places which, in soil and exposure, are much unlike their native haunts. Many of them make thickened roots, and they may be safely transplanted at any time after the flowers have passed. To most persons, the wild flowers are less known than many exotics which have smaller merit, and the extension of cultivation is constantly tending to annihilate them. Here, then, in the informal flowerborder, is an opportunity to rescne them. Then one may sow in freely of easy-growing anmuals, as marigolds, China asters, petunias and phloxes, and sweet peas. One of the advantages of these borders is that they are always ready to receive more plants, unless they are full. That is, their symmetry is not marred if some plants are pulled out and others are put in. And if the weeds now and then get a start, very little harm is done. 
Such a border half full of weeds is handsomer than the average well kept geranium bed, because the weeds enjoy growing and the geraniums do not. I have such a border, three feet wide and ninety feet long, beside a rear walk. I am putting plants into it every month in the year when the frost is out of the ground. Plants are dug in the

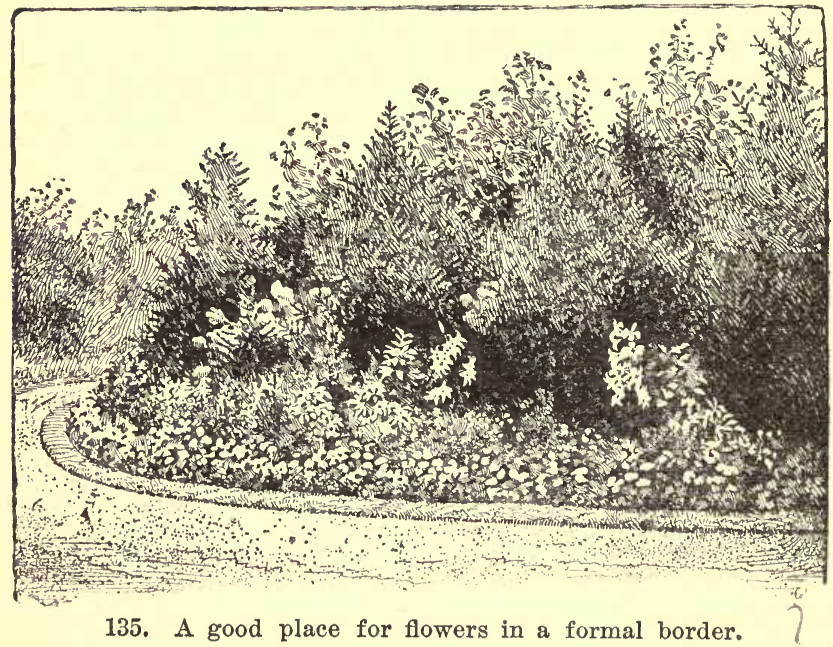

woods or fields, whenever I find one which I fancy, even if in July. The tops are cut off, the roots kept moist, and even though the soil is a most unkindly one, most of these much-abused plants grow. To be sure, there are some weeds in it; but then, the weeds are a part of the collection! A well grown hull-thistle in such a place is worth 
more than a bushel of potatoes. These plants have been lifted from the ficlds in the most careless fashion. A noble plant of the pink-hearted Spiræa lobata was pulled from a swamp in July when it was in full bloom; the bluebells have been stolen from cliffs without regard to time or season; some of the roots were carried in the pocket for hours before the opportunity came for planting, and this, too, in the height of summer. Of course, some plants have resented this treatment, but the border is a happy family, and it is all the better and more personal because it is the result of moments of relaxation. Such a border has something new and interesting every month of the growing season; and even in the winter the tall clumps of grasses and aster-stems wave their plumes above the snow and are a source of delight to every frolicksome bevy of snowbirds.

I have spoken of this choice little weedland to show how simple and easy a thing it is to make an attractive mass-plantation. Set aside a bit of ground in the right place. Make the most of a rock (Fig. 136), or bank, or other undesirable feature of the place. Spade up the ground and make it rich, and then set plants in it. That is all there is of it. You will not get it to suit you the first year, and perhaps not the second or the third one. You can always pull out plants and put more in. I should be sorry if it did. perfectly suit you, for I should then feel that you 
had lost interest in it. I should never want a lawn-garden if I could not change it a little or plant something new each year.

What kinds of shrubs and flowers shall I plant? This is a wholly secondary and largely a personal consideration. Be sure that the main plantings are made up of hardy and vigorous species, and have lots of them. Then get the things which you like. I like bull-thistles, lilacs, hollyhocks, burdocks, rhubarb, dogwoods, spireas, elders and

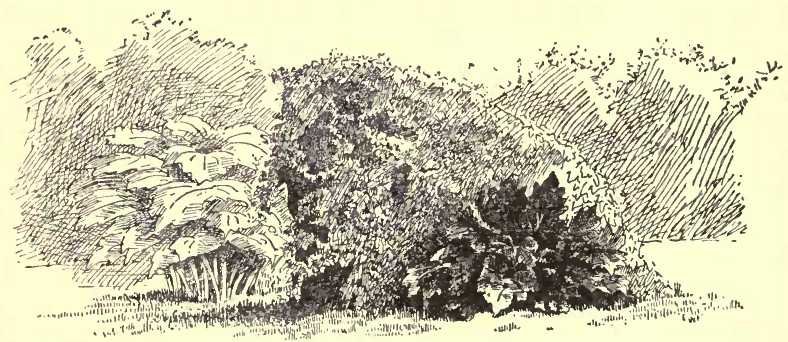

136. Making the most of a rock.

such eareless things. But others have better taste. There is endless merit in the choice of species, but the point I wish to emphasize is that the arrangement or disposition of the plants is far more important than the kinds.

It should be said that the appreciation of foliage effects in the landscape is a higher type of feeling than the desire for mere color. Flowers are transitory, but foliage and plant forms are abiding. The common roses have very little value 
for landscape planting, because the foliage and habit of the rose bush are not attractive, the leaves are inveterately attacked by bugs, and the blossoms are fleeting. Some of the wild roses and the Japanese Rosa rugosa, however, have distinct merit for mass effects. Wild bushes

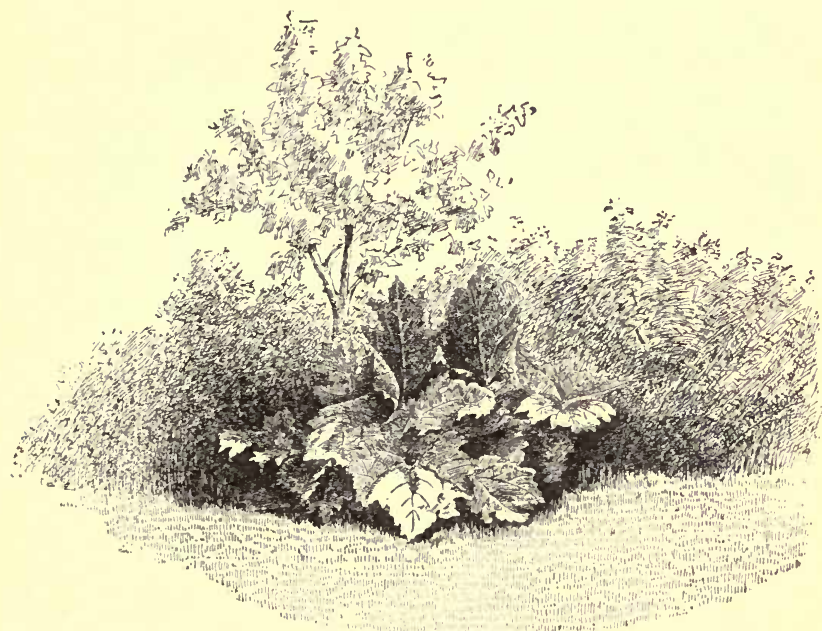

137. Making a picture with rhubarb.

are nearly always attractive when planted in borders and groups. They improve in appearance under cultivation, because they are given a better chance to grow. In wild nature, there is such a fierce struggle for existence that plants usually grow to few or single stems, and they are sparse and scraggly in form; but once given all 
the room they want and a good soil, and they become luxurious, full and comely. In most home grounds in the country, the body of the planting may be very effectively made by the use of bushes taken from adjacent woods and fields. The masses may then be enlivened by the addition here and there of cultivated bushes, and the planting of flowers and herbs about the borders. It is not essential that one know the names of these wild bushes, although a knowledge of their botanical features will add greatly to the pleasure oi growing them. Neither will they look common when transferred to the lawn. There are very few people who know even the commonest wild bushes intimately, and the bushes change so much in looks when removed to rich grounds that few people recognize them. I have a mass of shrubbery (Fig. 140) which is much admired, and visitors are always asking me what the bushes are; yet I dug most of the roots in the neighborhood.

It is but a corollary of this discussion to say that plants which are simply odd or grotesque or unusual should be used with the greatest caution, for they introduce extraneous and jarring effects. They are little in sympathy with a landscape garden. An artist would not care to paint an evergreen which is sheared into some grotesque shape. It is too formal, and it has no elements of true beauty. It is only curious, and shows what a 
man with plenty of time and long pruning shears can accomplish. A weeping tree is nearly always seen to best advantage when it stands against a group or mass of foliage (Fig. 138) as a promontory, adding zest and spirit to the border. This leads me to speak of the planting of the Lombardy poplar, which may be taken as a type

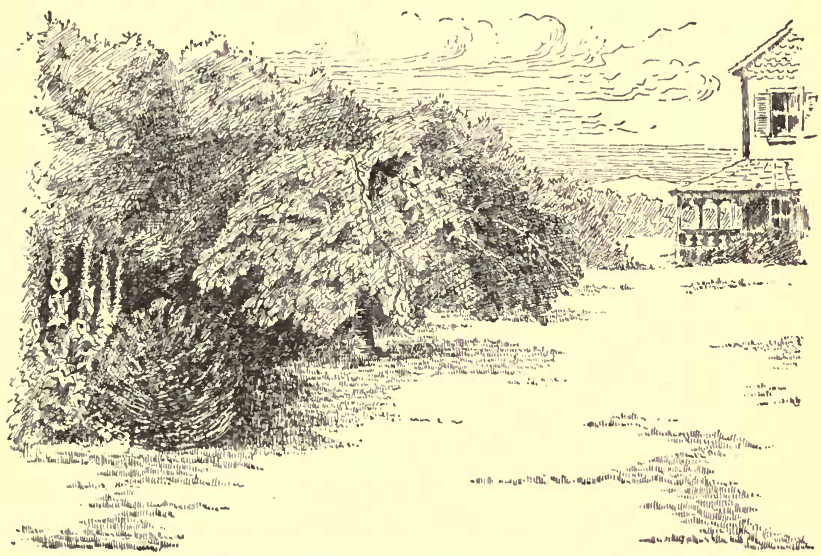

138. A weeping tree well placed.

of the formal tree. Fortunately, this tree is less planted in New York than in many western states. Its chief merits to the average planter are the quickness of its growth and the readiness with which it multiplies by cuttings. But in the north it is apt to be a short-lived tree, and it suffers from storms, and it has few really useful qualities. It may be used to some advantidge in wind- 
breaks for peach orchards and other short-lived plantations; but after a few years a screen of Lombardies begins to fail, and the habit of suckering from the root adds to its undesirable features. For shade it has little merit, and for timber none. People like it because it is striking, and this, in an artistic sense, is its gravest fault. It is unlike anything else in our landscape, and does not fit into our scenery well. The Lombardy should rarely, if ever, be seen as a single specimen; and above all, its formality and stiffness should not be emphasized by planting it in rows along country roads. A row of Lombardies along a roadside is like a row of exclamation points!

But the tree can often be used to good effect as one factor in a group of trees, where its spire-like shape, towering above the surrounding foliage, may lend a spirited charm to the landscape. It combines well in such groups if it stands in visual nearness to chimneys or other tall formal objects. Then it gives a sort of architectural finish and spirit to a group of trees; but the effect is generally lessened, if not altogether spoiled, if more than one Lombardy is in view. One or two specimens may often be used to give vigor to heavy plantations about low buildings, and the effect is generally best if they are seen beyond or at the rear of the building.

Another feature of common ornamental planting, which is well illustrated in the use of poplars. 
is the desire for plants merely because they grow rapidly. A very rapid-growing tree nearly always produces cheap effects. This is well illustrated in the common planting of willows and poplars about summer places or lake shores. Their effect is almost wholly one of cheapness and temporariness. There is little that suggests strength or durability in willows and poplars, and for this reason they should always be used as minor or secondary features in ornamental or home grounds. Where quick results are desired, nothing is better to plant than these trees, but better trees, like maples, oaks, or elms, should be planted with them, and the poplars and willows should be removed as fast as the other species begin to afford protection. When the plantation finally assumes its permanent characters, a few of the remaining poplars and willows, judiciously left, may afford very excellent effects; but no one who has an artist's feeling would be content to construct the frame work of his place of these rapid-growing and soft-wooded trees.

I have said that the legitimate use of poplars in ornamental grounds is in the production of minor or secondary effects. As a rule, they are less adapted to isolated planting as specimen trees than to use in composition,-that is, as parts of general groups of trees, where their characters serve to break the monotony of heavier foliage. The poplars are gay trees, as a rule, 
especially those, like the aspens, which have a trembling foliage. Their leaves are bright and the tops are thin. A few of them in judicious positions give a place a sprightly air. I especially love the common aspen, or Populus tremuloides, of our woods. Its dangling catkins (Fig. 139), light, dancing foliage and silver-gray limbs always cheer me, and its autumn color is one of the purest golden-yellows of our landscapes. I like to see a tree of it standing out in front of a group of maples or evergreens. Its whole attitude is then one of familiarity.

I will conclude this sketch of the ideas associated with the picture in the landscape with an article which I contributed to a recent issue of "Park and Cemetery," entitled "What are the fundamental concepts in landscape gardening?"

If the teacher or writer is to make any subject plain to his pupils or readers, he must be able to single out a few simple and fundamental prineiples. To state facts and rules is to treat only the incidents of the subject. Rules are not final. They express only the experience of the author or the combined experiences of others; and since experiences vary, the nature and the application of the rules must vary according to circumstances. People are forever misunderstanding what landscape gardening is, because we are always telling them what kinds of trees to plant and how to 


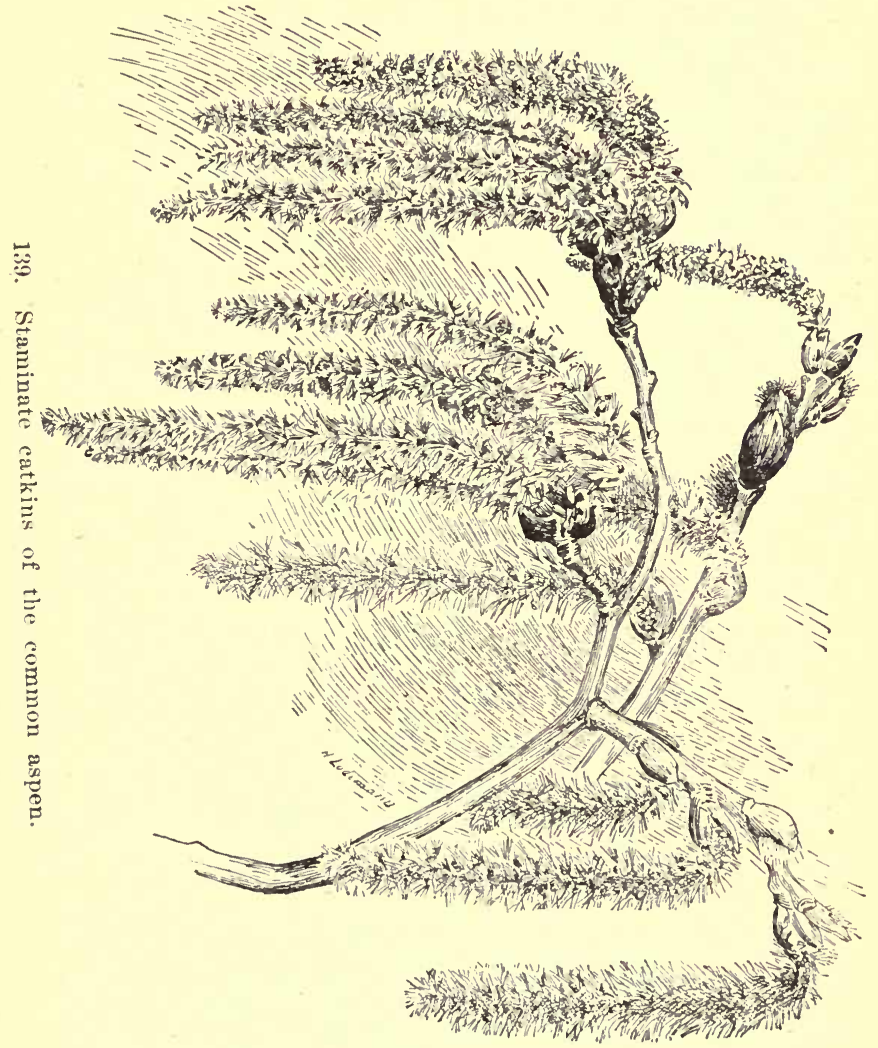


plant them. But the planter may not know why he plants.

The first instruction which should be given in landscape gardening, I think, is this: The object of landscape gardening is to make a picture. All the grading, seeding, planting, are incidental and supplemental to this one central idea. The greensward is the canvas, the house or some other prominent point is the central figure, the planting completes the composition and adds the color.

The second fundamental idea, I think, is the principle that the picture should have a landscape effect. That is, it should be nature-like. Carpetbeds are masses of color, not pictures. They are the little garnishings and reliefs which are to be used very cautiously, in the same way that little eccentricities and conventionalisms in a building should never be more than very minor features.

Every other concept in landscape gardening is subordinate to these two. They are explanations of the means and methods of making the picture. Some of the most important of these secondary, yet fundamental, concepts are as follows:

Conceive of the place as a unit. If a building is not pleasing, ask an architect to improve it. The real architect will study the building as a whole, grasp its design and meaning, and suggest improvements which will add to the forcefulness of the entire structure. A dabbler would add a chimney here, a window there, and apply various 
daubs of paint to the building. Each of these features might be good in itself. The paints might be the best of ochre, ultramarine or paris green, but they would have no relation to the building as a whole and would be only ludicrous. These two examples illustrate the difference between landscape gardening and the scattering over the place of mere ornamental features.

Have some one central and emphatic point in the picture. A picture of a battle draws its interest from the action of a central figure or group. The moment the incidental and lateral figures are made as prominent as the central figures, the picture loses emphasis, life and meaning. The borders of a place are of less importance than its venter. Therefore

Keep the center of the place upen. Frame and mass the sides.

Avoid scattered effects. Flowers and highcolored foliage are most effective against a background of green foliage. A flower-bed in the middle of a lawn is only a flower-bed; against the border-planting it is not only a flower-bed, but it may be also a structural part of the picture.

Flowers are incidents in a landscape picture. They add emphasis, supply color, give variety and finish; they are the ornaments, but the lawn and the mass-plantings make the framework. One flower in the border, and made an incident of the 
picture, is more effective than twenty flowers in the center of the lawn.

More depends upon the positions which plants occupy with reference to each other and to the
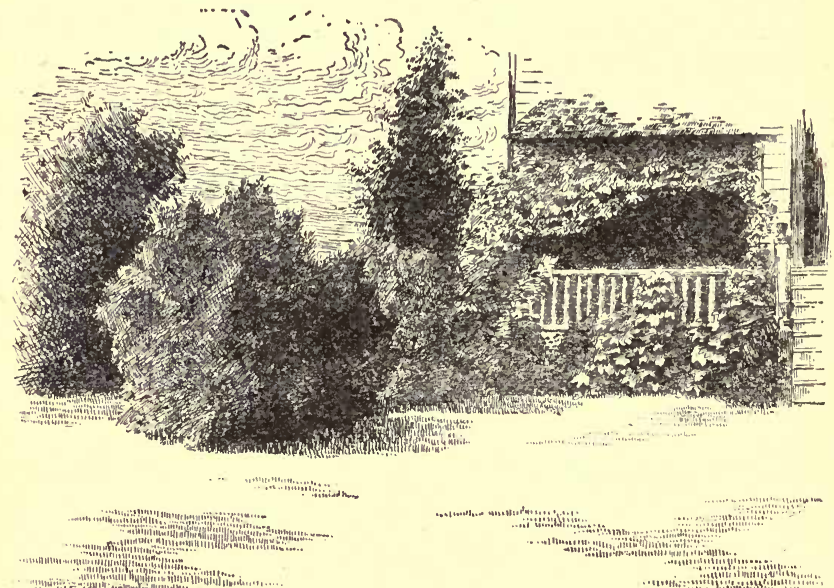

140. A front yard planting.

structural design of the place, than upon the intrinsic merits of the plants themselves.

Landscape gardening, then, is the embellishment of grounds in such a way that they will have a nature-like or landscape effect.

\section{VARIOUS SPECIFIC EXAMPLES}

The foregoing remarks will mean more if the reader is shown some concrete examples. I have selected a few cases, not because they are the 
best, or even because they are always good enough for models, but because they lie in $\mathrm{my}$ way and illustrate what I desire to teach. We will first look at a very ordinary front yard. It contained no plants, except a pear tree standing near the corner of the house. Four years later sees the yard as shown in Fig. 140. An exochorda is the large bush in the very foreground, and the porch foundation is screened and a border is thereby given to the lawn. The length of this planting from end to end is about

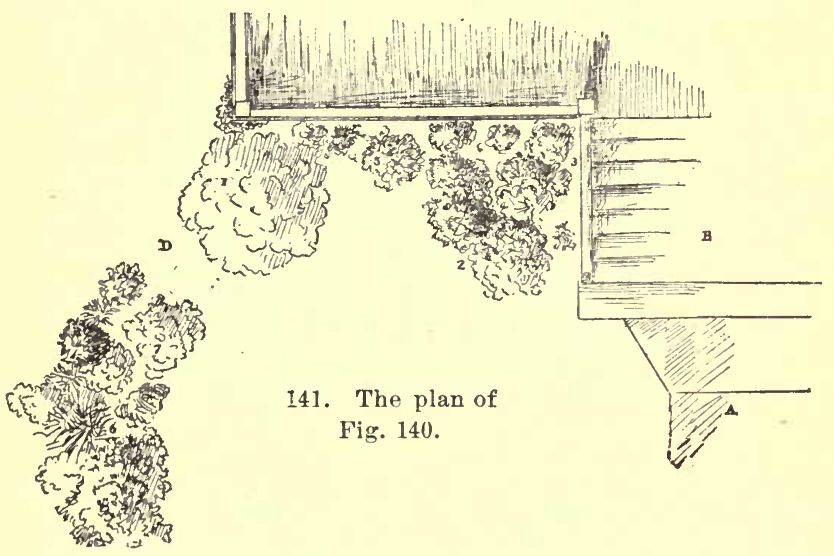

fourteen feet, with a projection towards the front on the left of ten feet. In the bay at the base of this projection the planting is only two feet wide, and from here it gradually swings out to the steps, eight feet wide. The promi- 
nent large-leaved plant near the steps is a bramble, Rubus odoratus, very common in the neighborhood, and it is a choice plant for decorative planting. The plants in this tangle in front of the porch are all from the wild, and

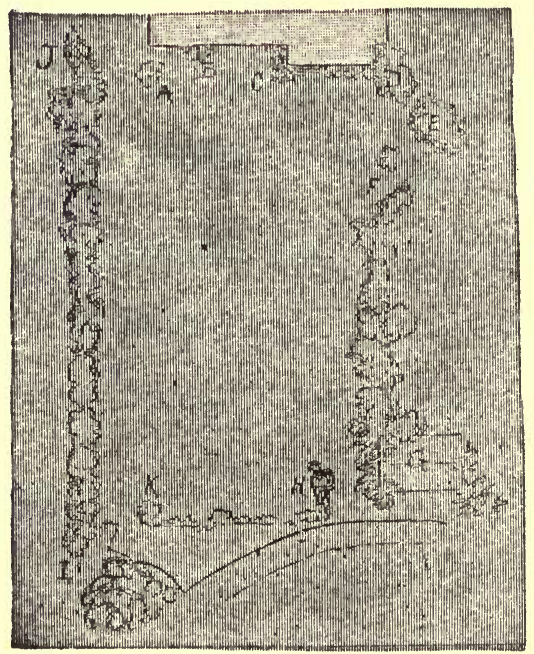

142. Diagram of back-yard. $50 \times 90 \mathrm{ft}$.

comprise a prickly ash, several plants of two wild osiers or dogwoods, a spice bush, rose, wild sunflowers and asters and golden-rods. The promontory at the left is a more ambitious but less effective mass. It contains an exochorda, a reed, variegated elder, sacaline, variegated dogwood, tansy, and a young tree of wild crab. At the 
rear of the plantation, next the house, one sees the pear tree. The best single part of the planting is the reed (Arundo Donax) overtopping the exochorda (not shown in the picture). The photograph was taken early in summer, before the reed had become conspicuous.

A ground plan of this planting is shown in Fig. 141. At $\mathrm{A}$ is the walk and $\mathrm{B}$ the steps. An opening at $\mathrm{D}$ serves as a walk. The main planting, in frout of the porch, fourteen feet long, received twelve plants, some of which have now spread into large clumps. At 1 is a large bush of osier, Cornus Baileyi. At 2 is a mass of Rubus odoratus; at 5 asters and golden-rods; at 3 a clump of wild sunflowers. The projecting planting on the left comprises about ten plants, of which 4

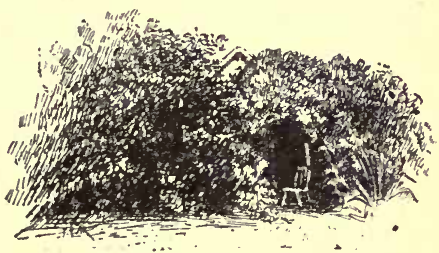

143. Cabin opening out from the border planting. is exochorda, 6 is arundo or reed, at the back of which is a large clump of sacaline, and 7 is a variegated-leaved elder.

A back yard is shown in Fig. 142. The owner wanted a tennis court, and the yard is so small as not to allow of wide planting at the borders. However, something could be done. Upon the left is the weed-land border, mentioned on page 146. In the first place, a good lawn was made. In the second place, no walks or drives were 
laid in the area. The drive for grocers' wagons and coal is seen in the rear, ninety feet from the house. From I to $\mathrm{J}$ is the weedland, separating the area from the neighbor's premises. Near I is a clump of roses. At $K$ is a large bunch of golden-rods. $\mathrm{H}$ marks a clump of yucca. $G$ is a cabin, covered with vines on the front, and shown in Figs. 143. 144. From G

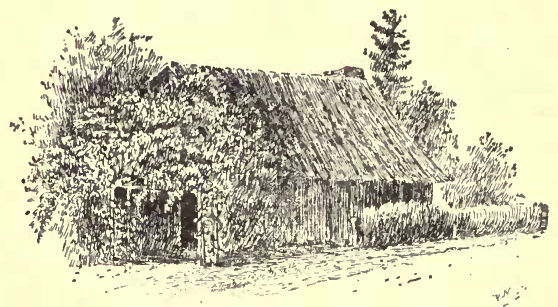

144. Rustic bark-covéred cabin.

to $\mathrm{F}$ is an irregular border, about six feet wide, containing barberries, forsythias, wild elder, and other bushes. D E is a screen of Russian mulberry, setting off the clothes yard from the front lawn. Near the back porch, at the end of the screen, is an arbor covered with wild grapes, making a playhouse for the children. A clump of lilacs stands at $A$. At $B$ is a vine-covered screen, serving as a hammock support. The lawn made and the planting done, it was next necessary to lay the walks. These are wholly informal affairs, made by sinking a plank ten inches wide into the ground to a level with the 

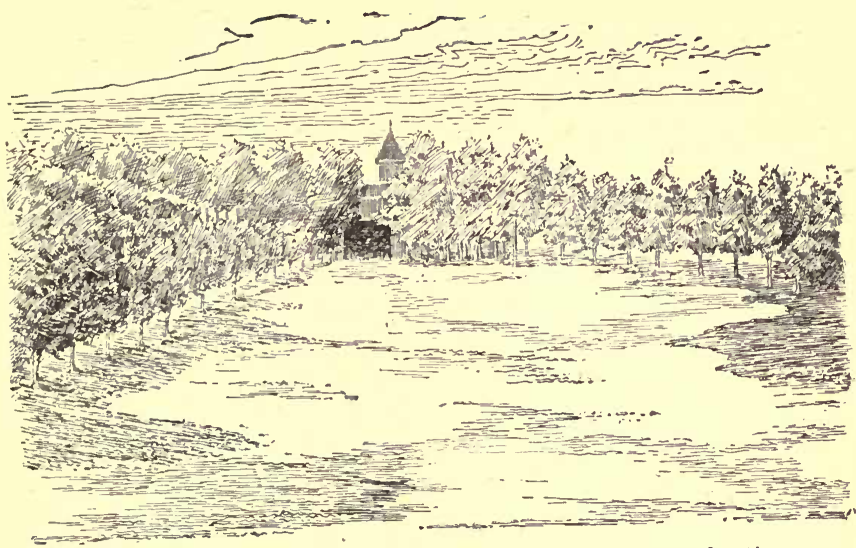

145. An area made ready for the seeding and planting.

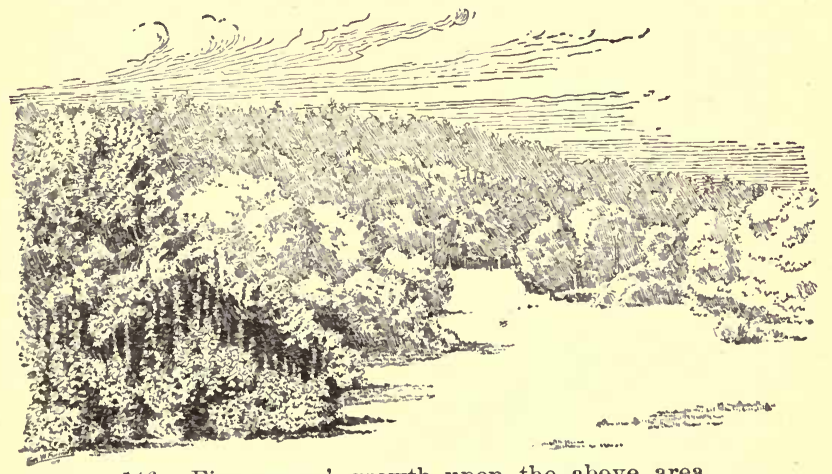

146. Five years' growth upon the above area. 
sod. The border plantings of this yard are too straight and regular for the most artistic results, but such was necessary in order not to encroach upon the central space. Yet the reader will no doubt agree that this yard is much better than it could be made by any system of scattered and spotted planting. Let him imagine how a glowing carpet-bed would look set down in the center of this lawn!

The making of a landscape picture is well illustrated in Figs. 145, 146. The former shows a small clay field (seventy five feet wide and three hundred feet deep), with a barn at the rear. In front of the barn is a screen of willows. The observer is looking from the dwelling house. The area has been plowed and seeded for a lawn. The operator has then marked out a devious line upon either border with a hoe handle, and all the space between these borders has been gone over with a garden roller to mark the area of the desired greensward. The borders are now planted with a variety of small trees, bushes and herbs. Five years later the view shown in Fig. 146 was taken.

A back yard is shown in Fig. 147. It is approximately sixty feet square. At present it contains a drive, which is unnecessary, expensive to keep in repair, and destructive of any attempt to make a picture of the area. The place could be improved by planting it somewhat after the manner of Fig. 148. 

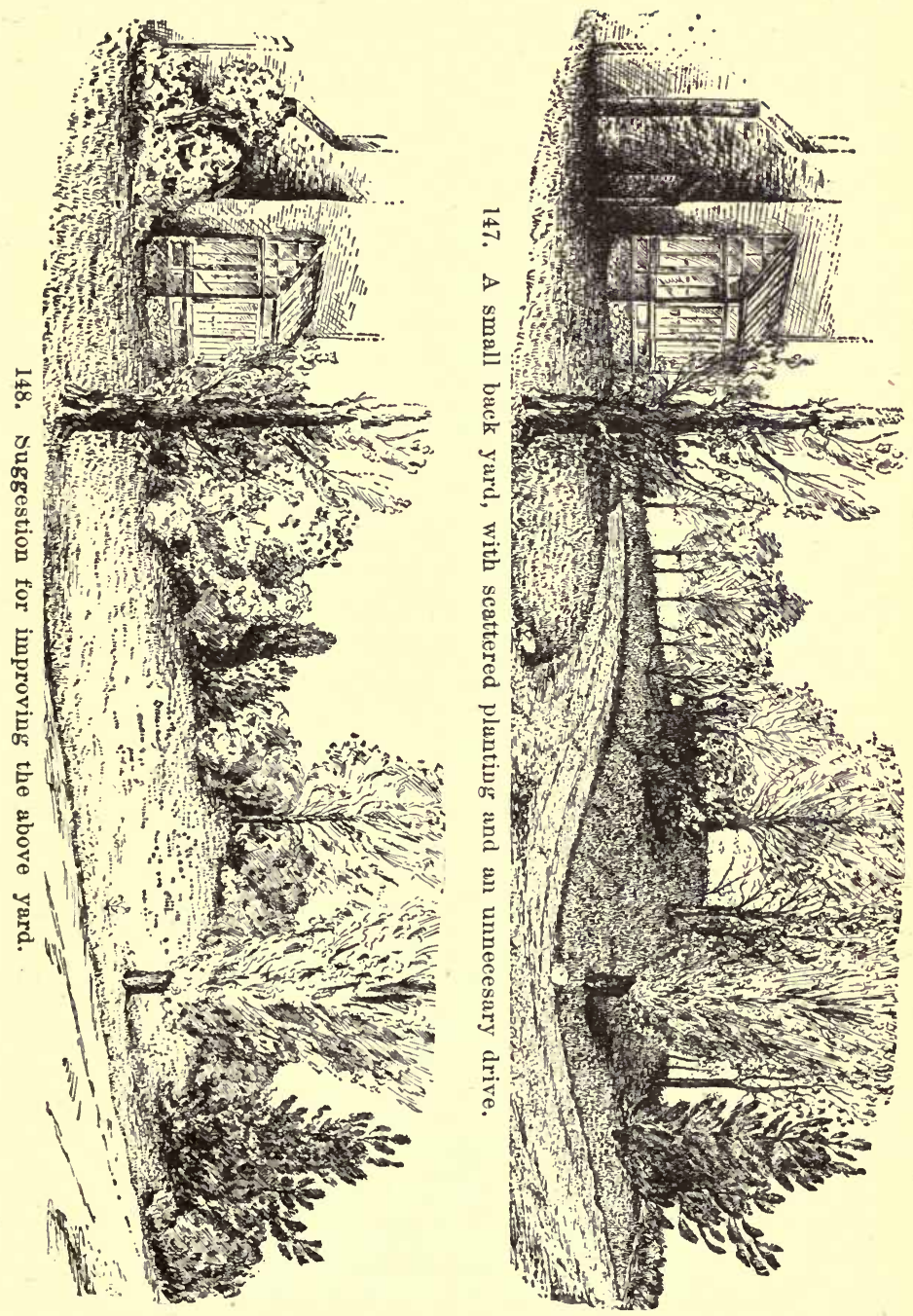


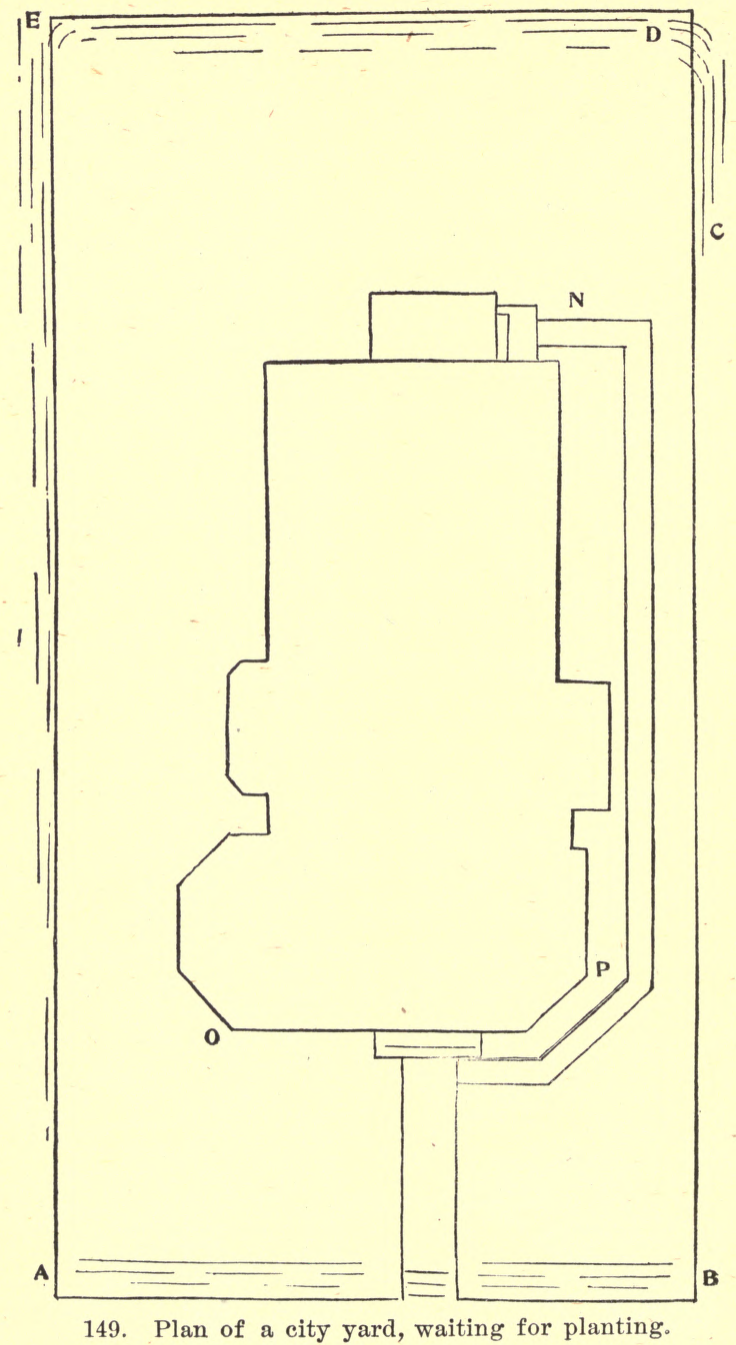


A plan of a city lot is given in Fig. 149. The area is fifty by one hundred, and the house occu. pies the greater part of the width. It is level, but the surrounding land is higher, resulting in a sharp terrace, three or four feet high, on the rear, $\mathrm{E} D$. This terrace vanishes at $\mathrm{C}$ on the right, but extends nearly the whole length of the other side, gradually diminishing as it approaches A. There is a terrace two feet high extending from A to B, along the front. Beyond the line E D is the rear of an establishment which it is desired to hide. Since the terraces set definite borders to this little place, it is desirable to plant the boundaries rather heavily. If the adjoining lawns were on the same level, or if the neighbors would allow one area to be merged into the other by pleasant slopes, the three yards might be made into one picture; but the place must remain isolated.

There are three problems of structural planting in the place: to provide a cover or screen at the rear; to provide lower border masses on the side terraces; to plant next the foundations of the house. Aside from these problems, the grower is entitled to have a certain number of specimen plants, if he has particular liking for given types, but these specimens must be planted in some relation to the structural masses, and not in the middle of the lawn.

The following shrubs were actually selected and planted. The place is in central New York。 
Shrubs for Tall Background.

2 Barberry, Berberis vulgaris and var. purpurea.

1 Cornus Mas.

2 Tall deutzias.

3 Lilacs.

2 Mock oranges, Philadelphus grandiflorus and P. coronarius.

2 Variegated elders.

2 Elæagnus, $E$. hortensis and $E$. longipes.

1 Exochorda.

2 Hibiscuses.

1 Privet.

3 Viburnums.

1 Snowball.

1 Tartarian honeysuckle.

1 Silver Bell, Halesia tetraptera.

These were planted on the sloping bank of the terrace, from E to D. The terrace has an in-

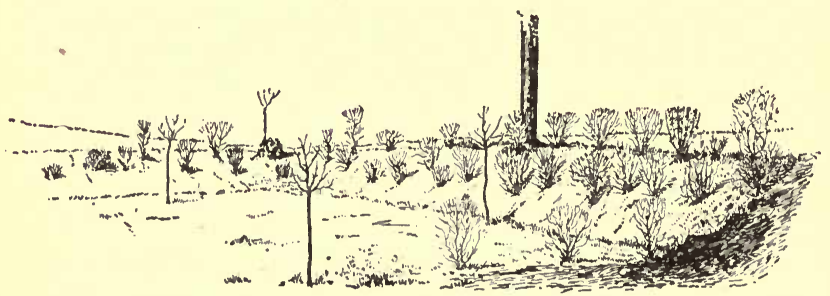

150. The planting of the terrace in Fig. 149.

cline, or width, of about three feet. Fig. 150 shows this terrace after the planting was done, looking from the point $\mathrm{C}$. 
Shrubs of Medium Size, Suitable for Side Plantings and Groups.

3 Barberries, Berberis Thunbergii.

3 Osier dogwoods, variegated.

2 Japanese quinces, Cydonia Japonica and C. Maulei.

4 Tall deutzias.

1 Variegated elder.

7 Weigelas, assorted colors.

1 Rhodotypus.

9 Spireas of medium growth, assorted

1 Rubus odoratus.

1 Lonicera fragrantissima.

Most of these shrubs were planted in a border two feet wide extending from $\mathrm{B}$ to $\mathrm{C} \mathrm{D}$, the planting beginning about ten feet back from the street. Some of them were placed upon the terrace at the left, extending from $\mathrm{E}$ one-fourth of the distance to A. The plants were set about two feet apart. A strong clump was placed at $\mathrm{N}$ to screen the back yard. In this back yard a few small fruit trees and a strawberry bed were planted.

Low Informal Shrubs for Front of Porch and Banking Against House.

3 Deutzia gracilis.

6 Kerrias, green and variegated.

3 Daphne Mezereum.

3 Lonicera Halliana.

3 Rubus phœenicolasius.

3 Symphoricarpus vulgaris.

4 Mahonias.

1 Ribes aureum. 
1 Ribes sanguineum.

1 Rubus cratægifolius.

1 Rubus fruticosus var. laciniatus.

These bushes were planted against the front of the house (a porch on a high foundation extends to the right from $\mathrm{O}$ ), from the walk around to $\mathrm{P}$, and a few of them were placed at the rear of the house.

Specimen Shrubs for mere Ornament.

Azalea.

Rhododendron.

Rose.

2 Hydrangeas.

1 Snowball.

1 each Forsythia suspensa and F. viridissima.

2 Flowering almonds.

These were planted in conspicuous places here and there against the other masses.

Here are one hundred excellent and interesting bushes planted in a yard only fifty feet wide and one hundred feet deep, and yet the place has as much room in it as it had before! There is abundant opportunity along the borders for dropping in cannas, dahlias, hollyhocks, asters, geraniums, coleuses, and other brilliant paints. The bushes will soon begin to erowd, to be sure, but a mass is wanted; but the narrowness of the plantations will allow each bush to develop itself laterally to perfection. If the borders become too thick, 
however, it is an easy matter to remove some of the bushes; but they probably will not. Picture the color and variety and life in that little yard! And if a pigweed now and then gets a start in

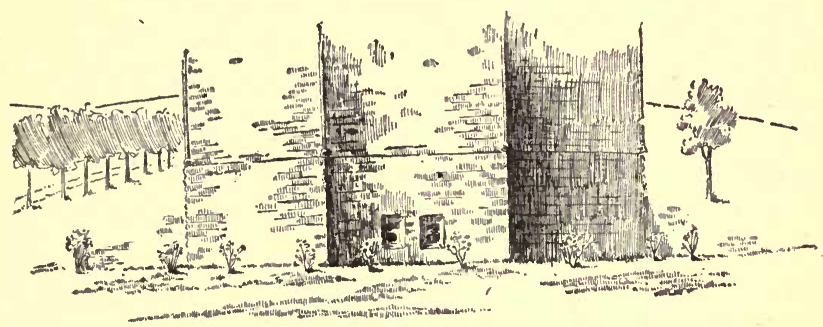

151. Nine shrubs.

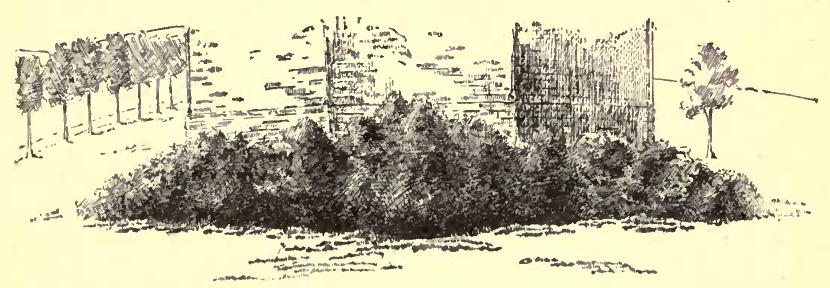

152. A bank of verdure and color.

the border, let it alone: it belongs there! Then picture the same area filled with disconnected, spotty, dyspeptic and unspirited flower-beds and rose bushes!

Strong and bare foundations should be relieved by heavy planting. Fill the corners with snowdrifts of foliage. The corner by the steps is a perennial source of bad temper. The lawn mower 
will not touch it, and the grass has to be cut with a butcher-knife. Plant a burdock in it!

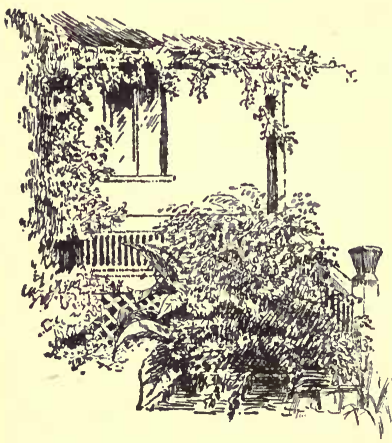

153. The corner by the steps.

The tennis-screen may be relieved by a background (Fig. 154) and a clump of ribbon-grass is out of the way against a post (Fig. 155).

A word should be said about just how to make a group. Dig up the entire area. Never set the bushes in holes dug in the sod (Fig. 156). Spade up the ground, set the bushes thick, hoe them at intervals, and then let them go. If you do not like the bare earth between them,

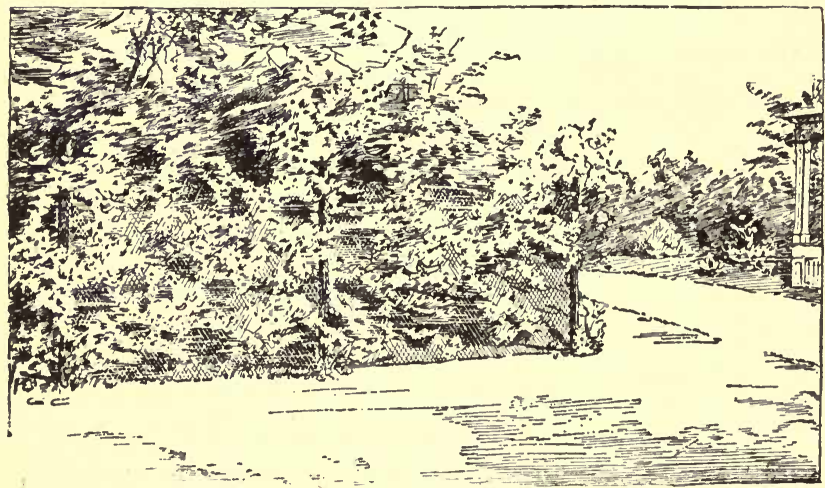

154. Tennis-screen against the border-mass. 
sow in the seeds of hardy annual flowers, like phlox, petunia, alyssum and pinks. The person who plants his shrubs in holes in the sward does not seriously mean to make any foliage mass, and it is likely that he does not know what relation the border-mass has to artistic planting. I have said to plant the bushes thick. This is for

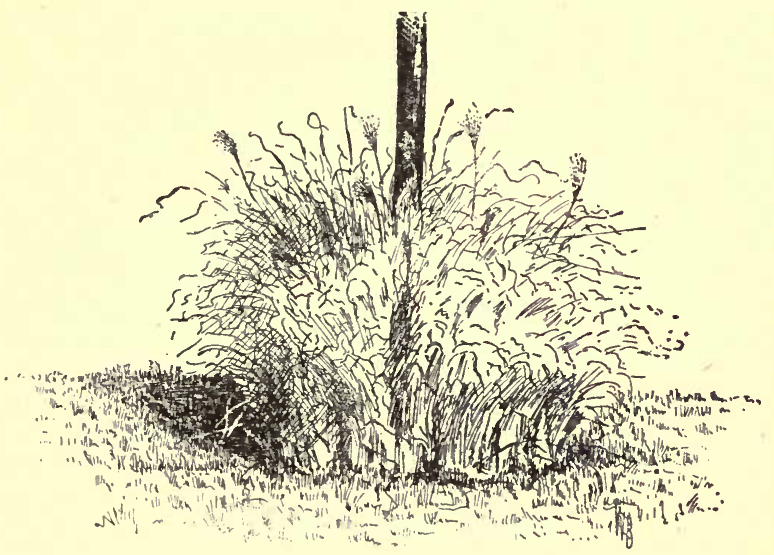

155. Clump of ribbon-grass against the clothes-post.

quick effect. It is an easy matter to thin the plantation if it becomes too thick. I should generally plant all common bushes as close as two feet apart each way, especially if I get most of them from the fields, so that I do not have to buy them. Excellent mass effects may also be obtained by eutting well established plants of sumac, ailanthus, basswood, and other strong- 
growing things, to the ground each year, for the purpose of securing the stout shoots. Fig. 157 will give the hint.

But if one has no area which he can make into a lawn and upon which he can plant such verdurous masses, what then may he do? Even then there may be opportunity for a little neat and artistic planting. Even if one lives in a rented house, he may bring in a bush or an herb from the woods, and paint a picture with it. Plant it in the corner by the steps, in front of the porch,

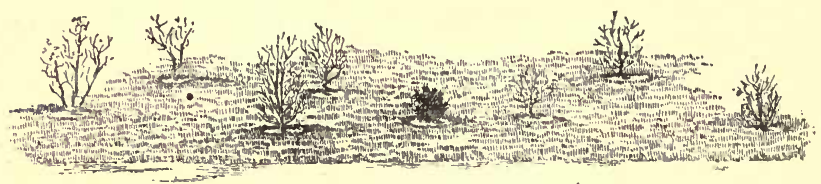

156. Poor little things!

at the corner of the house,-almost anywhere except in the center of the lawn. Make the ground rich, secure a strong root and plant it with care; then wait. The little clump will not only have a beauty and interest of its own, but it will add immensely to the furniture of the yard. About its base one may plant stray bulbs of glowing tulips or dainty snowdrops and lilies-of-thevalley; and these may be followed with pansies and phlox and other simple folk. Very soon one finds himself deeply interested in these random and detached pictures, and almost before he is aware he finds that he has rounded off the corners 
of the house, made snug little arbors of wild grapes and clematis, covered the rear fence and the outhouse with actinidia and bitter-sweet, and has thrown in dashes of color with hollyhocks, cannas and lilies, and has tied the foundations of the buildings to the greensward by low strands of

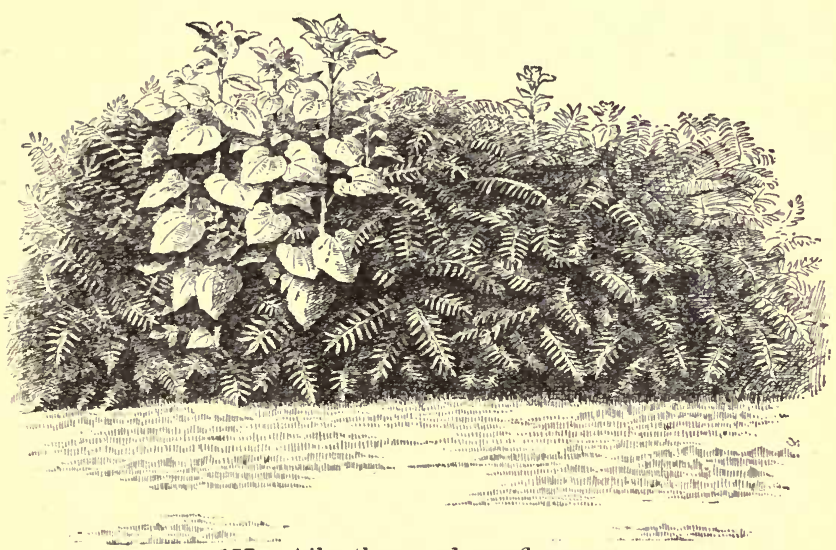

157. Ailanthus and sunflowers.

vines or deft bits of planting. He soon comes to feel that flowers are most expressive of the best emotions when they are daintily dropped in here and there against a background of foliage. Presently he rebels at the bold, harsh and impudent designs of some of the gardeners, and grows into a pure and subdued love of plant forms and verdure. He may still like the weeping and cutleaved and party-colored trees of the horticul- 
turist, but he sees that their best effects are to be had when they are planted sparingly, as flowers are, as borders or promontories of the structural masses.

These various discussions and pictures will fix in the reader's mind the importance of a simple structural design for the home grounds. The essential elements of this design are the open center and the well-planted sides. It is particularly important that the view to and from the front of the dwelling house be kept open, for otherwise there can be little conception of pictorial effect in the composition. It is a grave mistake to cover up or to obscure the one central and important feature of the place.

It all amounts to this, that the best planting, like the best painting and the best music, is possible only with the best and tenderest feeling and the closest living with nature. One's place grows to be a reflection of himself, changing as he changes, and expressing his life and sympathies to the last.

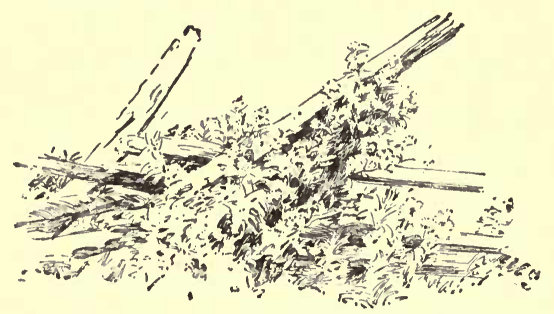

158. Birds build their nests here. 
HOW TO MAKE THE IMPROVEMENTS.

After the home maker has devised a general scheme or plan of his area, he will inquire how to go about it to prepare the land and to lay out the structural design. The remarks which have been made in Section I, respecting the preparation, tillage and enriching of land, will apply to the lawn and the oruamental grounds, but a

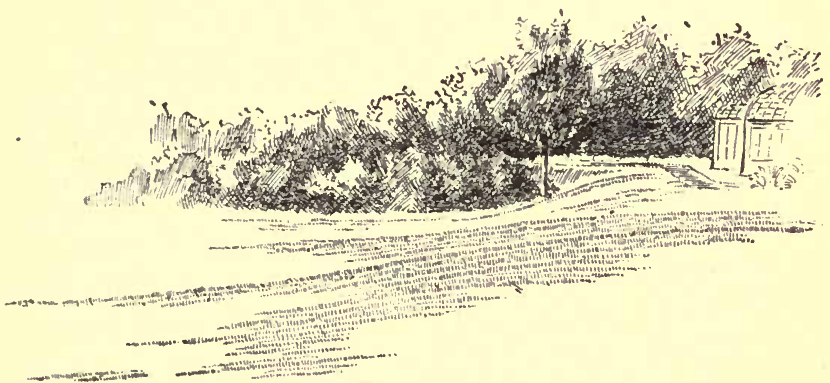

159. An ideal bank in the foreground.

few specific remarks may be useful. The reader should also consult the best writings upon landscape gardening and related topies, if he intends to make permanent or extensive improvements. A priced list of current American horticultural books will be found in the third edition of "The Horticulturist's Rule-Book." The reader may consult with profit Long's "Ornamental Gardening for Americans" for details of home-making. For discussions of the artistic values of plants, 
Parson's "Landscape Gardening" is invaluable Other books, and horticultural periodicals, may be consulted.

The first consideration is to grade the land. Grading is very expensive, especially if performed at a season when the soil is heavy with moisture. Every effort should be made, therefore, to reduce. the grading to a minimum and still secure a pleasing contour. The smaller the area, the more pains must be taken with the grading; but in any plat which is one hundred feet or more square, very considerable undulations may be left in the surface with excellent effect. In lawns of this size, or even half this size, it is rarely advisable to have them perfectly flat and level. They should slope gradually away from the house, and when the lawn is seventy-five feet or more in width, it may be slightly crowning with good effect. A lawn should never be hollow, - that is. lower in the center than at the borders,-and broad lawns which are perfectly flat and level often appear to be hollow. A slope of one foot in twenty or thirty is none too much for a pleasant grade in lawns of some extent.

In places in which the natural slope is very perceptible, there is a tendency to terrace the lawn for the purpose of making the various parts or sections of it more or less level and plane. In nearly all cases, however, a terrace is objectionable. It cuts the lawn into two or more pror- 
tions, and thereby makes it look smaller and spoils the effect of the picture. Terraces are also expensive to make and to keep in order; and a shabby terrace is always to be avoided. When formal effects are desired, their value will depend

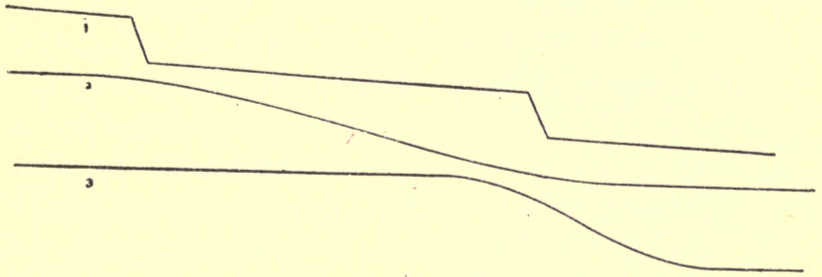

160. Treatment of a sloping lawn.

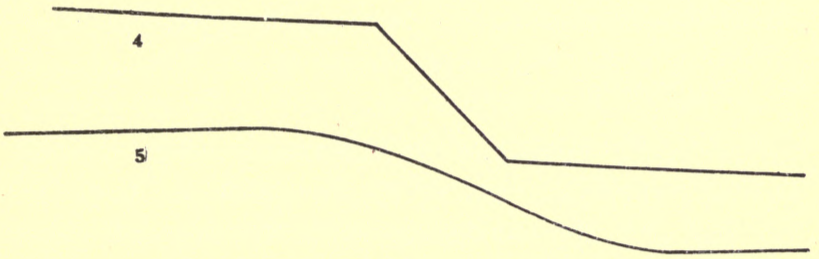

161. Treatment of a very steep bank.

very largely upon the rigidity of the lines and the care with which they are maintained. If a terrace is necessary, it should be in the form of a retaining wall next the street, or else it should lie next the building, giving as broad and continuous a lawn as possible. It should be remembered, however, that a terrace next a building should not be a part of the landscape, but a part of the architec- 
ture: that is, it should serve as a base to the building. It will at once be seen, therefore, that terraces are most in place against those buildings which have strong horizontal lines, and 1. they are not suitable against buildings with very broken lines and mixed or gothic features. In order to join the terrace to the building, it is usually advisable to place some architectural feature upon its erown, like a balustrade, and to

162. Terrace falling too suddenly away from the building.

ascend it by means of architectural steps. The terrace elevation, therefore, becomes a part of the base of the building, and the top of it is an esplanade.

A simple and gradually sloping bank can nearly always be made to take the place of a terrace. For example, let the operator make a terrace, with sharp angles above and below, in the fall of the year; in the spring, he will find that nature has taken the matter in hand and the upper angle of the terrace has been washed away and deposited in the lower angle, and the result is the beginning of a good series of curves. Fig. 159 
shows an ideal slope, with its double eurve, comprising a convex curve on the top of the bank, and a concave curve at the lower part. This is a slope which would ordinarily be terraced, but in its present condition it is a part of the landscape picture. It can be mown as readily as any other part of the lawn, and takes care of itself. A terrace always obtrudes a hard and rigid line, and fastens the attention upon itself rather than upon the landscape.

The diagrams in Fig. 160 indicate poor and good treatment of a lawn. The terraces are not needed in this ease; or if they are, they should never be made as at 1 . The same dip could be taken up in a single eurved bank, as at 3 , but the better way, in general, is to give the treatment shown in 2. Fig. 161 shows how a very high terrace, 4 , ean be supplaced by a sloping bank, 5 . Fig. 162 shows a terrace which falls away too suddenly from the house.

In grading to the borders of the place, it is not always necessary, nor even desirable, that a continuous contour should be obtained. This is especially true if the border is higher or lower than the lawn. A somewhat irregular line of grade will appear to be most natural, and lend itself best to effective planting. This is especially true in the grade to water-courses, which, as a rule, should be more or less devious or winding ; and the adjacent land should, therefore, present 
various heights and contours. It is not always necessary, however, to make distinct banks along water-courses, especially if the place is small and

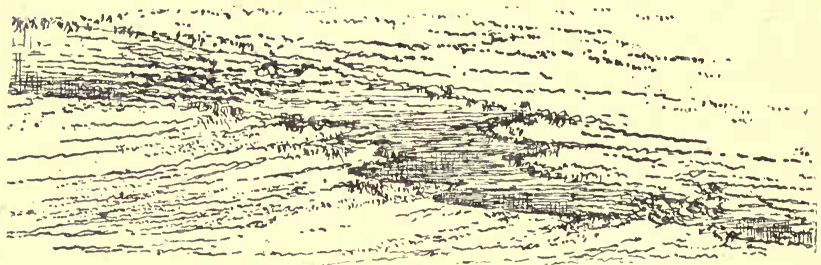

163. Gradual grade to a water-course. Before planting.

the natural lay of the land is more or less plane or flat. A very slight depression, as shown in Fig. 163, may answer all the purposes of a water grade in such places.

If it is desirable that the lawn be as large and spacious as possible, then the boundary of it should be removed. Take away the fences, curbing and other right lines. In rural places, a sunken fence may sometimes be placed athwart the lawn at its farther edge for the purpose of keeping cattle off the place, and thereby bring in the adjacent landscape. Fig. 164 suggests how this may be done. The depression near the foot of the lawn, which is really a ditch and scarcely visible from the upper part of the place because of the slight elevation upon its inner rim, answers all the purposes of a fence.

Nearly all trees are injured if the dirt is filled about the base to the depth of a foot or more. 
The natural crown of the plant should be exposed so far as possible. Oaks, maples, and, in fact, most trees will lose their bark near the crown if the dirt is piled against them; and this is especially true if the water tends to settle about the trunks. Fig. 165 shows how this difficulty may be obviated. A well is stoned up about the tree, allowing a space of a foot or two upon all sides, and tile drains are laid about the base of the well, as shown in the diagram at the right. It is often possible to make a sloping bank just above the tree, and to allow the ground to fall away from the roots of the tree on the lower side, so that there is no well or hole about the tree; but this is possible only when the land below the tree is considerable lower than that above it.

WALKS AND DRIVES. - So far as the pic: ture in the landscape is concerned, walks and drives are blemishes. Since they are necessary,

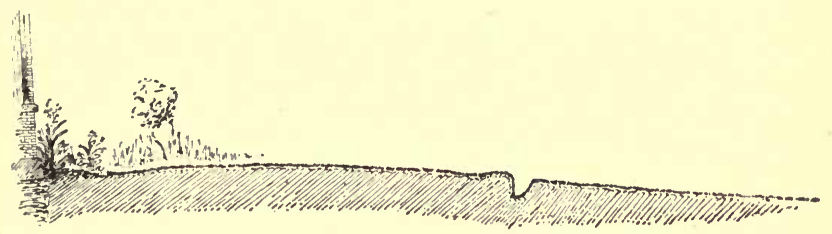

164. The sunken fence.

however, they must form a part of the landscape design. They should be as few as possible, not only because they interfere with the artistic composition, but also because they are expensive to 
make and to maintain. Most places have too many, rather than too few, walks and drives. Small city areas rarely need a driveway entrance, not even to the back door. The back yard in Fig. 142 illustrates this point. The distance from the house to the street on the back is about ninety feet, yet there is no driveway in the place. The coal and provisions are carried in; and, although

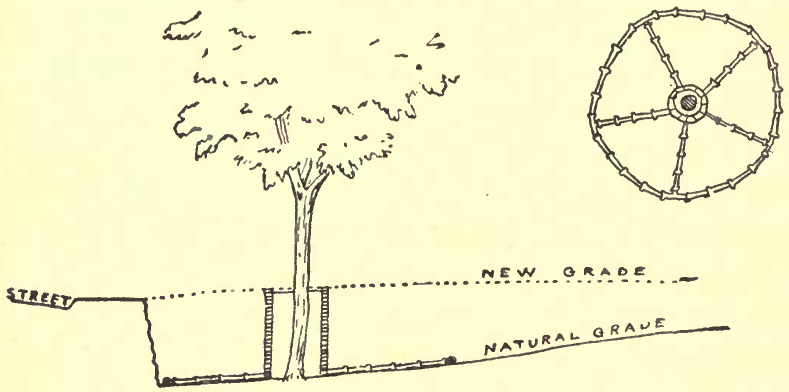

16.5. Protecting a tree in filled land.

the deliverymen may complain at first, they very soon accept the inevitable. It is not worth the while to maintain a drive in such a place for the convenience of truckmen and grocers. Neither is it often necessary to have a dive in the front yard if the house is within seventy-five or one hundred feet of the street. When a drive is necessary, it should enter, if possible, at the side of the residence, and not make a circle in the front lawn. This remark will not apply to large areas of a half acre or more. 
The drives and walks should be direct. They should go where they appear to go, and should be practically the shortest distances between the points

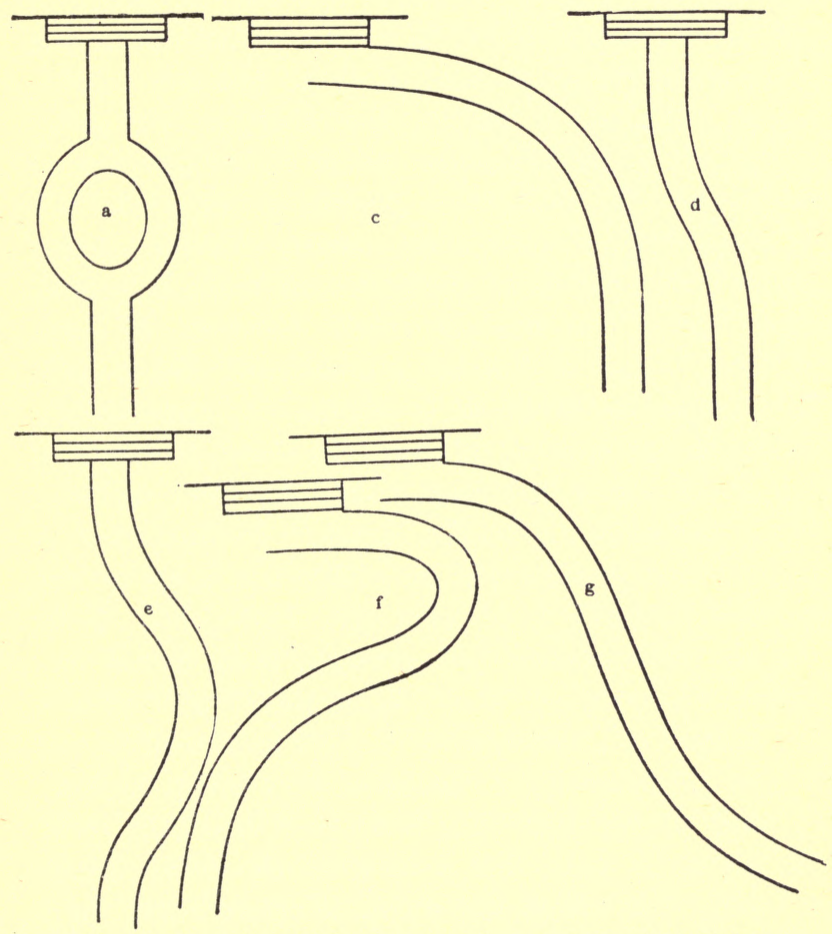

166. Various types of curves, only $g$ being admissib.e.

to be reached. Fig. 166 illustrates some of the problems connected with walks to the front door. A common type of walk is at $a$, and is a nui- 
sance. The time which one loses in going around the cameo-set in the center would be sufficient, if conserved, to lengthen a man's life by several months or a year. Such a device has no merit in art or convenience. It is merely an effort on the part of the maker to show that he has done something. Walk $c$ is better, but still is not ideal, inasmuch as it makes too much of a right-angled curve, and the pedestrian desires to cut across the corner. Such a walk, also, usually extends too far beyond the sorner of the house to make it appear to be direct. It has the merit, however, of leaving the center of the lawn practically untouched. The curve in walk $d$ is ordinarily unnecessary unless the ground is rolling. In small places, like this, it is better to have a straight walk directly from the sidewalk to the house. In fact, this is true in nearly all cases in which the lawn is not more than forty to seventy-five feet deep. Plan $e$ is also inexcusable. A straight walk would answer every purpose better. Any walk which passes the house, and returns to it, $f$, is inexcusable unless it is necessary to make a very steep ascent. If most of the traveling is in one direction from the house, a walk like $g$ may be the most direct and efficient. It is known as a direct curve, and is a compound of a concave and a convex curve.

It is essential that any walk or drive, however long, should be continuous in direction and design from end to end. Fig. 167 illustrates a long drive 
which contradicts this principle. It is a series of meaningless curves. The reason for these curves is the fact that the drive was extended from time to time as new houses were added to the villa. The reader will easily perceive how all the kinks might be taken out of this drive and one direct and bold curve be substituted.

The sides of walks and drives may often be planted with shrubbery. It is not necessary that they always have prim and definite borders. Fig. 168 illustrates a bank of foliage which breaks up the hard line of a walk, and serves also as a border for the growing of flowers and interesting specimens. This walk is also characterized by the absence of high and hard borders.

Even in cities, it is not always necessary that stone copings be used. Fig. 169 illustrates this fact, and also shows how the parking between the walk and the street may be effectively planted. Upon the draining of residence streets, a wellknown landscape gardener, O. C. Simonds, writes as follows in "Park and Cemetery:"

"The surface drainage is something that interests us whenever it rains or when the snow melts. It has been customary to locate eatch-basins for receiving the surface water at street intersections. This arrangement causes most of the surface water from both streets to run past the crossings, making it necessary to depress the pavement, so that one must step down and up in going from 


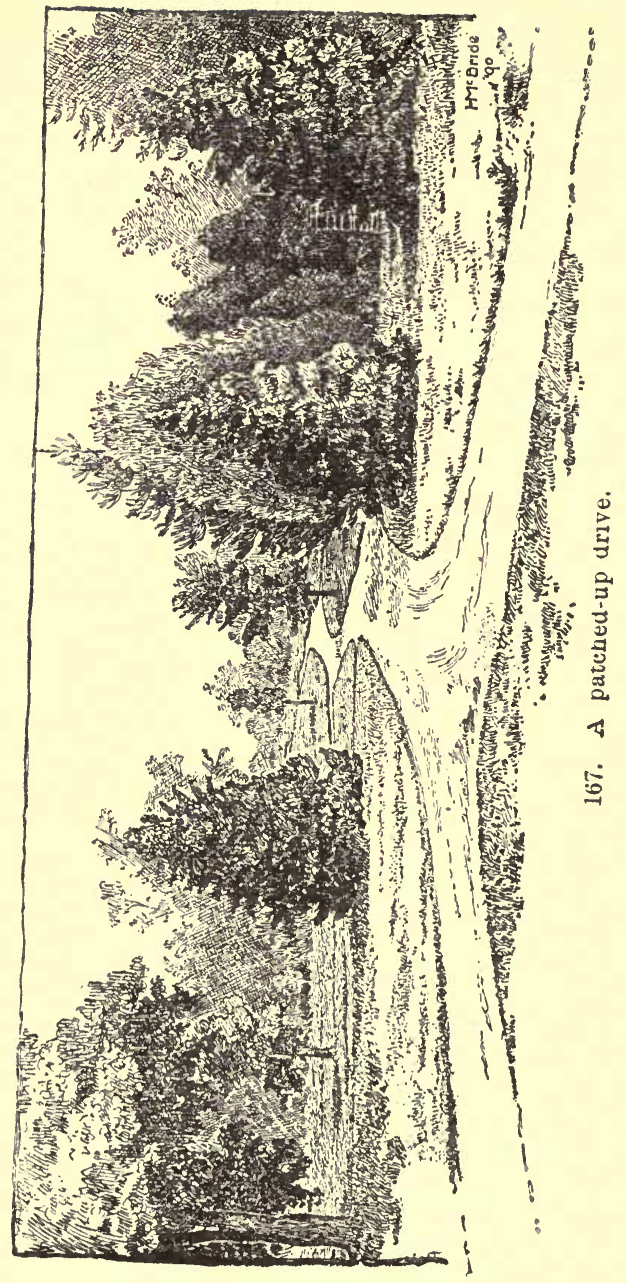


one side of a street to the other, or else a passageway for the water must be made through the crossing. It may be said that a step down to the pavement and up again to the sidewalk at the street intersections is of no consequence, but it is really more elegant and satisfactory to have the walk practically continuous. With the catch-

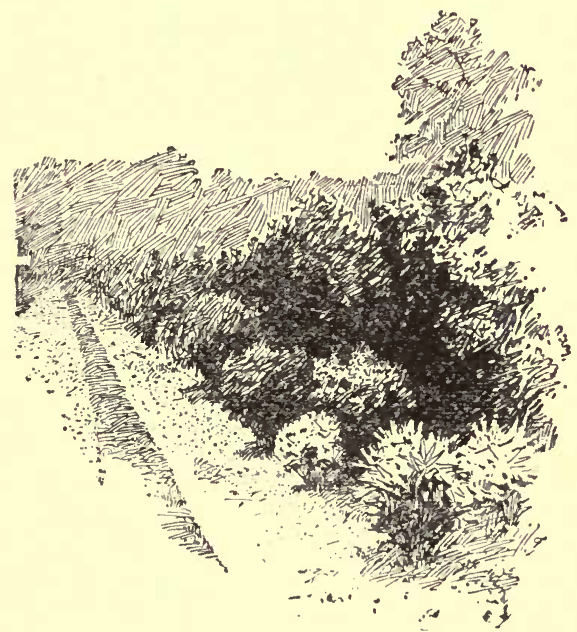

168. Informal treatment of a walk.

basin at the corner, the stoppage of the inlet, or a great fall of rain, sometimes covers the crossing with water, so that one must either wade or go out of his way. With catch-basins placed in the center of the blocks, or, if the blocks are long, at some distance from the crossing, the intersections 


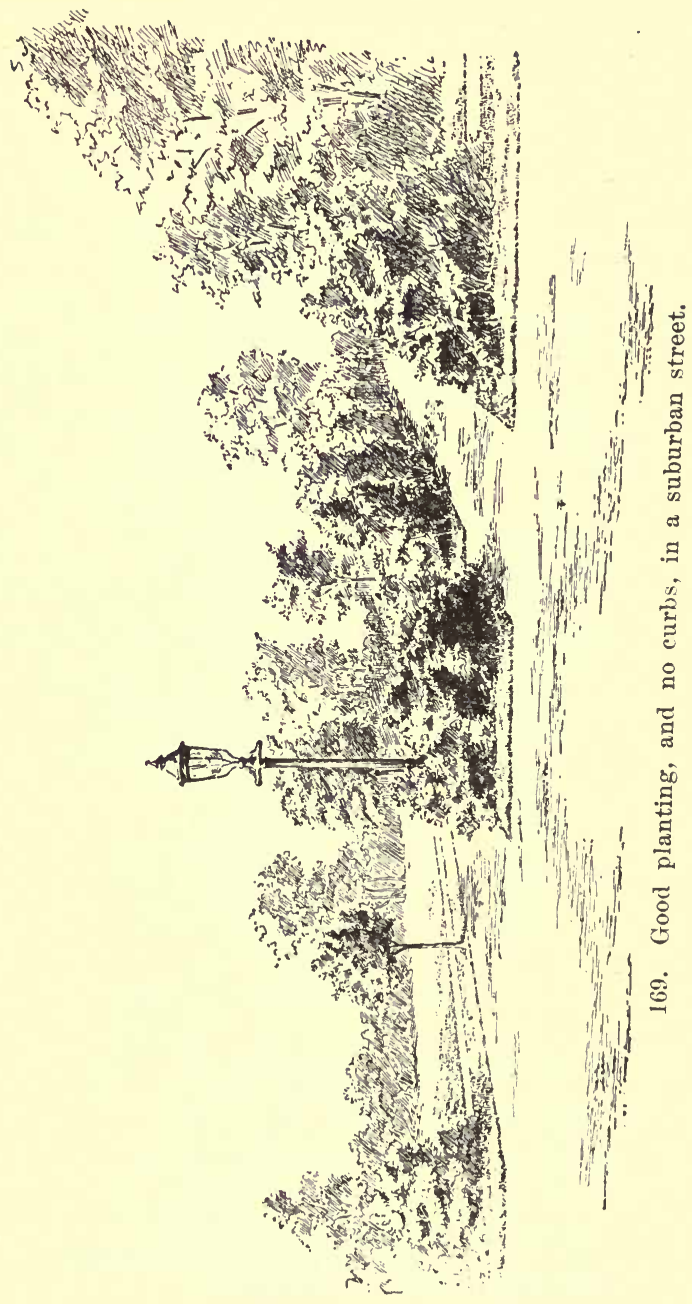


can be kept relatively high and dry. Roadways are generally made crowning in the center, so that water runs to the sides, but frequently the fall lengthwise of the roadway is less than it should be. City engineers are usually inclined to make the grade along the length of a street as nearly level as possible. Authorities who have given the subject of roads considerable study recommend a. fall lengthwise of not less than one foot in one hundred and twenty-five, nor more than six feet in one hundred. Such grades are not always feasible, but a certain amount of variation in level can usually be made in a residence street which will make it much more pleasing in appearance, and have eertain practical advantages in keeping the street dry. The water is usually confined to the edge of the pavement by curbing, which may rise anywhere from four to fourteen inches above the surface. This causes all the water falling on the roadway to seek the eatch-basin and be wasted, excepting for its use in flushing the sewer. If the curbing, which is really unnecessary in most cases, were omitted, much of the surface water would soak into the ground between the sidewalk and the pavement, doing much good to trees, shrubs and grass. The roots of the trees naturally extend as far, or farther, than their branches, and for their good the ground under the pavement and sidewalk should be supplied with a certain amount of moisture. 
"The arrangement made for the removal of surface water from the street must also take care of the surplus water from adjacent lots, so there is a practical advantage in having the level of the street lower than that of the ground adjoining. The appearance of houses and home grounds is also much better when they are higher than the street, and for this reason it is usually desirable to keep the latter as low as possible and give the underground pipes sufficient covering to protect them from frost. Where the ground is high and the sewers very deep the grades should, of course, be determined with reference to surface conditions only. It sometimes happens that this general arrangement of the grades of home grounds, which is desirable on most accounts, causes water from melting snow to flow over the sidewalk in the winter time, where it may freeze and be dangerous to pedestrians. A slight depression of the lot away from the sidewalk and then an ascent toward the house would usually remedy this difficulty, and also make the house appear higher. Sometimes, however, a pipe should be placed underneath the sidewalk to allow water to reach the street from inside of the lot line. The aim in surface drainage should always be to keep the traveled portions of the street in the most perfect condition for use. The quick removal of surplus water from sidewalks, crossings, and roadways will help to insure this result." 
These remarks concerning the curbings and Lard edges of city streets may also be applied to walks and drives in small grounds. Fig. 170, for example, shows the common method of treating the edge of a walk, by making a sharp and sheer elevation. This edge needs constant trimming, else it becomes unshapely; and this trimming tends to widen the walk. For general purposes, a border, like that shown in Fig. 171, is better. The sod rolls over until it meets the walk, and the lawn-mower is able to keep it in condition. If it becomes more or less rough and irregular, it is pounded down.

If it is thought necessary to trim the edges of walks and drives, then one of the various kinds of sod-cutters which are sold by dealers may be used for the purpose, or an old hoe may have its shank straightened and the corners of the blade rounded off, as shown in Fig. 172, and this will answer all purposes of the common sod-cutter; or, a sharp, straight-edged spade may sometimes be used. The loose overhanging grass on these edges is ordinarily cut by large shears made for the purpose.

Walks and drives should be laid in such direction that they will tend to drain themselves; but if it is necessary to have gutters, these should be deep and sharp at the bottom, for the water then draws together and tends to keep the gutter clean. A shallow and rounded gutter does not clean 
itself; it is very apt to fill with weeds, and vehicles often drive in it. Fig. 173 shows a catchbasin at the left of a walk or drive, and the tile laid underneath for the purpose of carrying away the surface water.

The best materials for walks are cement, or artificial stone, and flagging. In many soils, however, there is enough binding material in the land

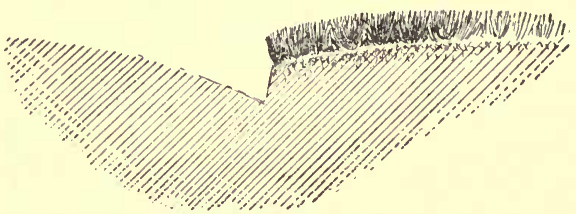

170. The common type of porder for a walk or drive.

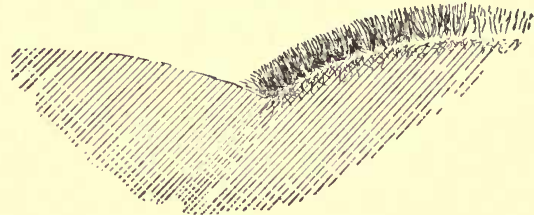

171. A better border.

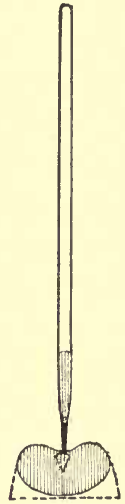

172. Sod cutter.

to make a good walk without the addition of any other material. Gravel, cinders, ashes, and the like, are nearly always inadvisable, for they are apt to be loose in dry weather and sticky in wet weather. In the laying of artificial stone, it is very important that the walk be well drained by a layer of a foot or two of broken stone or brick- 
bats, unless the walk is upon loose and leachy land. In back yards, it is often best not to have any well-defined walk. A ramble across the sod may be as good. For a back walk, over which deliverymen are to travel, one of the very best means is to sink a foot-wide plank into the land on a level with the surface of the sod; and it is not necessary that the walk be perfectly straight. These walks do not interfere with the work of the lawn mower, and they take care of themselves. When the plank rots, at the expiration of five to ten years, the plank is taken up and another

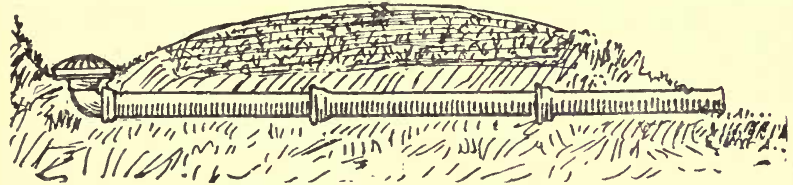

173. Draining the gutter.

one dropped in its place. This ordinarily makes the best kind of a walk alongside a rear border.

MaKing THE PLAN. - It is often desirable to have a definite plan on paper for the location of the leading features of the place. These features are the residence, the out-houses, the walks and drives, the border planting, flower-garden, vegetable garden and fruit garden. It should not be expected that the map plan can be followed in every detail, but it will serve as a general guide; and if it is made upon a large enough scale, the different kinds of plants ean be located in their 
proper positions, and a record of the place be kept. It is nearly always unsatisfactory, for both owner and designer, if a plan of the place is made without a personal inspection of the area. Lines which look well upon a map may not adjust themselves readily to the varying contours of the place itself, and the location of the features inside the

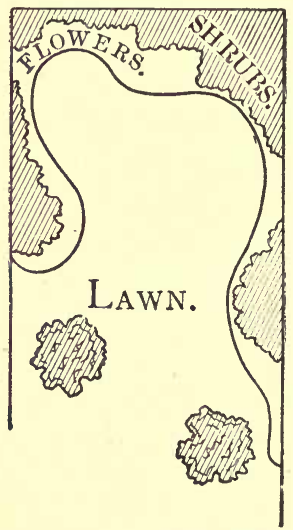

174. Diagram of a back yard.

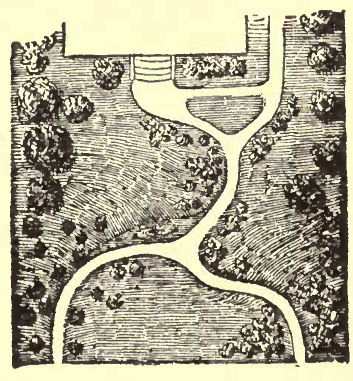

175. Plan of a rough area.

place will depend also in a very large measure upon the objects which lie outside it. For example, all interesting and bold views should be brought into the place, and all unsightly objects in the immediate vicinity should be planted out. Fig. 174 illustrates a plan of a back yard of a narrow city lot, showing the heavy border planting of trees and shrubs, with the skirting border of flowers. In the front are two large trees which 
are desired for shade. It will readily be seen from this plan how extensive the area for flowers becomes when they are placed upon such a devious border. More color effect can be got from such an arrangement of the flowers than could be secured if the whole area were planted to flowerbeds. Fig. 175 illustrates a map plan of a very rough piece of ground. The sides of the place are high, and it becomes necessary to carry a walk through the middle area; and upon either side of the front, it skirts the banks. Such a plan is usually unsightly on paper, but may nevertheless fit special cases very well. The plan is inserted here for the purpose of illustrating the fact that a plan which will work upon the ground does not necessarily work upon a map. In charting a place, it is important to locate the points from which the walks are to start, and at which they are to emerge from the grounds. These two points are then joined by direct and simple curves, and alongside the walks, especially in angles or bold curves, planting may be inserted.

A suggestion for school premises upon a fourcorners, and which the pupils enter from three directions, is made in Fig. 176. The two playgrounds are separated by a broken group of bushes extending from the building to the rear boundary; but in general, the spaces are kept open, and the heavy border-masses clothe the place and make it home-like. The lineal extent 
of the group margins is astonishingly large, and along all these margins flowers may be planted, if desired.

If there is only six feet between a school-house and the fence, there is still room for a border of shrubs. This border should be between the walk

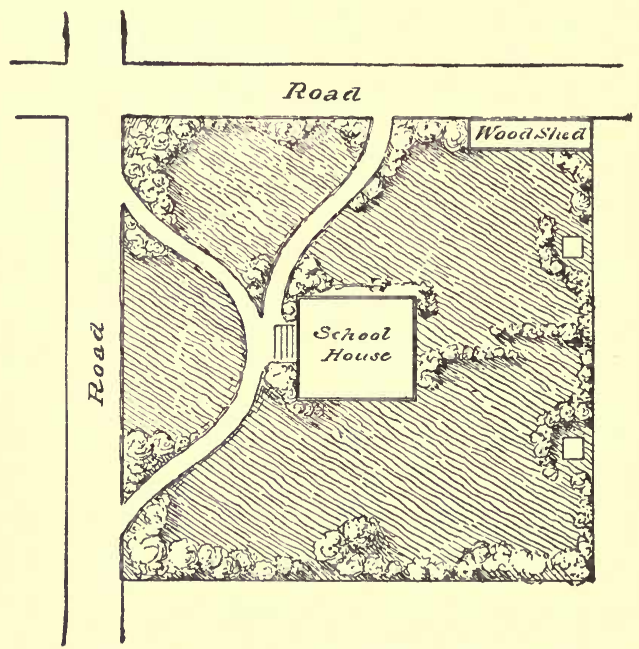

176. Suggestion for a school-ground upon a four corners.

and the fence,-on the very boundary, - not between the walk and the building, for in the latter case the planting divides the premises and weakens the effect. A space two feet wide will allow of an irregular wall of bushes; and if the area is one hundred feet long, thirty to fifty kinds of shrubs and flowers can be grown to perfection, 
and the school-grounds will be practically no smaller for the plantation. In country districts and large grounds, effects like that in Fig. 146 can be obtained with little trouble. If there is no money with which to buy shrubs, they can be got from adjacent woods and fields and gardens; and such plants usually thrive best, because they are hardy and well adapted to the region. One week's well directed work in each year, by one man, coupled with donations of plants from private yards, could make every school-yard in the land a little paradise.

MaKing a LAWn.-The first thing to do in making a lawn is to establish the proper grade. This should be done with the greatest care, from the fact that when a lawn is once made, its level and contour should never be changed. The next important step is to prepare the ground deeply and thoroughly. The permanence of the sod will depend very largely upon the richness and preparation of the soil in the beginning. The soil should be deep and porous, so that the roots will strike far into it, and be enabled thereby to withstand droughts and cold winters. The best means of deepening the soil, as already explained, is by tile-draining, but it can also be done by the use of the subsoil plow and by trenching. Since the lawn cannot be refitted, however, the subsoil is apt to fall back into a hard-pan in a few years if it has been subsoiled or trenched, whereas a 
tile drain affords a permanent amelioration of the under soil. Soils which are naturally loose and porous may not need this extra attention. In fact, lands which are very loose and sandy may require to be packed or cemented rather than loosened. One of the best means of doing this is to fill them with humus, so that the water will not leach through them rapidly. Nearly all lands which are designed for lawns are greatly benefited by heavy dressings of manure thoroughly worked into them in the beginning.

The first grading operation is the plowing of the surface. If the area is large enough to admit a team, the surface is worked down by means of harrows of various kinds. Afterwards it is leveled by means of shovels and hoes, and finally by garden rakes. The more finely and completely the soil is pulverized, the quicker the lawn may be obtained, and the more permanent are the results.

The best grass for the body or foundation of lawns in the North is June-grass or Kentucky blue grass (Poa pratensis). Inasmuch as we desire to obtain many very fine stalks of grass rather than a few large ones, it is essential that the seed be sown very thick. Pains should also be taken to distribute the seed evenly over the area, thereby avoiding bare and weedy spots. From three to four bushels to the acre is the ordinary application of grass seed. The question as to whether white clover or other seed should 
be sown with the grass seed, is very largely a personal one, depending upon whether the owner wants white clover in his lawn or not. Some persons like it, and others do not. If it is desired, it may be sown directly after the grass seed is sown, at the rate of one to three quarts to the acre. For particular purposes and for personal tastes, various other grasses may be used for lawns. Various kinds of lawn mixtures are upon the market.

In most cases, the June-grass germinates and grows somewhat slowly, and it is generally advisable to sow four or five quarts of timothy grass to the acre with the June-grass seed. The timothy comes on quickly and makes a green the first year, and the June-grass soon crowds it out. It is not advisable, as a rule, to sow grain in the lawn as a nurse to the grass. If the land is well prepared and the seed is sown in the cool part of the year, the grass ought to grow much better without the other crops than with them. Lands which are hard and lacking in nitrogen may be benefited if four or five quarts of crimson clover are sown with the grass seed. This will make a green the first year, and will break up the subsoil by its deep roots and supply nitrogen, and being an annual plant it does not become troublesome. In the southern states, where June-grass does not thrive, Bermuda-grass is the leading species used for lawns; although there are two or three others, 
like the goose-grass of Florida, which may be used in special localities.

The lawn should be seeded when the land is moist and the weather comparatively cool. It is ordinarily most advisable to grade the lawn in late summer or early fall, because the land is then comparatively dry and can be moved cheaply. The surface can also be got in condition, perhaps, for sowing late in September or early in October in the North; or, if the surface has required much filling, it is well to leave it in a somewhat unfinished state until spring, in order that the soft places may settle and then be refilled before the seeding is done. If the seed can be sown early in the fall, before the rains come, the grass should be large enough, except in northernmost localities, to withstand the winter; but it is generally most desirable to sow in very early spring. If the land has been thoroughly prepared in the fall, the seed may be sown on one of the late light snows in spring, and as the snow melts the seed is carried into the land, and germinates very quickly. If the seed is sown when the land is loose and workable, it should be raked in; and if the weather promises to be dry, perhaps the surface should be rolled.

The lawn will ordinarily produce a heavy crop of weeds the first year, especially if much stable manure has been used. The weeds need not be pulled, unless such vicious intruders as docks or 
other perennial plants gain a foothold; but the area should be mown frequently with a lawnmower. The weeds, being annuals, will die at the approach of cold, and they are kept down by the use of the lawn-mower, while the grass is not injured. As soon as the grass begins to fill the land, the weeds are crowded out. It rarely happens that every portion of the lawn will have an equal catch of grass. The bare or sparsely seeded places should be sown again every fall and spring until the lawn is finally complete.

Lawns which have a heavy cover of sod are rarely troubled with weeds. It is commonly said that weeds run out the grass; the fact is that grass is run out by poor soil, insufficient seeding, careless preparation of the land, or some other fault, and the weeds take the opportunity to fill the vacant places. The proper way to keep the weeds out of the lawn, therefore, is not primarily to pull the weeds, but to put in more grass. If a dandelion is pulled, the hole must be filled or some weed may grow therein. The remedy, therefore, is to rake over the thin places vigorously with a steel garden rake, apply commercial fertilizers, and sow more grass seed; and this, as a rule, will correct the difficulty. Lawns of several acres which become thin and mossy may be treated in essentially the same way by dragging them with a spike-tooth harrow in early spring as soon as the land is dry enough to hold a team. Chemical fertilizers 
and grass seed are now sown liberally, and the area is perhaps dragged again, although this is not always essential; and then the roller is applied to bring the surface into a smooth condition. To plow up these poor lawns is to renew all the battle with weeds, and really to make no progress; for, so long as the contour is correct, the lawn may be repaired by these surface applications. If lawns are to be kept in the very best condition it is usually necessary, in this country, to patch them every year by this method of re-seeding.

The mowing of the lawn should begin as soon as the grass is tall enough in the spring, and continue at the necessary intervals throughout the summer. The most frequent mowings are needed early in the season, when the grass is growing rapidly. If it is mown frequently-say once or twice a week -in the periods of most vigorous growth, it will not be necessary to rake off the mowings. In fact, it is preferable to leave the grass upon the lawn, to be driven into the surface by the rains and to afford a mulch. It is only when the lawn has been neglected and the grass has got so high that it becomes unsightly upon the lawn, that it is necessary to take it off. The grass should be rather long when it goes into the winter. The last two months of open weather are times in which the grass makes comparatively small growth, and it tends to lop down and to cover the surface densely, which it should be allowed to do. The 
best lawn mowers, in the writer's opinion, are those with large wheels and which eut very wide swaths. In his own practice, he uses no machine which cuts less than eighteen inches.

As a rule, it is not necessary to rake the leaves off lawns in the fall. They afford an excellent mulch, and during the autumn months the leaves upon the lawn are among the handsomest features of the landscape. The leaves generally blow off after a time, and if the place has been constructed with an open center and heavily planted sides, the leaves will be caught in these masses of trees and shrubs and there afford an excellent mulch. The ideal landscape planting, therefore, takes care of itself to a very large extent. It is bad economy to burn the leaves, especially if one has herbaceous borders, roses and other plants which need a mulch. When the leaves are taken off the borders in the spring, they should be piled with the manure or other refuse and there allow to pass into compost. (Pages 115, 116.)

If the land has been well prepared in the begin ning, it is ordinarily unnecessary to cover the lawn with manure in the fall. The common practice of covering grass with manure should be discouraged because the material is unsightly and unsavory, and the same results can be got with the use of commercial fertilizers and by not raking the lawn too clean of the mowings of the grass.

The common watering of lawns by means of 
lawn sprinklers usually does more harm than good. This results from the fact that the watering is generally done in clear weather, and the water is thrown through the air in very fine spray, so that a considerable part of it is lost in vapor. The ground is also hot, and the water does not pass deep into the soil. If the lawn is watered at all, it should be soaked; turn on the hose at nightfall and let it run until the land is wet as deep as it is dry, then move the hose to another place. A thorough soaking like this, once or twice in a dry summer, will do more good than sprinkling every day. If the land is deeply prepared in the first place, so that the roots strike far into the soil, there is rarely need of watering unless the place is arid or the season unusually dry. The surface watering by means of lawn sprinklers engenders a tendency for the roots to start near the surface, and therefore the more the lawn is watered, the greater is the necessity for it.

Every spring the lawn should be firmed by means of a roller, or if the area is small, by means of a pounder or the back of a spade in the hands of a vigorous man. The lawn-mower itself tends to pack the surface. If there are little irregularities in the surface, caused by depressions of an inch or so, and the highest places are not above the contour-line of the lawn, the surface may be brought to level by spreading fine, mellow soil over it, thereby filling up the 
depressions. The grass will quickly grow through this soil.

Persons who desire to get a lawn very quickly may sod the area rather than seed it. Sodding, however, is expensive, and is to be used only about the borders of the place, near buildings, or in areas in which the owner can afford to expend considerable money. The best sod is that which is secured from an old pasture, and for two or three reasons. In the first place, it is the right kind of grass, the June-grass being the species which oftenest runs into pastures and crowds out other plants. Again, it has been so closely eaten down, especially if it has been pastured by sheep, that it has made a very dense and well-filled sod, which can be rolled up in thin layers. In the third place, the surface soil in such old pastures is likely to be rich from the droppings of animals.

In taking sod, it is important that it be cut very thin. An inch and a half thick is usually ample. It is ordinarily rolled up in strips which are a foot wide and of any length which will allow the rolls to be handled by one or two men. A foot-wide board is laid upon the turf, and the sod cut along either edge of it. One person then stands upon the strip of sod and rolls it towards himself while another euts it loose with a spade, as shown in Fig. 177. When the sod is laid, it is unrolled upon the land and then firmly beaten down. Land which is to be sodded should 
be soft on top, so that the sod can be well pounded into it. If the sod is not well pounded down, it will settle unevenly and present a bad surface, and will also dry out, and perhaps not live through a dry spell. It is almost impossible to pound down sod too firm. If the land is freshly plowed, it is important that the borders which are sodded be an inch or two lower than the adjacent land, because that land will settle in the course of a

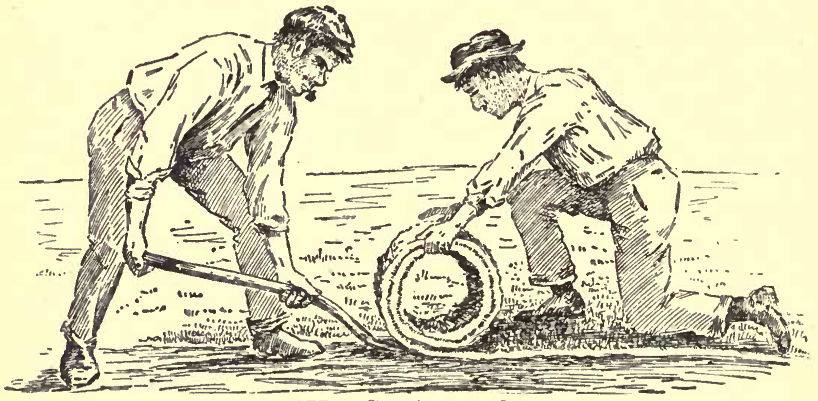

177. Cutting sod.

few weeks. If it is necessary to do sodding in a dry time, the sod may be covered from a half inch to an inch deep with fine, mellow soil as a mulch, to prevent it from drying out. The grass will grow through this soil without difficulty. Upon terraces and steep banks, the sod may be held in place by driving wooden pegs through it.

Lawns may be sown with pieces of sods rather than with seeds. Sods may be cut up into bits an inch or two square and these can be scattered 
broadcast over the area and rolled into the land. While it is preferable that these pieces should lie right side up, it is not necessary that they should, if they are eut thin, and if they are sown when the weather is cool and moist. Sowing pieces of sod is a most excellent practice in lands in which it is difficult to secure a catch from seed.

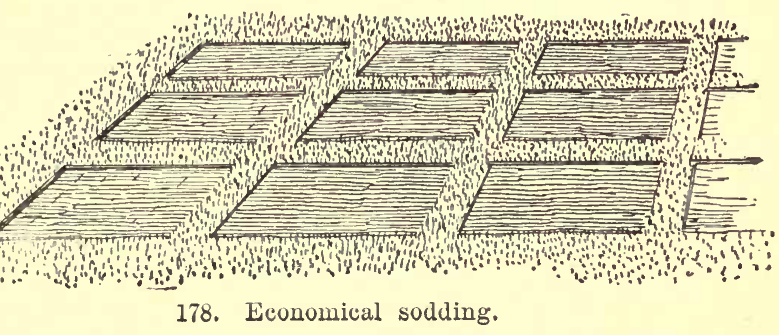

An "economical sodding" is described in American Garden (Fig. 178): "To obtain sufficient sod of suitable quality for covering terrace-slopes or small blocks that for any reason cannot well be seeded, is often a difficult matter. In the accompanying illustration we show how a surface of sod may be used to good advantage over a larger area than its real measurement represents. This is done by laying the sods, cut in strips from six to ten inches wide, in lines and cross-lines, and after filling the spaces with good soil, sowing thesc spaces with grass-seed. Should the catch of seed for any reason be poor, the sod of the strips will tend to spread over the spaces between them, and 
failure to obtain a good sward within a reasonable time is almost out of the question. On the other hand, if one needs sod and has no place from which to cut it except the lawn, by taking up blocks of sod, leaving strips and cross-strips, and treating the surface as described above, the bare places left are soon covered with green."

Under trees, and in other shady places, it may be necessary to cover the ground with something else than grass. Good plants for such uses are periwinkle (Vinca minor, an evergreen trailer, often called "running myrtle"), moneywort (Lysimachia nummularia), lily-of-the-valley, and various kinds of sedge or carex. 


\section{Section III}

\section{PLANTING THE ORNAMENTAL GROUNDS}

In choosing the kinds of plants, the gardener should carefully distinguish two categories,-those to compose the structural masses and design of the place, and those which are to be used for mere ornament. The chief merits to be sought in the former are good foliage, pleasing form and various habit, shades of green, and color of winter twigs. The merits of the latter lie chiefly in flowers or colored foliage.

Each of these categories should be again divided. Of plants for the main design, there may be a list of trees for a windbreak, another of trees for shade, another of shrubs for screens or heavy plantings, another for the lighter side plantings, and another for incidental masses about the buildings or on the lawn, and perhaps another of vines for porches and arbors and evergreens, and also for hedges. The lists on pages 221 to 240 will be suggestive.

Plants used for mere embellishment or ornamentation may be ranged into categories for permanent herbaceous borders, for display beds, ribbon edgings, annuals for temporary effects, 
foliage beds, plants for adding color and emphasis to the shrubbery masses, and plants desired to be grown as isolated specimens or as curiosities.

It is always legitimate, and, in fact, desirable, to plant for immediate effect. One may plant very thickly of rapid-growing trees and shrubs for this purpose. It is a fact, however, that very rapid-growing trees usually lack strong or artistic character. Other and better trees should be planted with them, and the insipid and rapidgrowing kinds be gradually removed. These remarks apply with particular force to summer resorts and pleasure grounds, at which there is a great tendency to secure quick effects by profuse planting of willows and poplars. These trees always look cheap and characterless. Maples, elms, oaks, catalpas, or other trees, should be planted with the willows or poplars, and eventually only an occasional specimen of the nurse-planted willows and poplars should remain. That is, in the completed picture, willows, poplars and the like, should be only incidents. (See, also, pages 152, 153.)

Some of the silver or white-leaved poplars produce the most striking contrasts of foliage, especially if set near darker trees, and for this reason they are much desired by many planters. Bolle's poplar (Populus Bolleana of the nurseries) is one of the best of these trees. Its habit is something like that of the Lombardy. The upper surface of 
the deeply lobed leaves is dark, dull green, while the under surface is almost snowy white. Such emphatic trees as this should generally be partially obscured by planting them amongst other trees, so that they appear to mix with the other foliage; or else they should be seen at some distance. Other varieties of the common white poplar or abele are occasionally useful, although most of them sprout badly and may become a nuisance. But the planting of these immodest trees is so likely to be overdone that I scarcely dare recommend them, although, when skilfully used, they may be made to produce most excellent effects. If any reader has a particular fondness for trees of this class (or any others with woolly-white foliage) and if he has only an ordinary city lot or farm-yard to ornament, let him reduce his desires to a single tree, and then if that tree is planted in the interior of a group of other trees, no harm can result!

However much the planter may plan for immediate effects, the beauty of trees and shrubs comes with maturity and age, and this beauty is often delayed, or even obliterated, by shearing and excessive heading-back. At first, bushes are stiff and erect, but when they obtain their full character they droop or roll over to meet the sward. Some bushes make mounds of green much sooner than others which may be even closely related. Thus the common yellow-bell, Forsythia viridis- 


\section{PLANTING THE ORNAMENTAL GROUNDS}

sima, remains stiff and hard for some years, whereas $F$. suspensa makes a rolling heap of green in two or three years. Quick, informal effects can also be obtained by the use of Hall's Japanese honeysuckle (Lonicera Halliana of nurserymen), an evergreen in the South and holding its leaves until midwinter or later in the North. It may be used for covering a rock, a pile of rubbish, a stump (Fig. 179), to fill a corner against a foundation, or it may be trained on a porch or arbor. There is a form with yellow-veined leaves. Rosa Wichuraiana, and some of the dewberries, are useful for covering rough places.

Many vines, which are commonly used for porches and arbors, may be used also for the borders of shrub-plantations and for covering rough banks and rocks. Such vines, among others, are various kinds of clematis, Virginia creeper, actinidia, akebia, trumpet creeper, periploca, bittersweet (Solanum Dulcamara), wax-work (Celastrus scandens).

For hedges, either evergreens or deciduous trees and shrubs may be used. Of common evergreens, the various kinds of arborvitæ, native hemlock, and the retinosporas, may be used. They stand cutting well. Privet (particularly the so-called Californian), mahonia, box and Citrus trifoliata are also either evergreen or partially so, depending somewhat upon the region in which they are grown. Mahonia and box are true evergreens, and 


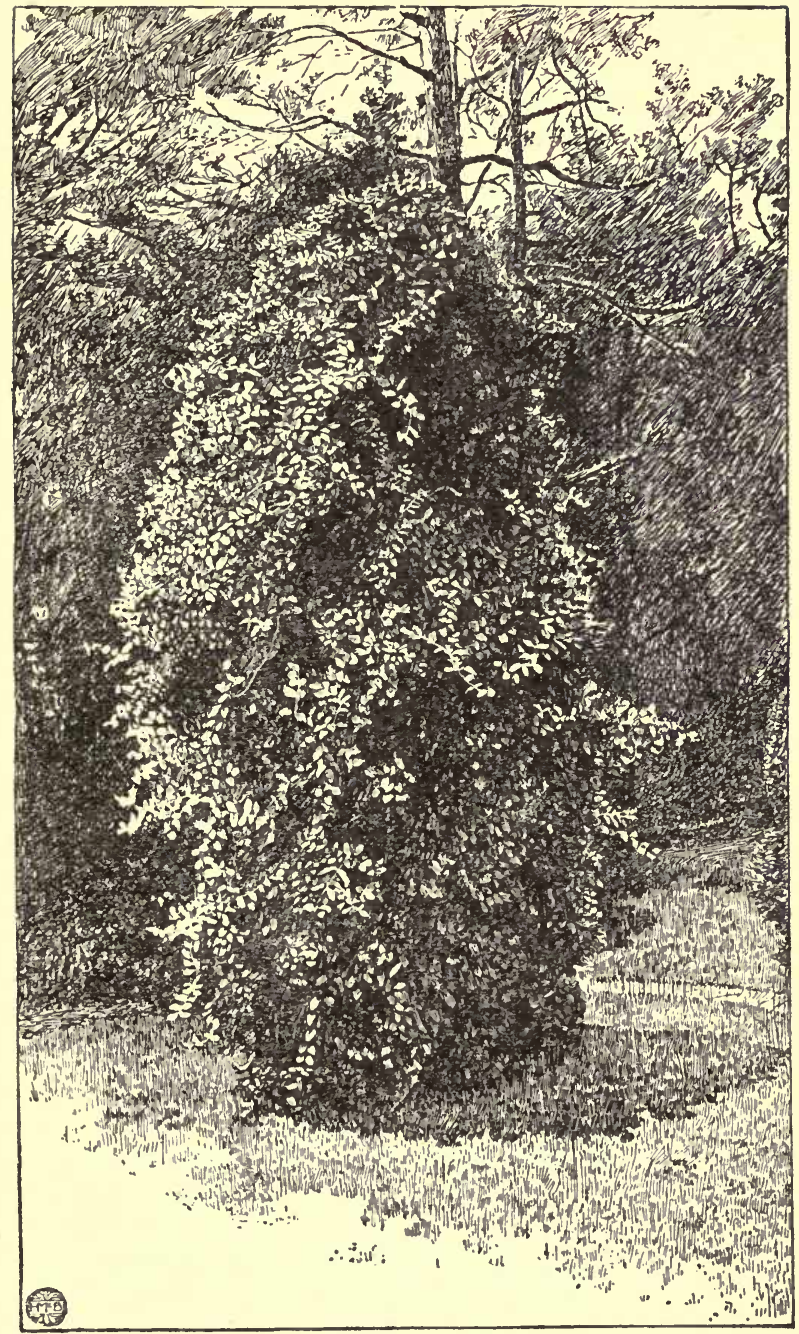

179. Stump covered with Japanesa boneysuckle. 
are also adapted for low hedges and edgings. The citrus is hardy as far north as Washington in protected places, and in some cases even farther. For hedges, plants should be set as close as two feet or less, and they should be rigidly headed-in even from the first, in order to develop a thick bottom growth. For deciduous hedges, osage orange, buckthorn, pyracantha, locust, and various other plants may be used.

Coniferous evergreens-as pines, spruces, cedars - may be planted in fall, spring or summer. There is much difference of opinion as to the proper season, which only means that the transplanting may be done in various seasons. The writer has had best success in transplanting them late in spring, when the new growth is beginning, especially when he can choose a rainy or moist time. As a rule, evergreens are not trimmed upon being transplanted; but if the top seems to be very large in proportion to the root, the branches may be headed-in a few inches. In transplanting evergreens from the wild into sunny places, it is well to choose those which naturally grow in the sun. This is particularly important with the hemlock.

The verdurous beauty of spruces, hemlocks and firs may be much prolonged if a few inches of the tips of the strongest branches be cut off every year or two. This treatment induces a thick growth of the top, while it is not severe enough to reduce the tree to a formal figure. Even the 
leader may be cut if the tree tends to grow too tall and open, and a new leader will soon take its place. Spruces which have become very open and ragged may be severely headed-back, and the interior of the top will finally feather out and fill up. Of course, the lower limbs should never be removed from spruces, for the beauty of the tree lies in its pyramidal and half-formal figure.

A few trees and shrubs demand a special preparation of the land. This is true of the hardy rhododendrons, and, to some extent, of kalmias and andromedas (pages 227, 231). They thrive best in a soil containing much leaf-mold. It is a good practice to remove the soil to a depth of two feet and fill the place with woods earth. In the North, rhododendrons should be partially screened from winter and spring suns by planting them near or among deciduous trees.

In the planting of any kind of trees, it is well to remember that nursery-grown specimens generally transplant more readily and thrive better than trees taken from the wild; and this is particularly true if the stock was transplanted in the nursery. Trees which transplant with difficulty, as the papaw or asimina, and some nut trees, may be prepared for removal by cutting some of their roots,-and especially the tap-root, if they have such,-a year or two in advance.

In making borders of flowers, the most satisfactory results are obtained if a large clump of each 


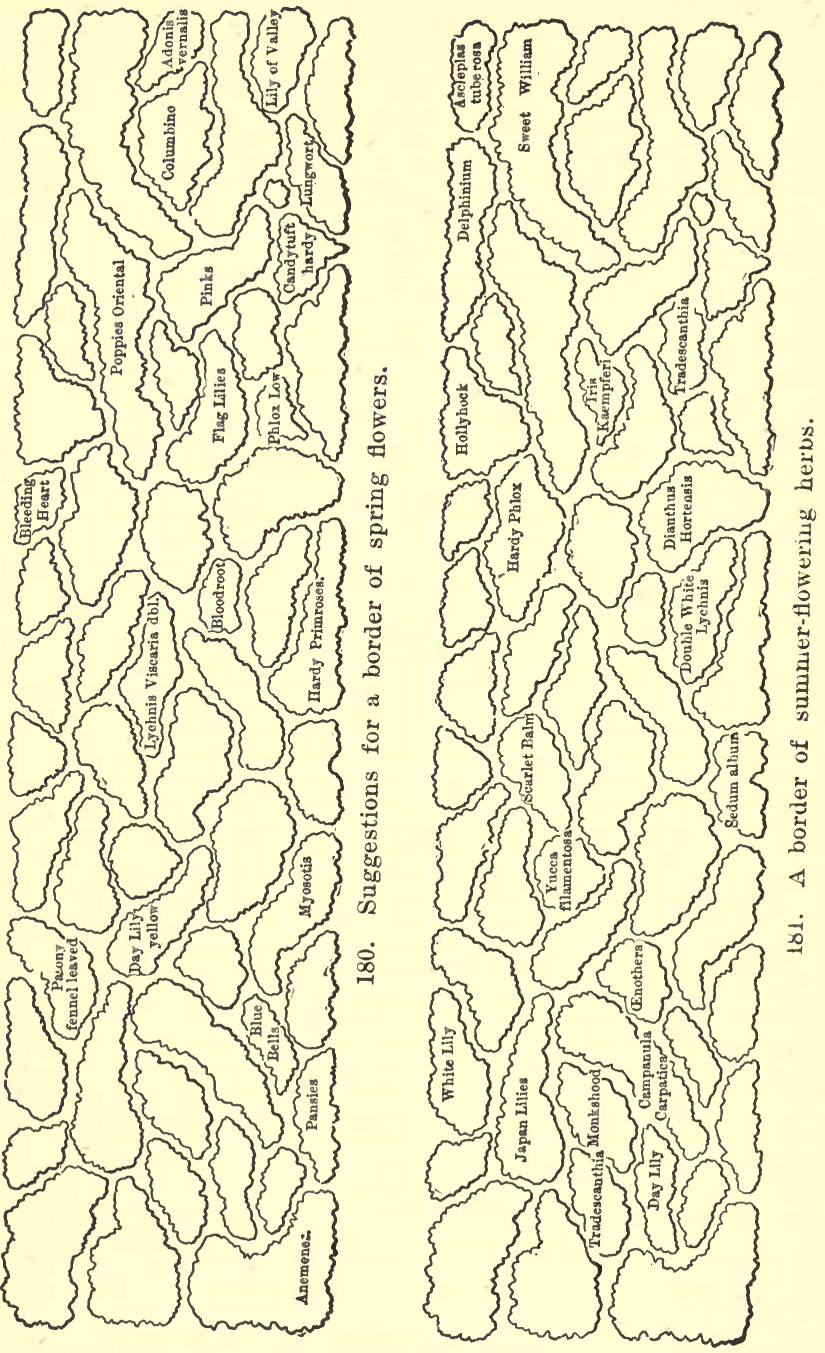




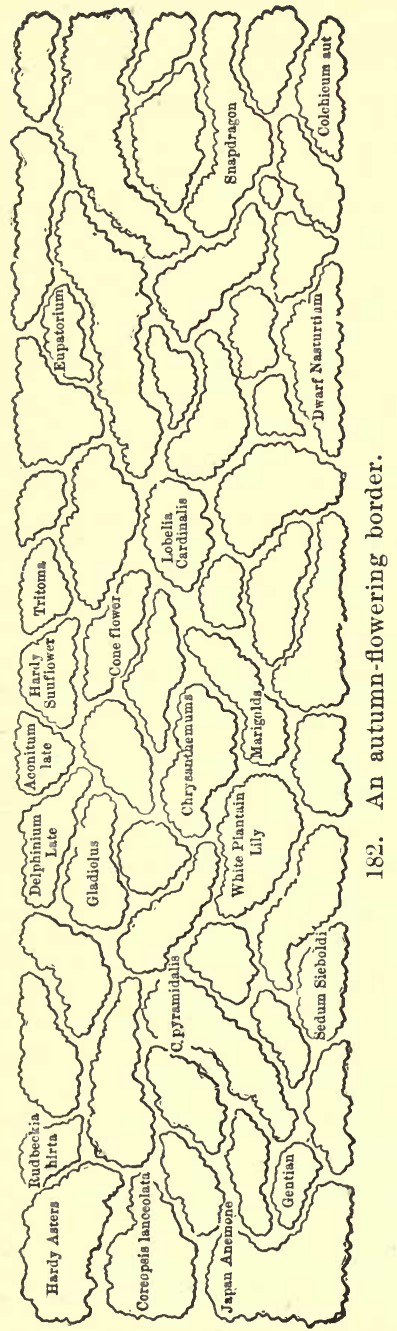

kind or variety is grown. Some of the most effective borders are those which are filled with miscellaneous perennial herbs taken at odd times from fields and woods. The herbaceous border is one of the most flexible parts of grounds, since it has no regular or formal design. Allow ample space for each perennial root,-often as much as three or four square feet,-and then if the space is not filled the first year or two, scatter over the area seeds of poppies, sweet peas, asters, gilias, alyssum, or other annuals. Prepare the ground well in the beginning, taking particular care to make it deep, and mulch liberally every fall. Even perennials usually bloom better when not more than two or three years planted, and the grower must expect, therefore, to renew or 


\section{PLANTING THE ORNAMENTAL GROUNDS}

change the clumps from time to time, if they show signs of failing. Figs. 180-182, from Long (Popular Gardening, i., 17, 18, from which journal, now discontinued many pictures in this volume are taken), suggest methods of making such borders. They are on a scale of ten feet to the inch. The entire surface is tilled, and the irregular diagrams designate the sizes of the clumps. The diagrams containing no names are to be filled with bulbs, annuals and tender plants.

LIST OF ORNAMENTAL PLANTS WHICH ARE HARDY IN CENTRAL MICHIGAN

The following list was made some years ago for use in the author's classes in the Agricultural College of Michigan. It is now revised, and is believed to contain the greater part of the desirable trees and shrubs which are hardy in the northernmost states, although it is not intended to be complete. The notes were originally the result of several years' observation upon the large collection of plants growing upon the grounds of the Agricultural College, at Lansing. The winters there are severe, the thermometer occasionally registering twenty degrees below zero, and sometimes even a lower temperature. In the following list the plants are arranged somewhat in the order of merit, as they appeal to the author. The species of each genus are intended to be strictly so arranged. The home-maker will know which of the native trees of his region are valuable for planting 
as single specimens on the lawn or roadside for purposes of shade; some of the best for this purpose in the following list are marked with a dagger $(\dagger)$. Those plants marked with an asterisk (*) are native to Michigan.

I. Trees for Windbreaks, or Shelter Belts.

White pine, Pinus Strobus.*

Austrian pine, P. Austriaca.

Scotch pine, $P$. sylvestris.

Red pine, $P$. resinosa.*

Norway spruce, Picea excelsa.

Any of the rapidly growing, native forest trees, especially:

American elm, Ulmus Americana.* +

Sugar maple, Acer saccharinum ${ }^{*} \dagger$ and var. nigrum. ${ }^{*} \dagger$

Basswood, Tilia Americana. ${ }^{*}+$

Cottonwood, Populus monilifera.*

Balsam poplar, $P$. balsamifera. *

Balm of Gilead, $P$. balsarnifera var. candicans. ${ }^{*}$

Wild black cherry, Prunus serotina.*

Box-elder, Negundo aceroides.*

\section{Trees for Groutp or Single Specimens.}

\section{A. Deciduous Trees.}

Norway maple, Acer platanoides. $\dagger$

One of the finest trees for single lawn specimens, especially in tranquil scenes. It droops too much and is too low-headed for roadside planting. Black sugar maple, A. saccharinum var. nigrum. ${ }^{* \dagger}$

Darker and softer in aspect than the ordinary sugar maple. Sugar maple, A. saccharinum. ${ }^{*} \dagger$

This and the last are the best roadside trees.

Wier's cut-leaved silver maple, A. dasycarpum, hort. var.

Light and graceful. Especially desirable for pleasure grounds. Silver maple, A. dasycarpum. ${ }^{*} \dagger$

Desirable for water-courses and for grouping. Succeds on both wet and dry lands. 
Red, soft, or swamp maple, A. rubrum.*

Valuable for its spring and autumn colors, and for variety in grouping. Sycamore maple, A. Pseudo-platanus.

A slow grower, to be used mostly as single specimens.

American elm, Ulmus Americana.*†

One of the most graceful and variable of trees; useful for many purposes.

Cork elm, U. racemosa.*

Softer in aspect than the last, and more picturesque in winter, having prominent ridges of bark on its branches. Slow grower.

Red, or slippery elm, U. fulva.*

Occasionally useful in a group or shelter-belt. A stiff and straggling grower.

European silver linden, Tilia argentea and varieties (T.alba). $\dagger$

Very handsome. Leaves silvery white beneath. Among others, is a weeping variety.

American linden or basswood, Tilia Americana. ${ }^{*} \dagger$

Very valuable for single trees on large lawns, or for roadsides.

European linden, T. Europoea, and varieties. $\dagger$

Has the general character of the American basswood.

Tulip tree or whitewood, Liriodendron Tulipifera. *†

Valuable for the southern half of the Lower Peninsula. Unique in foliage and flower.

Cucumber tree, Magnolia acuminata. $\dagger$

Not reliable north of Lansing. Handsome.

Yellow-wood, or Virgilia, Cladrastis tinctoria.

The finest hardy flowering tree.

Swamp white oak, Quercus bicolor. ${ }^{*} \dagger$

A very desirable tree, usually neglected. Very picturesque in winter. The oaks are slow growers and usually transplant with difficulty. Natural specimens are most valuable. A large, well-grown oak is one of the grandest of trees.

Bur oak, Q. macrocarpa.*十

Chestnut oak, Q. Prinus, ${ }^{*} \dagger$ and especially the common var. acuminata (or Q. Muhlenbergii).* $\dagger$

White oak, Q. alba.*†

Shingle oak, Q. imbricaria.* ${ }^{*}$ 
Scarlet oak, Q. coccinea. ${ }^{*} \dagger$

This and the next two are glossy-leaved, and are desirable for gay scenes.

Black oak, Q. tinctoria. ${ }^{*} \dagger$

Red oak, Q. rubra.*†

Pepperidge or gum-tree, Nyssa multiflora.*

One of the oddest and most picturesque of our native trees. Especially attractive in winter. Foliage brilliant red in autumn. Most suitable for low lands.

Horse chestnut, Esculus Hippocastanum. $\dagger$

Useful for single specimens and roadsides.

Showy catalpa, Catalpa speciosa. $†$

Very dark, soft-foliaged tree of small to medium size. Showy in flower. To be used as single specimens.

Smaller catalpa, $C$. bignonioides. $\dagger$

Less showy than the last, blooming a week or two later. Less hardy. Black ash, Fraxinus sambucifolia. ${ }^{*} \dagger$

One of the best of the light leaved trees. Does well on dry soils, although native to swamps. Not appreciated.

White ash, F. Americana.* ${ }^{*}$

Kentucky coffee-tree, Gymnocladus Canadensis.*

Light and graceful. Unique in winter.

Bitter-nut, Hicoria minima, or Carya amara.*

Much like black ash in aspect. Not appreciated.

Hickory, Hicoria ovata, or Carya alba, *and others.

Useful in remote groups or belts.

Cut-leaved weeping birch, Betula alba, hort. var.

The finest of gay trees. To be used sparingly as single specimens.

Cut-leaved birch, B. alba, hort. var.

European birch, B. alba.

American white birch, B. populifolia.

Paper, or Canoe birch, B. papyrifera.*

Purple birch, B. alba, hort. var.

Cherry birch, B. lenta.*

Well grown specimens resemble the sweet cherry. Both this and the next make attractive light leaved trees. They are not appreciated.

Yellow birch, B. lutea.* 
Aspen, Populus tremuloides.*

Very valuable when well grown. Too much neglected. Most of the poplars are suitable for pleasure grounds, and as nurses for slower growing and more emphatic trees. (Pages 152, 153, 213.)

Large-toothed aspen, $P$. grandidentata. *

Unique in summer color. Heavier in aspect than the last. Old trees become ragged.

Weeping poplar, $P$. grandidentata, hort. var. pendula.

An odd, small tree, suitable for small places, but, like all weeping trees, apt to be planted too freely.

Cottonwood, P. monilifera.*

Desirable in a group or near water. The staminate specimens, only, should be planted if possible, as the cotton of the seed-pods is disagreeable when carried by winds.

Balm of Gilead, P. balsamifer ${ }^{*}$ and var. candicans.*

Desirable for remote groups or belts. Foliage not pleasant in color.

Lombardy poplar, P. nigra, var. Italica.

Desirable for certain purposes, but used too indiscriminately. It is apt to be short-lived in this climate.

Bolle's poplar, P. alba, var. Bolleana.

Habit much like the Lombardy. Leaves curiously lobed, very white be neath, making a pleasant contrast. Evidently hardy at Lansing. (P. 212.)

Locust, Robinia Pseudacacia.†

Should be planted at some distance from the dwelling. Useful in grouping. Attractive in flower. Handsome as single specimens when young.

Honey locust, Gleditschia triacanthos. ${ }^{*} \dagger$

Like the last, this should be planted rather remote from the residence, or near the borders. The foliage of both is light.

Beech, Fagus ferruginea. *†

Specimens which are symmetrically developed are among our best lawn trees. Picturesque in winter.

Chestnut, Castanea vesca $\dagger$ and var. Americana. ${ }^{*} \dagger$

Plane or Buttonwood, Platanus occidentalis. ${ }^{*} \dagger$

Young or middle-aged trees areisoft and pleasant in aspect, but they soon become thin and ragged below. Most desirable in belts. Unique in winter.

Sassafras, Sassafras officinalis. ${ }^{*} \dagger$

Suitable in the borders of groups or for single specimens. Peculiar in winter. Too much neglected. 
Maiden-hair tree, Ginkgo biloba.

Very odd and striking. To be used for single specimens.

Rowan or European mountain ash, Pyrus Aucuparia.

Peach-leaved willow, Salix amygdaloides.*

Very handsome small tree, deserving more attention. This and the next valuable in low places or along water courses.

Black willow, S. nigra.*

Weeping willow, S. Babylonica.

To be planted sparingly, preferably near water. The sort known as the Wisconsin weeping willow appears to be much hardier than the common type.

White willow, $S$. alba, and various varieties, one of which is the golden willow.

May be used sparingly. Tree willows are most valuable, as a rule, when used for temporary plantations or as nurses for better trees. (P. 212.)

Wild black cherry, Prunus serotina.*

Nettle-tree, Celtis occidentalis.*

Box-elder, Negundo aceroides. ${ }^{*}$

Very hardy and rapid-growing. Much used in the West as a windbreak, but not strong in ornamental features.

European larch, Larix Europoa.

American lareh or tamarack, L. Americana.*

Bald eypress, Taxodium distichum.

Not entirely hardy at Lansing. Generally becomes scraggly after fifteen or twenty years.

Butternut, Juglans cinerea.*

Walnut, J. nigra.*

Ailanthus, Ailanthus glandulosus.

A rapid grower, with large pinnate leaves. The staminate plant possesses a disagreeable odor when it flowers. Suckers badly. Most useful as a shrub. See the same under Shrubs (page 234; also Fig. 157).

\section{B. Coniferous Evergreens.}

Norway spruce, Picea excelsa.

Loses much of its peculiar beauty when thirty to fifty years of age. (See page 217.) 
White spruce, $P$. alba.*

One of the finest of the spruces. A more compact grower than the last, and not so coarse. Grows slowly.

Oriental spruce, $P$. orientalis.

Especially valuable from its habit of holding its lowest limbs. Grows slowly.

Blue fir, Colorado blue spruce, P. pungens.

In color probably the finest of the conifers. Grows slowly. Varies in blueness.

Nordmann's fir, Abies Nordmanniana.

Balsam fir, A. balsamea.*

Loses most of its beauty in fifteen or twenty years.

Hemlock spruce, Tsuga Canadensis.*

Young and well-grown specimens are the most graceful of our evergreens. In the West, if given some protection from the sun it does better. Should therefore be planted near large trees. (See page 216.)

Arborvitæ, Thuja occidentalis.*

Becomes unattractive after ten or fifteen years, especially on poor soils. Cembrian pine, Pinus Cembra.

A very fine slow-growing tree. One of the few standard pines suitable for small places.

White pine, P. Strobus.*

Scotch pine, $P$. sylvestris.

Red pine, $P$. resinosa.*

Valuable in groups and belts. Not sufficiently known. Usually called "Norway pine." Rather heavy in expression.

Scrub pine, P. Banksiana.*

A small tree, more picturesque than beautiful. Desirable. Red cedar, Juniperus Virginiana.*

III. Shrubs and very Small Trees, not Scandent.

A. Deciduous, or Broad-leaved if Evergreen.

Many rapid-growing trees may be utilized as shrubs by cutting them off near the ground every year, or every other year, and allowing young shoots to grow. Basswood, black ash, some of the maples, tulip tree, mulberry, and others, may be treated in this manner. (Fig. 157.) 


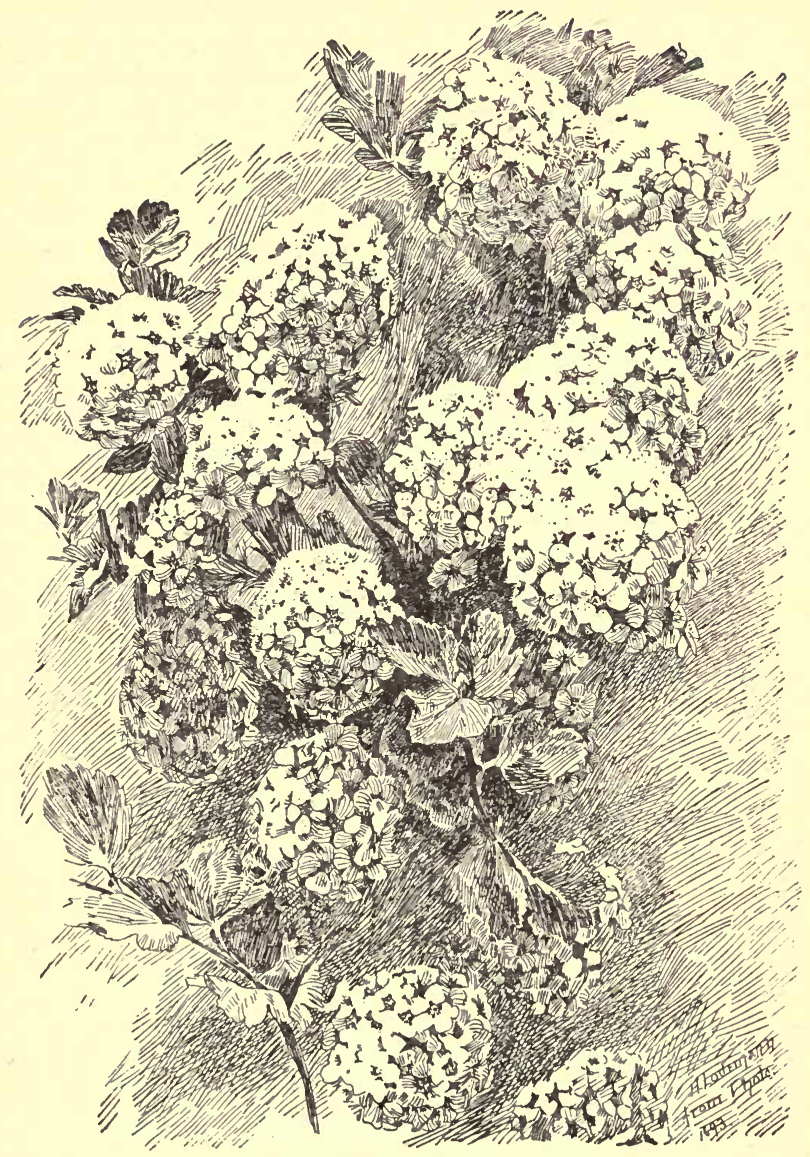

183. A spirea, one of the most serviceable flowering shrubs. 


\section{Wild laurel, Kalmia latifolia.}

Ericaceous evergreen. The kalmias and rhododendrons are among the choicest of shrubs. They require a rather peaty soil and a somewhat shaded situation, especially in winter (page 217).

Rhododendron, Rhododendron Catawbiense, garden varieties. Styrax, Styrax Japonica.

One of the most graceful of flowering shrubs. It may not be hardy northward.

Common snowball, Viburnum Opulus. *

The cultivated sort is a native of the Old World, but the species grows wild in Michigan (known as High-bush Cranberry), and is worthy of cultivation.

Japanese snowball, $\boldsymbol{V}$. plicatum (properly $\boldsymbol{V}$. tomentosum).

Common lilac, Syringa vulgaris.

Josika lilac, S. Josikaxa.

Persian lilac, S. Persica.

Various other lilacs are also hardy and desirable.

Mock-orange, Philadelphus coronarius and $P$. grandiflorus. Smoke-tree, Rhus Cotinus.

One of the best shrubs for massing. Two eolors are grown.

Dwarf sumac, $R$. copallina. *

Attractive in foliage, and especially conspicuous in autumn from the brilliant red of its leaves.

Sumac, smooth and hairy, R. glabra* and $R$. typhina.*

Useful for the borders of large groups and belts. They may be cut down every year and allowed to sprout (as in Fig. 157). The young tops are handsomest. R. glabra is the finer species for this purpose.

Three-lobed spirea, Spiraa trilobata.

One of the most showy early-flowering shrubs. Excellent for massing.

Sorbus-leaved spirea, S. sorbifolia.

Desirable for its late blooming,-late June and early July.

Plum-leaved spirea, S. prunifolia.

Fortune's spirea, S. Japonica, or S. callosa.

Thunberg's spirea, S. Thunbergii.

Neat and attractive in habit. Dwarf.

St. Peter's Wreath, S. hypericifolia. 
Douglas' spirea, S. Douglasii.

Blossoms late, -in July.

Hard-hack, S. tomentosa.*

Much like the last, but less showy.

Willow-leaved spirea, S. salicifolia.*

Various other spireas are hardy and desirable.

Nine-bark, Physocarpus opulifolia* (Spiraa opulifolia).

Exochorda, Exochorda grandiflora.

A large and very showy shrub, producing a profusion of apple-like white flowers in early spring.

Various roses.

Hardy roses are not always desirable for the lawn. For general lawn purposes the older sorts,' single or semi-double, and which do not require high culture, are to be preferred. (See pages $148,149$. )

Japanese rose, Rosa rugosa.

Most excellent for lawn planting, as the foliage is thick and not attacked by insects (Fig. 184).

Wild swamp rose, Rosa Carolina.*

Wild dwarf rose, Rosa humilis* (R. lucida of Michigan).

Say's Rose, Rosa Sayi.*

Excellent for lawns.

Weigela, Diervilla Japonica and other species.

Free bloomers, very fine, in many colors.

Dwarf buckeye, Asculus parviflora.

Attractive in habit, foliage and flower. Produces a large mass.

Flowering almond, Prunus Japonica.

Daphne, Daphne Mezereum.

Produces rose-purple or white flowers in abundance before the leaves appear. Our earliest shrub in flowering. Dwarf, and should be planted or the edges of groups.

Forsythia, Forsythia viridissima.

Blossoms yellow, appearing before the leaves. Requires protection in many places.

Drooping forsythia, F. suspensa.

Makes an attractive mass on a bank or border. (Page 213.)

White alder, Clethra alnifolia.

A very fine, hardy shrub, producing very fragrant flowers in July and August. Should be better known. 


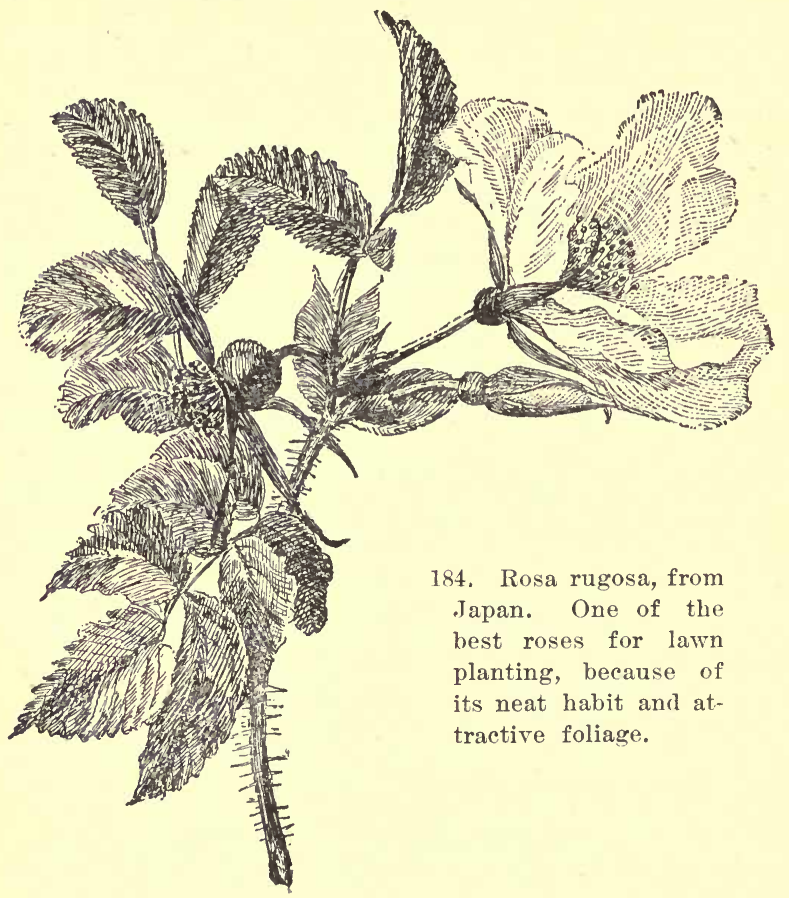

Sand myrtle, Leiophyllum buxifolium.

Hydrangea, Hydrangea paniculata, hort. var. grandiflora.

One of the best and most showy small flowering shrubs.

Downy hydrangea, H. radiata.

Attractive in both foliage and flower.

Oak-leaved hydrangea, $H$. quercifolia.

This is especially valuable for its luxuriant foliage. Even if killed to the ground in winter, it is still worth cultivating for its strong shoots. Ceanothus, Ceanothus Americanus.*

A very small native shrub, desirable for dry places under trees. Azalea, Azalea viscosa and $A$. nudiflora. 
Andromeda, Andromeda floribunda.

A small ericaceous evergreen. Should have some protection from the winter sun. It may, for this purpose, be planted on the north side of a clump of trees (Page 217.

Wild thorns, Cratcogus punctata, ${ }^{*}$ C. coccinea, ${ }^{*}$ C. crus-galli, and others.

Bailey's osier, Cornus Baileyi.*

The finest of the native osiers for color of twigs and foliage.

Red-twigged osier, Cornus stolonifera.*

The red twigs are very showy in winter. Some bushes are brighter in color than others.

Flowering dogwood, C. florida.*

Coarse but very showy tree, desirable for borders of groups and belts. A red-flowered variety is on the market.

Rose acacia, Robinia hispida.

Purple plum, Prunus cerasifera, hort. var. Pissardi.

One of our most reliable purple-leaved trees.

Sand cherry, P. pumila* and P. Besseyi.

June-berry, Amelanchier Canadensis* and others.

Flowers profusely in spring before the leaves appear.

Fringe tree, Chionanthus Firginica.

Tartarian maple, Acer Tataricum.

Attractive as a lawn specimen when grown as a shrub. The autumn color is very bright.

Mountain maple, A. spicatum.*

Very bright in autumn.

European maple, A. campestre.

Not generally hardy, but attractive if cut down and allowed to throw up new shoots.

Tartarian honeysuckle, Lonicera Tatarica.

One of the most chaste and comely of shrubs.

St. John's Wort, Hypericum Kalmianum, ${ }^{*}$ and H.prolificum.*

Small undershrubs, producing bright yellow flowers in profusion in July and August.

Burning-bush, Euonymus atropurpureus. *

Very attractive in fruit. 
Flowering, or fragrant currant, Ribes aureum.

Well known and popular.

Snow-berry, Symphoricarpus racemosus.*

Cultivated for its snow-white berries.

Indian currant, Symphoricarpus vulgaris. *

Foliage delicate. Berries red. Valuable.

Witch hazel, Hamamelis Virginiana.*

Blossoms in October and November. Unique and desirable if well grown.

Elders, Sambucus racemosa* (S. pubens) and S. Canadensis. *

The former, the common "red elder," is ornamental both in flower and fruit. $S$. Canadensis is desirable for its profusion of fragrant flowers appearing in July.

Kerria, Kerria Japonica.

A bramble-like shrub, producing attractive yellow single or double flowers from July until September. There is a variegated-leaved form. Good for banks and borders. Twigs very green in winter.

Japanese bramble, Rubus cratogifolius.

Very valuable for holding banks. Spreads rapidly. Very red in winter.

Winter-berry, Ilex verticillata.*

Produces showy red berries, which persist through the winter. Should be massed in rather low ground. Flowers imperfect.

Leatherwood, Dirca palustris.*

If well grown, the leatherwood makes a very neat plant. Blossoms appear before the leaves, but not showy.

Button-bush, Cephalanthus occidentalis. *

Blossoms in July and August. Desirable for water courses and other low places.

Privet, Ligustrum vulgare, and L. ovalifolium (L. Japonicum). Much used for low hedges and borders.

Barberry, Berberis vulgaris.

Mahonia, Berberis Aquifolium.

Evergreen. Dwarf. Needs some protection in exposed places.

Wild crab, $P$. coronaria ${ }^{*}$ and $P$. Ioensis.

Very showy while in flower, blooming after apple blossoms have fallen. Old specimens become picturesque in form. 
Japanese quince, Pyrus Japonica.

An old favorite. Not hardy at Lansing.

Chinquapin or dwarf chestnut, Castanea pumila.

Sweet viburnum or sheep-berry, Viburnum Lentago.*

Arrow-wood, $\boldsymbol{V}$. dentatum.*

Withe-rod, lilac viburnum, $V$. cassinoides.*

Other native and exotic viburnums are desirable.

Spice-bush, Lindera Benzoin.*

Box, Buxus sempervirens.

A diminutive evergreen shrub, nseful for edgings in cities.

Kilmarnoek willow, Salix Caprcea, hort. var. pendula.

A very small weeping plant, usually more curious than ornamental.

Rosemary willow, S. rosmarinifolia of nurserymen.

Shining willow, S. lucida.*

Very desirable for the edges of water,

Long-leaved willow, S. longifolia.*

Our narrowest-leaved native willow. Useful for banks. Apt to spread too rapidiy.

Fountain willow, S. purpurea.

Pussy willow, S. discolor.*

Attractive when massed at some distance from the residence.

Siberian pea-tree, Caragana arborescens.

Small pea-tree, C. pygmoxa.

Red-bud or Judas-tree, Cercis Canadensis.*

Produces a profusion of rose-purple pea-like flowers before the leaves appear. Foliage attractive.

Mountain ash, Pyrus Aucupariı. (Page 225.)

Service-tree, $P$. domestica.

Fruit handsomer than that of the mountain ash and more persistent. Small tree.

Oak-leaved mountain ash, $P$. hybrida.

Small tree, deserving to be better known.

Weeping aspen, Populus grandidentata, hort. var. pendula. (Page 224.)

Cut-leaved alder, Alnus glutinosa, hort. var. 
Wild alder, A. serrulata.*

Dwarf birch, Betula pumila.*

Desirable for low places.

Ailanthus, Ailanthus glandulosus.

Most attractive when cut to the ground each year and allowed to sprout (Fig. 157). The young shoots give a tropical effect. For this purpose the soil should be very rich.

Paulownia, Paulownia imperialis.

Of this and the following magnolias, the tops are not hardy, and they should be used in the same manner as the ailanthus.

Magnolias, Magnolia Umbrella and cordata.

Hop-tree, Ptelea trifoliata. *

Prickly ash, Zanthoxylum Americanum.*

Bladder-nut, Staphylea trifolia. *

Horn-beam or Blue beech, Carpinus Americana.*

Iron-wood, Ostrya Virginica.*

European Bird Cherry, Prunus Padus.

A small tree much like the choke cherry, but a freer grower, with larger flowers and racemes which appear about a week later.

Choke Cherry, P. Virginiana.*

Very showy while in flower.

Kæmpfer's Catalpa, Catalpa Kampferi.

Flowering crab, Pyrus floribunda.

Pretty both in flower and fruit. A large shrub or small tree. Various forms.

B. Coniferous Evergreens.

Dwarf arborvitæ, Thuja occidentalis, hort. var.

There are many dwarf and compact varieties of arborvitæ, most of which are excellent for small places. The most desirable for general purposes, and also the largest, is the so called Siberian. Other very desirable forms are those sold as globosa, ericoides, Hoveyi and pyra. midalis.

Japanese arborvitæ or retinospora, Retinospora of various species.

Very attractive small plants, of which the following nursery forms appear to be hardy in Central Michigan : $R$. squarrosa, $R$. pisifera, $R$. plumosa, $R$. obtusa. There are various varieties of these. 


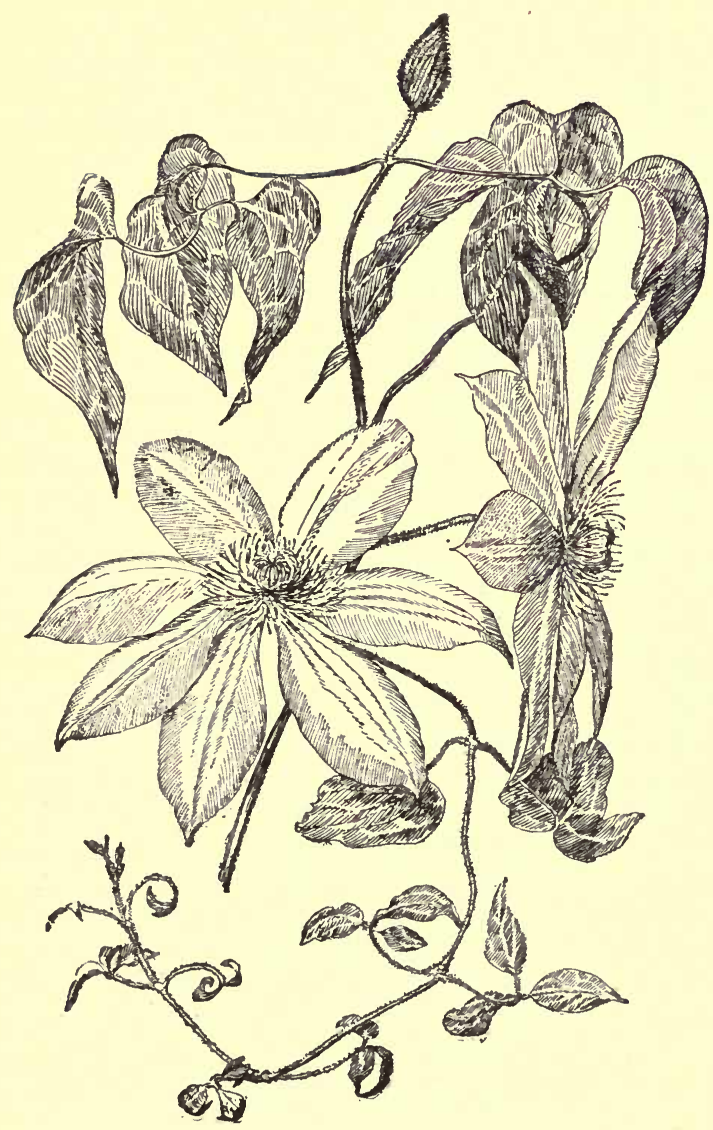

185. Clematis Henryi. One-third natural size. 
Juniper, Juniperus communis, ${ }^{*}$ and garden varieties.

The juniper is a partially trailing plant, of loose habit, suitable for banks and rocky places. There are upright and very formal varieties of it, the best being those sold as var. Hibernica, "Irish juniper," and var. Suecica, "Swedish juniper."

Northern juniper, J. Sabina, var. procumbens.*

One of the best of the low, diffuse conifers.

Dwarf Norway Spruce, Picea excelsa, hort. var.

Several very dwarf sorts of the Norway spruce are in cultivation, some of which are to be recommended.

Dwarf pine, Pinus pumilio.

There are other desirable dwarf pines.

\section{Perennial Climbers.}

A. Shrubby.

1. Tendril Climbers, Root Climbers and Scramblers.

Virginia creeper, Ampelopsis quinquefolia. *

The best vine for covering buildings in the climate of Michigan. Plants should be selected from vines of known habit, as some individuals cling much better than others.

Japanese ivy, Boston ivy, A. tricuspidata (A. Veitchii).

Handsomer than the Virginia creeper, and elings closer, but is often injured by winter in exposed places, especially when young.

Garden clematis, Clematis of various species.

Plants of robust and attractive habit, and gorgeous bloomers. $C$. Jackmanni, and its varieties, is one of the best. C. Henryi (Fig. 185) is excellent for white flowers. Clematises bloom in July and August.

Wild clematis, C. Virginiana.*

Very attractive for arbors and for covering rude objects. The pistillate plants bear eurious woolly_balls of fruit.

Wild Clematis, $C$. verticillaris.

Less vigorous grower than the last, but excellent.

Trumpet creeper, Tecoma radicans.

One of the best of all free-flowering shrubs. Climbs by means of roots.

Frost grape, Titis cordifolia.

One of the finest of all vines. It is a very tall grower, producing thick, heavy, dark leaves. Its foliage often reminds one of that of the moon-seed. Does not grow readily from cuttings. 
Summer and River bank grapes, $\nabla$. bicolor ${ }^{*}$ and $\nabla$. vulpina $^{*}$ (riparia).

The common wild grapes.

Ivy, Hedera Helix.

The European ivy does not endure the bright sun of our winter. On the north side of a building it often does well. The best of vines for covering buildings where it succeeds. Hardy in middle states

Greenbrier, Smilax rotundifolia* and S. hispida.*

Unique for the covering of small arbors and summer houses

2. Twiners.

Actinidia, A. polygama.

Very strong grower, with beautiful thick foliage which is not attacked by insects or fungi; curious flowers and edible fruit. The best vine for arbors. Japanese.

Akebia, A. Japonica.

Very handsome and odd Japanese vine; a strong grower, and worthy general planting.

Honeysuckles, Woodbine, Lonicera sempervirens, L. flava, and others.

Everywhere known and appreciated.

Dutehman's pipe, Aristolochia Sipho.

A robust grower, possessing enormous leaves, Useful for covering verandas and arbors. Needs to be more thoroughly tested in Michigan regarding its hardiness.

Wax-work or Bitter-sweet, Celastrus scandens.*

Very ornamental in fruit. Flowers imperfect.

Wistaria, Wistaria Sinensis and $W$. frutescens.

The wistarias evidently do not thrive in exposed places in Michigan The Chinese species, Sinensis, is a superb plant.

Moonseed, Menispermum Canadense.*

A small but very attractive twiner, useful for thickets and small arbors.

$$
\text { B. Herbaceous. }
$$

Hop, Humulus Lupulus* and H. Japonicus.

Should be in common use as ornamental plants.

Chinese yam, Dioscorea Batatas (D. Japonica).

Climbs high, but does not produce foliage enough to cover unsightly objects. 
Wild yam, D. villosa.*

Smaller than the preceding; otherwise fully as good.

Ground-nut, Apios tuberosa.*

A bean-like vine, producing many chocolate-brown flowers in August and September.

Scarlet Runner and White Dutch Runner beans, Phaseolus multiflorus.

Perennial in the South. Excellent.

Moonflowers, Ipomcea, various species.

Some are perennials far south.

\section{Herbaceous Perennials for Lawns.}

This list includes only a few striking plants, which are valuable for lawn planting, selected chiefly on account of their size, foliage and habit. They are usually not suitable for flower gardens. Many common wild plants when transplanted to grounds and well grown, produce a good effect. It is impossible to give to this list any degree of completeness.

Yucea, Yucca filamentosa.

Funkia, Funkia, of several species.

Peltate saxifrage, Saxifraga peltata.

Rose Mallow, Hibiscus Moscheutos.*

Elecampane, Inula Helenium (Fig. 186).

Wild sunflowers, Helianthus of various species, especially $H$. orygalis, $H$. giganteus, ${ }^{*} H$. grosse-serratus, $H$. strumosus.*

Compass-plants, Silphium of various species, especially S. terebinthinaceum, * S. laciniatum, ${ }^{*} S$. perfoliatum.*

Sacaline, Polygonum Saghalinense.

Strong and excellent.

Bocconia, Bocconia cordata.

Wild wormwood, Artemisia Stelleriana and others.

Butterfly-weed, Asclepias tuberosa.*

Wild asters, Aster of various species, especially A. NoveAngliae, ${ }^{*}$ A. lovis,${ }^{*}$ A. multiflorus, ${ }^{*}$ A. spectabilis. 


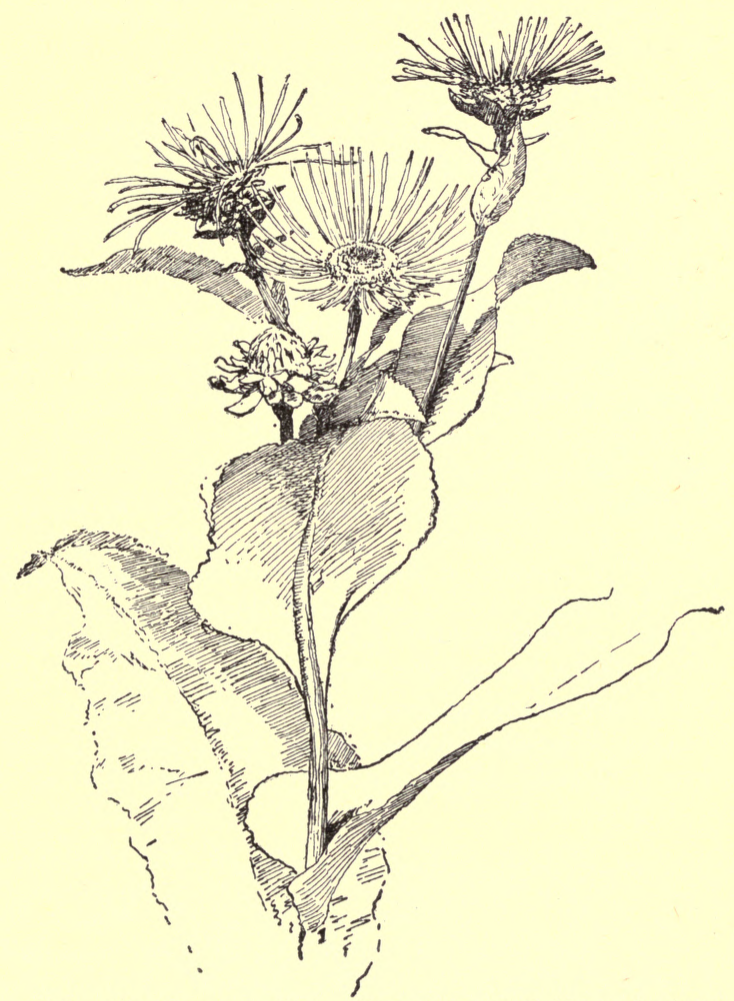

186. Elecampane. Naturalized in old fields and along roadsides. 


\section{PLANTING THE ORNAMENTAL GROUNDS}

Golden-rods, Solidago of various species, especially S. speciosa, ${ }^{*}$ S. nemoralis, ${ }^{*}$ S. juncea, ${ }^{*}$ S. gigantea. *

Loose-strife, Lythrum Salicaria.

Flags, Iris of very many species.

Japanese wind-flower, Anemone Japonica. Blooms in fall.

Goat's beard, Spirca Aruncus.

Baptisia, Baptisia tinctoria.*

Thermopsis, Thermopsis mollis.

Wild senna, Cassia Marilandica.*

Wild trefoil, Desmodium Canadense ${ }^{*}$ and others.

Ribbon grass, Phalars arundinacea hort. var. picta.

Zebra grass, Eulalia, or (Miscanthus) species.

Wild panic grass, Panicum virgatum.*

Arundo, Arundo Donax.

One of the most striking of reed-grasses.

Reed, Phragmites communis. *

This and the remaining plants of the list should be planted in the edges of water.

Wild rice, Zizania aquatica. ${ }^{*}$

Cat-tail, Typha angustifolia and T. latifolia.*

Lizard's-tail, Saururus cernuus.*

Peltandra, Peltandra undulata.*

Orontium, Orontium aquaticum.

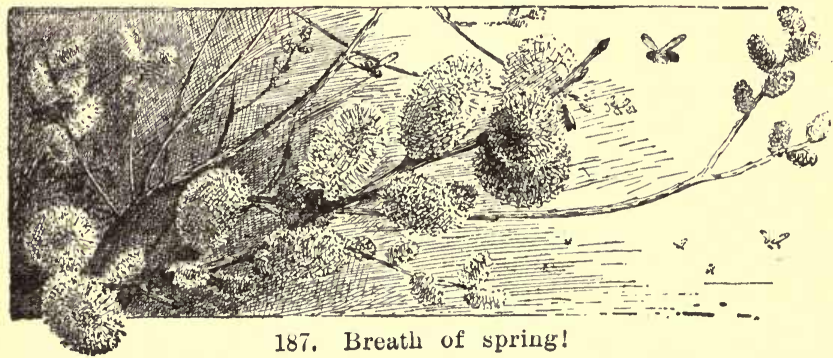




\section{PLANTS FOR FLORAL EFFECTS*}

(ERNEST WALKER)

\section{Remarks on Flower-beds}

The various styles of Planting.-The mixed border, planted with various hardy plants, and extending along either side of the garden-walk, was popular years ago; and, with modifications in position, form and extent, has, during the past few years, been a popular attachment to home grounds. (See Hardy Herbaceous Plants, page 278.) To produce the best effects, the plants should be planted close enough to cover the ground; and the selection should be such as to afford a continuity of bloom.

There is also the border of tender summer-blooming plants, in which the kinds are planted in a mixed fashion.

In ribbon-bedding, so-called, flowering or foliage plants are arranged in ribbon-like lines of harmoniously contrasting colors, commonly accompanying walks or drives, but also suitable for marking limits, or for the side borders. In such beds, as well as the others, the tallest plants, if the bed is to be seen from one side only, will be placed at the back, and the lowest at the front. If it is to be seen from both sides, then the tallest will stand in the center.

A modification of the ribbon-line, bringing the con. trasting colors together into masses forming circles or other patterns, is known as "massing," or "massing in color," and sometimes is spoken of as carpet-bedding.

Carpet-bedding, however, belongs more properly to a style of bedding in which plants of dense, low, spreading

* Since new and good varieties of flowering plants are constantly being offered, and fashious are changing, it is generally impracticable to give lists of named varieties in a book. These varieties should be chosen after consulting the annual or periodical publications, as seeds. men's and plantsmen's catalogues, journals, and bulletins.-I, H, B. 
habit-chiefly foliage plants, with leaves of different forms and colors-are planted in patterns not unlike carpets or rugs.

Beds composed of the large foliage plants, for producing tropical effects, are composed, in the main, of plants which are allowed to develop naturally. In the lower and more orderly massing, the plants are arranged not only in circles and patterns according to habit and height, but the selection is such that some or all may be kept within proper limits by pinching or trimming. Circles or masses composed of flowering plants usually cannot be cut back at the top, so that the habit of the plants must be known before planting; and they must be placed in parts of the bed where trimming will not be necessary. They may, however, be clipped at the sides in case the branches or foliage of one mass or line in the pattern grows beyond its proper bounds.

Aquatics may often be used to good effect in the landscape. This is especially true of such large and bold kinds as the lotus, which makes a very strong contrast against a building or a background of foliage. Ponds are usually protected at the edges by mason-work, and in loose soils they have eement bottoms. In some soils, a simple excavation will hold water, but it is usually necessary to give the tank some kind of lining. Clay is often used. The bottom and sides of the tank are pounded firm, and then covered with three to six inches of clay, which has been kneaded in the hands, or pounded and worked in a box. Handfuls or shovelfuls of the material are thrown forcibly upon the earth, the operator being careful not to walk upon the work. The elay is smoothed by means of a spade or maul, and it is then sanded. These lily tanks are from two to three feet deep.

Aquatics in the open nearly always show to best advantage if a few tall bog plants are grown with them. 
Swamps yield many interesting tall plants, and there are many exotics in the market which can be grown with water lilies. The common wild water lilies can be grown

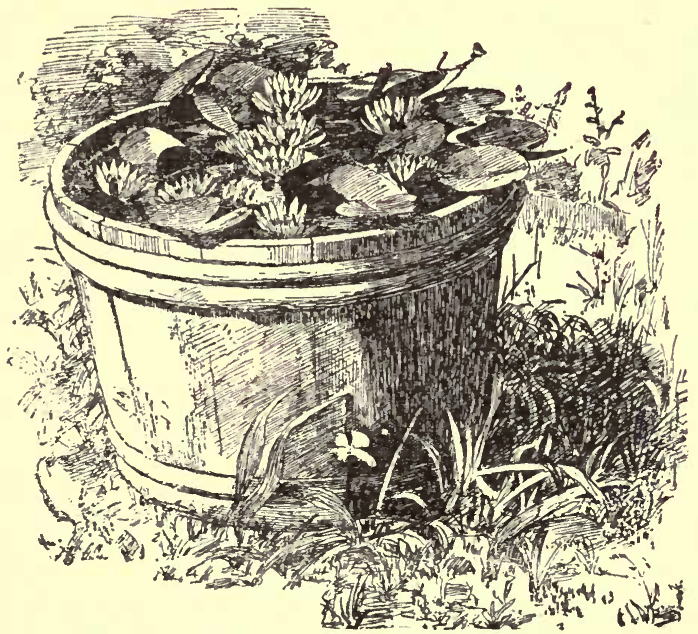

189. A tub of water lilies.

in tubs (Fig. 189), strong flowering roots being got each year or two from the wild. The subject of aquatics is too special for this book, and the reader who wishes the best information should consult Tricker's "Water Garden."

\section{Carpet-bedding}

The beauty of the carpet-bed lies largely in its unity, sharp contrast and harmony of color, elegance-often simplicity-of design, nicety of execution, and the continued distinctness of outline due to scrupulous eare. A generous allowance of greensward on all sides contributes greatly to the general effect,-in fact is indispensable. 


\section{PLANTING THE ORNAMENTAL GROUNDS}

Let us pass to considerations purely practical: Whatever place is selected for the bed, it should be in a sunny situation. This, nor any kind of bed, should not be planted near large trees, as their greedy roots will rob the soil not only of its food, but of moisture. The shade, also fwill be a menace. As the plants stand so thick, the soil should be well enriched, and spaded at least a foot deep. In planting, a space of at least six inches must be left between the outer row of plants and the edge of the grass. The very style of the bed requires that lines be straight, the eurves uniform, and that they be kept so by the frequent and careful use of the shears. During dry periods watering will be necessary. The beds, however, should not be watered in the hot sunshine. Foliage plants are most in use, and are the ones which will prove the most satisfactory in the hands of the inexperienced, as they submit to severe clipping and are thus more easily managed.

The following list will be found helpful to the beginner. It embraces a number of the plants in common use for carpet-bedding. Other useful kinds will be found under the discussion of annuals (page 255). The usual heights are given in inches. This, of course, in different soils and under different treatment is, more or less, a variable quantity. The figures in parentheses suggest in inches suitable distances for planting in the row when immediate effects are expected. A verbena in rich soil will in time cover a circle three feet or more in diameter; other plants mentioned spread considerably; but when used in the carpet-bed they must be planted close. One can not wait for them to grow. The aim is to eover the ground at once. Although planted thick in the row, it will be desirable to leave more room between the rows in ease of spreading plants like the verbena. Most of them, however, need little if any more space between the rows than is indicated by the figures given. In the 
list those plants which bear free clipping are marked with an asterisk $\left(^{*}\right)$ :

\section{PLANTS FOR CARPET-BEDS}

The figure immediately following the name of plant indicates its height; the figures in parentheses the distance for planting, in inches.

\section{Low-growing Plants}

A. Foliage Plants.

Crimson.-*Alternanthera amœna spectabilis, 6 (4-6). " paronychioides major, 5 (3-6). " $\quad$ versicolor, $5(3-6)$.

Yellow.- “ aurea nana, 6 (4-6).

Grey, or Whitish.-Echeveria secunda, glauca, 11/2 (3-4). “ metallica, $9(6-8)$.

Cineraria maritima $15(9-12)$.

Sempervivum Californicum 1/2 (3-4). Thymus argentea 6 (4-6).

Bronze Brown.-Oxalis tropœoloides, 3 (3-4). Variegated (White and green).-

Geranium Mme. Solleroi, 6 (6-8).

* Sweet alyssum, variegated, 6 (6-9).

B. Flowering Plants.

Scarlet.-Phlox Drummondii, Dwarf, 6 (4-6).

Cuphea platycentra, Cigar Plant, 6 (4-6).

White.-Sweet alyssum, Little Gem, 4 (4-6).

$$
\text { " " common, } 6(6-8) \text {. }
$$

Phlox Drummondii, Dwarf, 6 (4-6).

Blue.-Lobelia, Crystal Palace, 6 (4-6).

Ageratum, Dwarf Blue, 6 (6-8).

\section{Plants of Taller Growth}

A. Foliage Plants.

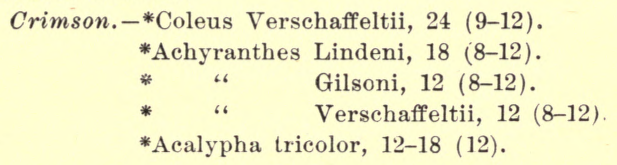


Yellow.-**oleus, Golden, 24 (9-12).

*Achyranthes, aurea reticulata, 12 (8-12).

Golden feverfew (Pyrethrum parthenifolium aureum), (6-8).

Bronze geranium, $12(9)$.

Silvery White.-

Dusty Miller (Centaurea gymnocarpa), 12 (8-12).

*Santolina chamæcyparissus incana, 6-12 (6-8).

Geranium, Mountain of Snow, $12(6-9)$.

Variegated (white and green).-

*Stevia serrata var., 12-18 (8-12).

Phalaris arundinacea var. (grass), 24 (4-8).

Cyperus alternifolius var. 24-30 (8-12).

Bronze.-**Acalypha marginata, 24 (12).

B. Flowering Plants.

Scarlet.-Salvia splendens 36 (12-18).

Geraniums, 24 (12).

Cuphea tricolor (C. Llavæ), 18 (8-12).

Dwarf nasturtium (Tropæolum) 12-18 (12-18).

Begonia, Vernon, $12(6-8)$.

Verbenas, 12 (6-12).

Phlox Drummondii, dwarf, 6 (4-6).

White.-Salvia splendens, White-flowered, 36 (12-18)

Geraniums, 18-24 (12).

Lantana, Innocence, 18-24 (8-12).

“ Queen Victoria, 24 (8-12).

Verbena, Snow Queen, 12 (6-12).

Ageratum, white, 9 (6-9).

Phlox Drummondii, dwarf, 6 (4-6).

Pink.-Petunia, Countess of Ellesmere, 18 (8-12)

Lantana, 24 (8-12).

Verbena, Beauty of Oxford, 6 (8-12).

Phlox Drummondii, dwarf, 6 (4-6).

Yellow.-Dwarf nasturtium, 12 (12-18).

Anthemis coronaria fl. pl., $12(6-8)$.

Blue.-Ageratum Mexicanum, 12 (6-8).

Verbenas, 6 (6-12).

Heliotrope, Queen of Violets, 18 (12-18). 

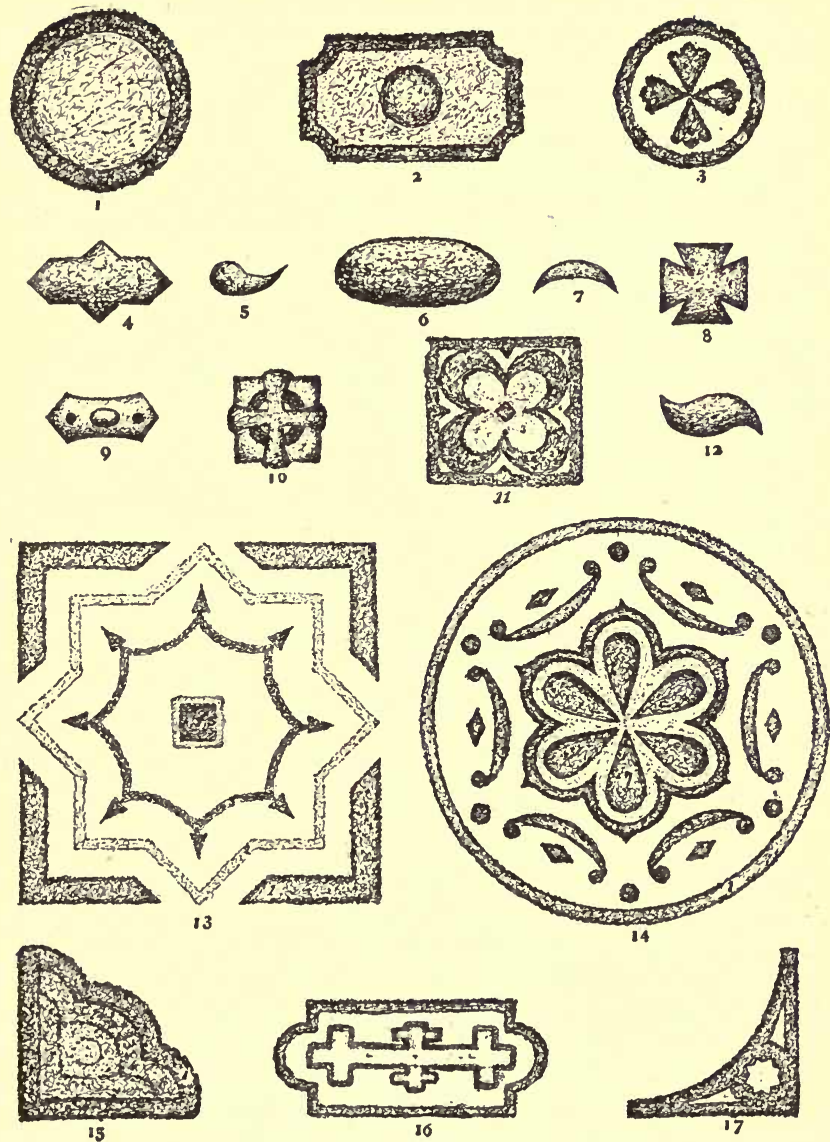

190. Designs for carpet-beds. 
In Fig. 190 are shown a few designs suitable for carpet beds. They are intended merely to be suggestive, not to be copied precisely. The simple forms and component parts of the more elaborate beds may be arranged into other designs. Likewise the arrangement of plants which will be mentioned as suitable for making a given pattern, is only one of many possible arrangements. The idea is merely to bring out the design distinctly. To accomplish this it is only necessary to use plants of contrasting color or growth. To illustrate how varied are the arrangements that may be used, and how easily different effects are produced with a single design, I will mention several different combinations of color for the bed No 1 .

No. 1.-Arrangement A: Outside, Alternanthera amœna spectabilis; inside, Stevia serrata variegata. B: lobelia, Crystal Palace;.Mme. Solleroi geranium. C: lobelia, Crystal Palace; scarlet dwarf phlox. D: sweet alyssum; petunia, Countess of Ellesmere. E: coleus, Golden Bedder; coleus Verchaffeltii. F: Achyranthes Lindeni; yellow dwarf nasturtium. No. 2.-Outside, red alternanthera; middle, Dusty Miller; center, pink geranium.

No. 3.-Outside, Alternanthera aurea nana; middle, Alternanthera amœna spectabilis; center, Anthemis coronaria.

No. 4, 5, 6, 7, 8, 12 may each be filled with a single color, or given a border of suitable plants if the planter so chooses. No. 9.-Ground, Alternanthera aurea nana; center, Acalypha tricolor; black dots, scarlet geranium.

No. 10.-Ground of Centaurea gymnocarpa; circle, Achyranthes Lindeni; cross, golden coleus.

No. 11.-Border, Oxalis tropæoloides; center, blue heliotrope, blue ageratum, or Acalypha marginata; cross about the center, Thymus argentea, or centaurea; scallop outside the cross, blue lobelia; corners inside border, santolina.

Designs 13 and 14 are, in character, somewhat in the style of a parterre; but instead of the intervening spaces in the bed being ordinary walks they are of grass. Such beds are of a useful type, because they may be made large and yet be 
executed with a comparatively small number of plants. They are especially suitable for the center of an open plot of lawn with definite formal boundaries on all sides, such as walks or drives. Whether they are to be composed of tall-growing or of low-growing plants will depend upon the distance they are to be from the observer. For a moderate sized plot the following plants might be used:

No. 13.-Border, red alternanthera; second row, dwarf orange or yellow nasturtium; third row, Achyranthes Gilsoni, or

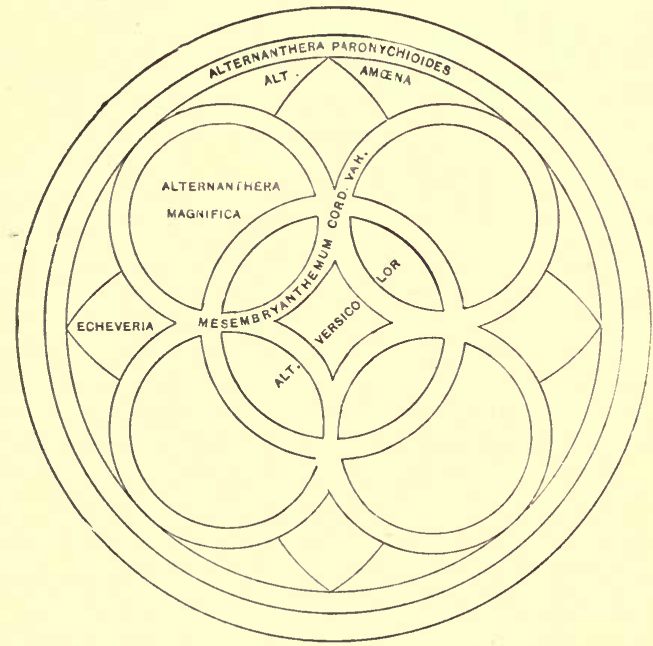

191. Carpet-bed for a bay or recession in the border planting.

Acalypha tricolor; central square, scarlet geraniums, with a border of Centaurea gymnocarpa, intervening spaces, grass. Instead of the square of geraniums, a vase might be substituted, or a clump of Salvia splendens.

No. 14.-Composite beds like this and the former are always suggestive. They contain various features which may readily be re-combined into other patterns. Sometimes it may be convenient to use only portions of the design. The reader 
should feel that no arrangement is arbitrary, but merely a suggestion which he may use with the utmost freedom, only keeping harmony in view. For No. 14, the following may be an acceptable planting arrangement; Border, Mme. Solleroi geranium; small dots, dwarf scarlet tropæolum; diamonds, blue lobelia; crescents, Stevia serrata variegata; inner border, crimson achyranthes or coleus; loops, Centaurea gymnocarpa; wedge-shape portions, scarlet geranium.

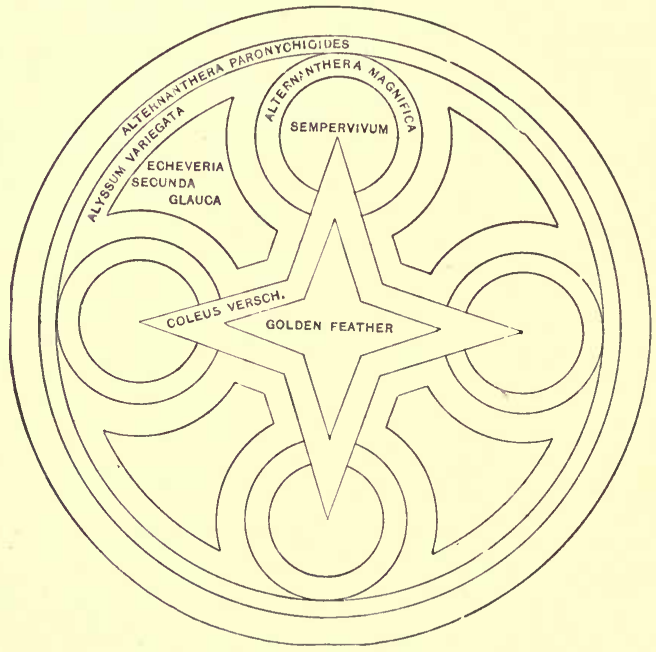

192. Another circular carpet-bed.

No. 15. - Suitable for a corner. Border, red alternanthera; second row, Alternanthera aurea nana; third row, red alternanthera; center, Echeveria Californica.

No 16.-Border, crimson alternanthera (another border of yellow alternanthera might be placed inside of this); ground, Echeveria secunda glauca ; inner border, Oxalis tropæoloides; center, Alternanthera aurea nana. Or, inner border, Echeveria Californica; center, crimson alternanthera.

No. 17.-Another bed intended to fill an angle. Its curved 
side will also fit it for use with a circular design. Border, dwarf blue ageratum; circle, blue lobelia; ground ( 3 parts), crimson alternanthera.

Other carpet or mosaic beds (after Long), with the plants indicated, are shown in Figs. 191, 192.

\section{Edgings and Mass-beds}

PLANTS FOR EDGINGS, BORDERS AND RIBBON-BEDS

\section{(Blooming all summer)}

Ageratus Mexicancy, Hh.* Dwarf blue, Height, 9 inches. Sow when danger of frost is over, in the open ground; or for early plaits, in March, in the greenhouse or hotbed. Plant them 6 inches apart.

Alrsscy (Sweet) H. White. Of spreading habit, growing 6 to 8 inches high. A valuable plant. Treatment the same as for ageratum.

Candytcfi, $H$. The annual kinds are useful bedding plants. The white and carmine sorts are the best colors. Height, 1 foot. The dwarf Iberis affinis grows only about 6 inches high. Its colors are white, rose, and purple. Treatment similar to the last. When sown early, transplant while small to pots.

Clarkia. See Annuals, page 259.

Gilia. See Annuals, page 259.

Lobelia ERINUs, Hh. P. Of compact, trailing habit. Small blue flowers. Height, 6 inches. Crystal Palace is perhaps the best. Sow in a hotbed or greenhouse in January.

Marigold. See Annuals, page 261.

Nemophila. See Annuals, page 261.

Portulaca, T. Beautiful and brilliant, for either lines, edgings, or masses-especially the double sorts. The flowers are like little roses, and of a great variety of shades in scarlet, white, pink, yellow, and purple. Height, 6 inches. Blooms from July till frost. Sow thickly in the open

${ }^{*}$ H., Hh. and T. P., hardy, half-hardy and tender perennial respectively. 


\section{PLANTING THE ORNAMENTAL GROUNDS}

ground when danger of frost is past. They begin to flower soon, and any single ones that appear may be removed. Thin to about 4 or 6 inches. They prefer a dry, warm situation, delighting in the hottest and sunniest weather.

Tonenia, T. For a partially shaded situation, as with pansies, these are attractive. T. Fournieri has porcelain-blue and rich violet flowers. Of $T$. Bailloni the flowers are deep yellow and maroon. There is also a white variety known as White Wings. Height, 6 inches or more. Sow in March in a hotbed, or window. They must have a temperature of at least $60^{\circ}$. Plant out when danger of frost is past.

Whitlavia, H. Flowers bell-shaped, white and violet-blue, or purple. Height, 1 foot or more. Should have light, sandy soil to do best. Sow in the open ground when the soil is right, and danger of frost is over. For early plants, start in Mareh in a temperature of about $60^{\circ}$.

\section{PLANTS FOR TROPICAL EFFECTS, MASSING}

(Or for the center or back of a group)

The number of plants in this eategory which may be readily grown from seed, is limited. Some of the best kinds are included below. It will often be worth while to supplement these with others, to be had at the florists, such as caladiums, screw pines, Ficus elastica, Musa Ensete, palms, crotons, and others.

In the use of such plants, there are opportunities for the exercise of the nicest taste. A gross feeder, as the ricinus, in the midst of a bed of delicate annuals, is like a lion among lambs; and a stately, royallooking plant among humbler kinds often makes the latter look common, when if headed with a chief of their own rank all would appear to the best advantage.

Amaranthus, T. These have ornamental foliage and make handsome plants for the center of beds. The seeds may be sown in a warm hotbed temperature in March, and the young plants set out about the first of June. Seed saved 
from the best kinds will produce some inferior plants, so it is well to plant three or four together. When they show their color, all but the best one may be removed or cut off. A. tricolor is the well-known "Joseph's Coat." The leaves are red, yellow and green. Height, 3 feet. A. caudatus grows to a similar height, is of drooping habit and has fine red foliage. A. salicifolius is of drooping habit, and from its graceful appearance has received the name of the "Fountain Plant." It attains a height of 4 feet.

Aralia, Hh. P. A. Sieboldii, or Fatsia Japonica as it is sometimes called, and the variety variegata, have large palm-like, leaves and a rather tropical appearance. Height 3 feet. Sow in February, in shallow trays and light soil, in a temperature of $65^{\circ}$. Continue the temperature. When two or three leaves have formed, transplant into other trays 1 inch apart. Sprinkle them with a fine rose or spray; and do not allow them to suffer for water. Later, transfer them to small pots and repot them as they grow. Plant out in beds after the weather has become warm and settled.

Cannas, T. P. These are well known and are among the most ornamental and important plants used in decorative gardening. They make fine herbaceous hedges, groups, masses, and-when desirable-good center plants for beds. They grow from 3 to 10 feet or more high. Formerly they were valued chiefly for their magnificent foliage, but since the introduction, in 1884, of the Crozy Dwarf French type with their splendid flowers, cannas are grown as much for their flowers as for their foliage effects. The flowers of these new kinds are as large as those of gladioli, and are of various shades of yellow and red, with banded and spotted forms. These grow about 3 feet high. The older forms are taller. In both sections there are green-leaved and dark coppery-red-leaved varieties. It requires two years to raise strong plants of the canna from seed. The seeds are bullet-like and hard. File a small notch through the coat of each seed-avoiding the round germinating point. Sow in light, sandy soil where the earth may be kept at $70^{\circ}$ till after germination. After the plants have got well up, transplant them to about 3 or 4 inches apart, or place in pots three inches wide, in good rich soil. They may now be kept at $60^{\circ}$. 
Plant out when there is no longer danger of frost. The old (foliage) sorts may be left out late to ripen up the fleshy root-stocks. Cut the tops off immediately after frost. The roots are safe in the ground as long as it does not freeze. Dig, and dry or "cure" for a few days, then winter them like potatoes in the cellar. It is a common mistake to dig canna roots too early. The French sorts are commonly thought to keep best if kept growing somewhat during the winter; but if managed right, they may be carried over like the others. Immediately after frost, cut off the tops next the ground. Cover the stumps with a little soil and leave the roots in the ground till well ripened. Clean them after digging, and cure or dry them for a week or more in the open air and sun, taking them indoors at night. Then place them away from frost in a cool, dry place.

Malze, T. The variegated Japanese corn, Zea Japonica variegata, is a splendid variegated plant for the center or back of beds, clumps, etc. The leaves are striped with white. Sow out of doors when there is no longer danger of frost. It is well to have at least three plants in a group for beds. This variety grows only about 4 feet high.

Ricinus, T. This is the well-known castor oil plant. It has a very tropical appearance, and may be used as a single specimen on the lawn, for a hedge-like row, or for the center of large beds, especially with cannas and caladiums. The plant branches freely and grows to a height of 9-12 feet or more. Leaves large and palmate. Start the seed in small pots in March in a temperature of $60^{\circ}$ or more, and plant out when the weather is settled. The seed may also be started in the open ground. Give them a dry situation and deep, rich soil. The variety $R$. Cambodgensis has bronzy foliage and is one of the best, growing about 6 feet high. $R$. Borboniensis attains a height of 15 feet, and $R$. Zanzibariensis likewise.

Wigandia, T. P. This plant, although perennial, should be grown from the seed each year. It has leaves 2 or 3 feet long by half as wide, and grows 4 feet high. The stems are covered with red hairs, and the leaves are handsomely veined. The plant requires room and light, and is most suitable for spacious grounds, where it may be used for massing or as 
single specimens for the lawn. $W$. macrophylla and $W$. Vigieri are to be had of seed-dealers. Sow the seed in February or March in a temperature averaging $65^{\circ}$ to $70^{\circ}$. Transplant at first to boxes, afterward to pots, and grow till time for planting out.

\section{Annuals}

Many of the showy annuals are especially well suited to growing in masses, while the dwarf kinds make fine flowery edging for beds or walks. It is also possible to make handsome riblon-beds with the dwarf sorts; but here, as shearing is well nigh precluded, we should limit ourselves to simple designs. For the best effects, much depends both upon a judicious selection of kinds, and arrangement. In purchasing seeds, it is best to buy the different colors in separate packages, and to buy the best. Hardy annuals are such as develop readily without the aid of artificial heat. They are commonly sown in May or earlier, directly in the open ground where they are to grow. Florists often sow certain kinds in the fall, and winter the young plants in coldframes. They may also be wintered under a covering of leaves or evergreen boughs. The half-hardy and tender annuals are alike in that they require more warmth for their germination and growth. They, like the hardy kinds, may be sown in the open ground, but not until the weather has become settled, and warm, which for the tender kinds will not commonly be before the first of June. A few of the annuals thrive in partial shade or where they receive sunshine for half the day; but most of them prefer a sunny situation.

Any good garden soil is suitable for annuals. If not naturally fertile and friable, it should be made so by the application of well rotted stable-manure or humus. The spading should be at least one foot deep. The upper six inches is then to be given a second turning to pulverize 
and mix it. After making the surface fine and smooth, the soil should be pressed down with a board. The seed may now be sprinkled on the soil in lines or concentric circles, according to the method desired. After covering the seed, the soil should be pressed down with a board. This promotes capillarity, by which the surface of the soil is better supplied with moisture than would be possible otherwise. Always mark the kind and position of all seed sown with a label.

While many kinds of annuals may be sown directly in the open ground, some of the sorts, especially the tender ones, will flower sooner in the season and give much more satisfaction if sown early under cover. The majority of these may be sown about the middle of March, but some must be sown in February. Where but a few are to be grown, a sunny window answers, especially for March sowings; but it is more satisfactory to have a hotbed, or greenhouse, at command. The danger with early sown seedlings is "drawing up," and weakness from erowding and want of light. This is most liable to occur with window-grown plants. Vigorous June-sown plants are better than such weaklings.

Poppies, bartonia, Venus' looking-glass, the dwarf convolvulus, lupinus, and malope do not bear transplanting well. It is best, therefore, to sow them where they are to grow. Some annuals do not bloom all summer, especially if allowed to produce seed. Of such kinds a second or third sowing at intervals will provide a succession. Preventing the formation of seeds, if possible, is like manure to annuals, in prolonging their life and flowering.

Below is given an annotated list of some of the best continuous flowering kinds, which may be raised from seed. The terms hardy, half-hardy and tender are abbreviated H., Hh., and T. respectively. Perennials are indicated by P.; all others are annuals. 
AlonsoA, Hh., P. Rich scarlet flowers. A white variety is also to be had. Height, $1 \frac{1}{2}$ to 2 feet. They may be propagated both by seeds and cuttings. They need a light, rich soil. Sow the seeds in February, in the hotbed or greenhouse, and plant them out in May, 1 foot apart. Asters, Hh. These fall flowers, known as the China and German asters, present an almost endless number of varieties. The flowers are large, double and of rarious shades of red, blue and white. Some of them, especially the Washington asters, rival chrysanthemums. They grow from 1 to 2 feet high. Sow in the middle of March, in a coldframe, or in the open ground, in early May. If sown in the fall and wintered in a cool greenhouse, they may be had in bloom in the spring. For fine flowers they should have rich soil, stand about 10 to 12 inches apart, and never receive any check.

Bailey writes as follows on these flowers (Bull. 90, Cornell Exp. Sta.): “The China asters are among the best of all the annual garden flowers. They are of the easiest culture, most free of bloom, and comprise a multitude of forms and colors. They are therefore admirably adapted to profuse and gen-

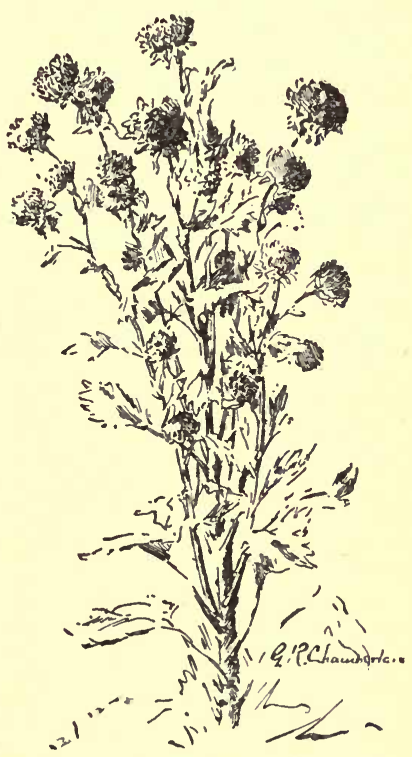

193. Showing the habit of one of the types of tall asters, - Truffaut's peony-flowered. erous effects in schemes of planting. They are also worthy of wide attention because they are adapted to many of the purposes for which chrysanthemums are grown, and they can be raised to perfection wholly without use of glass. They attain their best in the decline of the season, from late August till 


\section{PLANTING THE ORNAMENTAL GROUNDS}

frost, at a time when many of the annuals and the greater part of the perennials are spent and gone. No garden flowers carry such a profusion of bloom and color down to the very closing in of winter. Last fall our aster border still had blooms when the snows fell in November, and when even the wild goldenrods had waned and died."

BARTonia, H. Flowers golden yellow, glistening in the sunlight; fragrant in the evening; flowering all summer. $B$. aurea grows 3 feet high, while $B$. aurea nana attains a height of $1 \frac{1}{2}$ feet. They need a moist situation and should always be grown in masses. Sow early, where they are to grow. The dwarf may be planted 1 foot apart; the former, 2 feet.

BRAchyсомe, Hh. Handsome for either edgings or masses. The flowers somewhat resemble those of the single daisy, and are fine for cutting. The original color was blue, but there is now also a white variety. Plant bushy; 1 foot high. Start the seed in March, in a hotbed or other warm place. They may also be sown the last of May, in the open, but bloom later. Set the plants 6 to 8 inches apart in beds.

Calliopsis (Coreopsis), H. Splendid for rich and strong effects. Of rapid growth and slender, branching habit, they attain a height of 3 feet or more. They flower all summer, and are useful for cutting. The colors are orange, yellow, and rich, reddish brown. The plants must have room to spread. Two feet will be close enough. The seed may be sown at the end of March, in the open ground, as these plants are of very hardy nature. For very early bloom the plants should should be grown in mild heat, and set out in May. Coreopsis lanceolata and its variety, "Golden Glory," are closely allied hardy perennials, growing only from 12 to 18 inches high. Their flowers are golden yellow, and the plants are of dense, low, leafy habit.

Chrysanthemum, H. Of the annual Chrysanthemums, $C$. multicaule and $C$. coronarium are of especial value as bed. ders. The former has yellow flowers, and grows to a height of 4 feet. The latter grows but $1 \frac{1}{2}$ feet high, and is white. Both flower freely all summer. Sow the seed in March, in a mild hotbed, or in the house for early flowering plants. 
Or they may be sown where they are to grow as soon as the soil will permit. The latter needs about one foot space in the beds; the former more.

Clarkia, H. A bed of the double white or rose-colored $C$. elegans is very beautiful. The plants grow $1 \frac{1}{2}$ feet high. They may also be used for edgings to beds of taller plants. The dwarf variety, called White Tom Thumb, grows only about 10 inches high. They grow in any soil. Sow the seed in March, or later, in the open ground. For very early bloom sow the seed in September. If the winter is mild they will survive. A few can always be depended on. Plant them 1 foot apart, in an open situation.

Eschscholtzia, H. (Fig. 194). Originally from California. Known as the California poppy. One foot in height; foliage greyish. Flowers yellow, orange, and white, produced all summer. Also to be had in double varieties. Of easy culture. The seeds may be sown in the open border in spring as soon as the ground will permit. But it is best to obtain seeds during the summer or fall, as soon as they are ripe, and sow for the following season where they are to grow. Thin to about 10 inches apart.

Gaillardia, Hh. These are beautiful; the only objection to them is that the seeds germinate slowly, and must be sown as early as February in the greenhouse or a hotbed. They do best in a rich, light soil. The plants grow 2 feet high and flower freely through the summer and fall. Set the plants from 12 to 18 inches apart. $G$. amblyodon is a fine red. G. picta (Aurora Borealis) is scarlet and yellow.

Gilia, H. Of the Gilias, $G$. achillecofolia, $G$. rosea and $G$. linifolia are satisfactory and pretty for bedding. The first two grow 1 foot or more in height, the one being blue, the other rose-color. The last mentioned grows but 6 inches high and has white flowers. It is a good edging kind. They bloom through the spring and summer and are desirable for eutting. Unless done when they are very small they do not transplant well. It is a good plan, therefore, to sow the seed in the fall where they are to grow, and cover the beds lightly during winter with leaves.

Godftia, H. These bloom profusely and continuously from early till late, and are very handsome. Colors, red, pink, and 


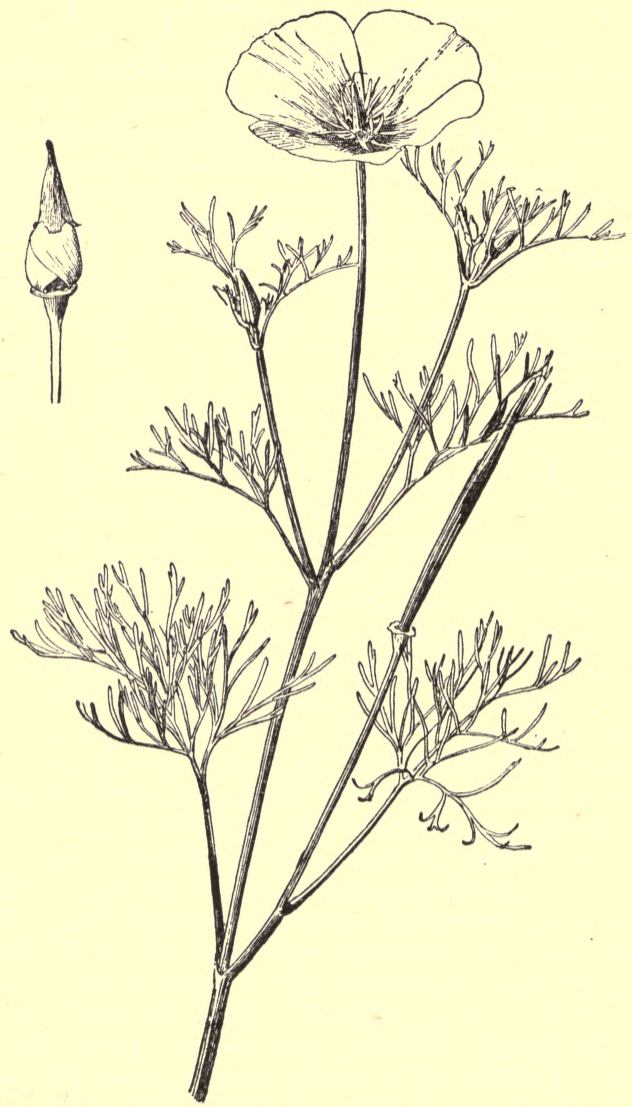

194. Eschscholtzia maritima of florists. One-half size. 
white, several shades. They grow to a height of about $1 \frac{1}{2}$ feet. Let them stand a foot or more apart. They grow too freely in rich soil, so should be planted in rather poor. Sow the seed in March in a hotbed and transplant them to their beds the latter half of May, or when the weather has become settled.

MARIgold, H. Three or four species of this plant (Tagetes) are found in gardens, and are old friends. The African grow about 2 feet high and are valuable for mass effects and distant groups. Some object to them on account of the ill-scent of the herbage when handled. The flowers are large, yellow, or orange, and come in summer and autumn. Sow the seeds in a coldframe in March, and transplant them to beds in May, 14 inches apart or more. The Dwarf French, of yellow and brown colors, are suitable for closer planting in small beds and borders. Legion of Honor is a pretty dwarf.

Mimulus, H. P. Under this genus may be mentioned $M$. hybridus cupreus as a useful kind. The flowers are bright, of mixed colors, orange and crimson, and are produced from early till late. The plant grows $1 \frac{1}{2}$ ieet in height. It does best when somewhat shaded, but is not particular about the soil. Sow in the open as soon as it is dry enough.

Nasturtium. See Tropæolum.

Nemophila, H. For a shady situation this plant is delicate and pretty. $N$. insignis grows 1 foot high, and blooms all summer. Flowers blue. Sow in March in a frame and transplant early. Set them 6 inches apart in the beds. Fallsown plants do nicely during the winter in a cool greenhouse.

Passy, H. The pansy is generally mentioned with plants suitable for partial shade, but it also thrives in other localities, especially where the sun is not very hot nor the weather very dry. It thrives at a low temperature. The seed should be sown in the fall (September) if possible, in light, rich well prepared soil. When they are well up they may be transplanted to good, rich, loamy soil, 3 or 4 inches apart. A frame or sheltered spot is the proper place. Here they may be covered, at the approach of cold weather, with a frame, with evergreen-boughs, or boards, to be removed 
whenever the weather is mild. The plants will make a good growth before cold weather, and will be ready for a mass of bloom the following spring. In hot summer weather they bloom, but the flowers become small. Pansies delight in cool weather and moisture. They may also be sown in the spring as soon as the ground can be worked, but fall sowing is generally preferable.

Papaver, H. Poppies are of the most brilliant tulip-like colors. The Shirley race is distinct and of special value for bedding. For continuity of bloom, allow no seed-pods to develop. The plants grow 1 foot in height. A sandy loam suits them best. The Shirleys bloom the first year. As they do not bear transplanting, sow the seed in early spring where they are to grow.

Petunia, H. P. Well known, and by all accorded a place near the bead of the list of bedding plants. The single blotched, plain or fringed are preferable, as bedders, to the double. The colors are white and crimson. Height, 2 feet. Countess of Ellesmere is a pink of solid color, excepting its white throat. It is of compact habit, and comes practically true from seed. Putunias do well in any garden, and may be sown early in the hotbed, coldframe, or later in the open ground. Set the plants 18 inches apart, and they will be a mass of bloom all summer.

Phlox Drummondi, H. For clear and brilliant colors, the many varieties of this, the only annual species of the Phlox genus, are certainly unrivaled. The dwarf kinds are the more desirable for ribbon beds, as they are not so "leggy." There are whites, pinks, reds and variegated of the most dazzling brilliancy. The dwarfs grow 10 inches high, and bloom continuously. Set them 8 inches apart in good soil. Seed may be sown in the open ground in May, or for early plants, in the hotbed in March. They may be sown close in the fall if sown very late, so that the seeds will not start till spring.

Poppy. (See Papaver.)

Portulaca. (See Plants for Edging, page 251.)

Salvia splendens, Hh. P. Of the numerous species of this genus, the one mentioned is, beyond doubt, the best for garden decoration, and has long been a favorite for this 
purpose. The plant is a blaze of scarlet all summer. Height, 2 to $2 \frac{1}{2}$ feet. Easily grown. Sow the seed in a temperature of $60^{\circ}$ to $70^{\circ}$. The plants may be set out when the weather has become settled. Plant 18 inches apart.

Tropcelum mives, H. The Dwarf Nasturtiums grow but 1 foot high. They flourish in the hottest weather, and in poor soil. The flowers are scarlet, golden, cream, pink, and sometimes almost black, and borne in the greatest profusion. Fine effects are produced by planting them so as to contrast with white or blue flowers. Sow in March, in a temperature of $60^{\circ}$, or in the open ground like the last.

Verbena, Hh. P. Fig. 195. Easily grown from seed, which may be started in a hotbed in February or March. Once transplanted, the plants may be set out in May. Plant them 2 feet apart, or farther in rich soil. They love a loam, and fresh soil each year. The colors are white, blue, red, puinle and pink, of various shades. Seedlings cannot be depended on when the separate colors are wanted, so it is better to buy than to grow them.

Zivis, H. The dull colors of the old-time Zinnias have given place to the brightest shades of scarlet, rose, orange, and yellow. They are easily grown and succeed almost anywhere. Height, 2 feet. The flowers last a long time, and are produced from June till frost. Sow in the open, when danger of frost is past, and thin the plants to 2 feet apart. For earlier flowers, sow in March, in the window, hotbed or greenhouse. The white and orange Tom Thumb are dwarf-growing about 6 or 8 inches high-and may be used for edging.

\section{ANNUAL CLIMBING PLANTS}

The following, for arbors, verandas, etc., are some of the best summer climbers, and are readily grown from seed, flowering the first season.

Bryonopsis laciniosa, var. ERYTHRocarpa, Hh. 10 feet. Small, scarlet fruit, striped with white, about the size of cherries. Sow in the garden when danger of frost is over. Tendrils. 


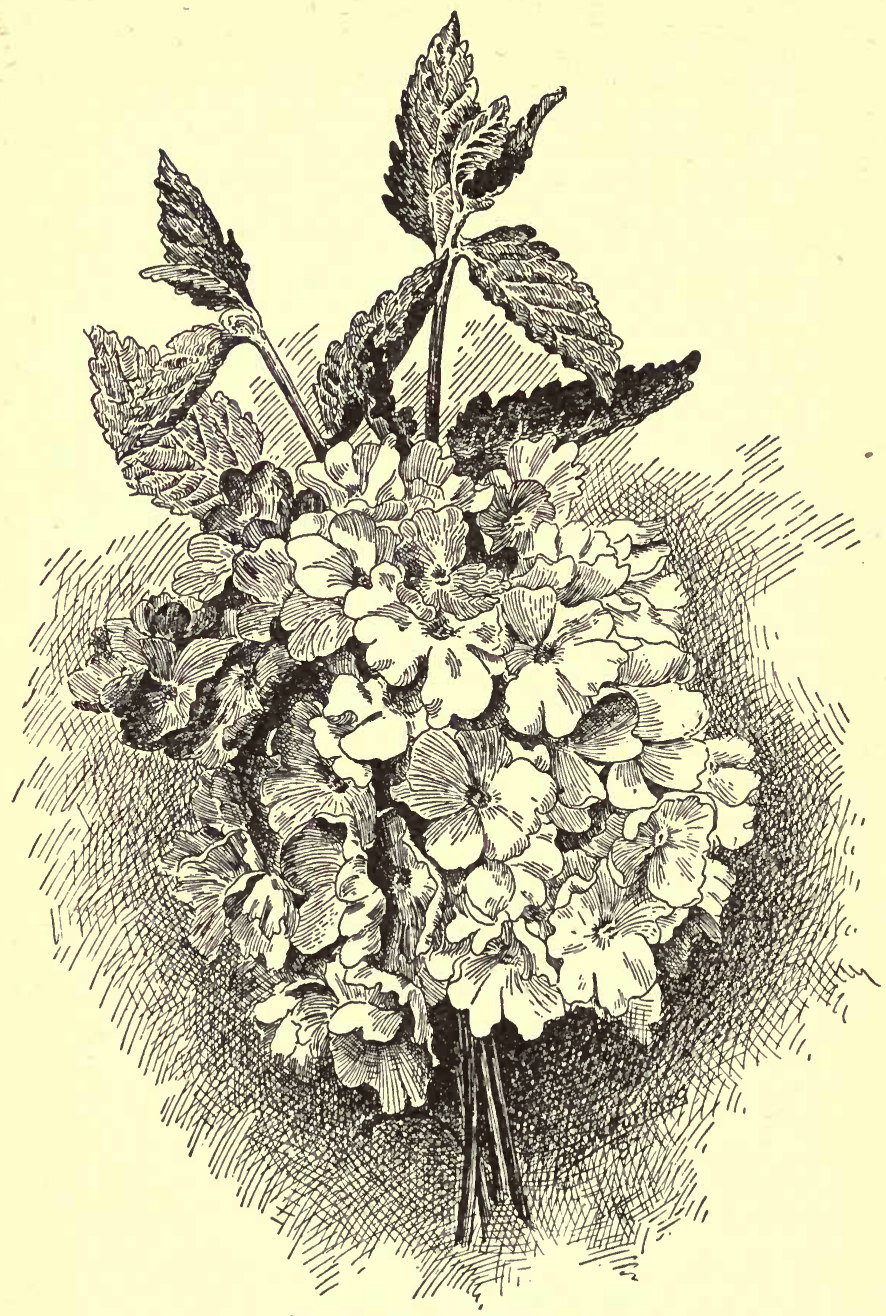

195. Bouquet of verbenas. 
Cardiospermum Halicacabum, Hb. 5 to 10 feet. Has an inflated membranous capsule, and is also known as Balloon Vine. Sow as for Bryonopsis.

Cobcea scandens, T. P. 20 feet. Flowers the first season if sown in March or earlier. Flowers purple. Tendrils. Sow in light, sandy soil, pressing the thin seed down edgewise into the soil. They will then need no further covering. $60^{\circ}$ to $65^{\circ}$ will suit them. Keep the soil barely moist till they are up.

Convolvelus Major, H. 15 feet. Flowering freely. Showy. The new Japanese strain of Mlorning-Glories are much more brilliant in coloring. Twining. Sow as early as pos. sible, in a warm, sunny place, when the soil is suitable.

Dolichos Lablab, T. 10 to 20 feet. Flowers in clusters, purple and white. Sow like the last. Known also as the Hyacinth Bean. Twining.

ECCREMOCARPUS SCABRA, Hh. P. 6 to 10 feet. Flowers tubular, in elusters; orange. Graceful and pretty. If eut down in the fall, and protected with leaves or straw, it will shoot up the following season. Sow early, in a temperature of $60^{\circ}$ to $70^{\circ}$, or in the garden when the soil has become warm.

Humulus Japonicus, T. The Japanese Hop. An excellent, rapid climber. The variety variegatus has leaves blotched with white. Twining. 15 feet. Sow in deep, rich soil, as soon as' dry enough.

IPosca COCcINeA, H. 10 feet or more. Small scarlet flowers. Twining.

I. Quamochit, T. The "Cypress Vine." Delicately dissected green foliage. Flowers rose, white, or scarlet. 10 feet or more. Twining.

I. GRANDiflora, and others, T. The "Moon Flower," Evening Glory." 20 to 30 feet. Flowers large, white, opening in the evening twilight. Twining. The last, to flower, should, if possible, be started in March. A temperature of $65^{\circ}$ or $70^{\circ}$ insures rapid germination. If a small notch is cut through the hard shell, the seeds germinate in four or five days. The other kinds may be started early, or sown in the open ground after danger of frost is past.

Maurandya Barclayana, Hh. P. A delicate and slender elimber. Purple flowers. 6 to 12 feet. There are also rose 
and white-flowered varieties. A leaf climber. Sow in March, in a temperature of $60^{\circ}$.

Sweet Peas, H. 4 feet or more. Flowers pink, scarlet, purple, blue, white and yellow, of various shades; fragrant. Useful for cutting and for low screens. The Sweet Pea has been much improved during the last few years, and has become one of the most popular flowers. It delights in a heavy, though deep and rich, stiff loam. For early spring bloom, sow the seed in the fall, 4 or 5 inches deep, giving them a dry situation. In the spring it is well to make several sowings at intervals, beginning as soon as the frost is out of the ground. The other sowings may be at intervals of two or three weeks till June. A successful method is to sow them in trenches about 6 inches deep, covering them, at first, with only one inch of soil. As the plants grow the trench is filled up, an inch at a time, till full. When the trench is about full they should be copiously watered. Provide a support trellis of cords. Brush, as for common peas, also answers. The more the flowers are cut and used, the better it is for the plants. Keeping the pods picked off, as they begin to grow, will prolong and promote flowering. A little bone-meal worked into the surface of the soil, among the plants, also has a good effect. Varieties of the Sweet Pea have become very numerous, and the list changes from year to year. (See writings of Hutchins, and Cornell Bulletins 111 and 127.)

Tropalolum MaJUs, Hh. Well known, commonly under the name of Nasturtiums. Flowers buff, pink, orange and scarlet. 10 or 12 feet. $T$. peregrinum is the "Canary Bird Flower," and is of more delicate appearance than the ordinary kinds. Flowers pale yellow, fringed. Leaves palmately lobed. Leaf climbers. Sow the Tropæolums, especially $T$. peregrinum, if possible, in March, in a temperature of $55^{\circ}$ to $60^{\circ}$. They may also be sown in the garden where they are to grow, when it is safe. Give them rich, ligint soil. 


\section{Bulbous and Tuberous Plants}

THE FALL-PLANTED BULBS

All kinds of bulbs are partial to a deep, reh, welldrained soil. This is no small part of their successful culture. The site selected should be well-drained, either naturally or artificially. Again, in flattish lands, the beds may be made above the surface, some 18 inches high, and bordered with grass. A layer of rough stones a foot deep is sometimes used in the bottom of ordinary beds for drainage, and with good results, where other methods are not convenient. The soil for beds should be well enriched with old manure. Fresh manure should never be used in the soil about bulbs. The addition of leaf-mold and some sand also improves the texture of heavy soils. For Lilies the leaf-mold may be omitted. Let the spading be at least a foot deep. Eighteen inches will be none too deep for Lilies.

The bulbs should be ordered some time in advance, if possible, and are to be planted from September to the middle of November. All kinds of bulbs look best planted in masses, or at least in groups. Details as to the time, depth and distance apart will be found under the sereral kinds mentioned below.

During planting or previously, the surface of the beds should be made somewhat rounding, to prevent water standing on them in winter, which is always likely to work damage. A layer of sand below the surface, or a generous handful about each bulb, will also materially assist in carrying away water from the bulbs.

As the time of severe winter freezing approaches, the ground planted to bulbs should receive a mulch of leaves, manure, or litter, to the depth of four inches or more, according to the latitude. It will be well to let the mulch extend one foot or more beyond the border of 
the beds. When cold weather is past, half of the mulch should be removed. The remainder may be left on till there is no longer danger of frost. Upon removing the last of the muleh, lightly work over the surface of the soil among the bulbs with a thrust-hoe. If the weather happens to be very bright during the blooming season, the duration of the flowers may be prolonged by light shading-as with muslin, or slats placed above the beds. If planted where they have partial shade from surrounding trees or shrubbery, the beds will not need attention of this kind.

Lilies, and other flowers which will be mentioned below, may remain undisturbed for years. Others will be greatly benefited, and afford more satisfactory results, if taken up and replanted every two or three years. Crocuses and Tulips may stand two years, but Hyacinths should be taken up each year and replanted, as will be explained. Tulips also will be better for the same treatment.

Bulbs which are to be taken up, or removed in the spring, should be left in the ground after flowering, till the foliage turns yellow, or dies down naturally. This gives the bulbs a chance to ripen. Cutting off the foliage and digging too early is a not uncommon and serious mistake. Bulbs which have been planted in the border, or in beds, and which are wanted for summer bedding-plants, may be dug with the foliage on and "heeled-in" under a tree, or along a fence, to stand till ripened. The foliage should be injured as little as possi'ble, as the foliage of this year makes the flowers of the next. When the foliage has turned yellow or died down, the bulbs-after cleaning, and curing them for a few hours in the sun-may be stored in the cellar or other cool, dry place, to await fall planting.

Following are the ehief kinds of bulbs for setting in the fall: 
Hracinths. The bulbs of Hyacinths may be planted from October till freezing weather. Set them from 4 to 5 inches deep-a little shallower in heavy soils-and about 4 to 6 inches apart. They are not quite hardy at the North unless protected, so should always have a winter mulch where the ground freezes hard in winter. Hyacinth bulbs are all imported. Over 200 varieties are extensively grown, but many of the varieties are very similar. Most any of the single sorts are readily forced. Generally speaking, the singles are preferable. For bedding purposes, medium or small-sized bulbs are preferable and cheaper.

Tulips. September is the best time for planting these, but as the beds are usually occupied at this time, planting will have to be postponed till October or November. For garden culture the Single Early Tulips are the best. There are Early Double-flowered varieties also. Some prefer the double, as their flowers last longer. Late Tulips are gorgeous, but occupy the beds too long in the spring. Tulips are quite hardy, but are benefited by the winter mulch.

For simple designs in colors, they are the most brilliant in effect of all bulbs. In working out such patterns, the utmost care should be used to have the lines and curves uniform, which is only to be secured by marking out the design, and eareful planting. Formal planting is, however, by no means necessary for pleasing effects. Borders, lines and masses of single colors, or groups of mixed colors which harmonize, are always in order and pleasing. Clear colors are preferable to neutral tints. As varieties vary in height and season of blooming, only named varieties should be ordered.

Crosus. The Crocus is useful as a border-plant for other beds, for small groups, or beds to itself. It loves a sunny situa. tion and a well-drained soil. Two kinds are commonly cultivated. One is the Autumn Crocus (C. sativus). The other is the spring-flowering (C. versicolor). The latter is the more popular. The bulbs should be planted as early as possible, and not later than the first of October, if it can be aroided. They grow if kept out of the ground, and will, therefore, suffer when planted late. It is advisable to get the best corms, and those under name.

Narcissus. Daffodils, Jonquils and the Poet's Narcissus, all 


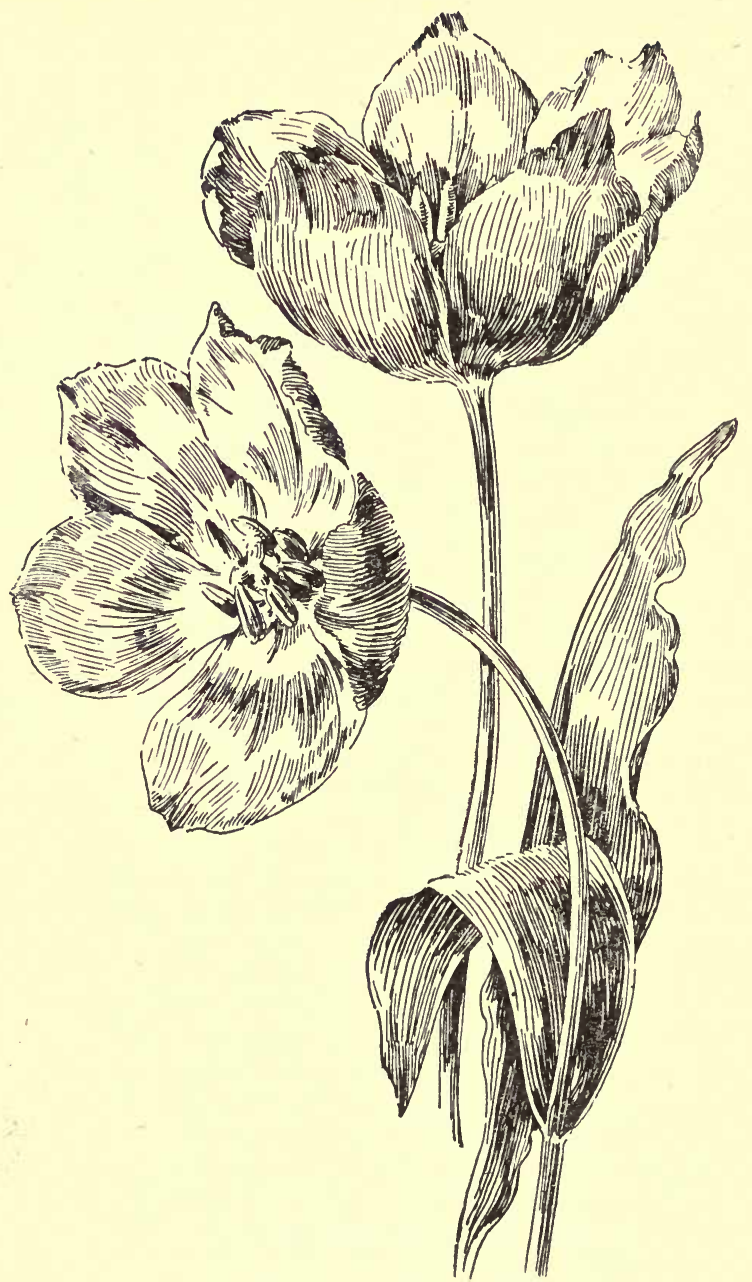

196. Tulips, the warmest of spring flowers. 
are perfectly hardy. The polyanthus section, however, which includes the Paper-white Narcissus, and Sacred Lily or Chinese Joss-Flower, are not hardy except with unusually good protection, and are, therefore, most suitable for growing indoors. It is common to allow the hardy sorts to take care of themselves when once planted. This they will do, but much more satisfactory results will be had by lifting and dividing the clumps every three or four years. A single bulb in a few years forms a large clump. In this condition the bulbs are not properly nourished, and consequently do not flower well. Lifting is preferably done in August or September, when the foliage has died down and the bulbs are ripe.

These flowers are well suited to partially shaded places, and will grow and please wherever good taste may place them. They should be freely used, as they are fragrant, bright of color, and easily managed-growing among shrubbery, trees, and in places where other flowers would refuse to grow. They should be planted in clumps or masses, in September or October, setting the bulbs from 5 to 8 inches apart, according to size, and 3 or 4 inches deep. If necessary to move them in the spring, follow the instructions previously mentioned under Bulbs. Several species and numberless varieties, both double and single, are grown. A few good types only can be mentioned.

Daffodils, or Trumpet Narcissus.

Single-flowered, Yellow.-Golden Spur, Trumpet Major.

White.-Albicans.

White and Yellow.-Empress, Horsefieldi.

Double-flowering, Yellow.-Incomparable fl. pl., Von Sion.

White.-Alba plena odorata.

Poet's Narcissus, or Daffodil. Flcwers white, with yellow cups edged crimson. Very fragrant.

JoNQuils. These have very fragrant yellow flowers, both double and single, and are old garden favorites.

Polyanthus Narcissus. These will be mentioned under the chapter on window gardening.

SNow-Drop (Galanthus nivalis). These are well known. The snow is scarcely gone before they appear. When once planted, they may remain for years. Plant thick, in 
groups or masses in the border, or scatter them about the lawns. September or October is the proper season.

Chionodoxa. Spikes of intense blue flowers, coming with Snow-drops, and lasting a long time in perfection. Plant them like Snow-drops, as early in the fall as the bulbs can be obtained.

Scllla (Scilla Sibirica). Also known as the Star Hyacinth. Flowers blue, coming early, like the last. They may be used like Snow-drops. The bulbs should be planted 2 inches deep, in October, to remain undisturbed thereafter.

Winter Aconite (Eranthis hyemalis). Bright yellow blossoms, appearing even before the Snow-drops, and continuing in flower for several weeks. Perfectly hardy, growing about 3 inches high. Plant them as soon as obtained. They require little attention after once planting. All of the last four genera will grow in any garden soil.

Lily-OF-THe-VAlley (Convalluria). These are of the easiest culture, and no garden is complete without them. All that is necessary is some shade and a good loamy or sandy soil. The pips may be planted any time from November on.

LiLies. If good drainage is provided, Lilies will grow in any ordinary, fairly rich soil. The instructions previously given may be followed, but it is not necessary to make the soil as light as is sometimes done. Deep working, however, is always desirable; 18 inches, or even 2 feet, will be none too deep. A layer of sand, or a handful placed about each bulb, is excellent practice. For all Lilies it is safer to provide good winter protection in the form of a mulch of leaves or manure, and extending beyond the borders of the planting. Thls should be from 5 inches to a foot deep, according to the latitude or locality.

Where Lilies are to be moved from one part of the grounds to another, it may be done carefully in the spring after growth has started. They should be guarded against becoming dry, and replanted as quickly as possible. Most of the Lilies like partial shade. Planting them where they will be shaded from the hot noon-day sun by shrubbery, trees, or buildings, not only tends to improve the flowers, but helps to make the soil more comfortable for the bulbs during the summer. The well- 
known $L$. candidum is an exception, preferring an open situation. Plant the bulbs of Lilies in October or November, excepting $L$. candidum and $L$. excelsum. $L$. auratum should be set 10 or 12 inches deep; the others from 4 to 6 . Some of the best kinds are mentioned below:

L. CAndidum (Annunciation Lily). White. 3 to 4 feet high. It makes an autumn growth, and should, therefore, be planted in August. Set the bulbs from 4 to 6 inches deep.

L. SPEcIosum ( $L$. lancifolium), var. PRAcox. White, tinged with pink; bearing several flowers on a stem about 3 feet high.

L. SPEciosur var. RUBRLir. Rose color, spotted with red.

L. Brownil. Flowers white inside, chocolate-colored outside. The stems grow about 3 feet high, bearing from 2 to 4 tubular flowers. Not difficult to manage with good protection and drainage. The bulbs are impatient of being long kept out of the ground. After planting, they should not be disturbed as long as they flower well.

L. Haxsoni. Dark yellow. Stems 3-4 feet high; each producing from 6 to 12 flowers.

L. excelsuy ( $L$. Isabellinum). Rich buff color, with delicate spots. Plants about 3-5 feet high, with from 3 to a dozen flowers on a stem. Plant the bulbs in September.

L. LONGIFlonum. White. Large tubular flowers, 2 to 8 on a stem. Height about $2 \frac{1}{2}$ feet.

L. Batemanx:e. Apricot yellow. Six to 12 flowers on stems 3-4 feet high.

L. Auratum (Japanese Gold-banded Lily). Immense white flowers banded with yellow and dotted with red or purple, from 3 to 12 on a stem. Height. 3-4 feet. The bulbs need thorough protection, good drainage, and should be planted 10 or 12 inches deep.

L. Leichtinil. Flowers clear yellow, with small, dark spots, 10 to 12 on a stem. Height, 4 feet.

L. MONADELPHUM. Yellow tubular-shaped flowers in clusters of 6 to a dozen or more. Stems $2 \frac{1}{2}$ feet tall.

L. elegans ( $L$. Thunbergianum), var. Alice Wilson. Lemonyellow. Stems 2 feet high, bearing from 2 to 8 flowers.

L. elegans, vitr. fulgens atrosanguineum. Dark crimson. Height 1 foot. 


\section{SUMMER BULBS AND TUBERS}

Gladiolus. Of summer and fall-blooming bulbous plants these are, perhaps, the most widely popular. The showy kinds cultivated are, with rare exceptions, hybrids or their descendants. The colors range from scarlet and purple, to white, rose, and pure yellow. The plants are of slender, erect habit, growing from 2 to 3 feet high. They dislike a heavy clay soil. A light loam or sandy soil suits them best. They should have a new place every year, if possible, and always an open sunny situation.

The corms may be planted 2 inches deep in heavy soils, and 4 in light soils. For a succession, they may be planted at short intervals, the earliest planting being of smaller corms in the early spring as soon as the soil is dry enough to work; later the larger are to be planted-the last setting being not later than the Fourth of July. This last planting will afford fine late flowers.

The successive plantings may be in the same bed among those set earlier, or they may be grouped in unoccupied nooks, or portions of the border. The plants may stand as close as 6 inches from each other. The earlier planting may be-say a foot apart to admit of later settings between.

Late in the fall, after frosts, the corms are to be dug, cleaned, and dried in the sun and air for a few hours and then stored away in boxes about $2 \frac{1}{2}$ inches deep in a cool, dark and dry place.

The varieties are perpetuated and multipled by the little corms which appear about the base of the large new corm which is formed each year. These small corms may be taken off in the spring and sown thickly in drills. Many of them will make flowering plants by the second season. They are treated like the large corms in the fall.

Gladioli are easily grown from seed also, but this method can not be depended on to perpetuate desirable varieties, which can only be reproduced by the cormels. Some of the best flowers may be cross-pollinated, or allowed to form seed in the usual manner-the seed sown thickly in drills, and shaded till the plantlets appear, then carefully cultivated, will afford a 
crop of small corms in the fall. These may be stored for the winter, like the other young corms, and, like them, many will flower the second season, affording a great variety, and quite likely some new and striking kinds. Those which do not flower should be reserved for further trial. They often prove finer than those first to flower.

Gladiolus Childsil is the name under which is being sent out a set of tall-growing varieties with very large flowers. Of their merits the writer is not as yet prepared to speak personally. The Lemoine and Leichtlinii hybrids are interesting and show some handsome forms, but on the whole are, perhaps, not as desirable for general purposes as some other varieties.

DaHLia. Of showy plants for the garden, there are none more easily cultivated. The double or Show Dahlias require only plenty of food and moisture, while the single and other kinds, the writer has found, will grow and flourish in almost any soil, and under any of the conditions ordinarily met with in the garden.

The various sorts may be grouped into five classes. The Show Dahlia is the large familiar double-flowered type. The Pompon or Bouquet Dahlias have smaller double flowers, and dwarfer habit. The Cactus Dahlia has flowers with broad, flat florets, which are somewhat twisted, giving them a characteristic and striking appearance. It is a recent type. The Single Dahlias have handsome single flowers of many brilliant colors and styles of variegation. The Dwarf, or Bedding elass, is mainly single, and grows only 1 or 2 feet high. They are very free of bloom and desirable for the purpose indicated by their name.

One objection to the old Dahlia was its lateness of bloom. But by starting the roots early in a frame, or in boxes which are corered up at night, the plants may be had in flower, several weeks earlier than usual. They may be started in April, or at least three weeks in advance of planting time. Before, or shurtly after starting the roots, they should be divided with a stout knife so that a piece of old stem, with a bud, will be attached to each tuber. These are then set in the box in the moist earth. Little water will be required till they start. When they begin shooting up, the plants 
should have the full sun, and air, on all mild days. They will then make a slow, sturdy growth. All forcing should be avoided. These plants, set out when there is no longer

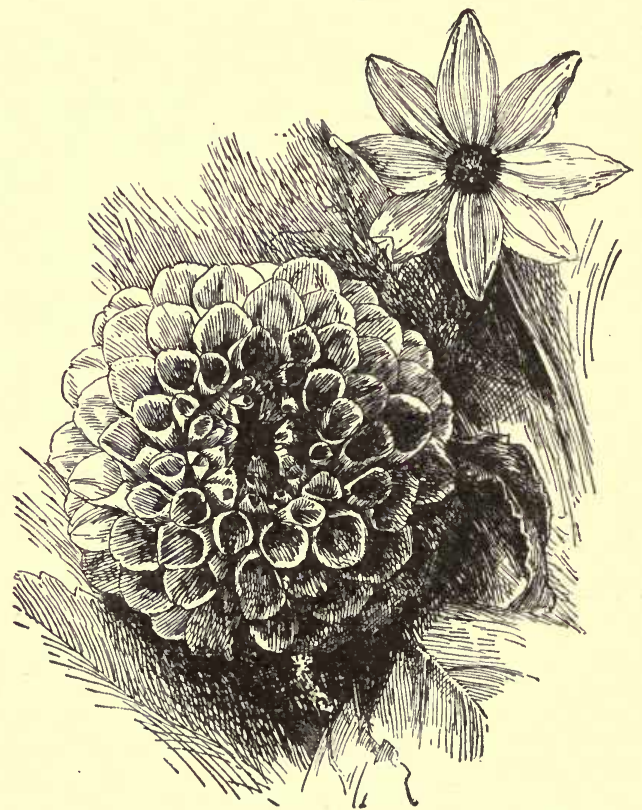

197. A modern dahlia and its ancestor. Each half size.

danger of frost, and well watered before completely covering the roots, will grow right on, and often commence blooming in July.

Dormant roots may be set out in May. The roots, unless small, should be divided before planting, as a single strong root is usually better than a whole clump. The roots of all but the Dwarf should be set about 3 feet apart, in rows. In poor soils none but the first class will need stakes. All but these the writer prefers to grow in rather poor soil, and 
not water unless absolutely necessary. They then have a dwarfer habit, and if the flowers are not so large, the plants begin to bloom soon and flower profusely. For the finest flowers, however, with any of the Dahlias, a rich and deep soil, with good cultivation and artificial watering during the summer, are the requisites. Staking will also be necessary.

The roots may be left in the ground till the approach of freezing weather, and for a week after the tops have been cut hy the frost. When lug they should be left out, exposed to the sun and air for a couple of days to dry, covering them at night if the weather is frosty. The dry soil having been shaken off, the roots may be stored away in a dry, cool llace. Any place that would answer for potatoes will keep I) allia roots.

In addition to multiplication by division, as previously mentioned, Dahlias are also easily propagated by seeds, and cuttings of the tender shoots. The latter should always be cut just below a joint, so that there will be a pair of buds near the lower end of the cutting. For further information anil varieties, consult Peacock on "The Dahlia", and Cornell Bulletin 128.

'Trberose. This plant, with its tall spikes of waxen and fragrant white flowers, is well known. It is a strong feeder, and loves warmth, plenty of water while growing, and a deep, rich and well-drained soil.

The bulbs may be set out in the garden or border the last of May or in June, covering them about one inch deep. Preparatory to planting, the old, dead roots at the base of the bulb should be cut away and the pips or young bulbs about the sides jemoved. After keeping them till their scars are dried over, these pips may be planted 5 or 6 inches apart in drills. With good soil and eultivation they will make blooming bulbs for the following year.

Before planting the large bulbs, it may be well to examine the points, to determine whether they are likely to bloom. The tuberose blooms but once. If there is a hard, woody piece of old stem in the midst of the dry scales at the apex of the bulb, $i$ ic has bloomed, and is of no value except for producing pips. Likewise if, instead of a solid core, there is a brownish, dry cavity extending from the tip down into the middle of the bulb, 
the heart has rotted or dried up, and the bulb is worthless as far as blooming is concerned.

Bulbs of blooming size set in the border in June flower toward the close of September. They may be made to flower three or four weeks sooner by starting them early in some warm place, where they may be given a temperature of about $60^{\circ}$ to $70^{\circ}$. Prepare the bulbs as above, and place them with their tips just above the surface in about 3 or 4 -inch pots, in light, sandy soil. Water them thoroughly, afterwards sparingly, till the leaves have made considerable growth. These plants may be turned out into the open ground the last of May or in June, and will probably flower in early September.

Just before frost dig up the bulbs, cut off the tops to within 2 inches of the apex of the bulb. They may then be placed in shallow boxes and left out in the sun and air for a week or more, to cure. Each evening, if the nights are cold, they should be removed to some room where the temperature will not fall below $40^{\circ}$. When the outer scales have become dry, the remaining soil may be shaken off and the bulbs stored away in shallow boxes for the winter. They keep best in a temperature of $45^{\circ}$ to $50^{\circ}$. It should never fall below $40^{\circ}$.

The Dwarf Pearl, originating in 1870, has long been popular, and is still so with many. But others, the writer included, have come to prefer the old, tall kind, the flowers of which, even if not so large, are perfect in form and seem to open better.

\section{Hardy Herbaceous Perennials}

The delights of the herbaceous border have already been laid before the reader. See pages 145-147, 217220 , but details may be useful.

Perennial herbs are propagated in various ways, - by seeds, and by cuttings of the stems and roots, but mostly by the easy method of division. The seed must often be sown as soon as ripe, as it is slow of germination; and it often takes from 2 to 4 years to grow blooming plants in this way.

To facilitate making a selection, the plants in the following list are arranged according to their blooming sea- 
son, beginning with the earliest. The name of the month indicates when they usually commence to bloom. In most eases both the scientific* and popular names are given; then follows the height; next the flowering season; and lastly, the color of the flowers, and other items. The descriptions are necessarily brief. It should be understood that the blooming season of plants is not a fixed period, but varies more or less with localities and seasons. These dates are applicable to most of the middle and northern states.

\section{LIST OF HARDY BORDER PLANTS}

\section{MARCH}

Anemone blanda (Blue Wind-flower), 6 in. March-May. Skyblue star-like flowers. Foliage deeply cut. For border and rockwork.

Sanguinaria Canadensis (Bloodroot). 6 in. March-April. Pure white. Glaucous foliage. Partial shade. Border or rockwork.

APRIL

Arabis albida (Mountain Rock-cress). 6 in. April-June. Flowers pure white; close heads in profusion. Fragrant. For dry places and rock-work.

Aubrietia deltoidea (Purple Rock-cress). 6 in. April-June. Small purple flowers in great profusion.

Bellis perennis (Daisy). 4-6 in. April-July. Flowers white, pink or red; single or double. The double varieties are the more desirable. Cover the plants in winter with leaves. May be raised from seed, like pansies.

Claytonia Virginica (Spring Beauty). 6 in. April-May. Clusters of light pink flowers. Partial shade. From six to a dozen should be set together.

*The scientific or botanical names are given only for the purpose of enabling the reader to find the plants in eatalogues and books, not for the purpose of expressing any opinion as to the proper nomenclature of the plants. 
Dodecatheon Meadia (Shooting Star). 1 ft. April-May. Rerldish purple flowers, orange-yellow eye, in clusters. Cool, shady location. Plant several in a place.

Doronicum plantagineum var. excelsum (Dog's-bane.) 20 in. April-June. Large, showy flowers; orange-yellow, Bushy plants.

Hepatica acutiloba (Liver Leaf), 6 in. April-May. Flowers small but numerous, varying white and pink. Partial shade. Iberis sempervirens (Hardy Candytuft). 10 in. April-May. Small white flowers in clusters; profuse. Large, spreading evergreen tufts.

Lychnis alpina (Alpine Lamp-flower). 6 in. April-May. Flowers star-like, in showy heads; pink. For border and rockery.

Myosotis dissitiflora (Eariy Forget-me-not). 6 in. April-June. Small clusters of deep sky-blue flowers. Tufted habit.

M. palustris var. semperflorens (Everblooming F.). $10 \mathrm{in.}$ Light blue; spreading habit.

Mertensia Virginica (Blue Bells). $1 \mathrm{ft}$. April-May. Flowers blue, changing to pink; pendent; tubular; not showy, but beautiful. Rich soil. .Partial shade.

Pronia Moutan (Tree Paeony). See May, Pæonia.

Phlox subulata (Moss Pink). 6 in. April-June. Numerous deep-pink, small flowers; creeping habit; evergreen. Suitable for dry places as a covering plant.

Trilliums. Of several species; are always attractive and useful in the border. (Fig. 198.) They are common in rich woods and copses. Dig the tubers in late summer and plant them directly in the border. The large ones will bloon the following spring. The same may be said of the erythronium, or dog's-tooth violet or adder's-tongue (Fig. i99), and of very many other early wild flowers.

\section{MAY}

Ajuga reptans. 6 in. May-June. Spikes of purple flowers. Grows well in shady places; spreading. A good cover plant.

Alyssum saxatile var. compactum (Madwort). $1 \mathrm{ft}$. MayJune. Flowers fragrant; in elusters; clear golden-yellow. 


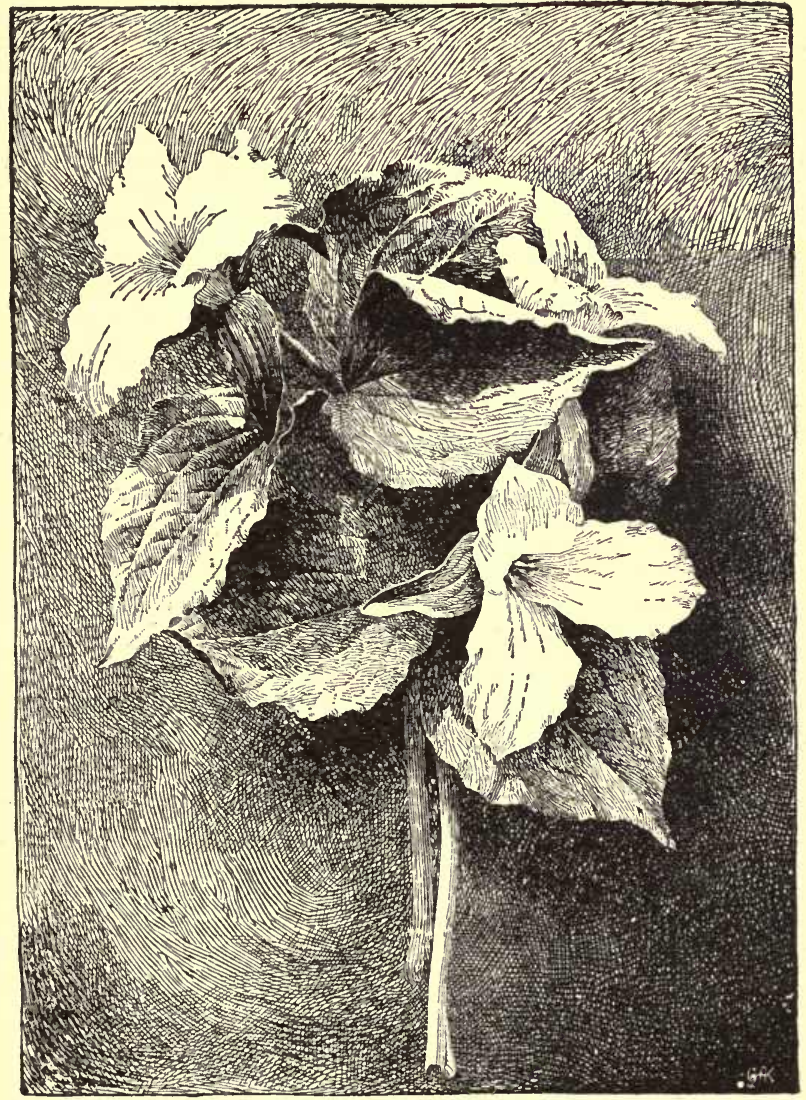

198. The wild Trillium grandiflorum. 


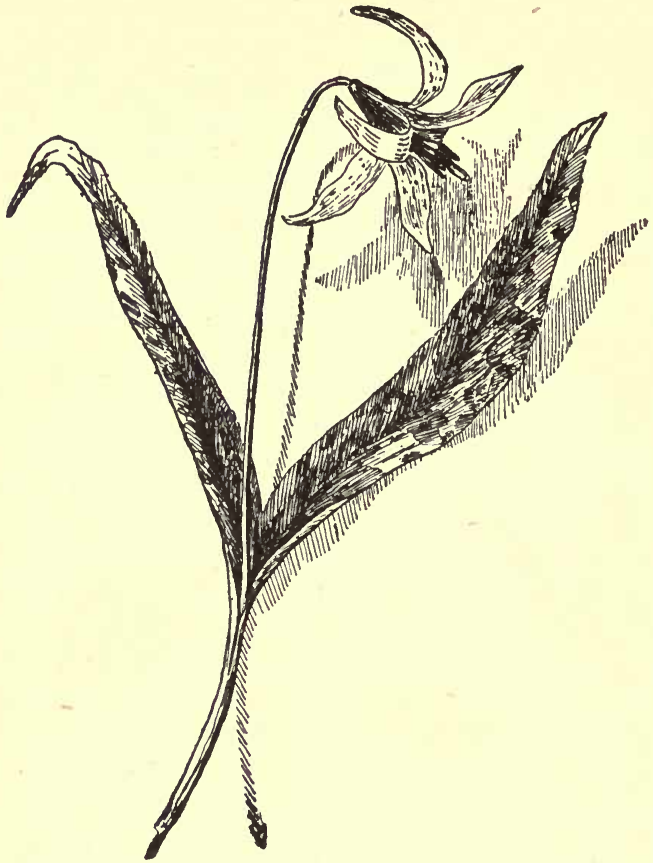

199. Erythronium Americanum, half size.

Foliage silvery. Well-drained soil. One of the best yellow flowers.

Aquilegia glandulosa and others (Columbine). Fig. 200. 1 foot. May-June. Deep-blue sepals; white petals. Aquilegias are old favorites. (See June.)

Convallaria majalis (Lily-of-the-Valley). 8 in. May-June.

Racemes of small white bells; fragrant. Well-known. Partial shade. (See page 272.)

Corydalis nobilis (Fumitory). 1 ft. May-June. Large clusters of fine yellow flowers. Bushy, upright habit. Does well in partial shade. 
Dicentra spectabilis (Bleeding-Heart). $2 \frac{1}{2} \mathrm{ft}$. May-June. Well known. Racemes of heart-shaped, deep-pink and white flowers. Will bear partial shade.

Iris cristata (Crested Iris). 6 in. May-June. Flowers blue, fringed with yellow. Leaves sword-shaped.

I. Germanica (German Iris). 12-15 in. May-June. Numerous varieties and colors. Large flowers, $3-4$ on a stem. Broad, glaucous, sword-shaped leaves.

Preonia officinalis (Pæonia). $2 \mathrm{ft}$. May-June. This is the well-known Herbaceous Pæonia. There are numerous varieties and hybrids. Large flowers, 4-6 inches across. Crimson, White, Pink, Yellow, etc. Suitable for lawn or the border.

P. Moutan (Tree Pæonia). 4 ft. April-May. Numerous named varieties. Flowers as above, excepting yellow. Branched, dense, shrubby habit.

Salvia pratense (Meadow Sage). $2 \frac{1}{2} \mathrm{ft}$. May-June, August. Spikes of deep blue flowers. Branching from the ground. Achillea Ptarmica, $f$. $p l$., var. "The Pearl." 1-2 ft. JuneAugust. Small, double white flowers, in few-flowered clusters. Rich soil.

\section{JUNE}

Anemone Pennsylvanica (Wind-flower). 18 in. June-September. White flowers on long stems. Erect habit. Does well in the shade.

Anthericum liliastrum (St. Bruno's Lily), 18 in. June-July. Bell-like, white flowers in handsome spikes.

Aquilegia chrysantha (Golden-spurred Columbine). $3 \mathrm{ft}$. June-August. Golden flowers with slender spurs; fragrant. A. cærulea (Rocky Mountain Columbine). $1 \mathrm{ft}$. June-August. Flowers with white petals and deep-blue sepals, 2-3 inches in diameter. (See May.)

Asperula odorata (Woodruff). 6 in. June-July. Small white flowers. Herbage fragrant when wilted. Does well in shade; spreading habit. Used for flavoring drinks, scenting and protecting garments.

Astilbe Japonica (Incorrectly called Spiræa). $2 \mathrm{ft}$. JuneJuly. Small white flowers in a feathery inflorescence. Compact habit. 


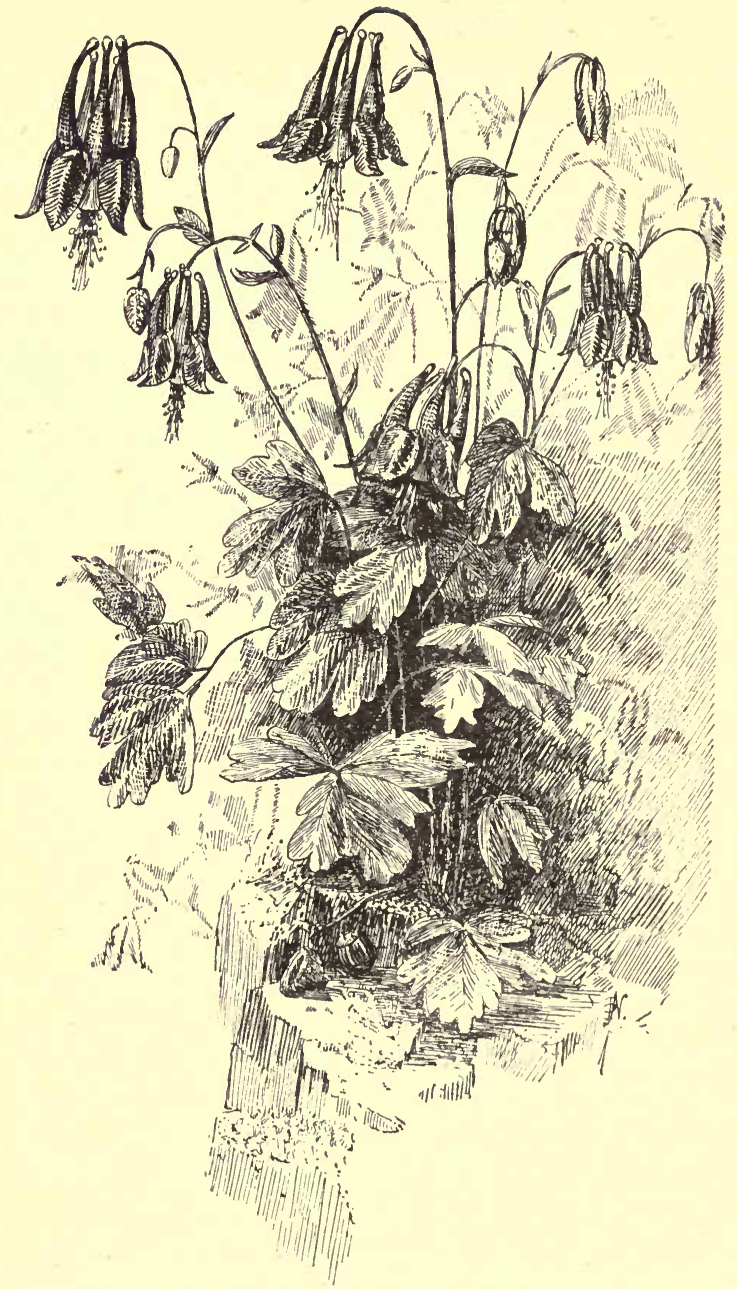

200. Common wild columbine. Handsome in cultivation. 


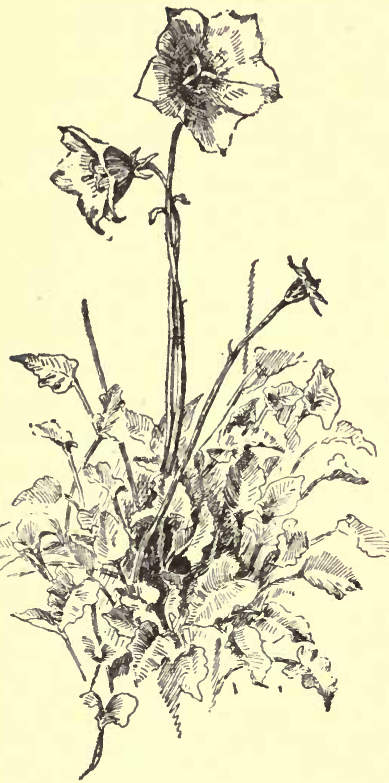

201. Campanula Carpatbica.

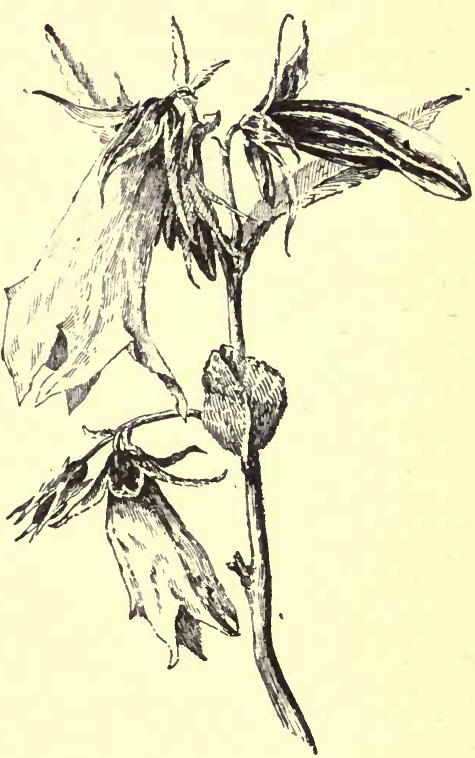

202. A Campanula.

Callirhö̈ involucrata (Poppy Mallow). 10 in. June to October. Large crimson flowers, with white centers. Trailing habit. For border and rockery.

Campanula Carpathica (Carpathian Harebell). Fig. 201. 8 in.

June-September. Flowers deep blue. Tufted habit. For border or rockery. Good for cutting.

C. glomerata var. Dahurica. $2 \mathrm{ft}$. June-August. Deep purple flowers in terminal clusters. Branching from the ground. Erect habit.

C. Medium (Canterbury Bell). Is an old favorite. It is biennial, but blooms the first season if sown early.

Coryclalis lutea. $1 \mathrm{ft}$. June-September. Flowers yellow, in terminal clusters. Loose branching habit. Glaucous foliagre. 
Dianthus plumarius (Scoteh Pink), 10 in. June-July. White and pink-ringed flowers on slender stems. Densely tufted habit.

D. superbus (Fringed Pink), 18 in. July-August. Fringed flowers. Lilac tint.

Dictamnus Fraxinella (Gas Plant). $3 \mathrm{ft}$. June. Flowers purple, showy, fragrant; in long spikes. Regular habit.

D.- var. alba. White.

Gaillardia aristata. $2 \mathrm{ft}$. June-October. Showy orange and maroon flowers on long stems. Good for cutting. Hybrid gaillardias offer quite a variety of brilliant colors.

Heuchera sanguinea. 18 in. June-September. Flowers in open panicles; scarlet, on clustered stems from a tufted mass of pretty foliage.

Iris Kampferi (Japan Iris). 2-3 ft. June-July. Large flowers of various colors, in variety. Green sword-like leaves. Dense tufted habit. Prefers a moist situation.

Liatris spicata (Blazing Star). $2 \mathrm{ft}$. June-August. Spikes of fine, small purple flowers. Slender foliage. Unbranched, erect stems. Will grow in the poorest soil.

Papaver nudicaule (Iceland Poppy). $1 \mathrm{ft}$. June-October. Bright yellow flowers. A close, dense habit. Erect, naked stems. The varieties Album, white, and Miniatum, last deep orange, are also desirable.

$P$. orientale (Oriental Poppy). $2-4 \mathrm{ft}$. June. Flowers 6-8 in. across; deep scarlet, with a purple spot at the base of each petal. There are other varieties of pink, orange and crimson shades.

Pentstemon barbatus var. Torreyi. 3-4 ft. June-September. Crimson flowers in long spikes. Branching from the base. Erect habit.

Phlox paniculata (Perennial Phlox), 2-3 ft. June. A great variety of colors in selfs and variegated forms. Flowers borne in large, flat panicles,

Rudbeckia maxima. 5-6 ft. August. Large flowers; cone-like center and long, drooping yellow petals.

Spircea Filipendula (Dropwort). $3 \mathrm{ft}$. June-July. White flowers in compact clusters. Tufted foliage, dark green and handsomely cut. Erect stems.

Yucca filamentosa (Adam's Needle). 4-5 ft. June-July. 
Waxen white, pendulous, liliaceous flowers in a great thyrsus. Leaves long, narrow, dark-green, with marginal filaments. For the lawn, and for massing in large grounds.

\section{JULY}

Althac rosea (Hollyhock). 5-8 ft. Summer and fall. Flowers white, crimson, and yellow, lavender and purple. Stately plants of spire-like habit; useful for the back of the border, or beds and groups. The newer double varieties have flowers as fine as a camellia. The plant is a biennial, but in rich, well-drained soil and with some winter protection it becomes perennial. Easily grown from seed, blooming the second year. Seeds may be sown in August in frames and carried over winter in the same place. The first year's bloom is usually the best.

Anthemis tinctoria (Yellow Chamomile). 12-18 in. July-November. Flowers bright yellow, 1-2 inches in diameter. Useful for cutting. Dense, bushy habit.

Delphinium Chinense. $3 \mathrm{ft}$. July-September. Variable colors; from deep blue to lavender and white. Fine for the border.

D. formosum. $4 \mathrm{ft}$. July-September. Fine spikes of rich blue flowers. One of the finest blue flowers cultivated.

Funkia lancifolia. (See under August.)

Helianthus multiflorus var. $f$. $p l .4$ ft. July-September. Large double flowers, of a fine golden color. Erect habit. A splendid flower.

Lychnis Viscaria var. flore pleno. 12-15 in. July-August. Double, deep, rose-red flowers in spikes. For groups and masses.

Monarda didyma. $2 \mathrm{ft}$. July-October. Showy scarlet flowers in terminal heads.

Pentstemon grandiflorus. $2 \mathrm{ft}$. July-August. Leafy spikes of showy purple flowers.

P. lovigatus var. Digitalis. $3 \mathrm{ft}$. July-August. Pure white flowers in spikes, with purple throats.

Platycodon grandiflora (Campanula grandifiora). $3 \mathrm{ft}$. JulySeptember. Deep blue, bell-shaped flowers. Dense, fine, erect habit.

P. Mariesii. $1 \mathrm{ft}$. July-September. Flowers larger; deep violet-blue. Heavier foliage. 


\section{August}

Funkia subcordata (Day Lily). 18 in. August-October. Trumpet, lily-like, pure white flowers in clusters, borne upon a stalk from the midst of a group of heart-shaped green leaves.

$\boldsymbol{F}$. lancifolia var. alba-marginata. July-August. Lavender flowers. Lance-like leaves margined with white.

Kniphofia aloides, Tritoma uvaria (Flame Flower). $3 \mathrm{ft}$. August-September. Bright orange-scarlet flowers, in close, dense spikes, at the summit of several scape-like stems. Leaves slender, forming a large tuft. For lawn and borders. Hardy only when covered with litter or straw in winter.

Lobelia cardinalis (Cardinal Flower). 21/4-4 ft. August-September. Flowers intense cardinal-red; of unrivaled brilliancy. Tall spikes. Stems clustered; erect. Native.

Pyrethrum uliginosum (Giant Daisy). 3-5 ft. July-October. Flowers white, with golden centers. About 2 in. across. A stout, upright, bushy plant. Useful for cutting.

Rudbeckia triloba, var. "Golden Glow." 6-7 ft. August-September. Large double golden yellow flowers in great profusion. Bushy habit. Cut off when done flowering. Leaves appear at the base and a new crop of flowers, on stems about $1 \mathrm{ft}$. high appear, in October.

Solidago rigida (Golden-Rod). 3-5 ft. August-October. Flowers large for this genus, in close, short racemes in a corymbose-paniculate cluster. Fine, deep yellow. Erect habit. One of the best of the Golden-Rods.

\section{SEPTEMBER}

Anemone Japonica (Japanese Wind-flower). 2 ft. AugustOctober. Flowers large, bright red. One of the best autumn flowers.

A. Juponica, var. alba. Flowers pure white, with yellow ceuters. Fine for cutting.

\section{OCTOBER}

Chrysanthemums. The Chinese and Japanese Chrysanthemums, so well known, are hardy in light, well-drained soils, if 
well protected with litter or leaves during the winter, and in such situations are hardy without protection south of Indianapolis. Chrysanthemums are gross feeders, and should have a rich soil.

There is a race of hardy or border ehrysanthemums which is again coming into favor, and it is sure to give much satisfaction to those who desire flowers in latest fall. These chrysanthemuns are much like the "artemisias" of our mother's gardens, although improved in size, form, and in range of color.

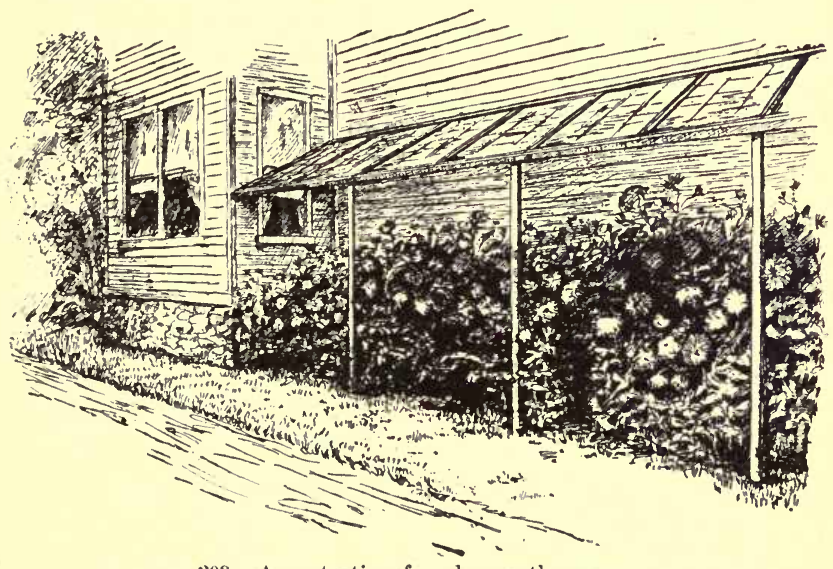

203. A protection for chrysanthemums.

The growing of the florists' chrysanthenums is accomplished only under glass and with the outlay of considerable time and the application of skill; therefore the subject is not germane to this book. Very good plants can be grown under a temporary shed cover, as shown in Fig 203. The roof need not necessarily be of glass. Under such a cover, also, potted plants, in bloom, may be set for protection when the weather becomes too colll. Respecting the cultivation of chrysanthemums, Bailey writes as follows: "The growing of the plants to a single bloom does not produce the most decorative results. It merely gives large specimen blooms. I much prefer to grow from three to six 
blooms on a plant. The plants may be flowered in pots, or in a solid soil bench. Very good small plants may be brought to perfection in 6-inch pots, but the best results, in pot plants, are to be obtained in 8 -inch or 10 -inch pots. If the plants are to be used for decoration, they should, of course, be grown in pots, but the best results for cut-flowers are usually obtained by growing in the earth. In any case, the cuttings are made from the tips of basal or strong lateral shoots, late in February to May. If the plants are to be flowered in pots-in which case they usually mature earlier-the cuttings may be started as late as April, or even June; but if they are grown in the soil and large plants are desired, the cuttings should be taken in February or March. The plants which are flowered in the soil are generally grown in pots until July. The grower must decide how many blooms he desires on a plant, and then train the plant accordingly, bringing up the different branches so that they will all bloom at the same time."

There is a large special literature on chrysanthemums. Current discussions may be found in the journals and in the Cornell bulletins.

\section{HARDY ORNAMENTAL GRASSES}

Arundo Donax (Great Reed Grass). $10 \mathrm{ft}$. Tall, straight stems; deep green. Broad, pointed foliage.

A. Donax var. variegata. Foliage striped with white. Both of these at the North profit by protection with a mulch of litter or manure.

Bambusa Metake (Bamboo, syn. Arundinaria). 4-7 ft. Shrubby, much branched stems. Almost evergreen.

Erianthus Ravennce (Ravenna Grass). 4-7 ft. Forms handsome clumps of foliage.

Eulalia Japonica var. variegata (Japan Eulalia). 4-7 ft. Leaves longitudinally striped with white.

E. Japonica var. zebrina (Zebra Grass). Leaves cross-barred with yellow bands.

Festuca ovina var. glauca (Blue Feseue). 8 in. Foliage glaucous, forming pretty tufts. Useful as an edging.

Panicum virgatum (Tall Prairie Grass). $4 \mathrm{ft}$. Culms slender and wand-like. Very graceful. 
Phalaris arundinacea var. variegata (Striped Ribbon Grass). $2 \frac{1}{2} \mathrm{ft}$. Leaves variegated with bands of white. Stipa pinnata (Feather Grass). 18 in. Graceful slender plumes of silky down. Should have light, rich soil.

\section{\%. Hardy Climbing Plants.}

There is scarcely a garden in which elimbing plants may not be used to advantage. Sometimes it may be to conceal obtrusive objects, again to relieve the monotony of rigid lines. They may also be used to run over the ground and to conceal its nakedness where other plants could not succeed. The shrubby kinds are often useful about the borders of elumps of trees and shrubbery, to slope the foliage down to the grass, and soften or erase lines in the landscape, which is often desirable and necessary for the most pleasing effects. (See pages 213, 214.)

Of herbaceous climbers, the tops die in winter, while those of woody elimbers live on from year to year. Only a few of each class will be mentioned. All climbers should have a rich soil if desired to climb high.

\section{HARDY HERBACEOUS CLIMBERS}

Apios tuberosa. 15-20 ft. July-August. Flowers brownish purple; in large clusters, with violet fragrance. Foliage similar to that of the wistaria. Roots tuberous. Plant 2 or 3 together.

Centrosema Virginiana (Butterfly Pea). 5-6 ft. June-August. Purple and white pea-shaped flowers.

Clematis coccinea (Scarlet Clematis). 5 ft. June-September. Flowers about 1 in. long, scarlet; glaucous foliage, delicate and graceful.

C. Davidiana. 3-4 ft. August-September. Porcelain-blue flowers of tubular outline. Dense bushy habit.

C. tubulosa. $7 \mathrm{ft}$. August-September. About two weeks later than the last; otherwise similar. 
Lathyrus latifolius (Perennial Pea). $6 \mathrm{ft}$. June-October. Flowers rose-color, on many-flowered stems.

L. latifolius var. albus (White P. P.). Flowers pure white, otherwise same as the last. Useful for cutting. Both are fine for trellises, walls, and for covering.

\section{HARDY WOODY CLIMBERS (See, also, page 236)}

Actinidia polygama. $20 \mathrm{ft}$. or more. June. White flowers, with purple centers; in axillary clusters; fragrant. Leaves entire, heavy, dark and glossy. Berries edible. Foliage immune from insects and diseases. For walls, trellises, screens. Very valuable.

Akebia quinata. $20 \mathrm{ft}$. or more. April. Chocolate colored, sweet-scented flowers, in clusters late in April. Leaves five-fingered, stems twining. Fine for verandas.

Ampelopsis bipinnata; properly Cissus stans. 15-20 feet or more. June. Compound cut leaves, dark, of a bluish metallic luster. Upright, scarcely twining. Fine for training on fences, or as a bush.

A. quinquefolia. 30-40 ft. June. Leaves digitate, on long leaf-stalks, turning scarlet in the fall. Climbing by tendrils and rootlets. For walls, rocks, etc.

A. tricuspidata, or Veitchii (Japan and Boston Ivy). $40 \mathrm{ft}$. or more. Leaves varying from trifoliate to simple, ovate on the same plant; on short stalks. Clinging like the list. The most valued climber for walls. Foliage crimson in the fall.

Aristolochia Sipho (Dutchman's Pipe). $30 \mathrm{ft}$. or more. MayJune. Flowers shaped like a Dutch pipe. Leaves large, roundish, heart shaped. Stems twining. Should have rich soil. Arbors and trellises.

Celastrus scandens (Bitter-Sweet). 25-40 ft. June. Leaves pointed; oblong; green. Stems twining. The racemed capsules orange-yellow, exposing the scarlet-coated seeds, which persist in quantity nearly all winter, making the plant an ornamental object. Arbors, trellises, etc.

C. articulatus (Japanese Bitter-Sweet). Fruit hangs long, but plant less desirable than above. 
Clematis. There are two sections of this cultivated in gardens. One is composed of hybrids with large flowers (Fig. 185), the other has small flowers. Of the first section is

C. Jackmanni. Climbs about $15 \mathrm{ft}$. high, and has large darkblue flowers. A continuous bloomer. There are a number of other varieties, double and single, but this is, perhaps, the best of all.

Of the small-flowered section is

C. paniculata. Climbs 10-15 ft.; blooming from July-September. Flowers small, white, fragrant, star-shaped; borne in masses and in great profusion. Fine for trellises and for covering banks. The best of the small-flowered sorts.

Lonicera Halliana (Hall's Honeysuckle). 10-20 ft. JuneOctober. Flowers white and buff; fragrant; mainly in spring and fall. Leaves small; evergreen. Stems prostrate and rooting, or twining and climbing. Trellises, etc., or for covering rocks and bave places. (Fig. 179.)

L. flexuosa var. aurea reticulata (Golden Variegated Honeysuckle). 12-15 ft. January-July. Similar to the last; but with handsome golden appearance.

L. Periclymenum var. Belgicum (Belgian Honeysuckle). 6-10 ft. Monthly. Flowers in clusters; rosy red, buff within. Makes a large, rounded bush.

L. sempervirens (Coral Honeysuckle). 6-15 ft. June. Scattering flowers through the summer. With no support makes a large rounded bush. For trellises, fences, or a hedge.

Lycium Chinense (Matrimony Vine). 10-20 ft. or more. Flowering all summer. Flowers rose-pink and buff; axillary, star-like; succeeded by scarlet berries in the fall. Stems prostrate, or climbing. Veraudas, etc., dry banks and rockwork.

Periploca graca (Silk Vine). 30-40 ft. June or July. Purplish flowers in axillary clusters. Long, narrow, shining leaves. Rapid growing. For arbors and walls.

Tecoma radicans (Trumpet Creeper). $30-40 \mathrm{ft}$. June-August. Flowers large; trumpet-shaped; orange scarlet; in clusters. Leaves pinnate; dark green. Climbing by aëreal rootlets. Fine for old stumps, trees and arbors.

Wistaria Chinensis. $40-50$ ft. May-August. Flowers pale blue, in pendulous racemes. Leaves dark green, pinnate. 


\section{PIAANTING THE ORNAMENTAL GROUNDS}

Stems twining. Fine for the piazza, the arbor, or the fence, but should not be allowed to grow on trees, as it will often cause the top to break off.

\section{The Rose}

The essentials of rose culture, after a thoughtful selection of kinds and the purchase of strong plants, are a sunny situation, good drainage, a rich, deep soil, and intelligent care.

The selection of kinds should be made in reference to the locality and purpose for which the roses are wanted. For bedding roses, those that are of free-blooming habit, even though the individual flowers are not large, are the ones which should be chosen. For permanent beds, the socalled hybrid perpetual or remontant roses, blooming prineipally in June, will be found to be hardy at the North. But if one can give them proper protection during the winter, then the Bengal, Tea, Bourbon, and Hybrid Teas, or Everblooming roses may be selected.

In sections where the temperature does not fall below twenty degrees above zero, any of the monthly roses will live without protection. At the South the remontants and other deciduous roses do not do as well as farther North. The tender climbers-Noisettes, Climbing Teas, Bengals, and others-are excellent for pillars, arbors, and verandas at the South; but are fit only for the conservatory in those portions of the country where there is severe freezing. For the open air at the North we have to depend for elimbing roses mainly on the Prairie Climbers; but we now have also the Crimson and Yellow Ramblers (Polyanthas), with their recent pink and white varieties, all of which are said to be perfectly hardy. The trailing Rosa Wichuraiana is also a useful addition in the shape of an excellent hardy rose for rocky banks, etc.

While roses delight in a sunny situation, our dry atmosphere and hot summer suns are sometimes trying on 
the flowers, as are severe wintry winds on the plants. While, therefore, it is never advisable to plant roses near large trees, or where they will be over-shadowed by buildings or surrounding shrubbery, some shade during the heat of the day will be a benefit. The best position is an eastern or northern slope, and where fences or other objects will break the foree of strong winds, in those sections where such prevail.

The best soil for roses is a deep and rich elay loam. If it is more or less of a fibrous character from the presence of grass roots, as is the case with newly plowed sod ground, so much the better. While such is desirable, any ordinary soil will answer, provided it is well-manured. Cow manure is strong and lasting, and has no heating effect. It will eause no damage, even if not rotted. Horse-manure, however, should be well rotted before mixing it with the soil. The manure may be mixed in the soil at the rate of one part in four. If well rotted however, more will not do any damage, as the soil ean scarcely be made too rich, especially for the Everblooming roses.

In planting, eare must be taken to avoid exposing the roots of roses to the drying influence of the sun or air. If dormant field-grown plants have been purchased, all broken and bruised roots will need to be cut off smoothly and squarely. The tops also will need eutting back. The eut should always be made just above a bud, preferably on the outer side of the cane. Strong-growing sorts may be cut back one-fourth or one-half, according as they have good or bad roots. Weaker-growing kinds, like most of the Everblooming roses, should be eut back most severely. In both eases it is well to remove the weak growth first. Plants set out from pots will usually not need eutting back. For pruning a sharp knife is preferable to pruning-shears when it can be used, as the latter bruise the bark more or less. 
Set open-ground plants about as deep as they stood previously, excepting budded or grafted plants, which should be set so that the union between the stock and graft will be from three to four inches below the surface of the soil. Plants from pots may also be set an inch deeper than they stood in the pots. The soil should be in a friable condition. Roses like to have the soil compact immediately about their roots; but we should distinguish between planting roses and setting fence posts. The dryer the soil the more firmly it may be pressed.

Hardy roses, especially the strong field-grown plants, should be set in the early fall if practicable. It is desirable to get them out just as soon as they have shed their foliage. If not then, they may be planted in the early spring. At that season it is advisable to plant them as early as the ground is dry enough, and before the buds have started to grow. Dormant pot-plants may also be set out early, but they should be perfectly dormant. Setting them out early in this condition is preferable to waiting till they are in foliage and full bloom, as is so often required by buyers. Growing pot-plants may be planted any time during the spring after danger of frost is past, or even during the summer, if they are watered and shaded for a few days.

North of the Ohio river all the Everblooming roses, even if they will endure the winter unprotected, will be better for protection. This may be slight southward, but should be thorough northward. The soil, location, and surroundings, will often be a great help. If the situation is not so favorable, more protection will be necessary. Along the Ohio, a heap of stable manure, or light soil which does not become packed and water-logged, placed about the base of the plants, will carry over many of the Tea roses. The tops are killed back; but the plants sprout up from the base of the old branches in the spring. Bon Silene, Etoile de Lyon, Perle des Jardins, 
Mme. Camille, and others are readily wintered there in this way.

About Chicago* beds have been successfully protected by bending down the tops, fastening them, and then placing over and among the plants a layer of dry leaves to the depth of a foot. The leaves must be dry, and the soil also, before applying them. This is very essential. After the leaves, a layer of lawn-clippings, highest at the middle, and 4 or 5 inches thick, placed over the leaves, holds them in place and sheds water. This protection carries over the hardiest sorts of Everblooming roses, including the Teas. The tops are killed back when not bent down, but this protection saves the roots and crowns; when bent down, the tops went through without damage. Even the Climbing rose Gloire de Dijon was earried through the winter of 1894-5 at Chicago without the slightest injury to the branches.

Strong plants of the Everblooming roses can now be had at very reasonable rates, and rather than go to the trouble of protecting them in the fall, many buy such as they need for bedding purposes each spring. If the soil of the beds is well enriched, the plants make a rapid and luxuriant growth, blooming freely throughout the summer.

Pruning is an important matter in rose growing. Climbing and pillar roses need only the weak branches and the tips shortened in; other hardy kinds will usually need cutting-back about one-fourth or one-third, according to the vigor of the branches, either in the spring or fall. A slight cutting-back also after their June flowering in the case of the Remontants, will encourage more flowers. Severe pruning, however, will only induce the growth of vigorous leafy shoots without flowers. The Everblooming roses will need to have all dead wood removed at the time of uncovering them in spring. Some pruning

\footnotetext{
* American Florist x., No. 358, p. 929 (1895). See pages 58 to 67.
} 
during the summer is also useful in encouraging growth and flowers. The stronger branches which have flowered may be cut back one-half or more. The rule in trimming roses is, cut back weak-growing kinds severely; strong growers moderately.

Roses should be carefully taken up every four or five years, tops and roots eut in, and then reset, either in a new place or in the old, after enriching the soil with a fresh supply of manure, and deeply spading it over. In Holland roses are allowed to stand about eight years. They are then taken out and their places filled with young plants.

ROSES FOR SPECIAL PURPOSES.

The following classified lists embrace some of the varieties of recognized merit for various purposes. There are many others, but it is desirable to limit the list to a few good kinds. The intending planter should consult recent catalogues.

Free-blooming Monthly Roses for bedding.-These are recommended not for the individual beauty of the floweralthough some are very fine-but because of their suitability for the purpose indicated. If to be carried over winter in the open ground, they need to be protected north of Washington. In beds, pegging down the branches will be found desirable. Those starred have been found hardy in Southern Indiana without protection, although they are more satisfactory with it. The name of the class to which the variety belongs is indicated by the initial letter or letters of the class name. (C., China; T., Tea; H. T., Hybrid Tea; B., Bourbon; Pol., Polyantha; N., Noisette; H. P., Hybrid Perpetual; Pr., Prairie Climber):

\section{Red-}

Sanguinea, C. Agrippina, C. Marion Dingee, T.

* Meteor, H. T.
Pink-

* Hermosa, B. Souvenir d'un Ami, T. Pink Soupert, Pol.

* Gen. Tartas, T. 


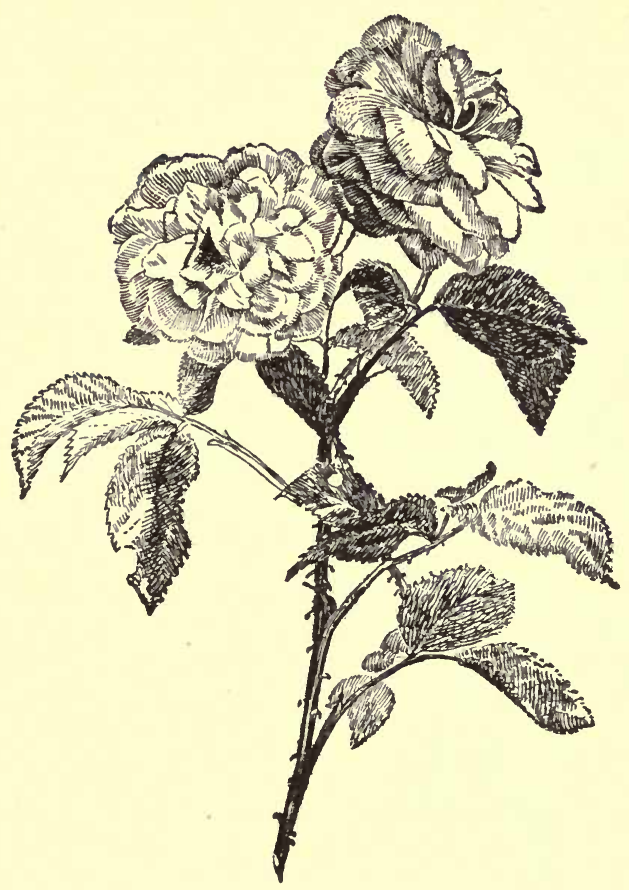

204. Climbing Jules Margottin.
Blush-
* Cels, C.
Mme. Joseph Schwartz, T.
White-
* Souvenir de la Malmaison, B.
Mignonette, Pol.
* Clotilde Soupert, Pol.
* Sombreuil, B. Snowflake, T. Pacquerette, Pol.

\section{Yellow-}
* Isabella Sprunt, T. Mosella (Yellow Soupert), Pol.
Yellow-continued.
La Pactole, T.
Marie van Houtte, T. 
Free-blooming Monthly Roses for summer cutting and beds.-These are somewhat less desirable for purely bedding-purposes than the preceding; but they afford finer flowers and are useful for their fine buds. Those starred are hardy in Southern Indiana without protection:

Red-

* Meteor.

* Dinsmore, H. P.

* Pierre Guillot, H. T.

Papa Gontier, T.

White-

The Bride, $\mathrm{T}$.

Senator McNaughton, T.

* Marie Guillot, T.

* Mme. Bavay, T.

Kaiserin Augusta Victoria, H. T. * Marie Ducher, T.

Yellow-

Perle des Jardins, T.

Mme. Welch, T.
Light Pink-

* La France, H. T.

Countess de Labarthe, T.

* Appoline, $\mathrm{B}$.

Dark Pink-

* American Beauty, H. T.

* Duchess of Albany, H. T. Mme. C. Testout, H. T. Adam, $\mathrm{T}$.

Selloro-continued.

Sunset, T.

Marie Van Houtte, T.

Hybrid Perpetual, or Remontant Roses.-These do not flower as freely as the groups previously mentioned; but the individual flowers are very large and unequaled by any other roses. They flower chiefly in June. Those named are among the finest sorts, and some of them flower continuously :

Red-

Alfred Colomb.

Earl of Dufferin.

Glorie de Margottin.

Anna de Diesbach.

Ulrich Brunner.
Pink-

Mrs. John Laing.

Paul Neyron.

Queen of Queens.

Magna Charta.

Baroness Rothschild.

\section{White-}

Margaret Dickson. Merveille de Lyon.

Hardy Climbing, or Pillar Roses.-These bloom but once during the season. They, however, come after the June 


\section{ROSES}

roses-a good season-and at that time are literally masses of flowers. They require only slight pruning.

White-

Baltimore Belle, Pr.

Washington, N.

Rosa Wichuraiana (trailing).
Pink-

Queen of the Prairies, Pr. Tennessee Belle, Pr.

Climbing Jules Margotten (Fig. 204), H. P.

\section{Crimson-}

Crimson Rambler, Pol.

Yellow-

Yellow Rambler, Pol.

Tender Climbing, or Pillar Roses.-For conservatories, and the South as far north as Tennessee. - Those with an asterisk are half-hardy north of the Ohio river, or about as hardy as the Hybrid Teas. These need no pruning except a slight shortening-in of the shoots and a thinning out of the weak growth.

Yellow-

Maréchal Niel, N.

Solfaterre, N.

* Gloire de Dijon, T.

Yellow Banksia (Banksiana).

Red-

* Reine Marie Henriette, T. James Sprunt, C.
White-

* Aimée Vibert, $\mathbf{N}$.

Bennett's Seedling (Ayrshire). White Banksia Banksiana). 


\section{Section IV}

\section{THE FRUIT PLANTATION}

There are few home plots so small that fruits cannot be grown. If there is no opportunity for planting the orchard fruits by themselves at regular intervals, there are still boundaries to the place, and along these boundaries and scattered in the border masses, apples, pears and other fruits may be planted. It is not to be expected that fruits will thrive as well in these places as in well tilled orchards, but something can be done, and the results are often very satisfactory. Along a back fence or walk, one may plant a row or two of currants, gooseberries or blackberries, or he may make a trellis of grapes. If there are no trees near the front or back of the border, the fruit plants may be placed close together in the row and the greatest development of the tops may be allowed to take place laterally. If one has a back yard fifty feet on a side, there will be opportunity, in three borders, for six to eight fruit trees, and bush fruits between, without encroaching greatly upon the lawn. In such cases, the trees are planted just inside the boundary line.
A suggestion for the arrangement of a fruit 


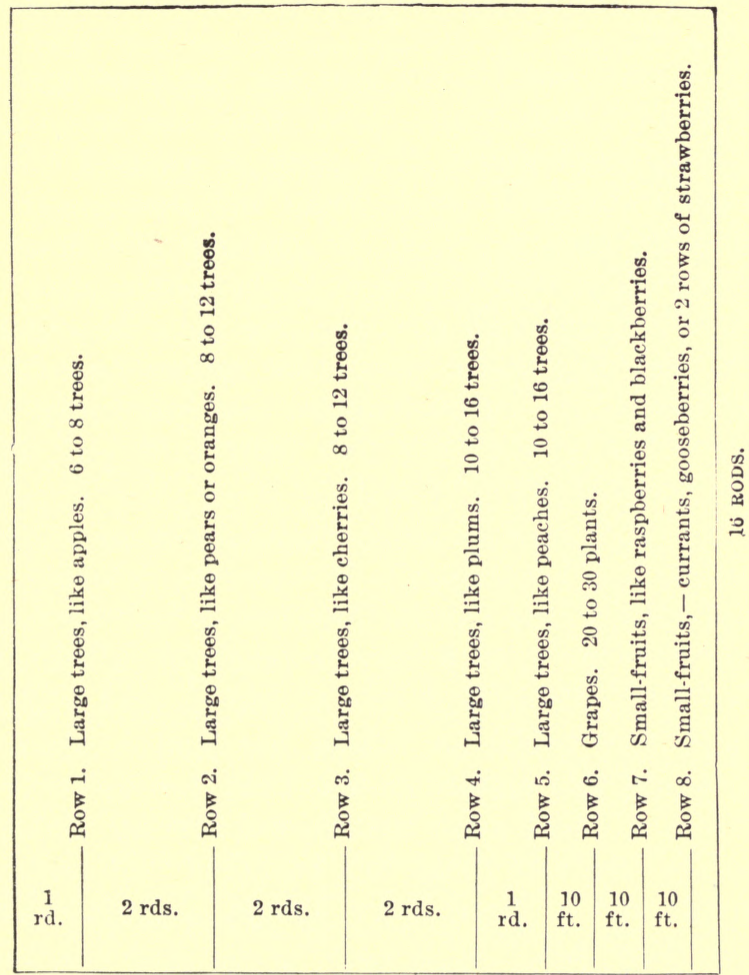

204. Plan for a fruit-garden of one acre. From "Principles of Fruit-growing."

garden of one acre is given in Fig. 204. Such a plan allows of continuous cultivation in one direction and facilitates spraying, pruning and harvesting; and the intermediate spaces may be used 
for the growing of annual crops, at least for a few years.

For very small areas, and for the growing of the finest dessert fruits, dwarf trees may be grown of apples and pears. The apple is dwarfed when it is worked upon certain small and slow-growing types of apple trees, as the paradise and doucin stocks. The doucin is usually the better, since it makes a larger and stronger tree than the other. The pear is dwarfed when it is grown upon the root of quince. Dwarf apples and pears may be planted as close as ten feet apart each way, although more room should be given them if possible. The trees should be kept dwarf by vigorous annual heading-in. If the tree is making good growth, say one to three feet, a half to twothirds of the growth may be taken off in winter. A dwarf apple or pear tree should be kept within a height of twelve or fifteen feet, and it should not attain this stature in less than ten or twelve years. A dwarf apple tree, in full bearing, should average from two pecks to a bushel of first quality apples, and a dwarf pear should do somewhat more than this.

Buy first-class trees of reliable dealers. It rarely pays to try to save a few cents on a tree, for quality is likely to be sacrificed. At the present time nursery stock is so cheap that one need not quibble about prices.

Some of the cardinal points to be observed in 
the growing of fruit are detailed in the following pages by Professor Taft. Persons who desire to pursue the subject further should consult "Principles of Fruit-Growing."

\section{ADVICE UPON THE GROWING OF FRUIT}

\section{(L. R. TAFT)}

\section{Northern Orchard Fruits}

There are few sections of the country where fruits of some kind cannot be grown with a fair degree of success. The grower should take special pains to select a location adapted to the kind of fruit he expects to grow, and should choose varieties that are known to be valuable in that section and for the specific purposes desired. With proper care in these respects and an intelligent handling of the trees, satisfactory returns may be received, while if any of the details are neglected, failure may result.

AGE AND SIZE OF TREES.-For ordinary planting, it is desirable to select trees two years from bud or graft, except in case of the peach, which should be one year old. Many growers find strong one-year trees preferable. A good size is about five-eighths of an inch in diameter just above the collar, and five feet in height, and if they have been well grown, trees of this size will give as good or better results than those seven-eighths of an inch, or nore, in diameter, and six or seven feet high.

If properly packed, trees can be shipped long distances and may do as well as those grown in a home nursery, but it will generally be best to secure the trees as near home as possible, provided the quality of the trees and the price are satisfactory. When a large number are to be obtained, it will be better to send the order direct to some reliable nursery, or to go and select the trees in person, than to rely upon tree peddlers. 
Pruning.-Having planted the trees, they should be carefully pruned. - As a rule, trees with low heads are desirable, and dwarf pears and peaches should have the lower branches from twelve to twenty-four inches above ground, and sweet cherries and standard pears can generally be headed not over thirty inches from the ground; plums, sour cherries and apple can be somewhat higher,

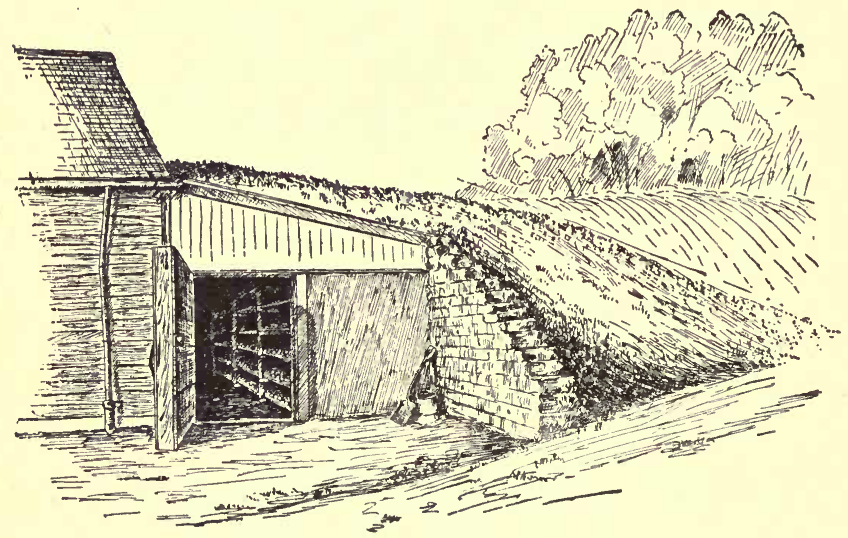

205. Lean-to fruit cellar, covered with earth. It should be built of mason work, with a roof of stone slabs, or of planks covered with an inch or two of cement. It should be provided with a ventilator at the top. Store the fruit on shelves or in barrels.

but if properly handled, when trimmed three feet from the ground, will not be in the way of the cultivation of the orchard. For all except the peach in the northern states, a pyramidal form will be desirable. To secure this, four or five side branches with three or four buds each, should be allowed to grow and the center shoot should be cut off at a height of from ten to twelve inches. After growth has started, the trees should be occasionally examined and all surplus shoots removed, 
thus throwing the full vigor of the plant into those ro. maining. As a rule three or four shoots upon each branch ean be left to advantage. The following spring the shoots should be cut back about one-half and about. half of the branches removed. Care should be taken to avoid crotches, and if any of the branches cross others, so that they are likely to rub, they should be cut out. This cutting back and trimming out should be kept up for two or three years, and in the case of dwarf pear trees, regular pruning each year should be continued. Although an occasional heading back will be of advantage to the trees, apple, plum and cherry trees that

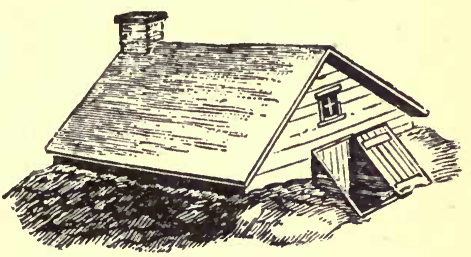

206. An outside cellar, fitted to keep fruit or vegetables. have been properly pruned while young will not require so much attention after they come into bearing.

GATHERING AND KEEPING FRUIT.-Nearly all fruits should be gathered as soon as they will readily part from the stems on which they are borne. With many perishable fruits the proper time for gathering will be cletermined largely by the distance they are to be shipped. With the exception of winter varieties of apples and pears and a few kinds of grapes, it will be best to dispose of fruit soon after it is gathered, unless it is kept for family use. If for winter use, the fruit should at once be placed in the cellar or fruit house in which it is to be stored, and there kept as near the freezing point as possible. There will be less danger of the shriveling of the fruit if placed at once in closed barrels or other tight packages, but if proper ventilation is given the fruit may be kept in bins with little loss. Even though no ice is used, it will be possible to maintain a fairly low temperature by opening the windows at night when the 
outside atmosphere is colder than that inside the building, and closing them during the day as the outer air becomes warmer. Fruit should be handled with great

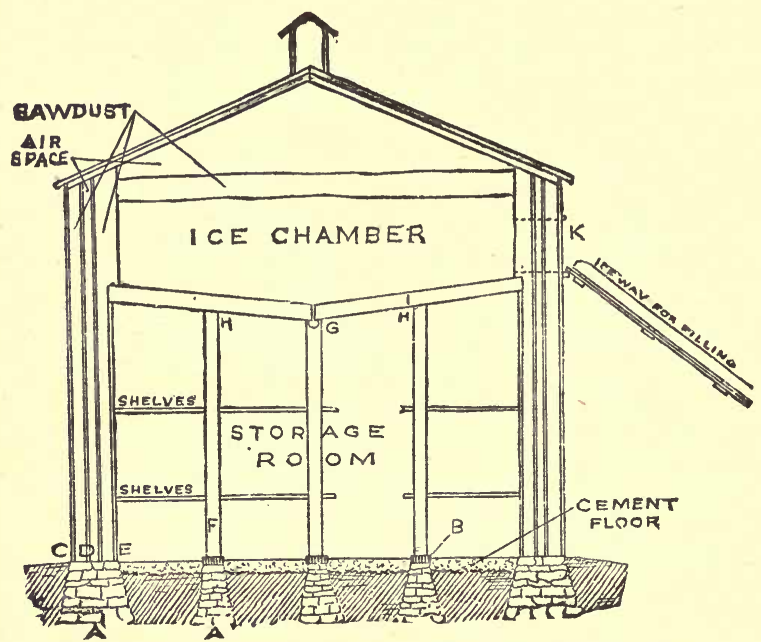

207. Diagram illustrating the construction and prineiples of operation of an ice-cooled store-house.

care at all times, for if the cells become broken by rough handling the keeping qualities will be greatly injured. The illustrations (Figs. 205-207) show three types of fruit storage houses.

Apples thrive best on a strong, sandy loam soil, or a light clay loam. While a soil very rich in organic matter is not desirable, good results cannot be obtained unless it contains a fair amount of vegetable matter. A clover sod 


\section{REMARKS ON APPLES}

is particularly desirable for this as well as for other fruits.

For a commercial orchard, most varieties should be from thirty-five to forty feet apart; but in the garden the

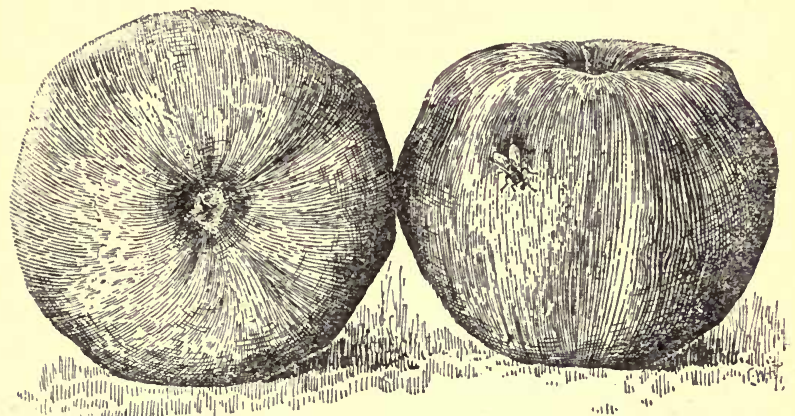

208. Jonathan.

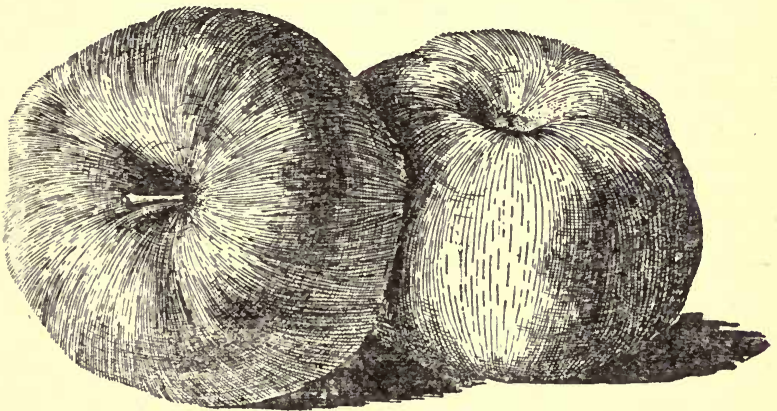

209. Wagener.

slow-growing and long-lived sorts may be at forty fect, and, half way between in both directions, some of the short-lived, early bearing varieties may be placed, to be removed after they begin to crowd. The same method 
may be used for large orchards, but from the fact that most people delay the removal of the extra trees until after they have become injured from overcrowding, it is not generally advisable.

VARIETIES OF APPLES. * For the northern and eastern states, the following varieties will generally be found valuable :

Early.-Yellow Transparent, Early Harvest, Primate, Early Joe, Red Astrachan, Golden Sweet, Oldenburg, *

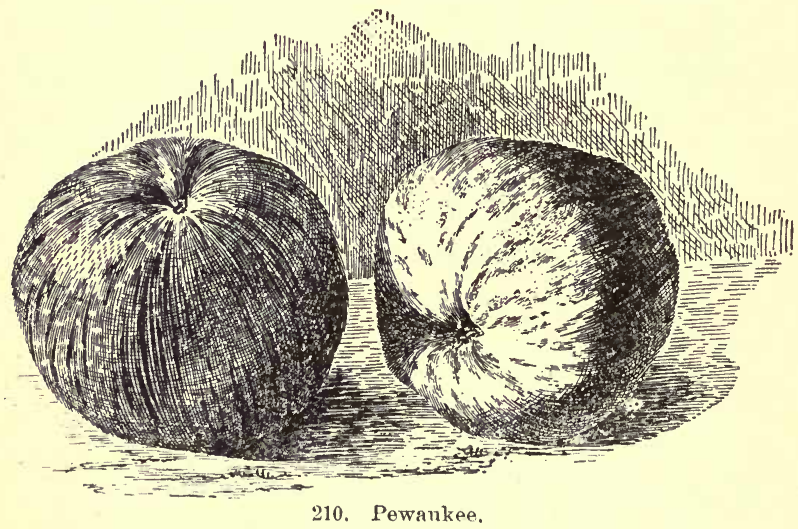

Summer Pearmain, Chenango, Bough (Sweet), Gravenstein*, Jefferis, Porter.

Autumn.-Maiden Blush, Bailey (sweet), Fameuse,* Fall Pippin, Wealthy* and Mother.

Winter.-Jonathan* (Fig. 208), Hubbardston,* Grimes' Golden,* Tompkins' King, * Wagener* (Fig. 209), Baldwin,* Yellow Bellflower, Talman, Northern Spy,* Red Canada,* and Roxbury Russet.

*The varieties marked with an asterisk (*) are particularly valuable for market purposes as well as for home use; the others are chiefly desirable for home use. 
For the South and Southwest the varieties named in the following list are of value :

Early.-Red June, Yellow Transparent, Red Astrachan, Summer Queen, Benoni, Oldenburg, Gravenstein.

Autumn.-Haas, Late Strawberry, Maiden Blush, Oconee, Rambo, Peck's Pleasant, Rome Beauty,* Carter's Blue.

Winter.-Paragon, ${ }^{*}$ Shockley, Smith's Cider, Hubbardston, Hoover, Horse, Grimes' Golden, Buckingham, Jonathan* (Fig. 208), Winesap, Kinnaird, Ben Davis,* York Imperial, Romanite, Rall's Genet, Limber Twig.

In the Northwest only such varieties as are extremely hardy will be satisfactory, and among those likely to succeed we may mention:

Early.-Yellow Transparent, Tetofski.

Autumn.-Oldenburg,* Fameuse, Longfield, Wealthy, MeMahan.*

Winter-Wolf River, * Hibernal, Northwestern Greening, Pewaukee (Fig. 210), Switzer, Golden Russet.

INsects AND Diseases of THE APPle.-Among the insects most commonly found upon the apple-tree are the codlin-moth, eanker-worm and tent-caterpillar. The codlin-moth lays its egg upon the fruit soon after the blossoms fall, and the larvæ, on hatching, eat their way inside. A thorough spraying of the trees with arsenites (page 98) within a week after the blossoms fall will do much toward destroying them; but a second application in about three weeks, will be desirable. The canker-worm (Fig. 92) and tent-caterpillars feed upon the leaves, and can also be destroyed by means of arsenites. To be effectual against the former, however, the applications must be made soon after they hatch, and in a very thorough manner.

Borers frequently do much injury to the trunks of trees, but if the trees are kept well cultivated and in a thrifty growing condition, the injury will be greatly reduced. It will be well, however, to wash the trunks of the trees and larger 
branches with soft soap, thinned with water so that it can be applied with a brush or broom, during the spring. The addition of an ounce of Paris green in each five gallons of the wash will be of value.

The most troublesome disease of the apple is the applescab, which disfigures the fruit as well as lessens its size.

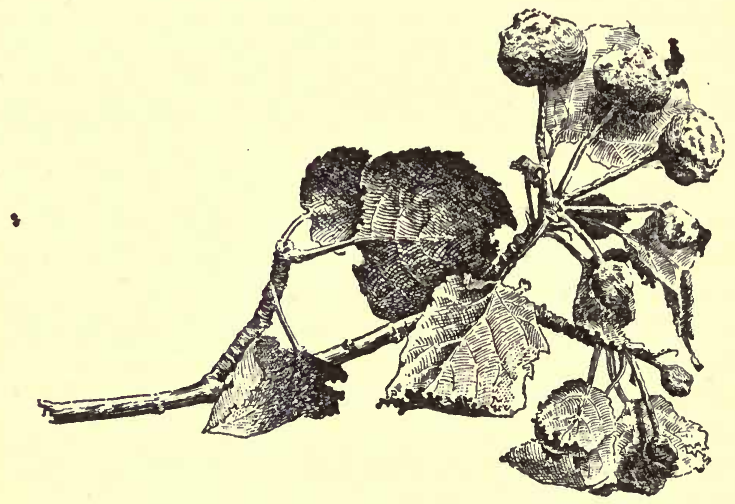

211. Blighted and broken foliage and injured fruit, the work of apple-scab.

It also often does much harm to the foliage, and thus checks the growth of the trees (Fig. 211). The Baldwin, Fameuse, Northern Spy and Red Canada are particularly subject to this disease, and it is much more troublesome in moist seasons than when the weather is dry. The use of fungicides will do much to lessen the injury from this disease. To be effectual, however, they must be applied in a thorough manner, and as a preventive rather than a cure. The trees should be sprayed with a solution of copper sulphate at the rate of one pound to fifteen gallons of water, before the buds open in the spring, and as soon as the blossoms have fallen, Bordeaux mixture (page 99) should be applied. In regions where the disease is troublesome 
and with varieties subject to its attack, the thorough spraying of the trees, after the blossoms have formed and just before they open, will often result in the saving of the erop. The frequeney of the later applications will depend upon the prevalence of the disease; but if there is likely to be trouble, the use of Bordeaux mixture upon winter varieties every three weeks up to the middle of July or first of August will be found profitable. The earlier applications can be made in connection with the arsenites, and will aid in preventing injury to the foliage by free arsenic.

\section{THE PEAR}

Pears require a rather stiff soil, and do best in a moderately heavy clay loam. While it should be retentive of moisture, it must be well drained. Dwarf pear-trees should have a rich, deep, loamy soil, and do best if it is of an alluvial nature. Standard pears should be placed from twenty to twenty-five feet each way, and dwarfs from twelve to fifteen. Dwarf trees are often more desirable than standard, as they are generally earlier bearers and require but one-half as much room as standard trees. To be grown successfully, however, they should be severely cut back each year, and all surplus shoots removed. As they have a comparatively small root system, they should be well supplied with plant-food, and be even more thoroughly eultivated than standard trees. While there is danger from using an excess of manure, the land should be kept well enriched with decomposed stable manure, wood ashes and ground bone.

VARIETIES OF THE PEAR.-As a selection to supply a succession of varieties throughout the season, the following list is recommended:

Early.-Summer Doyenne, Bloodgood, Clapp. Autumn.-Bartlett, Boussock, Flemish Beauty, Buffum, 
Howell, Seckel (Fig. 212), Louise Bonne, Duchess (d'Angouleme) (Fig. 213).

Winter.-Anjou, Sheldon, Clairgeau, Lawrence, Kieffer (Figs. 214, 215), Winter Nelis, and Easter Beurre.

For ordinary market purposes, the following have been proved valuable: Bartlett, Howell, Anjou, Clairgeau, and

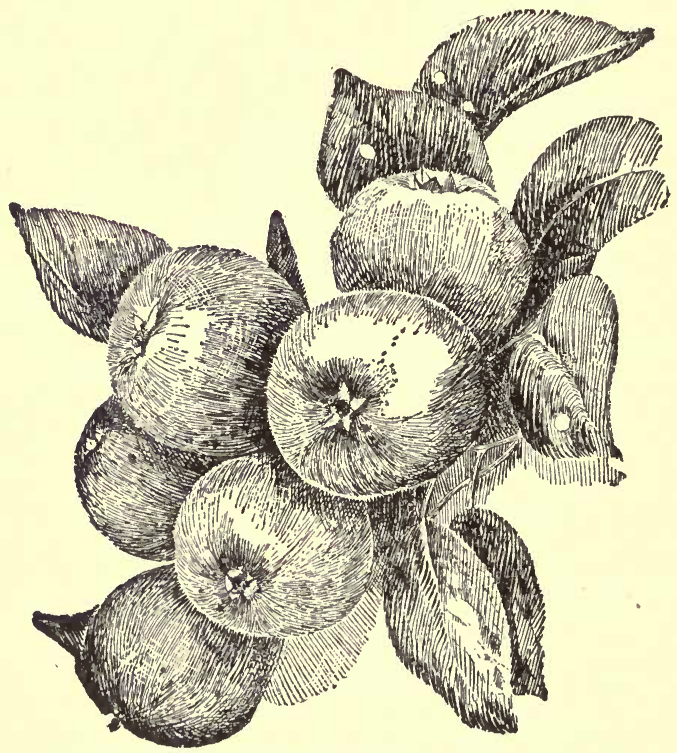

212. Seckel.

Lawrence. In the central and southern states, Kieffer is grown successfully, and in the extreme South LeConte is largely grown. For home use, the Kieffer is not to be recommended in the North, because of its poor quality and smaller size.

For growing as dwarfs, Duchess (d'Angouleme), Louise 

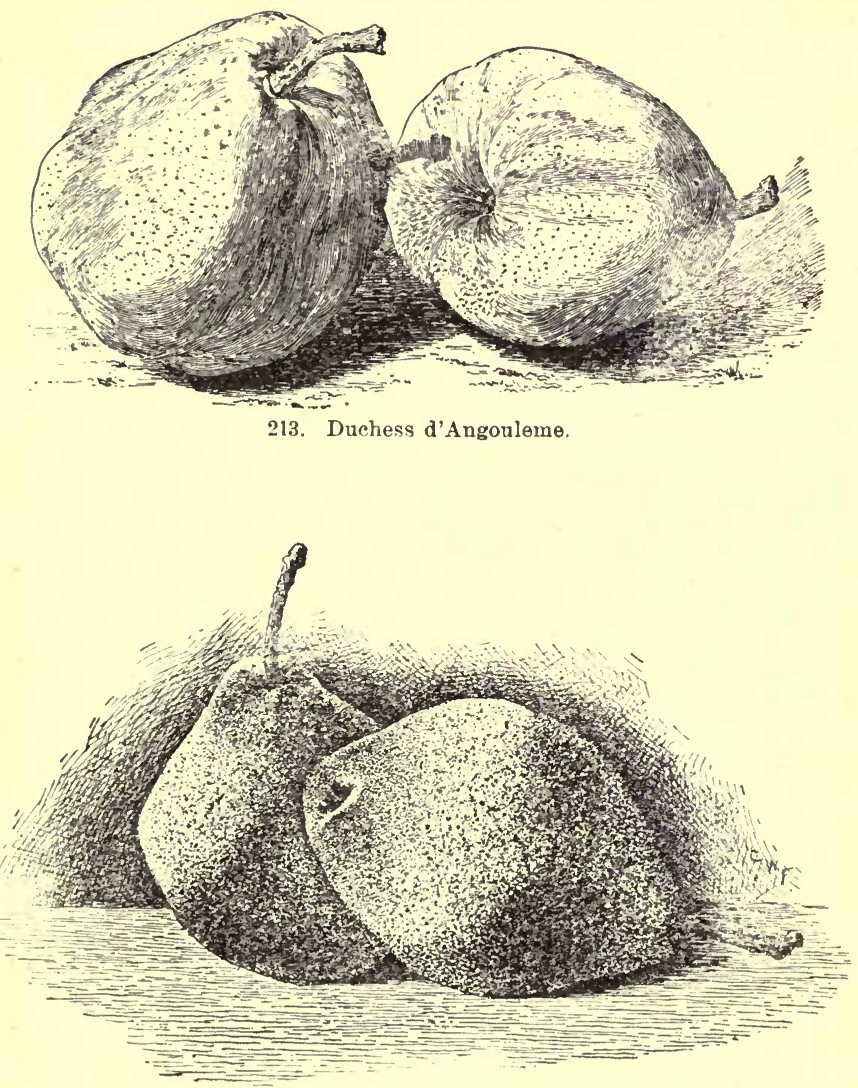

214. Kieffer pear. 
Bonne, Anjou, Clairgeau and Lawrence are most popular, but many other varieties thrive on the quince.

INSECTS AND DISEASES OF THE PEAR. - In addition to the attack of the cherry-tree slug, codlin-moth, and various insects common to other fruits, the foliage of the pear is attacked by a leaf-mite (Phytoptus) and the pear tree psylla, although neither are commonly troublesome over a wide range of country. The latter yields readily to a thorough application of kerosene emulsion, applied just before the leaves open in the spring.

The most common and destructive disease of the pear is fire-blight. This is of a bacterial nature, and may

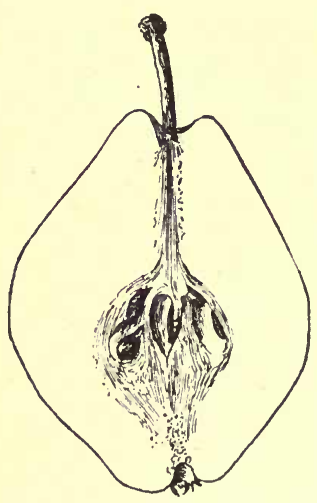

215. Kieffer. appear upon the trunk, branches, or foliage, and if allowed to spread, will generally kill the trees. A form known as twig-blight attacks the branches, but seldom spreads to the trunk. It is least troublesome upon slow-growing varieties, and where there is not an excess of organic matter in the soil. If an excessive growth can be avoided, the danger will be reduced. The blight manifests itself upon the growing shoots by the discoloring of the bark and underlying wood, and by the brownish-black color of the foliage. There is no known remedy, but as soon as the disease shows itself the affected portions should be removed, taking care to cut several inches below where any signs of the disease appears.

The foliage of the pear is also attacked by a fungous disease known as leaf-blight, which causes the leaves to drop prematurely; the same disease also affects the fruit, eausing it to erack and become misshapen. The use of Bordeaux mixture, as recommended for apple- 
scab, will be found to be a sure remedy for this trouble. This disease is distinguished from the true pear-blight or fire-blight by definite spots or blotches on the leaves and the tendency of the leaves to drop prematurely.

\section{THE PLUM}

While clay is not as necessary for plum as for pear trees, they succeed well on moderately heavy clay soils, but seem equally adapted to strong, sandy loams. Trees grown on myrobalan stocks are best for heavy soils, but if it becomes necessary to place them on a light soil, those grown on peach roots will give best results.

The distance at which plums should be placed varies from sixteen to twenty feet each way, according to the size of the trees and the nature of the soil; the stronggrowing sorts upon heavy soils require the greater, while weak varieties on lighter soils will succeed at the lesser distance.

VARIETIES OF THE PLUM. - The following varieties of European origin will be found desirable for growing in the northern and eastern states: Bradshaw, Imperial Gage, Lombard, McLaughlin, Pond, Jefferson, Fellenberg, Shropshire, Coe Golden Drop, Bavay or Reine Claude, Grand Duke, Monarch, and Black Diamond.

Several of the Japanese varieties are also well adapted to growing in these sections, as well as in the states farther south. The trees are generally hardy, but they bloom early, and are apt to be injured by late frosts in some localities. Among the better kinds are the Red June, Abundance, Chabot, Burbank, and Satsuma.

Few of the above sorts are hardy in the Northwest, and growers there have to rely upon varieties of Prunus Americana origin. Among these are: Forest Garden, De Soto, Rollingstone, Weaver, Quaker, and Hawkeye: Farther south still other classes of plums have been 
introduced, among them being Wild Goose, Clinton, Moreman, Miner, and Golden Beauty. And still farther south, Transparent, Paris Belle, Newman, Lone Star, and El Paso are grown.

INSECTS AND DISEASES OF THE PLUM.-Plum trees are attacked by a number of dangerous diseases and insects, and to be grown successfully, these require careful attention. The most troublesome disease is the "black-knot", which causes swellings upon the trunks and branches. If allowed to spread it will quickly be fatal to the orchard. All diseased branches should at once be removed, cutting a foot or so below the knot. The spread of the disease ean, to a large extent, be prevented by spraying the trees occasionally during the season with Bordeaux mixture, but to be effectual, the spraying and cutting out of the knots must be done promptly upon the first appearance of the disease.

Plum trees are also much injured by the "shot-hole fungus", which causes the leaves to drop, but it also can be prevented by the use of fungicides.

Brown-rot of the fruit is also very troublesome in warm, moist seasons; although less effective than with other diseases, the fungicides will largely prevent its spread.

The fruit is also frequently destroyed by the plum cureulio, an insect which deposits its egg beneath the skin of the fruit. The larva, on hatching, eats its way in to the

- pit, causing the fruit to drop from the tree. Thorough and persistent spraying with arsenites will sometimes save the crop, but many growers prefer to jar the trees early in the morning, and eatch the eurculios upon sheets spread for the purpose.

Plum trees, as well as most of our other fruits, are also subject to the attack of the San José scale and other scale insects. If very numerous, they will greatly injure and even destroy the trees. The San José seale, in particular, 
is very injurious, and if found in large numbers upon a tree, it should at once be destroyed; but if only a few are present, they may be killed by thoroughly spraying the trees in winter with a solution of whale-oil soap made at the rate of one and one-half pounds to a gallon of water. Even in summer, thorough spraying with kerosene and water will destroy the pest.

\section{THE PEACH}

Although peach trees are hardy, except in the more northern states, there are only comparatively a few sections in which they ean be grown successfully, as the flower buds are destroyed if the mercury reaches twenty degrees below zero, and frequently at zero or above, if the buds have swollen during warm periods in the winter and early spring. Peaches are generally grown upon sandy loam soils, but do well upon light clays if they are naturally well drained. Particular attention should be paid to having them in some elevated spot in order that they may have perfect air drainage, unless they are in sections where the natural surroundings prevent extremes of temperature.

Although most growers find it advisable to plant the trees from eighteen to twenty feet each way, some prefer to grow them as close as from twelve to fifteen feet, and do this by severely heading-back the trees. Trees one year frcm bud should be used, and should be eut back to a whip, unless there are side shoots where the head is to be formed, in which case three or four of them should be cut back to two buds each, and all others, as well as the center shoot, removed. In most sections it will be preferable to have the lower branches not more than eighteen to twenty-four inches from the ground, and in the southern states, twelve inches will be sufficient. Until the trees come into bearing, the shoots should be cut back 


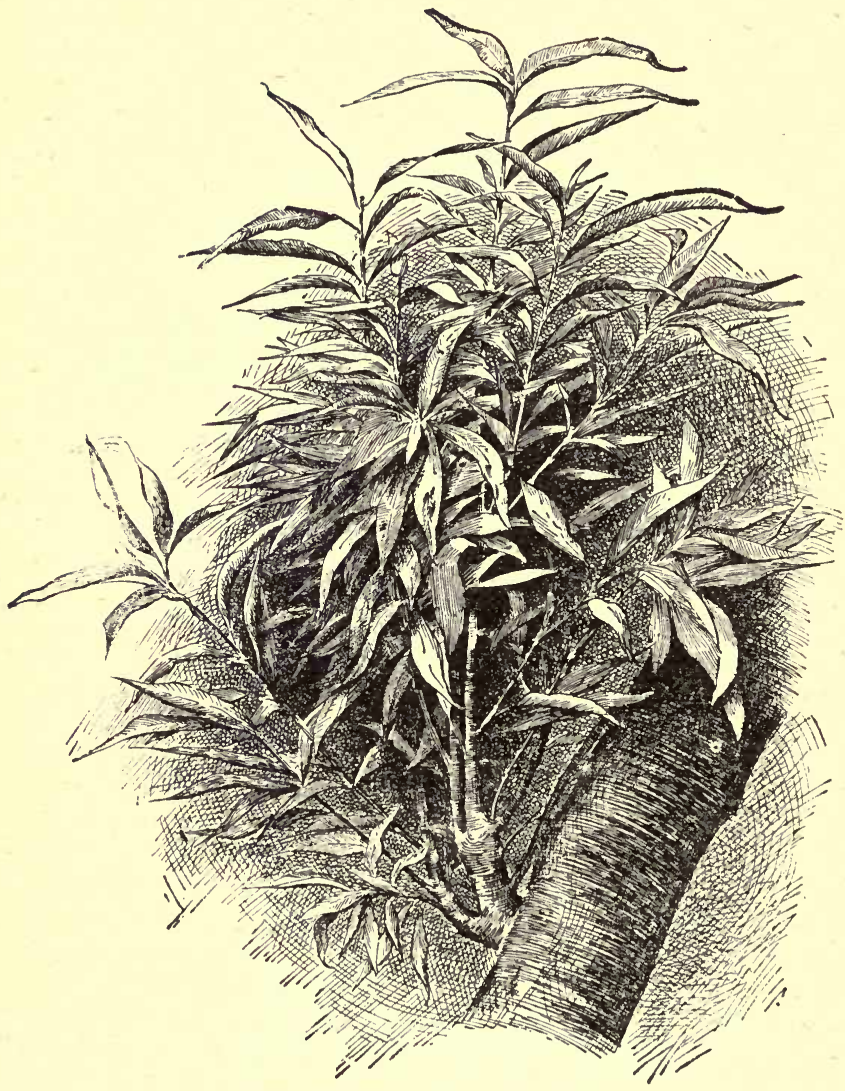

216. Bunch of yellows shoots. 
from one-half to two-thirds each year, and many of the weaker ones removed. At the North it is best to grow them in an open, vase-shaped form, that the sun may enter and ripen the fruit, while at the South the pyramidal form should be chosen. After the trees come into bearing they will need less pruning, but a little headingback and thinning out will be desirable each year. In case the crop is lost, it will be well to occasionally cut back branches to the main arms, and thus form a new head.

VARIETIES OF THE PEACH.-For home use it is advisable to provide varieties that will ripen in succession, but for market purposes, in most sections, the medium and late kinds should be most extensively planted. Although there are many varieties that have a local reputation, but are not commonly found in the nurseries, the following kinds are well known, and can be generally grown with success: Alexander, Hale's Early, Early Rivers, St. John, Crawford Early and Late, Oldmixon, Stump the World, Elberta, Crosby, Gold Drop, Smock, and Salway. Among the new kinds less commonly known are: Triumph, Lewis, Champion, Sneed, Greensboro, and Kalamazoo.

INSECTS AND DISEASES OF THE PEACH. - In some sections the peach industry has been entirely destroyed by "yellows." While its exact nature is not known, it is evidently contagious, and infected trees should be removed at its first appearance. It shows in red spots upon the surface,

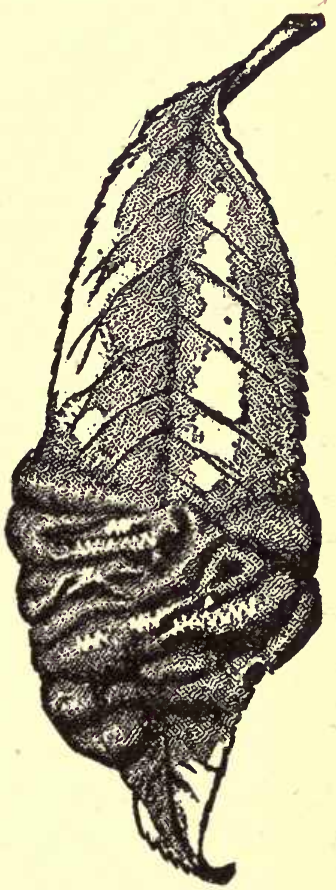

217. Leaf-curl. 
and streaks running from the pit to the outside of the fruit, and in the development of short, weak shoots late in the fall from buds that should remain dormant until spring. The leaves are small and light yellowish green in color. The following year tufts of wiry branches are developed in the erotehes of the trees and often from the large branches (Fig. 216), and the tree generally dies during the second or third year.

Curl-leaf (Fig. 217) is also troublesome in cold, wet springs, causing a thickening and folding of the leaves, and often resulting in the defoliation of the trees. It is a fungous disease, but is seldom troublesome when the weather in May and June is warm and dry. If the attack is severe, most, if not all of the fruit, will drop from the trees. Generally, the tree recuperates, and the disease is seldom serious in two succeeding years. Its attack can be prevented if the trees are thoroughly sprayed with Bordeaux mixture before growth starts, again after the blossoms have fallen, and a third time in about ten days. The material should be made of full strength, and double the amount of lime commonly used would be desirable, and to be effectual it should be thoroughly applied to all parts of the trees before the disease has attacked the leaves. Peach trees are often injured by spraying.

The peach is also subject to the attack of brown-rot, curculio (page 318), and shot-hole fungus. The borer of the peach is often very destructive, and the trees should be examined in June, and again in October, for its presence. Scrubbing the trunks of the trees about the middle of June in the northern states, and one or two months earlier in the South, with the wash recommended for the apple tree borer, may lessen the danger of their attack.

The black peach aphis is very numerous in some sections, and will quickly destroy young trees. They suck the sap from the roots of the trees, but appear above ground during the summer. They can be destroyed on 
the foliage by spraying with strong tobacco water, while below ground the best remedy will be to scrape away the surface soil and spread about the tree from a half bushel to a bushel of unleached wood ashes, or tobaceo stems.

The roots of peach trees are often covered with swellings known as crown or root-galls. Such trees should never be planted, for although they may grow, they will never be of value. Similar galls also appear on the plum, pear, apple, raspberry, and other fruits.

\section{APRICOTS AND NECTARINES}

These fruits are not commonly grown, as ordinarily the trees are short-lived and lacking in productiveness. They require the same care as the peach, are as hardy, are attacked by the same insects, and they are as easy to grow. A nectarine is only a peach with a smooth skin. Apricots thrive on a rather strong soil. Early Golden, Moorpark, Royal, Roman, Montgamet and Harris are among the best varieties of apricots, and Boston and Pitmaston Orange are the leading sorts of nectarines.

\section{THE CHERRY}

While cherries succeed upon a variety of soils, they do best and live longest upon a moderately light soil, provided it contains an abundance of plant-food. The presence of stagnant water in the soil will be fatal to them. For the ordinary planter, the sour kinds will do best and prove most productive, as, although ordinarily hardy, sweet cherry trees are likely to make a late growth in the autumn, and the action of frost upon the trunks will result in the eracking of the bark, and the life of the tree will thus be shortened. Trees grown on Mahaleb stocks will generally be found most hardy, particularly on heavy soils. The sour varieties may be placed at from eighteen 
to twenty feet each way, but in sections where the sweet cherries reach their full development, twenty-five or thirty feet will be none too much for them.

After the head has once been formed, sour cherries will require little pruning; but for a number of years it will be well to head back the upright-growing sweet cherries. The injury from the winter spoken of above, as injuring the sweet kinds, can be greatly reduced if the trunks are shortened so that the branches will come out not more than one and one-half feet above the ground.

VARIETIES OF THE CHERRY.-Of the sour varieties, May Duke, Early Richmond, Montmorency, Reine Hortense, Late Kentish and English Morello are the most valuable. The following sweet varieties are of value where they sueceed: Rockport, Yellow Spanish, Elton, Gov. Wood, Coe Transparent, Windsor, Black Tartarian, and Downer.

INSECTS AND DISEASES OF THE CHERRY.-Cherry trees are often nearly defoliated by a sthall, slimy larva known as the cherry-tree slug. It eats off the green portions of the leaf, giving them an appearance as if burned with fire. They can be readily destroyed by throwing dry road dust, wood ashes, or air-slaked lime over the trees, but if the trees are large and numerous, it will be easier to spray them with Paris green. The so-ealled cherry worms are the larva of the curculio, which also attacks the plum and the peach. (See Plum.)

Although the foliage of young trees is frequently attacked with powdery mildew, it seldom does much harm, and the only disease to be much feared is brown-rot, mentioned as attacking the plum and peach. If the weather is warm and moist at the time the trees are in blossom, or just as the fruit is ripening, the injury inflicted will be quite severe, and the fruit must be quickly picked. The disease is most serious on white varieties of the sweet cherry type. (Consult bulletins of Cornell and Delaware Experiment Stations.) 


\section{THE QUINCE}

Although not largely grown, quinces generally find a ready sale, and are desirable for home use. The trees are usually planted about twelve feet each way, and may be trained either in a shrub or tree form, but it will generally be best to grow them with a short trunk. They succeed best on a deep, moist and rich alluvial soil, and require the same care as the pear. The insects and diseases by which they are attacked are also the same as upon that fruit. The Orange is the nost common vaiety, but Champion, Meech and Rea are sometimes grown.

\section{Sub-Tropical Fruits}

Many sections in California, Florida and Louisiana are adapted to the growing of such fruits as oranges, lemons, figs and other tender fruits that can only be grown under glass in the northern states. In a general way they are planted and cultivated in about the same manner as other fruits.

\section{THE ORANGE}

Oranges are grown extensively in many parts of California, but in the most favored sections there is occasionally some injury from frost to the trees or fruit, while the recent destructive freeze in Florida caused great damage. The soil preferred for oranges in California is a rich, deep alluvium, avoiding hard-pan or adobe subsoils. Stagnant water in the subsoil is a fatal defect. Although they can be grown near the ocean at a lower level, an elevation of six hundred to twelve hundred feet is generally desirable. While Southern California is particularly adapted to orange culture, the fruit is successfully raised along the foot-hills of the San Joaquin and Sacramento 
valleys and in other parts of the state. In Florida, pine lands with a clay subsoil are generally preferred for oranges, but if properly handled good results can be obtained from hammock land. As elevated spots cannot be secured, a timber belt surrounding the orchard or along the north and west sides is desirable.

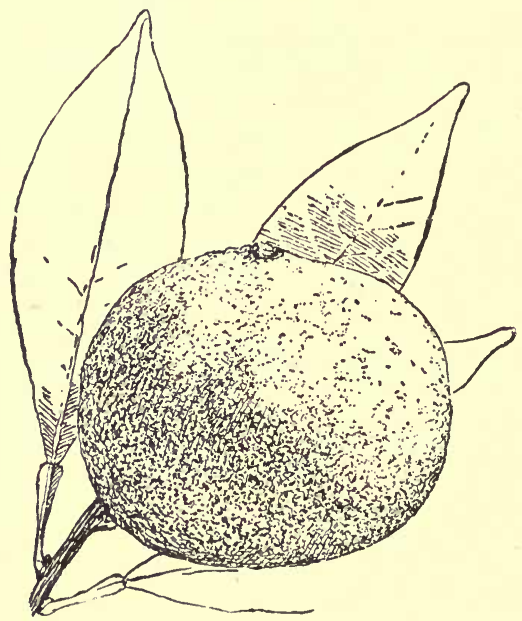

218. Oonshiu orange, one of the Tangerine type.

The distance for the large-growing kinds in the orchard is from twenty-five to thirty feet each way, but the halfdwarf kinds such as Bahia or Washington Navel may be as close as twenty feet each way, although twenty-five feet will be desirable. If the roots are sacked, the trees should be placed in the hole without removing the covering and the soil should then be packed about them, but if they are puddled, a mound should be made in the bottom of the hole. In the center an opening should be made into which the tap-root can be inserted. After the 
soil has been firmly packed about it, the other roots should be spread out and the hole filled with good soil, packing it carefully. Care should be taken that the roots are not exposed in handling the trees, and if the weather is hot and dry the tops should be shaded. Water may often be used with good results in settling the soil about the roots.

Pruning THE ORANGE.-When transplanted, the tops should be cut back in proportion to the amount of roots

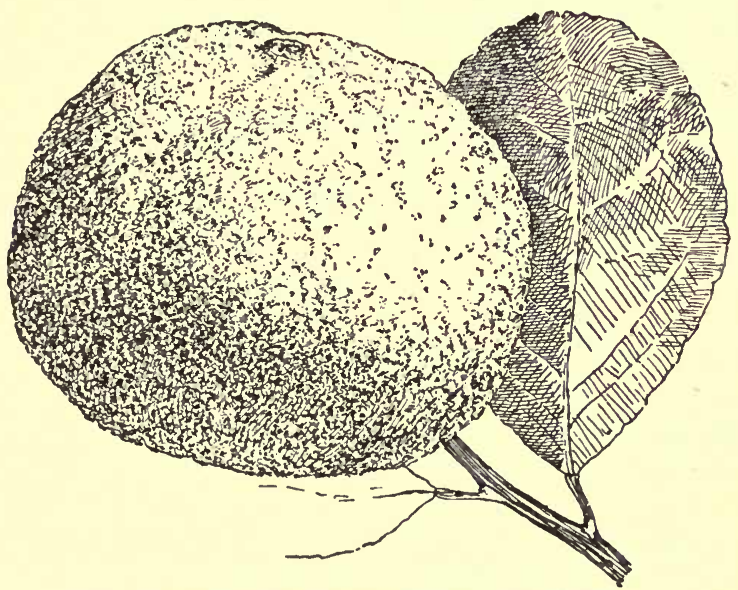

219. Kawachi, a Japanese-American type of orange.

lost in digging the trees. The head is usually started with the branches about two feet from the ground. Each year while the trees are small, the strong shoots should be cut back to preserve a symmetrical form and the weak and surplus shoots should be removed.

Cultivation of ORANGE ORCHARDS. - The eultivation of orange orchards should be the same as recommended for other fruits, except that as they grow in hot, dry climates, 
it should be even more thorough, that the evaporation of moisture from the soil may be reduced to a minimum. California growers have found that by frequent shallow cultivation they can reduce the amount of water that must be applied by irrigation, and that frequent tillage and a little water will give better results than little or no cultivation and a large amount of water. The amount of water required will also depend on the season and the character of the soil. Thus on strong soils and after a heavy rainfall, no irrigation will be required, while sandy soils will need irrigating as often as once in three or four weeks from May to October. As a general rule, two or three irrigations in a season will be ample. When used at all, water should be applied in sufficient quantities to wet down to the roots of the trees. Frequent scanty waterings may do much harm. The water is usually applied in furrows, and for young trees there should be one on either side of each row, but as the roots extend the number should be increased, until when five or six years old the entire orchard should be irrigated from furrows four or five feet apart. In Florida, irrigation is not necessary. Excellent oranges are also grown in the Delta country of the Mississippi, below New Orleans, where they ripen early.

VARIETIES OF THE ORANGE.-Among the best varieties are: Bahia, commonly known as Washington Navel, Maltese Blood, Mediterranean Sweet, Paper Rind, St. Michael, Valencia, and Beach No. 1. Homosassa, Magnum Bonum and Nonpariel are favorites in Florida. The Tangerines and Madarins, or the "Kidglove" oranges (Fig. 218), have a thin rind that is easily detached from the rather dry pulp. Orange trees are frequently injured by various scale insects, but for several of the most troublesome kinds, insect parasites have been found, and for others the trees are sprayed, or fumigated with hydrocyanic acid gas. 


\section{THE OLIVE}

Although olive trees thrive best on a warm, rich and well-drained soil, they may be grown with success on dry, rocky hillsides. The greater part of southern and central California is adapted to the culture of this fruit. While the mean annual temperature should not be lower than sixty degrees, the olive can be grown with success even though the mercury may fall to fifteen degrees, provided the average temperature for the coldest month is at least forty degrees.

The trees can be grown from seeds, if the pulp is first removed and the seeds freed from oil by soaking them in lye. They may also be readily propagated from either long or short half-hard cuttings, or by budding or grafting. The trees are planted from twenty to twenty-five feet apart each way, and on account of their drooping habit they should be trained with a moderately high trunk, with a center stem. The side shoots should be headed-back and the drooping branches removed.

Olives ripen during the winter, and should be gathered as soon as they turn purple. If to be used for oil, the fruit is first partially dried and then placed in masonry vats, where it is crushed with stone or iron rollers. The oil is then pressed out, poured into tanks or vats for settling, and then, after being filtered through several thickuesses of cotton batting or felt, is put into bottles.

If for pickling, care should be taken to handle the fruit when gathering it so that it will not be bruised. It should be poured into tubs of water, which should be changed daily for a month or so. The olives are then placed in weak brine, and after three or four days are changed into brine that will bear an egg, and in this can be kept indefinitely. Instead of going to the trouble of repeatedly changing the water, the same results can be secured, $i$. $e$, the removal of the bitter taste, if the 
olives are soaked in weak lye before they are placed in the brine.

Olive trees respond to good care and cultivation, and will remain in fruit for many years. The Mission olive is largely grown in California, and Manzanillo, Pendoulier, Uvaria, Columella and Macrocarpa are receiving attention.

\section{THE PINEAPPLE}

This fruit thrives on rich hammocks and clays, although sandy soil with a yellow subsoil is generally preferred. It is propagated either from suckers that spring up from the base of old plants, from the bud and tuft of leaves above the fruit, which is called the crown, or from "slips" which grow from the stems below the fruits. They root readily by inserting them in beds of damp moss or sand, after removing some of the lower leaves. The ground for pineapples is prepared by opening furrows or shallow trenches a foot or so wide and deep, in which a compost of manure, leaves and muck is placed. For large fruits, the plants should not be closer than two feet in the rows. The weeds must be kept down by frequent cultivation or by a heavy mulch. To secure against frost, the plants must be covered. For this purpose shingles or boards can be used while the plants are small, but as they become larger stout stakes are set in the ground; these are connected by rails, over which brush or burlaps are placed. With good care the fruit may ripen in two years, although three or four may elapse before it comes to maturity.

Spanish, Sugar Loaf, Egyptian, Ripley Queen, and Porto Rico are favorite varieties of pines.

\section{BANANA}

This fruit. can be grown in but few localities, as it is greatly injured by frost and, unlike the pineapple, it can- 
not be covered. It thrives on a well-drained, rich, warm, sandy loam. The plants, which ean be readily obtained from suckers sent up by the old stems, should be set eight or ten feet apart each way in holes two feet deep and three feet wide, which have been filled with a rich compost. They should be heavily mulched, and water should be freely applied when necessary.

Hart's Choice and Martinique are excellent varieties.

FIG

Few fruits can be grown under as varied conditions of soil and climate as the fig, which does well in all parts of California, except on the mountains and in the more northern counties; the only requirements are heat enough to ripen the fruit and a winter that will not injure the trees. It also grows well in Florida and parts of Georgia. They are propagated from euttings or by budding and grafting. For a permanent orchard, the trees should be forty feet apart, but at first they may be set at half that distance and removed later on, or other fruits may be grown between the rows for several years. Fig trees are headed rather higher than other fruits, especially if the fruits are to be used for drying. The branches should not be very close upon the trunks, and shoots on the under side of the limbs should be removed. After the . head has been formed little pruning will be required, and the trees will come into bearing the third year.

The greatest drawback to the fig industry in California is that growers have not been able to naturalize the insect necessary to secure fertilization of the seeds, which is required for fruit to be of the highest quality when eured.

White Adriatic is the most commonly grown white fig. Among the other varieties are California Black or Mission fig, Brown Ischia, Brown Turkey, Green Ischia and Celestial. 
Even as far north as Maryland, figs can be grown by laying them down in winter.

\section{The Grape}

In order that they may ripen, in most of the states grapes require a rather warm soil and a sunny exposure. That they may escape both the late spring and early autumn frosts, they should be planted in elevated spots, as far as possible. The distance should vary according to the growth of the variety and the method of training. Some of the small-growing sorts may be as close as eight feet each way, but ten feet between the rows is desirable for most kinds; although some growers prune strong-growing varieties so that they stand sixteen feet apart in the row, ten or twelve feet will ordinarily be better. Trellises are much more commonly used than stakes to support the vines. For these the posts are set about twenty-five feet apart, so that they will stand six feet out of the ground, and for a vertical trellis, two No. 10 galvanized wires are placed upon them; one being at the top of the posts, and the other two feet below it. A horizontal trellis is preferred by some. This is made by placing cross arms two feet long near the top of the posts, and upon these stretching three wires about one foot apart. Persons who desire specific information on training grapes, should consult "Pruning-Book."

VARIETIES OF GRAPES.-Under nearly all conditions, the Concord will be a valuable black variety, although Worden, which is a few days earlier, may be preferred by many. Moore's Early has been our best very early black variety, but is likely to be superseded by Campbell's Early, which is a stronger vine, more productive, bunches larger, fruit of better quality, and of superior keeping qualities, making it valuable for shipping purposes. $\mathrm{Ca}$ - 

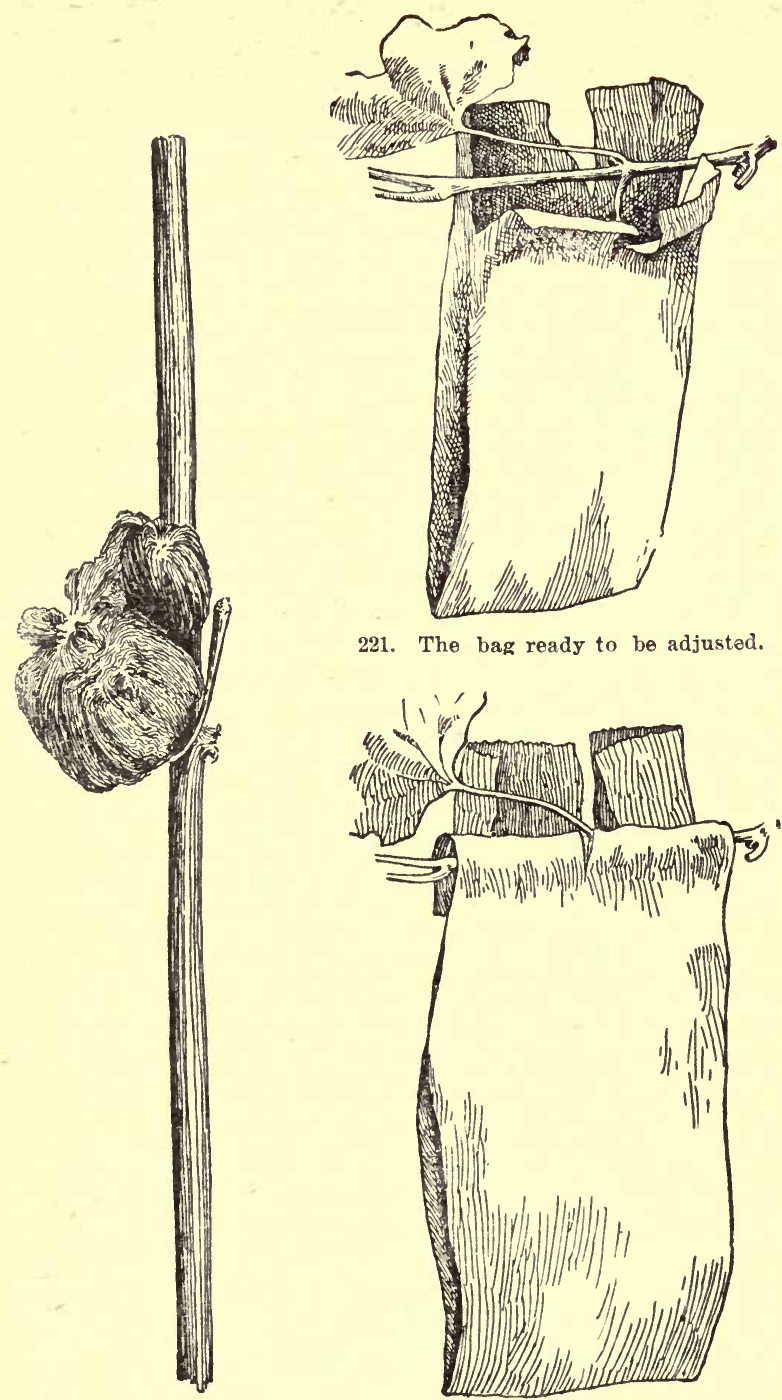

221. The bag ready to be adjusted.

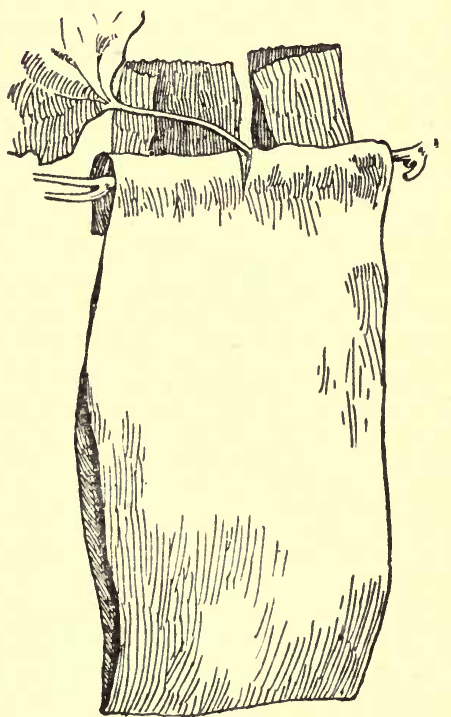

220. Gall on a

grape cane.

222. Second stage in adjusting the bag. 
tawba, Delaware and Brighton are among the best red varieties, although Agawam and Salem are much used. Winchell (Green Mountain) is the best early white variety, and in most sections Niagara, a late white sort, does well. Moore Diamond is a white grape of better quality than Niagara.

The diseases of THE GRAPE.-Grape-vines are subject to the attack of downy mildew in cold, wet seasons, of powdery mildew when it is hot and dry, as well as anthraenose and black-rot. All of these are most troublesome upon vines that have been weakened from overbearing, but there is a great diference in the ability of the vines of different varieties to resist their attacks. Where any of these diseases are troublesome, the prunings and the fallen leaves and fruit should be destroyed, and the vines thoroughly sprayed with fungicides. The first application should be made in the spring before growth starts, and the others at intervals or two or three weeks during the season, the number and frequency of the applications depending upon the prevalence of the disease.*

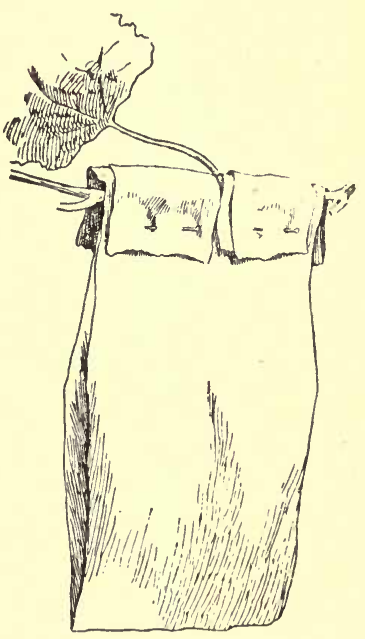

223. The operation completed

* A nurseryman sent me the object shown in Fig. 220, saying that he took it from a grape-vine near which grew a Kieffer pear; and judging from this perilous proximity of the two plants and the very suspicious shape of the excrescence, he was bound to conclude that he had a veritable hybrid between a grape and a pear! Even at the risk of seeming to be unappreciative of discoveries in pomology, I was obliged to report that the entomologist declared the object to be only a gall-aud a not uncommon one-produced by an inseet.-L H. B. 
For home use and special purposes, grapes may be bagged, to protect them from black-rot, frost, birds and insects. The operation consists in enclosing the cluster (when the grapes are half grown) in grocers' manilla bags, allowing these bags to remain until the grapes are fully ripe. Because of the greater and more uniform warmth in the bags, the fruits in them are usually earlier, larger and better. Figs. 221, 222, 223 show how the bags are prepared and applied, the flaps being secured with a pin.

\section{EUROPEAN GRAPES}

The cultivation of the European wine grape has reached immense proportions in California, where there are single vineyards of two to three thousand acres.

Table and wine grapes are grown successfully in nearly all parts of the state, but the raisin industry is confined to the hot, dry valleys where the fruit can be cured. The vine thrives upon a variety of soils, but for the best results an abundance of plant-food should be provided. The plants are propagated by layering, budding, grafting, and most commonly from euttings, which are inserted in the ground where the vine is to grow. Most of the grapes are grown without trellises, and in the case of the raisin grapes, the trunk is seldom more than fifteen inches high, while wine grapes are but little more than two feet. As generally pruned, the vine is cut back the first year after planting, leaving but one spur with two buds. Shoots are allowed to grow from these, and in the following winter the strongest one that is upright should be cut off at the height the head is desired, and all others removed. Upon the shoot that is left all but two strong buds at the top should be rubbed off. From these, arms are allowed to grow which are cut back at the end of the year to three or four buds each. From these buds the spurs are formed. The 
number should vary with the strength of the plants from five to eight, and the number of buds from three to five upon each. Every year all shoots are removed except one upon each spur, which is cut back to form a new spur. It is well to rub off all suckers that start and to pinch back the ends of the shoots when about two feet long.

Powdery and downy mildew attack this species, but yield to fungicides.

The leading table grapes are: Thompson Seedless, Mission, White Muscat of Alexandria, Black Hamburg, Flame Tokay, and Rose of Peru. The leading sorts for drying are: White Muscat, Muscatel, Thompson Seedless, White Malaga, and Sultana. From the fact that it seldom rains from April to October in the raisin district in California, the raisins can be cured in the open air. Large trays of the fruit are placed between the rows in the vineyards. These European types of grapes are the ones which are grown in glass graperies, a discussion of which is not germane to this book.

\section{Small-fruits}

\section{RED AND BLACK RASPBERRIES}

The distance at which raspberries should be planted varies with the variety. As a rule, the early sorts may be placed as close as six feet, by four feet in the row, or even less if they are to be allowed to. form matted rows, but the larger-growing late sorts, such as Gregg and Eureka among the black and Cuthbert and Columbian of the reds, should be seven or eight feet apart on rich soil, and four or five feet in the row. After the first year or two the red varieties may be allowed to throw up suckers, so as to form continuous rows. The shoots 
of raspberries sent up one season fruit and die the following year.

Pruning RASPBerries.-Most of the black-cap varieties naturally throw out branches the first season, and with all such it is a good plan to pinch back the new canes as soon as they have reached a height of from two to three feet, according to the full height of the variety. This will hasten the throwing out of side shoots, upon which fruit will be borne the following year. As soon as severe freezing weather is over in the spring, these

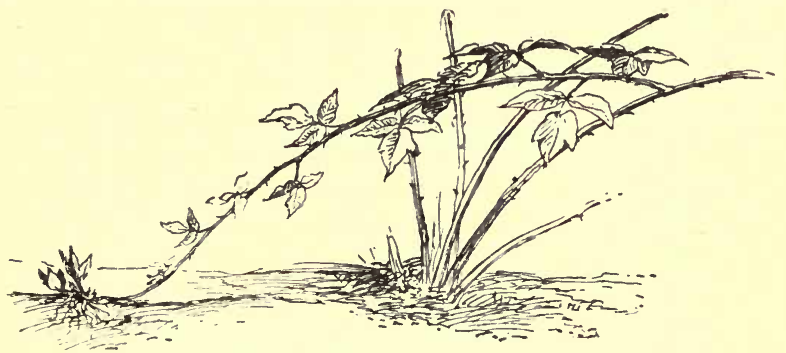

224. Rooting "tip" of black raspberry.

side shoots should be cut back to from nine to twelve inches, according to the strength of the canes and the number of side branches upon them.

The same method of pruning is advisable with red varieties like Cuthbert, which naturally branch freely. Other sorts, like King, Hansell, Marlboro, Turner, and Thwack, that seldom branch, should not be pinched back in summer, as, even though this might induce them to send out shoots, the branches will be weak, and if they survive the winter, will produce less fruit than would the strong buds upon the main canes had they not been forced into growth.

Pruned in this way, nearly all varieties will have stems sufficiently large to support themselves, but as there will 
be more or less breaking down, and injury to the fruit from the bending over of the canes, many growers prefer to support them by means of stakes or trellises. Stakes may be set in each hill, or for matted rows stout stakes three feet high are driven at intervals of forty feet and a No. 10 galvanized wire is stretched along the row, to which the canes are tied. It would be a saving of labor if a wire is stretched either side of the row, as then no tying will be required. As soon as the crop has been gathered, and the old canes are dead, they should be re-

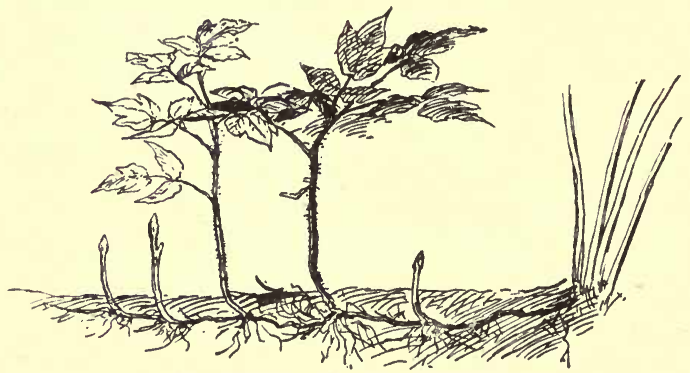

¿25. Suckers of red raspberries.

moved, and at the same time all of the surplus new shoots should be eut away. From four to five good canes will be sufficient for each hill, while in rows the number may be from two to three in each foot.

If it is desired to obtain new plants, the ends of the branches of the black varieties should be covered with soil about the middle of August, when the tips are seen to divide into several slender shoots, and to take root (Fig. 224); these can be taken up and planted the following spring. While the suckers that spring up from the roots of red varieties (Fig. 225), may be used in propagating them, it will be better to use plants grown from root cuttings, as they will have much better roots. 
VARIETIES OF RASPBERRIES.-Of the black sorts the following will be found desirable: Palmer, Conrath, Kansas, and Eureka, which ripen in the order named. In some sections the Gregg is still valuable, but it is somewhat lacking in hardiness. Ohio is a favorite variety for evaporating. Of the purple-cap varieties, Shaffer and Columbian generally succeed. Among the red varieties none are more universally successful than Cuthbert. King is a promising early variety, and Loudon is a valuable late kind. Many growers find Marlboro and Turner well worthy of cultivation, although rather local in their adaptations; while for home use, Golden Queen, a yellow Cuthbert, is much liked.

Diseases.-The most troublesome disease of the raspberry is anthracnose, which attacks the stems, causing large scars, and leads to the drying out of the canes. It is most troublesome in old, neglected plantations, and if very serious it will be best to abandon the plantation and start a new one with healthy plants. Many growers find it necessary to renew their plantation as often as once in five or six years, in order to secure the best results. The use of Bordeaux mixture in the spring, before growth starts, again when the young shoots have reached a height of one foot, and a third application at the end of two or three weeks, will generally secure a healthy growth, provided the old canes have not been severely injured.

\section{BLACKBERRIES AND DEWBERRIES}

In a general way the planting and care of a blackberry plantation is the same as required by raspberries. From the fact that they ripen later in the season, when droughts are most common, even greater attention should be given to locating them upon a soil that is retentive of moisture, and to providing an efficient mulch, which can generally best be secured with a cultivator. The 
stronger-growing varieties should have at least eight feet between the rows, but some of the smaller rows may be planted at six feet. While hill culture is desirable for the garden, commercial growers generally use continuous rows.

VARIETIES OF BLACKBERRIES.-Many of the better varieties of blackberries are lacking in hardiness, and cannot be grown except in the more favorable localities. Snyder and Taylor are most generally successful, although Wilson

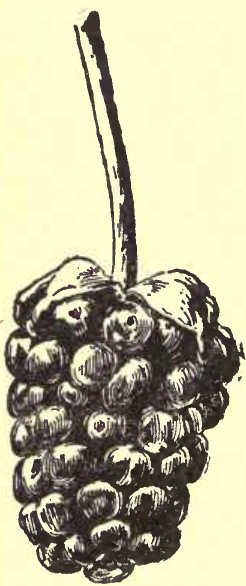

226. Lucretia dewberry. Natural size. and Early Harvest are often grown on a large seale for market, and do well with winter protection. Eldorado is a new sort much like Snyder, that seems hardy and productive. Erie, Minnewaski and Early King are in many sections large and valuable sorts.

Dewberries are trailing blackberries. They are usually earlier, and can be more easily protected in winter. They should be trained to a trellis or tied to stakes. Lucretia (Fig. 226) is the leading variety.

Diseases.-The most troublesome disease of the blackberry is orange rust, which often proves very destructive, particularly to Kittatinny and a few other sorts. While spraying may aid in preventing its spread, there is no remedy, and on the first appearance of the disease the infected canes should be removed and burned.

\section{CURRANTS}

Currants delight in a cool, moist soil, and cannot be grown successfully in the southern states. While many growers place them five feet each way, some prefer to 
have them six or seven feet between the rows. For the first year or two after planting, the currants require but little eare in pruning, except to eut back the new shoots about one-half; and if very thick, to remove the weaker ones. As the fruit is borne upon the old canes, there should be in each hill at least five or six fruiting stalks, which should be allowed to remain until four or five years old, when they should be removed and new canes provided to take their place. As the vines get older, the annual pruning will consist in the removal of one or two of the old canes and the thinning out of all surplus shoots. One or two new shoots should be allowed to remain, to take the place of the old ones that are removed.

INSECTS AND DISEASES OF THE CURRANT.-Currants are frequently much injured by borers, which work in the pith of the canes and destroy them. Varieties with a large pith and soft wood are most troubled by them. All dead and dying canes should at once be removed and burned, as should all canes that in pruning are found to have the borers in them. The currant worms also do much harm, and frequently defoliate the plants. The eggs hatch when the leaves are about one-half grown, and if the plants are at that time thoroughly sprayed with Paris green at the rate of one pound to one hundred and fifty gallons of water, the first brood will be destroyed and there will generally be little trouble from the second. If they appear after the fruit is half grown, they can be destroyed with pyrethrum, used at the rate of a tablespoonful to a gallon of water. Currants are also likely to be injured by various forms of leaf-blight, but the foliage can be preserved by the use of Bordeaux mixtur in the spring and again after the erop has been gathered. The first application may be made at the same time as that of the Paris green for the currant worms.

VARIETIES OF CURRANTS.-In most sections the Red 
Dutch will be found to be the most satisfactory variety, as the plants are much less injured by borers than are Cherry, Fay and Versailles, which are larger and better varieties, and are to be preferred in sections where the borers are not troublesome. Victoria is a valuable market sort where borers are numerous, as they are little injured by them. The same is also true of Prince Albert, which is little attacked by eurrant worms and is particularly valuable as a late sort. White Duteh and White Grape are valuable light-colored varieties, and Black Naples as a variety for jelly.

\section{GOOSEBERRIES}

While this fruit, like the currant, delights in a cool, moist soil, it should only be planted where it ean have a free circulation of air, unless it is in partial shade. The distance should be the same as given for the currant, and it will well repay the best of eultivation. From the tendency of most varieties to throw up suckers, eareful attention should be paid, particularly while the plants are young, to the removal of surplus shoots, in order to secure an open head. Aside from the heading-back of the young shoots and the removal of the older canes, little pruning will be required. If soil of a suitable nature cannot be secured, few plants will be more benefited by a mulch.

INSECTS AND DISEASES.-Gooseberries are, even more than the currant, attacked by the currant worms, and the same remedies should be used upon them. In addition to the leaf-blight, gooseberries, particularly the varieties of English origin, are often much injured by powdery mildew, which attacks stems, leaves and fruits. It is most troublesome in dry seasons and on dry soils, especially as the gooseberry thrives best in a cool, moist climate. Much ean be done to prevent its attack by a proper selection of soil; by planting either in a partiai shade, or upon a hill-side, where the air ean have a free 
circulation, as well as by the removal of the lower branches and training the plants in an open, vase-shaped form. The disease yields readily to the application of fungicides, and all plants of European origin should be sprayed in the spring, before growth starts, with Bordeaux mixture, and the application should be repeated at intervals of from ten days to two weeks, from the time the leaves are half-grown until there is danger of spotting the fruit. From that time until the fruit is gathered, a solution of sulphide of potassium, at the rate of one ounce to three gallons, should be used at frequent intervals. After the fruit has been picked, Bordeaux mixture should be applied, and the application repeated on the first appearance of the disease.

Varieties of gooseberries.-For ordinary use the Downing can generally be recommended. It is hardy, productive, of fair size and greenish white in color. Houghton is even more hardy and productive, but the fruit is rather small and of a dark red color. Among the varieties of European origin which can be successfully grown, if the mildew can be prevented, are Industry, Triumph, Keepsake, Lancashire Lad, and Golden Prolific. Among other varieties that are promising, are Champion, Columbus, Chautauqua, and Red Jacket.

\section{STRAWBERRIES}

While strawberries thrive upon a variety of soils, they generally succeed best upon a strong, sandy loam, or a light clay loam. For most purposes it will be found best to grow them in narrow, matted rows. The plants should be set as early in the spring as the ground can be worked, in lows three and one-half feet apart, and from one to two feet in the row, according to the tendency of the variety to form runners. The planting can be done with a trowel, spade, or dibble, taking eare to spread the roots 
out as much as possible and to press the soil firmly about them, holding the plant so that the bud will be just above the surface. If the season is late and the weather is hot and dry, some or all of the older leaves should be removed. If water is used, it should be poured about the roots before the hole is filled and as soon as it has soaked away the remaining soil should be packed about the plants. During the first season the blossom stalks should

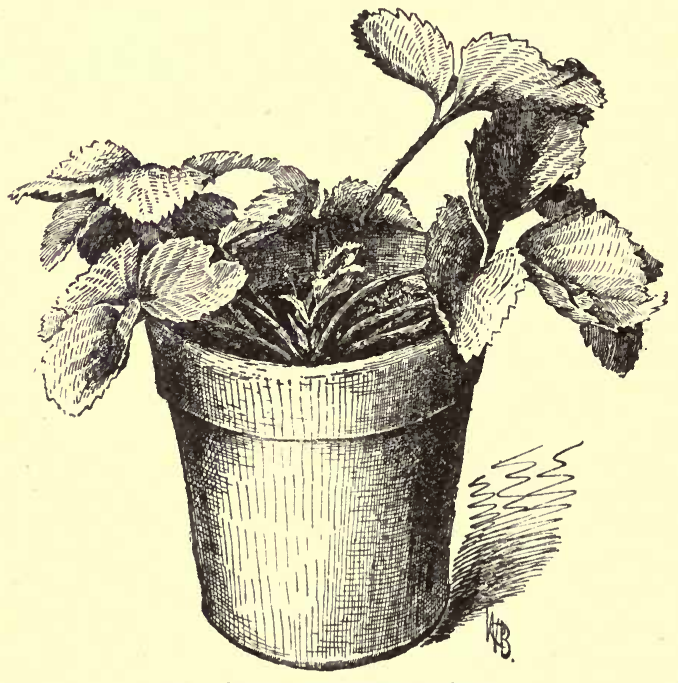

227. Potted strawberry plant.

he removed as soon as they appear, and the runners should he restricted to a space about one foot wide. Some persons prefer to still farther reduce the number of plants, and after layering from three to four plants between those originally set, all others are removed.

Strawberries are often set in August or September, but 
thi:s is advisable only for small patches or when the soil is in the best possible condition and the highest culture is given. For garden culture, it may pay to secure potted plants (Fig. 227). These are sold by many nurserymen, and they may be obtained by plunging pots beneath the runners as soon as the fruiting season is passed. In August, the plart should fill the pot (which should be three-inch or four-inch) and the plant is ready for setting in the plantation. Such plants should bear a good crop the following spring.

With the highest culture, good results can be obtained from the hill system of growing strawberries. For this the plants may be set in rows three feet apart and one foot in the row, or if it be worked both ways, they may be from two to two and one-half feet each way. In the small garden, where a horse cannot be used, the plants are frequently set one foot each way, arranging them in beds of from three to five rows, with walks two feet wide between them. As fast as runners form, they should be removed, so that the entire vigor of the plant will be exerted in strengthening the crown. When extra fine specimen berries are desired, the plant may be held above the ground by a wire frame, as shown in Fig. 228.

During the first season strawberries should be frequently worked, rather deep at first, but as the weather becomes warm and the roots fill the ground, it should be restricted to a depth of not more than two inches. The weeds should never be allowed to get a start, and if the season is dry, cultivation should be so frequent that the surface soil should at all times be loose and open, forming a dust mulch to conserve the moisture. If the fall is moist and the plantation free from weeds, there will be little oceasion for cultivation after the first of September, until just

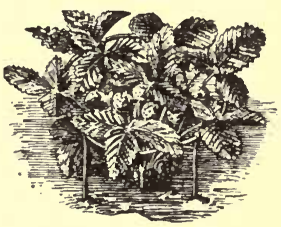

228. Strawberry grown on a rack. 
before the ground freezes up, when a thorough cultivation should be given. In addition to the horse cultivation, the hoe should be used whenever necessary to loosen the soil about the plants and to destroy weeds that may start in the row.

After the ground has frozen, it will be advisable to mulch the plants by covering the space between the rows with some waste material to the depth of about two inches. Directly over the plants a covering of one inch will generally suffice. The material used should be free from the seeds of grass and weeds, and should be such as will remain upon the beds without blowing off and that will not pack down too closely upon the plants. Marsh hay makes an ideal mulch, but where it can not be secured, straw will answer. Corn fodder makes a clean but rather coarse mulch, and where they can be held in place by some other material, forest leaves do well as a mulch between the rows. In the spring the straw should be removed from over the plants and allowed to remain between the rows as a mulch, or all of it may be removed and the soil worked with a cultivator.

A large crop should be produced the second season, and many believe it best to renew the plantation each year, but if the plants are healthy and the ground free from grass and weeds, the plantation can often be retained for a second crop. It will be well to plow the soil away from the rows so as to leave but a narrow strip, and along this the old plants should be cut out so as to leave the new plants about one foot apart. If this is done in July, the rows should fill up by winter, so as to be in about the same condition as a new bed.

VARIETIES OF STRAWBERRIES.-For most parts of the country, Haverland, Warfield, Bubach and Gandy afford a succession and are all hardy and productive varieties. The first three are imperfect-flowered varieties and some such perfect-flowering kinds, as Lovett or Beder Wood, 
should be provided to fertilize them. Among other varieties that do well in most sections, are Brandywine, Greenville, Clyde, and Woolverton. Parker Earle is very late, and is valuable for either home use or market, upon strong, moist soils, where it can have the best of care. William Belt and Marshall have large, showy fruits, and do well on strong soil.

INSECTS AND DISEASES OF THE STRAWBERRY.-The insect most eommonly troublesome to the strawberry grower is the common June-bug, or May-beetle, the larvæ of which are often very common in land that has been in sod. Two years should elapse before sod land is used for this crop.

Cut-worms are often troublesome, but plowing the land the fall previous to setting the plants will result in destroying many of them. They can be poisoned by sprinkling about the field elover or other green plants that have been soaked in Paris green water.

There are also a number of leaf-rollers and other larvæ that feed upon the foliage of the strawberry, but they will do little harm, if on their first appearance the plants are thoroughly sprayed with Paris green water.

The most common fungous disease of the strawberry is leaf-blight or "rust," which frequently causes much injury to the foliage, and may result in the loss of the crop. Varieties least subject to the disease should be chosen for planting, and upon suitable soils and well eared for, there need be little loss from this disease if the plantation is frequently renewed. 


\section{SECTION V}

\section{THE VEGETABLE GARDEN}

It is essential to any satisfaction in vegetable growing that the soil be rich and thoroughly subdued and fined. The plantation should also be so arranged that the tilling can be done with wheel tools, and, where the space will allow it,

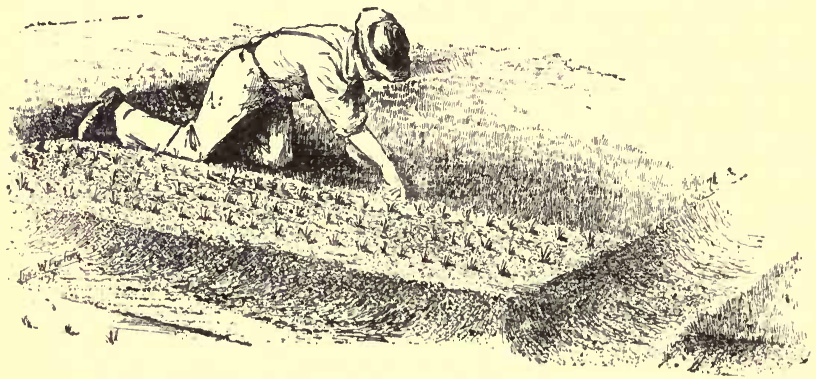

229. Cultivating the back-ache.

with horse tools. The old-time garden bed (Fig. 229) consumes time and labor, wastes moisture, and is more trouble and expense than it is worth.

The rows of vegetables should be long and continuous, to allow of tillage with wheel tools. If it is not desired to grow a full row of any 


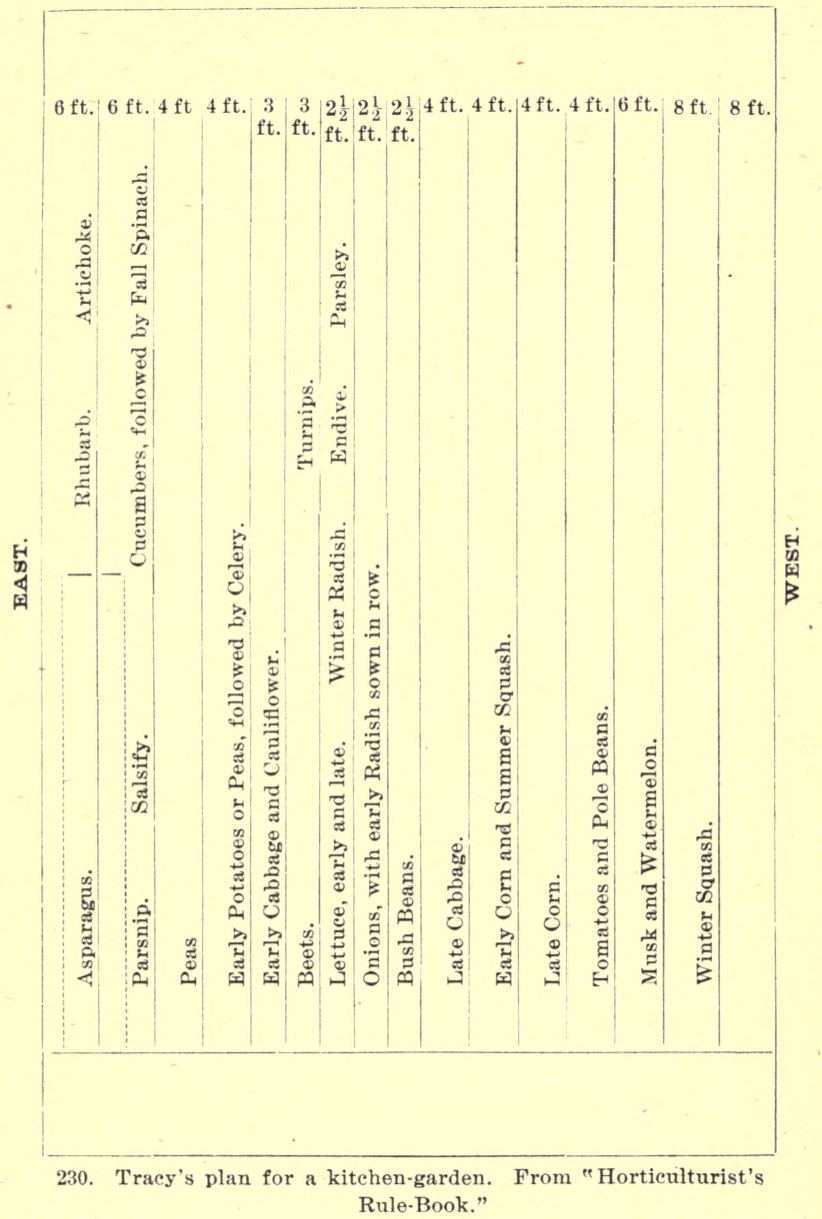


350

one vegetable, the row may be made up of sev. eral species, one following the other. One or

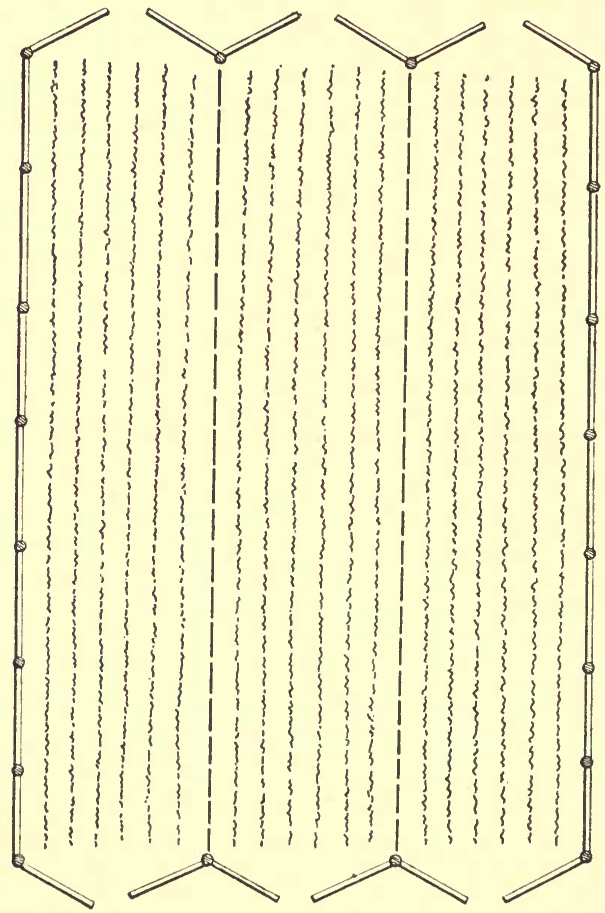

231. Suggestion for a garden fence.

two long rows containing a dozen kinds of vegetables are usually preferable to a dozen short rows, each with one kind of vegetable. Fig. 230 shows a good plan for a kitchen garden. Fig. 


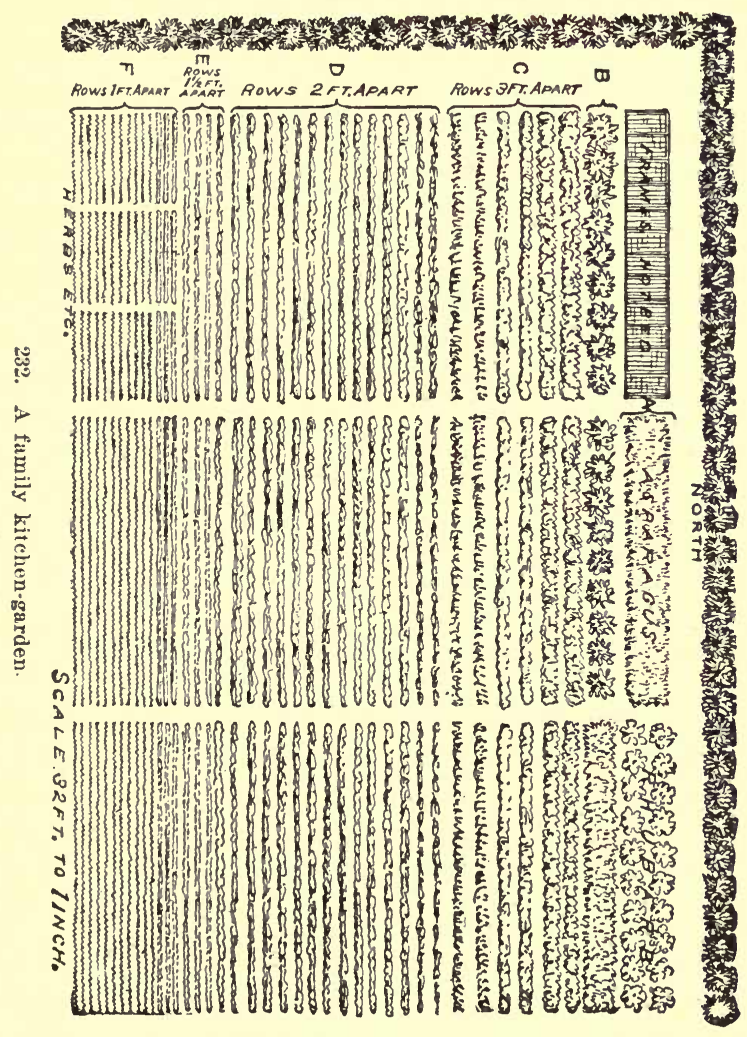


231 is a plan of a fenced garden, in which gates are provided at the ends to allow the turning of a horse and cultivator (Webb Donnell, in Ameriean Gardening). Fig. 232 shows a garden with continuous rows but with two breaks running across the area dividing the plantation into blocks. The area is surrounded with a windbreak, and the frames and permanent plants are at one side.

It is by no means necessary that the vegetable garden should contain only kitchen-garden vegetables. Flowers may be dropped in here and there, wherever a vacant corner occurs or a plant dies. Such informal and mixed gardens usually have a personal character which adds greatly to their interest, and, therefore, to their value. One is generally impressed with this informal character of the home-gardens in many European countries, a type of planting which arises from the necessity of making the most of every inch of land. It was the writer's pleasure to look over the fence of a Bavarian peasant's garden and to see, on a space about forty feet by one hundred feet in area, a delightful mixture of onions, pole beans, peonies, celery, balsams, gooseberries, coleus, cabbages, sunflowers, beets, poppies, cucumbers, morning-glories, kohl-rabi, verbenas, bush beans, pinks, stocks, currants, wormwood; parsley, carrots, kale, perennial phlox, nasturtiums, feverfew, lettuce, lilies! 


\section{HOW TO GROW VEGETABLES*}

(F. A. WAUGH)

\section{Root Crops and Tubers-Beet, Carrot, Parsnip, Potato, etc.}

To grow root crops, loose and deep soil, free from clods, is required. The land must also be perfectly drained, not only to remove superfluous moisture, but to provide a deep and friable soil. Subsoiling is useful in hard lands. A large admixture of sand is generally desirable, provided the soil is not apt to overheat in sunny weather.

To keep roots fresh in the cellar, pack them in barrels, boxes or bins of sand which is just naturally moist, allowing each root to come wholly or partly in contact with the sand. The best material in which to pack them is sphagnum moss, the same which nurserymen use in packing trees for shipment, and which may be obtained in bogs in many parts of the country. In either sand or sphagnum, the roots will not shrivel; but if the cellar is warm, they may start to grow. Roots can also be buried after the manner of potatoes.

BEETs are best grown in drills three and a-half feet apart. The seeds, if fresh, are sown rather sparsely very early in the season, and covered with an inch of mellow soil. The young plants will endure light frost. When the plants begin to grow they should be thinned to six or eight inches in the row. The young plants which are removed may be used for greens. For winter beets, sow in July or August in the same manner, and after the first heavy frost take up the roots, cut off the tops, sort, and store in a root cellar or pit. For first crop, select short or globular varieties, such as Extra Early Egyptian, Early Eclipse or Bastian's

*Mushrooms, being grown indoors, do not come under the purview of this book. Consult Falconer's book on "Mushrooms."

For suceinct advice on the treatmient of insects and fungi, consult the last edition of Horticulturist's Rule-Book. 
(Fig. 233) Blood Turnip. For winter crop, choose Long Dark Blood. Some of the early varieties, when sown late, are also good keepers. (For Swiss Chard, see page 379.)

Beets are generally free from insect and fungous troubles, although a leaf-blight is common in some places. For

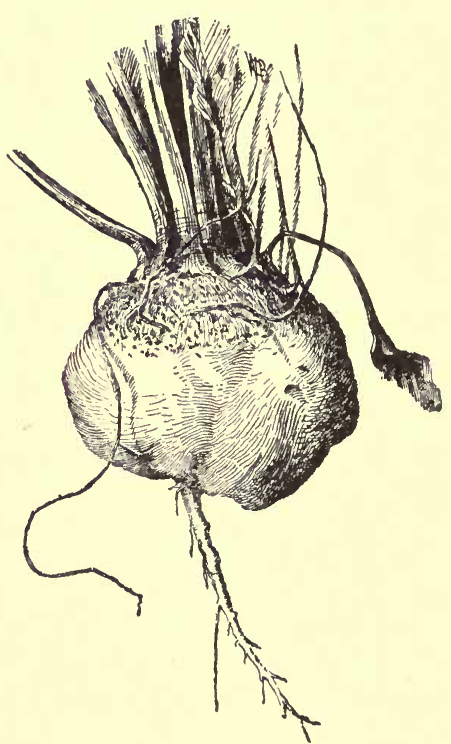

233. Bastian Turnip beet.

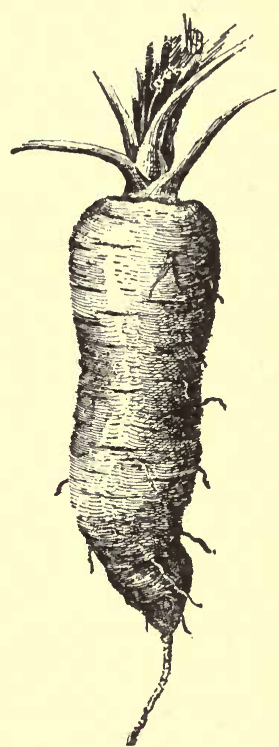

234. A half-long carrot.

this two or three sprayings with Bordeaux mixture, before the disease makes headway, are effective.

TuRnips should be grown in drills, like beets, for the early crop. The young plants will stand light frosts. Choose a rainy day for planting, if practicable. Cover the seed very lightly. Thin the young plants to five to seven inches in the row. Sow every two weeks if a con- 
stant supply is desired, as turnips rapidly become hard and woody in warm summer weather. For the fall and winter crop in the North,

"On the fourteenth day of July,
Sow your turnips, wet or dry."

In many parts of the Northern and Middle states tradition fixes the 25th of July as the proper time for sowing flat turnips for winter use. In the Middle states, turnips are sometimes sown as late as the end of August.

Or, take advantage of any convenient leisure at about that season to prepare a piece of very mellow ground, and sow the seed thinly and evenly broadcast. In spite of the old rhyme, a gentle shower will then be acceptable. These turnips are pulled after frost, the tops removed, and the roots stored in cellars or pits. For the early crop, Purpletop Strap-leaf, Early White Flat Dutch and Early Purpletop Milan are the favorite varieties. Yellow-fleshed sorts like Golden Ball are very fine for early table use, when well grown, but most eaters prefer white turnips in spring, although they occasionally patronize the yellow varieties in the fall. Yellow Globe is the favorite yellow fall turnip, though some persons grow yellow ruta-bagas and call them turnips. For late crop of white turnips, the same varieties chosen for spring sowing are also desirable.

RUTA-BAGAS are distinguished from turnips by their smooth, bluish foliage, long root and yellow flesh. They are richer than turnips; but they require the same treatment, except that the season of growth is longer. Fallsown or summer-sown bagas should have a month the start of flat turnips.

Except the maggot (see Radish), there are no serious insects or diseases peculiar to turnips and bagas.

CARrots should be kept on hand in a state of tender immaturity throughout the season, to be used in soups, salads, boiled dinners, and other savory cookery. With this in view, several small successional sowings should be made of 
small-growing, fine-grained varieties, as Early Scarlet Horn or Earliest Short-horn. Early Half-long Scarlet (Fig. 234) is desirable for later crops and for storing in

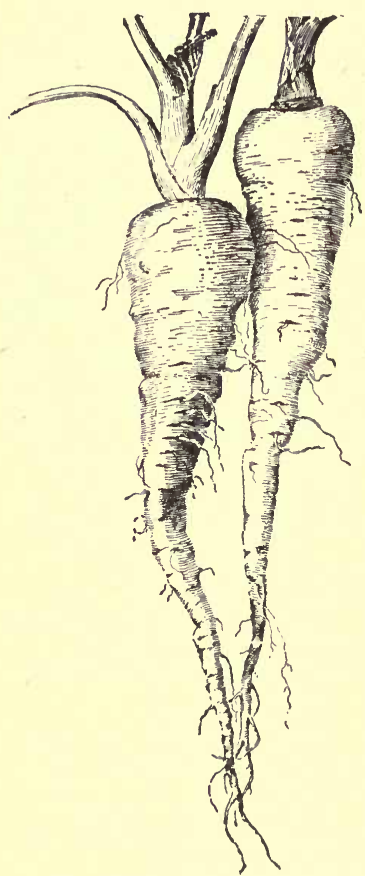

235. Student parsnip.

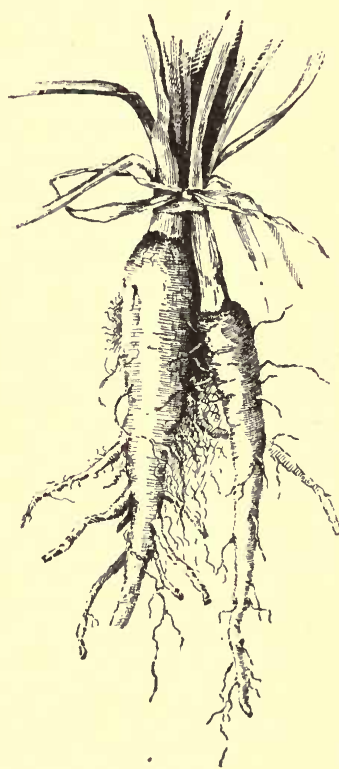

236. Salsify.

the root-cellar for winter use. Carrots for the kitchengarden may be sown very early in drills one foot apart in beds, or three by three and a half feet apart for horse cultivation. Cover the seed very lightly, pressing down the soil firmly. Thin young plants to four inches in a row. 
Carrot seed is small, and germinates slowly. Be careful that the earth does not bake over the row before the plants come up. Radish seed sown in the same drill (page 37) will break the crust and mark the row. For late crop, seed may be sown as late as midsummer, unless the very large varieties are used.

There are no serious enemies or diseases.

PARsNip. Treat exactly like carrot, so far as sowing and thinning are concerned. For early use and summer successions, plant Early Round, and for later crops Long Smooth, or some good strain of Hollow Crown. Parsnips may be left in the ground all winter without protection, and the roots are then dug in warm spells, or in spring, as wanted. The main-crop varieties, as Long Smooth, Hollow Crown and Student (Fig. 235) require the entire season in which to grow.

No serious enemies or diseases.

SALSify (Fig. 236). This delicious and much-neglected vegetable requires the entire summer for its development. Sow in early spring, being careful not to plant too thick. Thinning is a little diffleult, but the plants must not be crowded. Leave four to five inches between plants. When the ground does not freeze excessively, salsify roots may be left out throughout the winter, and dug whenever a potato fork or a crowbar will get them out. Usually, however, the roots should be dug before the soil freezes, and stored in slightly moist soil, or in moss, in a frame or cellar. Mammoth Sandwich Island is practically the only variety offered for sale.

No enemies.

RADISH. The first erop in spring should be grown in hotbeds or frames (See pages 67 to 88 ) ; but a tolerably early crop may be secured in the open ground. A mellow "quick" soil is essential. Radishes do not thrive in elay. Radishes must grow very rapidly to be tender, and they should be eaten while still small. Sow in drills a foot or 
fourteen inches apart, and thin to three inches in the row as soon as the young plants are well up. There are many desirable early varieties, as French Breakfast, Olive-shaped Scarlet, Early Scarlet Turnip and Red Turnip, the red or pink varieties usually having the preference for table use. Long Scarlet Shorttop is a standard late variety.

In summer, the small spring radishes do not thrive, but larger and white varieties are then used, as White Strasburg and Stuttgart. There are winter radishes, - as California Mammoth White, Long Black Spanish, Scarlet Chinese,-

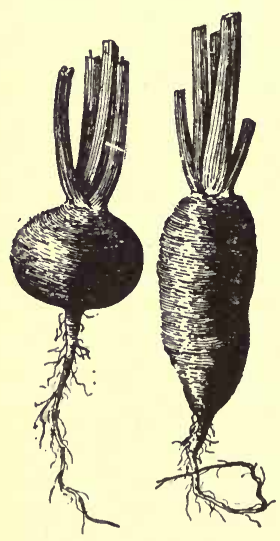

237. French Breakfast and Olive-shaped radishes.

which may be stored as beets and turnips are.

The radish is very liable to the attacks of grubs, which are the lavæ of a small fly. These insects burrow in the root, and make it "wormy." The only effective escape is to plant in soil which has not been infested within two or three years. Constant rotation will keep the pests in check; but they also work on turnips. When the insects are troublesome, the crops should be grown on op-

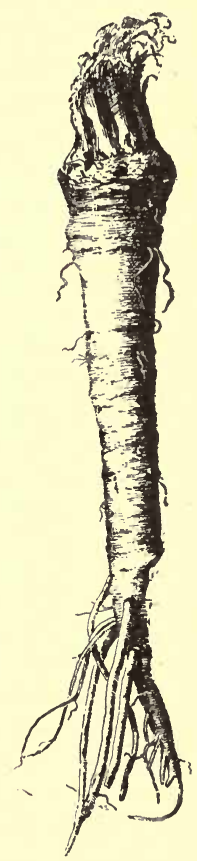

238. Good horse-radish root. posite sides of the garden in successive years, and when they are very bad it may be necessary to give up growing radishes and turnips for a time. The bisulphide of carbon treatment recommended for cabbage is effective, but would hardly pay with radishes. 
HoRSE-RADISH is a perennial, but for market it is chiefly grown as an annual erop. It is propagated by "sets," which are small roots (the size of one's finger or a lead pencil), which are trimmed from the large roots when the erop is stored in the fall. These sets should be four to six inches long, the top end eut off square, so as to mark the right end up, for if the sets are planted wrong end up, crooked roots will result. To raise good horse-radish, the land should be deep and loose. The sets are planted two or three inches deep in a vertical position, and fifteen to eighteen inches apart. It is customary to plant them in alternate rows or ridges in plantations of early beets or spinach, or other spring erops, allowing the roots to be three or three and one-half feet apart. Plant early, and by early summer let the horse-radish have all the land. The roots (Fig. 238) are dug in late fall, and eare is taken to get all the pieces of roots out of the land, for the plant is apt to become a bad weed. If the land is plowed up deep and loose in the fall, most of the remaining roots ean be picked out in spring. If old roots or erowns are planted, crooked and branchy roots are obtained.

Potato. The culture of the potato is so simple and well known as to need no description. Level culture is usually best. Early Ohio, Polaris, and Rural NewYorker are favorite varieties among hundreds of good ones. (Consult Farmers' Bulletin 35, U. S. Dept. Agr.; also Bulletin 140, Cornell Exp. Sta.)

SwEeT Potato plants are usually started in hotbeds, by planting the tubers. The plants are then slipped off the tubers with the thumb, and set two feet apart in rows five or six feet apart. Frequently the rows are ridged, but this will depend on soil, elimate and drainage. Varieties differ greatly; but selection among them is mostly a matter of taste. Some persons prefer the dry, mellow, yellow or white potatoes, others choose the sugary yams. Yellow Nansemond, White Nansemond, 
Southern Queen and Vineless are generally in good repute. (Consult Farmers' Bulletin 26, U. S. Dept. Agr.; also Price's "Sweet Potato Culture for Profit.")

\section{Alliaceous Group-Onions, etc.}

ONion: Onions may be grown from seeds or from sets. If seeds are used they may be sown in the open ground where the bulbs are to mature, or they may be sown in greenhouses or hotbeds and the young plantlets transplanted to the rows in the open ground. In sowing out of doors, seeds should be put in as early as possible, in shallow drills three to three and onehalf feet apart, and covered with a half inch of fine, moist earth. They need to be very carefully weeded at first, but if the ground is clean and mellow and the rows straight the wheel-hoe will be able to take full charge of the work early in the season. It has been repeatedly shown that cheaper, better and earlier onions can be grown by transplanting the plants from greenhouses or hotbeds, where the seeds are sown very early. When the plantlets are as large as a lead pencil, they are set four inches apart in rows

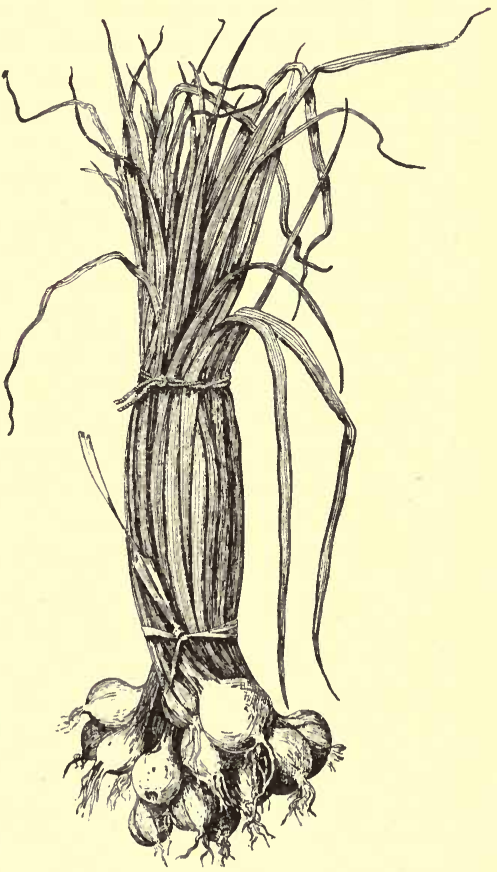

239. Bunch onions grown from seed of the Italian type. 
three feet asunder, and cultivation is immediately begun with the wheel-hoe. In growing from sets the planting is made in much the same way. Multiplier or potato onions are similarly managed.

Varieties.-Prizetaker is probably the most popular variety of the present day. Yellow Globe Danvers is also a favorite. The Wethersfield Red is the type of redbulbed sorts, and the Silver-Skin the most popular white variety. Varieties variously known as "Spanish," "Italian," "Bermuda," or "European" onions are often grown, particularly in the South and in California. Large White Italian Tripoli, Red Italian Tripoli and Giant Rocea are representatives of this class. (Consult T. Greiner, "New Onion Culture," and "Onions for Profit;" Watts, "Onion Culture," Farmers' Bull. 39, U. S. Dept. Agr.; W. J. Green, Ohio Exp. Sta. Bull. Vol. III, No. 9, 2d Ser., and N. Y. State Exp. Sta. Rpt. 1888, p. 190.)

Chives are propagated by division. Secure some of the divided plants, set them in a corner of the garden, and go to them when onion flavoring is wanted. The plants are vigorous, and will care for themselves if not choked out by weeds. Chives are perennials, and last for years.

LEEK may be grown in the same way as onions. If long white stems are wanted for eating raw, the plants should be blanched by deep planting and subsequent embanking, something after the manner of treating celery.

\section{Leguminous Group-Beans and Peas}

STRING BEANS are among the most popular of early spring vegetables. Their value depends largely on having them early, and for this reason they should be sown as soon as there is a reasonable probability of immunity from frost. Sow every two weeks thereafter for general use. For the earliest crops sandy soil and a southern exposure should be sought. The soil should be well prepared and well fertilized. It is useless to try to force early vegetables 
on a soil which compels plants to forage far and wide for a bare living. It is also evident that only the most soluble fertilizers should be used. The seed should be put in drills three and one-half feet apart if room can be afforded to work the ground with the horse, or the drills may be eight or nine inches apart in a bed if space is very limited. In the latter case, an abundance of water and manure is indispensable. Care should be taken, especially when rows are near together, not to sow too thick in the drills. One strong plant every four inches is better than three weak ones in the same row. If the ground is in good condition, without lumps, cultivation can be done with a horse eultivator, the wheel-hoe and the hand hoe. There is a grave mistake somewhere when beans or peas have to be weeded by hand.

Beans should not be planted too deèp, or the growing top of the germinating plantlets will be torn off as they are pushed through the ground. Cover one and one-half to two inches. All varieties which are to be used green should be scrupulously picked as soon as fit to eat. If allowed to ripen they stop growth and production on the bearing plants.

Probably the worst disease of string beans is the bean anthracnose, which causes brownish or reddish pitted spots upon the pods, spoiling their appearance and diminishing the yield. This may be successfully treated by soaking the seed for an hour before planting in a solution of three ounces of copper carbonate and one quart of ammonia to four and one-half gallons of water.

The bean weevil is often a serious enemy in dry beans. Its ravages may be somewhat controlled by killing the insects in seed beans, either by subjecting them to a temperature of $145^{\circ} \mathrm{F}$. for an hour as soon as gathered, or by treating with carbon bi-sulfid in a closed vessel.

Varieties of String Beans.-The German Black Wax is 
the type of most of the yellow-podded varieties and the progenitor of many; but the newer and more carefully selected sorts are likely to prove best in most situations. Of these Golden Wax, Flageolet Wax, Yosemite Mammoth Wax, Valentine Wax and Refugee Wax are best known. Green-podded snap beans are not so popular, but find fair sale in some markets. Of these Early Red Valentine, Extra Early Refugee and Long Yellow Six Weeks are very good.

Shell Beans.-The varieties most commonly grown for dry shelled beans are White Marrowfat, Boston Pea, and White Valentine.

THE POLE LIMAS are very successful in certain lo. calities, especially southward. Standard varieties are Early Jersey, Dreer's Improved, King of the Garden, Ford's Mammoth, and the Sievas.

THE DWARF LIMAS are of two general types, Burpee's Bush Lima being the best known large sort used shelled and green, and Henderson's Dwarf Lima being the commonest type of the small lima used green or dry. (Consult Bailey, Cornell Exp. Sta. Bulletins 87 and 115.; also N. Y., State Exp. Sta. Rpt. 1883, p. 235, and Kans. Exp. Sta. Rpt. 1889, p. 133.)

PEas. Sow the same as beans, except that they may be planted in earliest spring, even before frosts have passed.

The most serious pests attacking garden peas are the mildew and the pea weevil. The former can be treated with some success by spraying with Bordeaux mixture. The weevil may be killed by the same means suggested for the bean weevil.

Specially selected extra early varieties are offered in every seed catalogue. For the most part such sorts are good. Peas grown carelessly in the garden for a few years deteriorate greatly, and are not worth planting. Extra early varieties of merit are Alaska, Nott's Excel- 
sior, American Wonder, Little Gem, and Premium Gem. Second early varieties of general adaptability are Abundance, Advancer, Heroine, and Horsford's Market Garden. Late sorts and the so-called edible-podded sugar peas are of very limited utility in amateur gardens. The tall or standard sorts should be allowed to climb on brush or chicken wire. The half-standards and dwarfs may be planted in double rows, so that the plants tend to hold each other up.

4. Brassicaceous Group-Cabbage, Kale, Cauliflower, etc.

In the northern states, these plants will all do best when started early in hotbed, frame, or greenhouse, -from the last of February to April-and transplanted to the open ground May first to June first. Still, some persons are successful in growing late cabbage, kale, etc., by sowing the seeds in hills in the open ground where the plants are to mature. It is best to transplant the young plantlets twice, first from the seed-bed to boxes, or frames, about the time the second set of true leaves appears, placing the plants twenty-four inches apart each way, and transplanting again to the open ground in rows four to five feet apart, with plants two to four feet apart in the row. If the plants are started under cover they should be hardened off by exposure to light and air during the warmer hours of several days preceding the final transplanting.

The most serious enemy of cabbage-like plants is the root-maggot. See discussion of this insect on page 96, Fig. 96.

The cabbage-worm (larva of the white butterfly shown in Fig. 240) can be despatched with pyrethrum or kerosene emuision. It must be treated very early, before worm gets far into the head.

The club-root or stump-root, is a fungous disease, 
for which there is no good remedy. Use new land, if the disease is present.

CABbages. Early Jersey Wakefield, Early York and Early French Oxheart are best among extra early varieties. For a medium early erop, Winnigstadt, All Seasons, Succession, All Head, and Large Jersey Wakefield are all good. For late crop, Danish Ball Head, Late Flat Dutch and Large Late Drummond are valuable. Early Red Dutch Erfurt, Red Dutch Drumhead

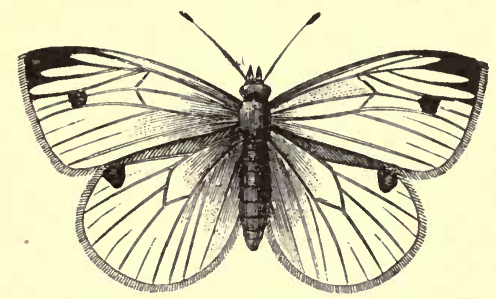

240. Cabbage buttertly (female), parent of the cabbage-worm.

and Mammoth Rock Red, are good red eabbages. Among the Savoys one might choose Perfection Drumhead, Early Ulm, and Extra Early Paris, with a preference for the earlier sorts.

There are many ways of storing cabbages for winter and spring use, none of which are uniformly successful. Upon this point T. Greiner writes as follows: "I have heretofore piled a lot of cabbages cut from the stump in a conical heap in the field, and covered them with clusters of the outer leaves cut off with a piece of the stump. The leaves are earefully placed over the heap in shingle fashion, so as to shed water. Cabbages thus piled and covered may. be left out until real winter weather sets in. But I find that slugs and earthworms frequently infest the cabbages thus stored, and do a good deal of damage. It might be well to 
366

place a solid floor of lime or salt upon the ground, and then pack the cabbages upon this. If to be left

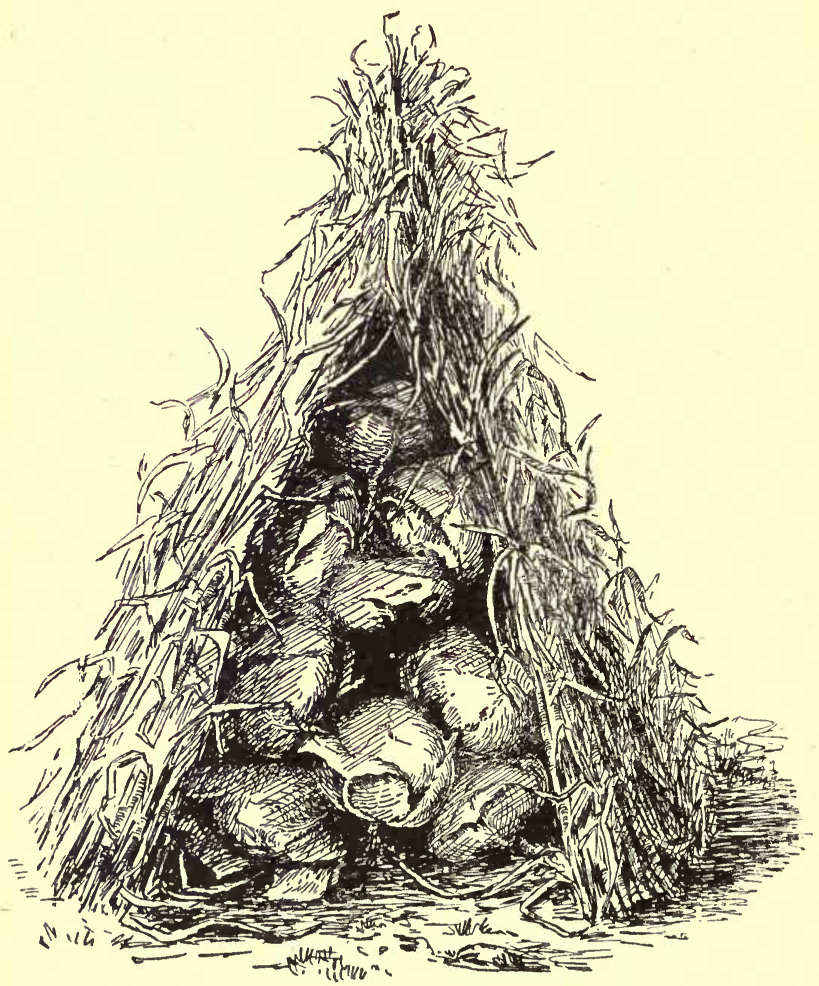

211. Suggestion for storing cabbages.

out after severe freezing has set in, one should put additional covering, such as straw, corn-stalks or marsh hay, over the whole heap. Mr. Burpee's little book, 'Cabbage and Canliflower for Profit,' written by the 
noted cabbage-grower, J. M. Lupton, suggests the following plan for early winter sales: "Take the cabbages up with the roots on, and store in well-ventilated cellars, where they will keep till mid-winter. Or stack them in some sheltered position about the barn, placing one above the other in tiers, with the roots inside, and covering deeply with seaweed; or if this eannot be obtained, something like corn-stalks may be used to keep them from the weather as much as possi-

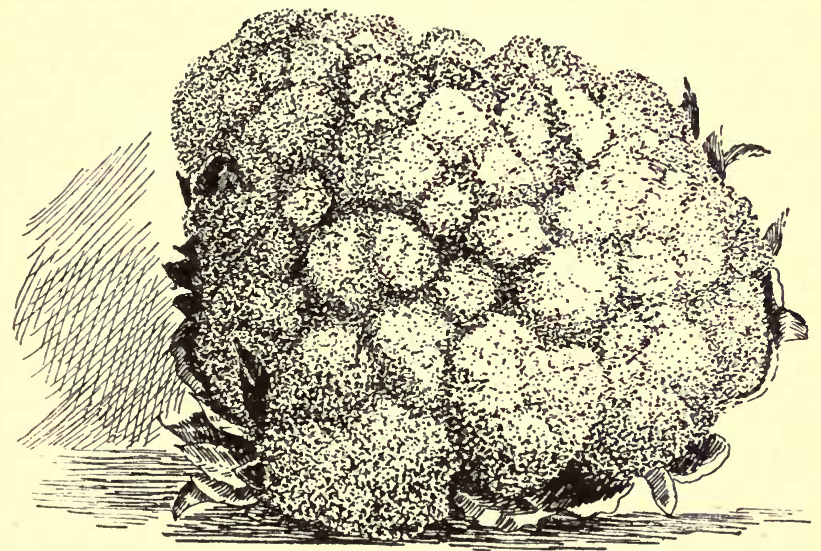

242. A good cauliflower head. Leaves trimmed off.

ble (Fig. 241). When thus stored, they may be obtained any time during the winter when prices are favorable.'"

Cauliflowers, more imperatively than cabbages, demand plenty of water and weather not too hot. When they begin to head, the large leaves should be bent over the inner part to whiten it. The earliest varieties may often be grown in localities where cauliflowers succeed only with difficulty. Extra-early Paris, Extra-early 


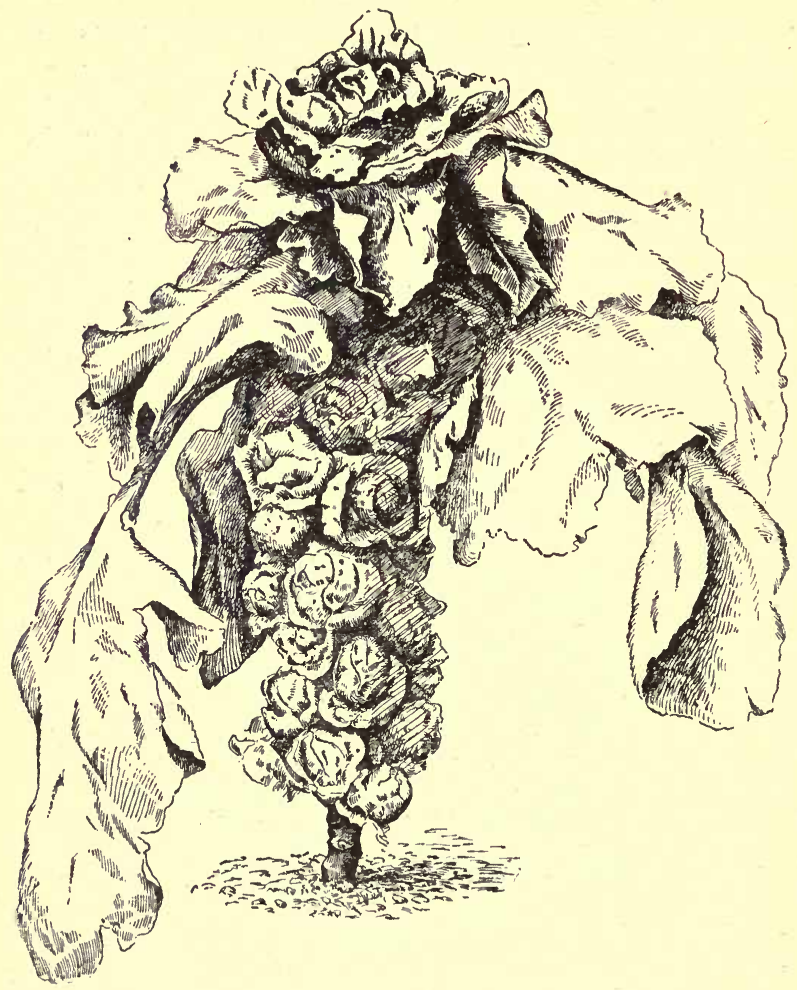

243. A good plant of Brussels Sprouts.

Dwarf Erfurt, and Early Snowball (Fig. 242), are good early varieties. For late planting, choose Autumn Giant and Lenormand Short Stem.

BrocCOLI is in some respects superior to cauliflower, which it very much resembles. The early varieties withstand drought and ill usage better than cauliflower, and 
are, on that account, easier for the amateur to grow. Purple Cape is the hardiest variety, and has the best flavor when cooked, being much finer than cauliflower, but its color is a drawback. The large late varieties, and especially those of a biennial nature, may be avoided. Cultivate in all respects like cabbage.

Brussels Sprouts may also be cultivated exactly like cabbage. As nearly all varieties are for late use, and are better after having been touched by frost, they may be handled with the erop of late cabbage or with kale. Paris Market is the best standard variety. Fig. 243 shows a plant well furnished with the little heads, each an inch or two in diameter.

KALE is also best for use after frost, or even when kept into the winter or till spring. It may thus come in with the later crop of cabbage, being handled in exactly the same way. Dwarf Curled and Tall Curled will please most people best. Kale produces no dense head. The plant is used for "greens."

Collards. This is a southern development of the kale type, which is suitable to warmer climates and longer seasons. It is ranker in growth and

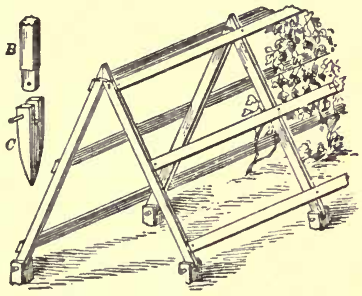

244. A good trellis for tomatoes, holding the vines apart and allowing all fruits to receive air and light. coarser in foliage than the common kales. It is treated precisely like cabbage or kale. Genrgia Collards is the variety mostly grown.

\section{Solanaceous Groups-Tomato, Eggplant, etc.}

These vegetables are all natives of southern zones, and have not yet become so far acclimatized in the North as not to need the benefit of our longest seasons. Plants 

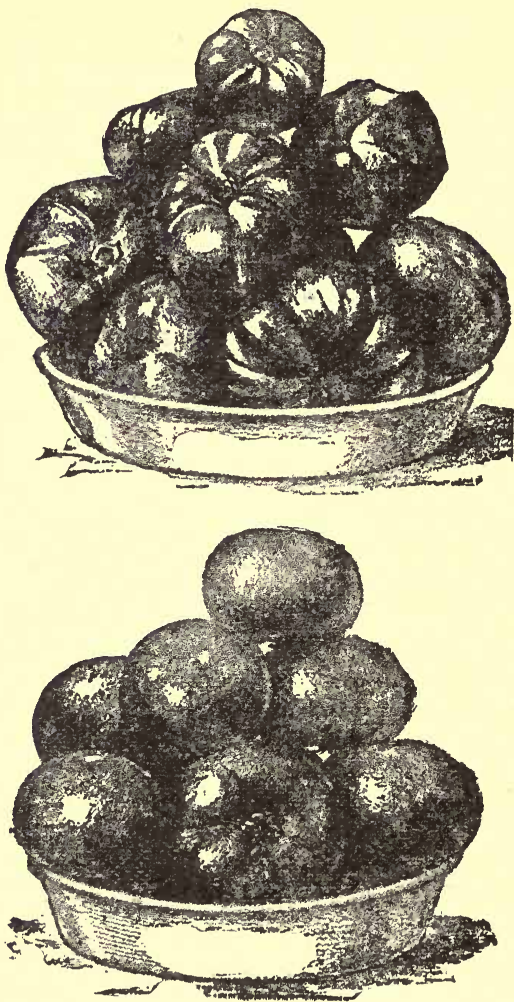

245. Same variety of tomatoes grown on dry and good soil. On the former (upper cut) there was not sufficient moisture to cause the fruit to fill out, and "rough" tomatoes were the result.

should be started early, about March 1, under glass. They should be "pricked off," when the second leaves appear, three or four inches apart, into flats or boxes. These boxes should be kept in a coldframe, to which an abundance of light and air is admitted on warm, sunny days, 
in order to harden them off. After all danger of frost is past, and the garden soil is well warmed, the plants may be finally transplanted.

Tomato plants should set two or four feet apart, according to training, in rows six feet apart. Elaborate systems of training are often discussed and illustrated, but the simplest device which will hold the plants partly off the ground is all that can be recommended to the beginner. Very moderate pruning will sometimes succeed, but systems of close pruning are to be adopted in garden practice with caution.

There are four distinct classes of tomatoes, elassified on the basis of color of the ripe fruit, viz.: Reds, pinks, whites or creamy yellows, and bright yellows. The yellows are of little value. The creamy yellows, like Golden Queen, are very good dessert fruits. The varieties yielding dark red fruits are most popular. Of these Matchless, Stone and Perfection may be safely recommended, though there are many others of value. The pink varieties are typified by Beauty, and by Dwarf Champion, which is a plant of odd, dwarf habit, and well suited to very small home gardens. The Cherry and Pear tomatoes are often grown for preserving. (Consult Bailey, Cornell Bull. 32, and other writings.)

The HUSK TOMatoes (Physalis) sometimes offered in the catalogues on account of their smaller stature, may be treated more like peppers.

Eggrlants are somewhat difficult to manage in the North. It is a prime necessity that the plants shall be vigorous and healthy at the time of transplanting to open ground. Set two to three feet apart in rows three and one half feet apart, and give plenty of fertilizer and cultivation. New York Improved Large Purple is the type of variety chiefly grown (Fig. 246), though some of the smaller white-fruited sorts will doubtless give satisfaction in the home garden. The plants must always 
be started indoors or under glass for the North. (Consult Bailey, Cornell Bull. 26.)

Peppers may be handled like eggplants, although some of the earlier varieties may be grown from seed sown in

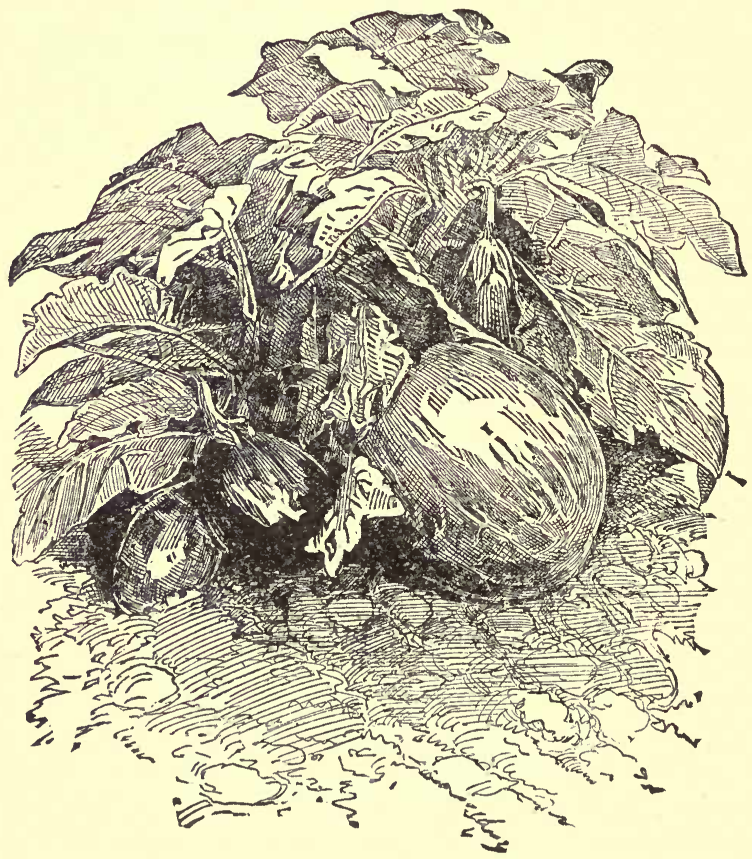

246. A good specimen of eggplant, ripening (in the North) two or three fruits.

the open ground at melon-planting time. Put plants one and one-half to two feet apart; rows three and one half teet apart. Bull Nose, Large Sweet Spanish, Procopp's Giant, Golden Dawn and Ruby King are useful large va- 
rieties for stuffing. Smaller varieties, like Chili, Bird's Eye, Red Cherry and Japan Cluster furnish the most pungency for seasoning.

\section{Cucurbitaceous Group-Cucumber, Melon, Squash, etc.}

All the members of this group are especially suited to outdoor culture, but they are all very tender to frost. Seeds must be planted somewhat shallow from early spring to midsummer. For the earliest cucumbers and melons, seeds are planted in frames. That is, each hill is enclosed by a portable box frame about three feet square and usually having a movable sash cover. The cover is raised or removed in warm days and the frame bodily taken away when all danger of frost is past. In field culture, seeds are planted an inch deep, four to six in a hill, with hills four by six feet apart, these distances being varied slightly according to location and variety. Fine cucumbers are sometimes grown in hills surrounding a barrel in which manure is placed to be leached out by successive waterings.

The omnipresent enemies of all the cucurbitaceous crops are the little cucumber beetle and the large black "stink bug." Ashes, lime, or tobacco dust occasionally seem to show some efficiency in preventing the ravages of these insects, but the only reasonably sure immunity is in the use of covers over the hills (Fig. 93). These covers are made by stretching mosquito netting over ares of barrel hoops or bent wires. If by some such means the plants are kept insect-free till they outgrow the protection, they will usually escape serious damage thereafter.

CuCumbers. The most popular type of this vegetable is the White Spine, which has run into many sub-varieties through diversities of cultivation and selection. The White Spine varieties are excellent for pickles, for slicing, or for foreing. For pickles, the smaller varieties, such as Wethersfield, Chicago Pickle, Farly Cluster, Early Frame, 
Parisian Prolific Pickle and Early Netted Russian are best. For slicing, Long Green and Nichol Medium Green may be added to White Spine. For use ripe, Giant Pera and Giant White are popular in some places.

The Snake cucumber makes good pickles, but is chiefly valuable as a curiosity.

West India Gherkins (Fig. 247) are thrifty and prolific, and make good piekles if eut young.

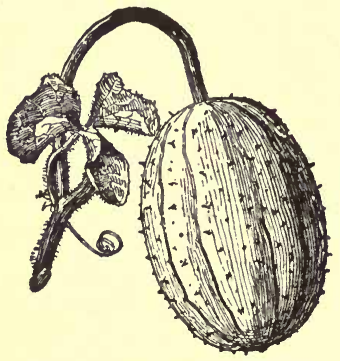

247. West India Gherkin.

Muskmelons should be grown on warm, sandy land. Soil and location make very much difference with the quality. The small green-fleshed netted varieties, improperly ealled canteloupes in many parts, are the favorites for garden culture. Of these, Early Netted Gem and Jenny Lind are the standards. Hackensack is a large spherical melon of fine quality for home or market garden. The Montreal Market is still a size larger, and may be relied on for yield and quality. Banquet is a fine, round, yellow-fleshed variety. Osage is an excellent melon of high quality. There are many other fine melons offered in almost every seed catalogue, and nearly every neighborhood has some favorite local variety.

WATERMELONS are grown to perfection only in. the South, but, South and North, demand a warm soil and exposure. There are several white or yellow-fleshed varieties, but aside from their oddity of appearance they have little value. A good watermelon has a solid, bright red flesh, preferably with black seeds, and a strong protecting rind. Kolb Gem, The Jones, Boss, Cuban Queen and Dixie are the best varieties in general eultivation.

SQdash. Most of the squashes are especially liable to the insect attacks mentioned on the last page. It is, there- 
fore, desirable to secure the most vigorous start possible with the young plants. Among summer varieties, the Patty-pan or Bush Scallop, Red and White, are wellknown. The Yellow Bush Summer Crookneck is one of the most desirable for cooking. The Hubbard squash is still the standard of winter sorts, followed by Marblehead, Fordhook, Essex Hybrid and Boston Marrow. Various Japanese types of squash (Fig. 248), are now

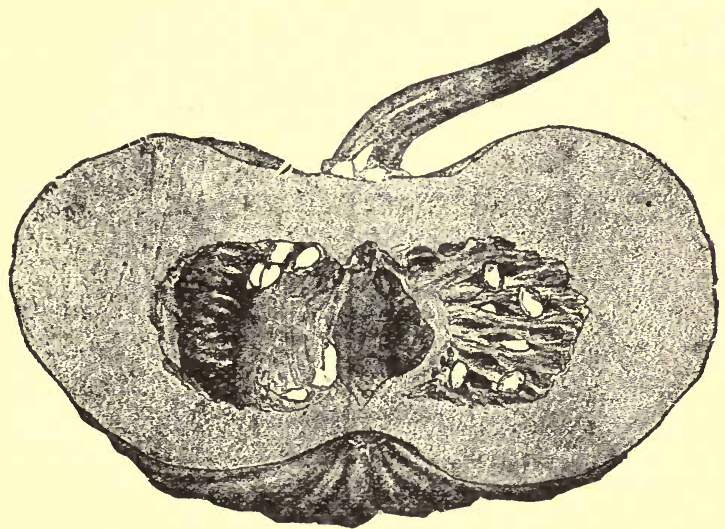

248. A Japanese squash, several types of which are now in cultivation in this country.

eoming to be popular, and many of them are excellent for both fall and winter use.

Pumprins. The old-fashioned yellow Connecticut Field pumpkin, which furnishes the basis of the New England pumpkin pie, has never been superseded in its own important line. The Quaker Pie pumpkin and certain varieties of so-called "sweet pumpkins" have mostly a local reputation and distribution.

Luffa. The "Dishcloth Gourd" or the "Vegetable 
Sponge" is a cucurbitaceous fruit (Fig. 249), seeds of which are now commonly sold by seedsmen. The fibrous interior of the mature fruit is dried and used as a sponge.

\section{Salad Plants and Pot-herbs.}

These plants are all grown for their tender, fresh, succulent leaves. It is, therefore, manifestly expedient that they be grown in warm, mellow ground, well cultivated and copiously watered. Such small plants as cress, corn salad and parsley can be grown in small beds, or even

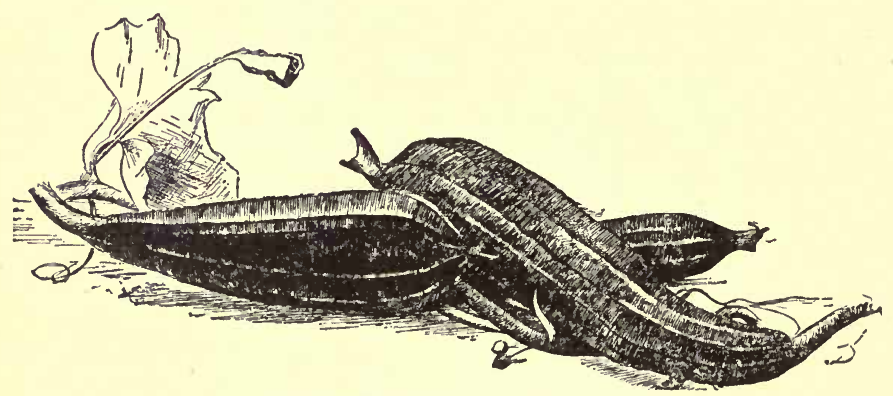

249. Luffa, or Dishcloth Gourd.

in boxes or pots; but in a garden where space is not too scant, they may be more conveniently managed in rows, like peas or beets. This remark applies to all garden erops. Nearly all the salad plants may be sown in the spring, and from time to time throughout the summer for succession. (Consult Waugh, Vermont Exp. Sta. Bull. 54.)

LETTUCE is a typical salad plant, and, unfortunately, the only one well known in America. Seeds may be sown early in drills, the rows being three to three and one half feet apart in the garden, or fourteen inches apart in the bed. Several successive sowings should always be made, 
for lettuce rapidly loses its freshness and crispness. Golden Queen is a desirable early light-colored variety. Boston Market is a favorite with many. Tennisball, Black-seeded Simpson and Hanson are widely known. New York is a fine, strong-growing variety. Of the Cos

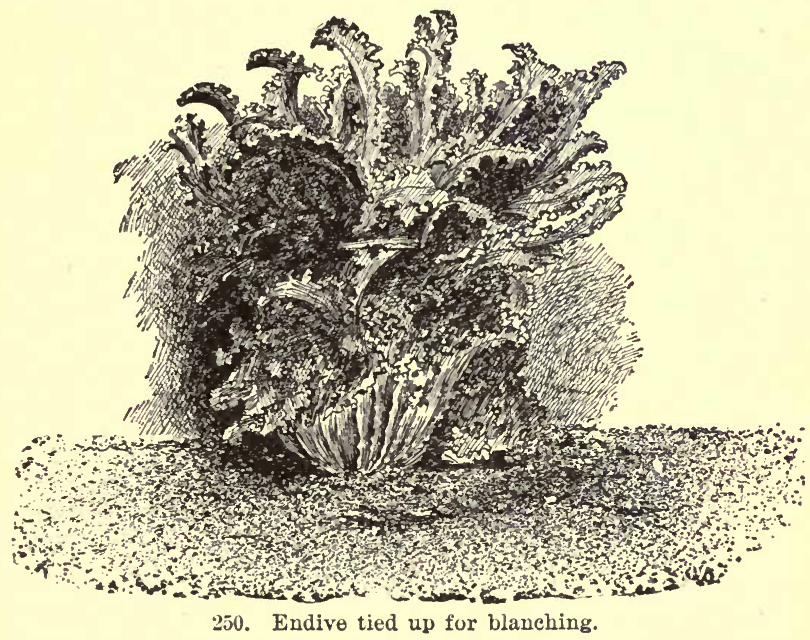

varieties, Trianon and Paris White Cos are best. These are often blanched for market by earthing up about the plants when they begin to head.

CRESS is a name which applies to several very diverse species of plants. The best for garden culture are Australian or Golden Cress, or Extra Curled, or American Curled. These grow rapidly, and are very fine. Upland cress is a different plant, resembling water cress in taste. Water cress may be easily grown almost anywhere that living, shallow water is at command. The garden varieties are sown in shallow drills, as already directed above. 
CoRN SALAD is less pungent than cress, but will not prove so generally useful. It is cultivated precisely like cress. Only one variety is offered by American seedsmen.

ENDIVE may be grown at almost any season of the year, from early spring to late fall. In mild climates it may also be sown in the fall, covered during winter, and harvested at the first opening of spring. Sow in drills, as directed for cress. The plants are best blanched. This is done by tying up the outer leaves on a bright, clear day (Fig. 250), or by covering the row with an inverted trough of boards, like a $\mathrm{V}$ upside down. It is then best to throw some earth against the trough to keep it cool. For winter use, plants may be taken out of the rows in fall, with a large ball of soil upon the roots, and stored in a cellar, or in a tight coldframe till wanted. White Curled is the best variety. Green Curled is hardier, but more refractory in blanching.

ChICory is cultivated like endive, except that it is not so good for successional sowings, but is better for fall sowing and spring use. The plants are grown in drills, and when blanched like endive, make a delectaable salad. The Large-rooted is the variety chiefly grown in America, the roots being used as a substitute for coffee.

DANDELion, when grown and blanched like endive or chicory, makes a very acceptable salad. It is more often used, however, as a pot-herb, that is, for "greens." To secure it early in the spring for this purpose, fall planting is necessary. The plants are then covered with a clean mulch, which is removed at the earliest possible moment in spring. It is worth while to sow selected seed. The Improved Large-leaved is a good variety.

SPINACH is more commonly grown for a pot-herb than any other plant. For early use it should be sown in the fall, and the plants wintered under a clean mulch, 
which is removed as early as possible in spring. But it may be sown early in spring and in succession through the summer. Norfolk Savoy-leaved, Large Round-leaved Viroflay and Prickly are good varieties. Victoria is a recent novelty of real merit. New Zealand is a very different plant; and though not so valuable as the true spinach, adds pleasing diversity to the garden. (Consult Kinney, R. I. Exp. Sta. Bull. 41.)

Mustard. Almost all the mustards are good for greens, though white mustard is usually best. Chinese mustard is also valuable. They should be sown in drills, three to three and one-half feet apart and covered with a half inch of soil. The ease with which they may be grown, and the abundance of herbage which they yield, mark their special utility. (Consult Bailey, Cornell Exp. Sta. Bull. 67.)

ChaRd, or Swiss Chard, is simply a development of the beet species characterized by large, succulent leaf-

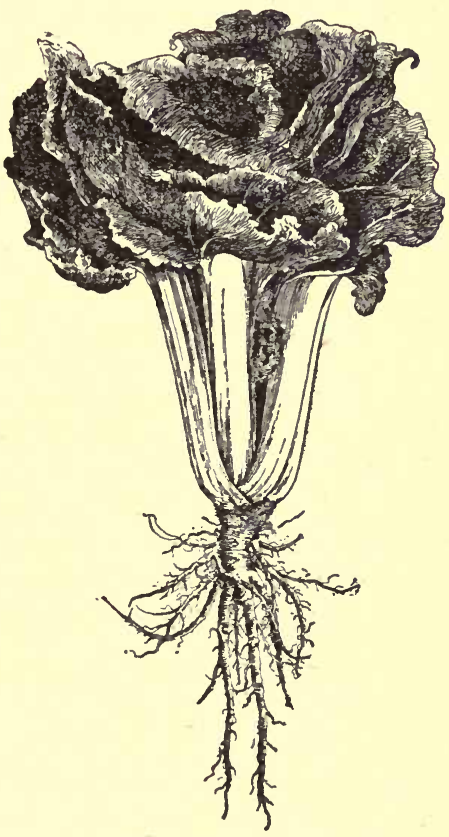

251. Swiss chard. stalks instead of enlarged roots. The leaves are very tender and make "greens" much like young beets. They are cultivated exactly like beets. Only one variety is offered by most seedsmen in this country, though in France and Germany several varieties are grown (Fig. 251). SORREL may be sown in spring, in drills sixteen inches 
apart in beds, or three to three and one half feet apart in rows. After the plants are well established they should be thinned to ten to twelve inches apart in the rows. They are perennial, and may be kept growing in the same place for several years. Broad-leaved French is the most popular variety.

PARsLey. Sow very early in the spring, in shallow drills fourteen inches apart, and thin out to six inches apart in the rows. For very early spring use, seed may be sown in the fall and the plants wintered under a light mulch.. Extra Dark Moss Curled and Dwarf Extra Curled are desirable varieties, though any others will be found satisfactory.

RHUBARB, while, strictly speaking, neither a salad plant nor a pot-herb, should be mentioned here. It may be grown from seed by sowing early in spring in fine, warm soil. But the best way to start it in a family garden is from the divided roots. These may be set two by three feet apart, in a corner of the garden, where they may remain undisturbed for several years. Victoria is perhaps the best named variety.

\section{Miscellaneous Vegetables}

Celery is by no means so difficult to grow as many people think. The seeds should be sown early by sprinkling them thinly on top of a pot, pan or box of good, fine soil, and sifting a very little earth over them. Put them in a moderately warm room, greenhouse or hotbed to germinate. About the time the second leaves put out the plants should be "pricked off" into flats or boxes, being set about one and one-half to two inches apart. As the young plantlets begin to grow they should be "hardened-off" by uncovering the hotbed during the day, or otherwise exposing the plants to sun and air. After the plants have made a growth of four to six 
inches, after the weather is bright and warm, in May or June, and after the soil has been thoroughly prepared, the ground may be marked off for rows three to four feet apart, and the plants set five inches apart in the row. They need to be liberally watered and fertilized, but fermenting manures must be avoided. The rows also need the most careful weeding and hoeing, especially at first.

When the plants are nearly full grown, the blanching may be begun. The older method, consists in drawing up a quantity of loose soil about the plants, holding each one in the hand as it is embanked, and being careful to keep the earth from falling into the celery head. A more modern way is to set up boards on either side of the row, fastening them in place so as to keep out the sunshine. With the self-blanching sorts, which are now mostly grown, this method is easy of practice. Another method consists in setting plants of selfblanching varieties eight or ten inches apart each way in solid blocks,

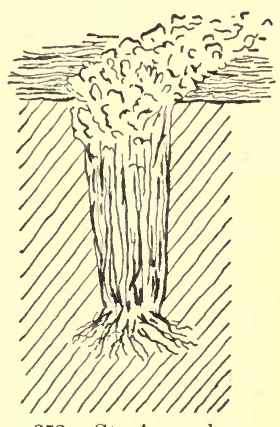

252. Storing celery in a trench.

fertilizing and watering heavily, and depending upon the shading of the crowded plants to do the necessary blanching.

Varieties most popular are White Plume, Pink Plume, Golden Self-blanching, Giant Pascal and Golden Heart. (Consult Greiner's "Celery for Profit," and Kinney's Bulletin 44, Rhode Island Experiment Station.)

There are various methods of storing celery. (Consult Hortieulturist's Rule-Book, 4th ed., and Bulletins, Cornell Exp. Sta.) It may be taken up in late fall and planted close together in trenches (Fig. 252), and then covered with boards; or wider trenches or pits may be made, 
and a temporary shed constructed over the transplanted plants (Fig. 253).

Celeriac, which is occasionally grown for home use, may be cultivated in the same way as celery, except that it does not need blanching. It is usually earthed up slightly, however, some time before harvesting. The edible portion is the turnip-like root (Fig. 254).

Asparagus plants may be grown from seed, but it is easier and cheaper to buy them for small gardens. Good strong two or three-year-old plants should be set in wide open furrows six inches deep, three feet apart in the rows, with rows five feet apart. The furrows are

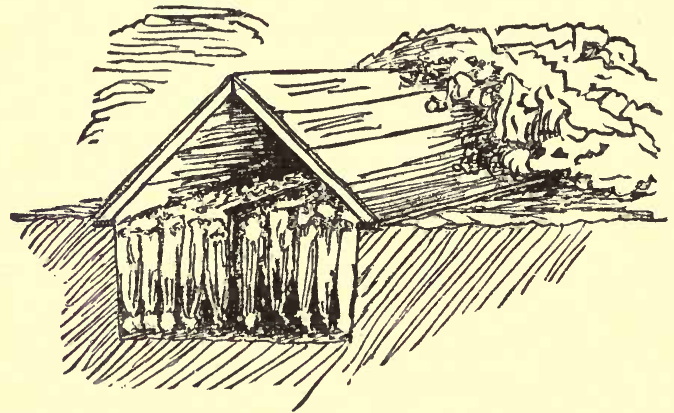

253. Storing celery in a pit.

then filled in slowly during summer cultivation, till the surface is entirely level. For the first two or three years, and occasionally thereafter, a heavy dressing of well-rotted manure should be worked into the surface in spring. Dressings with salt are often advised, but their value has not been fully ascertained.

It is not advisable to cut the bed until the plants are three years set, and the cutting should always cease in June or by the first of July.

In the fall all the old canes should be cut back and 
burned. There is no great difference among varieties, but some of the newer ones, like Columbian Mammoth White or Barr Mammoth, have the presumption in their favor.

In cutting asparagus, the knife should be inserted vertically (A, Fig. 255), so that the crowns will not be cut

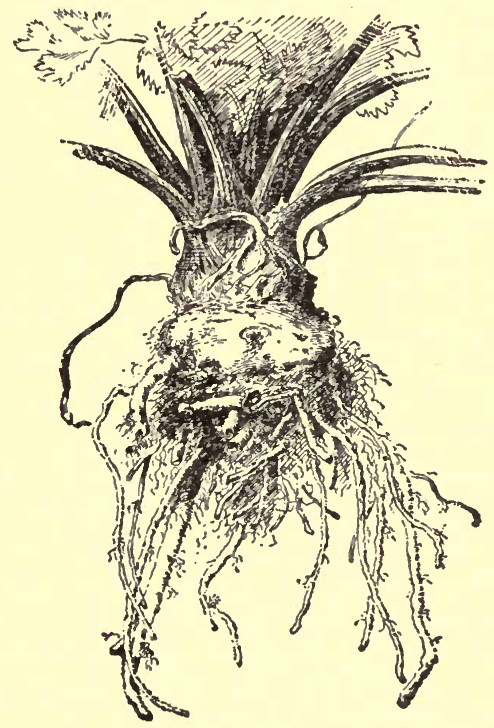

254. Celeriac.

or injured. In the position $B$, the knife may do much mischief.

SweEt Corn. Plant early sweet corn five or six grains to the hill, hills three feet apart, rows three and onehalf to four feet apart, as soon as danger of frost is over. Cover and press down solidly with the hoe. Cory Early, Early Minnesota and Crosby Early are among the 
first to give good eatable ears. For the main crop, Stowell Evergreen, Ne Plus Ultra and Country Gentleman may be relied upon.

OKRA, oR Gumbo. This delicious esculent thrives in heat and drought, but is more difficult to grow in the cooler, moister seasons of our northeastern states. It has the same geographical adaptations as the watermelon. Sow the seed in drills at corn-planting time, in rows three and one-half feet apart, eovering to a depth of one inch and pressing down the soil firmly. Thin the plants out

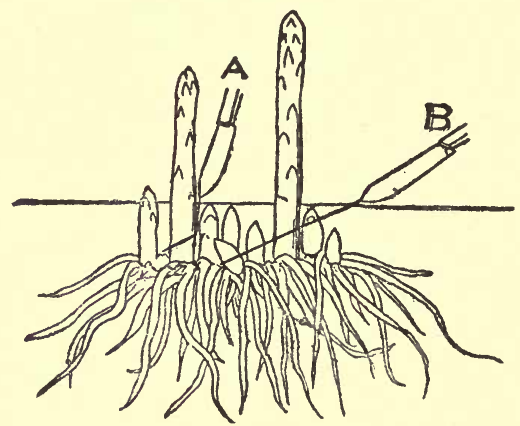

255. Good and poor methods of cutting asparagus.

to a foot or eighteen inches in the row. Cut the edible pods before they get stringy. White Velvet is the most desirable variety.

Martynia. Seed may be planted in late spring in hills three feet apart and rows three and one-half feet apart. Cultivate like tomatoes. The pods for pickling should be cut when quite small.

ARTichokes have never become so popular in this country as to have produced a long list of varieties. Large Green Globe is most commonly offered by seedsmen. The plant is allied to the thistles, and the edible 
part is the great unopened flower-head. It is perennial, and may be propagated by suckers, but it is also grown from seed. Sow the seed in beds and the second spring transplant the seedlings to permanent quarters, letting them stand in hills three to four feet apart each way, with three or four plants in a hill.

The Jerusalem artichoke is a subterranean tuber, and is most grown for pig forage.

\section{Sweet Herbs}

Every family garden should have a border permanently set aside for sweet herbs. A strip of land four feet wide and fifty feet long will ordinarily be ample, allowing the growing of squares or clumps of all the leading kinds of sweet, aromatic and condimental plants. One end or section of the border should be reserved for the perennial species, and the remainder for the annuals (those that must be re-sown each year).

The perennial sweet herbs may be propagated by division, although they are usually grown from seeds. The second year-and sometimes even the first year-the plants are strong enough for cutting. Even with the perennial kinds, it is advisable to renew or re-sow the plants every few years, to prevent the beds from running out. The common perennial sweet herbs are: Sage, lavender, peppermint, spearmint, hyssop, thyme, marjoram, balm, eatnip, rosemary, horehound, fennel, lovage, winter savory, tansy, wormwood, costmary.

The commoner annual species (or those which are treated as annuals) are: Anise, sweet basil, summer savory, coriander, pennyroyal, caraway (biennial), clary (biennial), dill (biennial), sweet marjoram (biennial). 


\section{SECTION VI}

\section{SEASONAL REMINDERS}

Although seasons and conditions vary so much in different years and different places that no hard and fast advice can be given for the performing of gardening operations, yet brief hints for the proper work of the various months may be useful as suggestions and reminders. Most of the older gardening books were arranged wholly on the calendar method,-giving specific directions for each month in the year. We have now accumulated sufficient fact and experience, however, to enable us to state principles; and these principles can be applied anywhere,- when supplemented by good judgment,-whereas mere rules are arbitrary and generally useless for any other condition than that for which they were specifically made.

The planting-table on page 387 is reprinted, by permission, from "American Gardening," February 22,1896 . It presents much advice in small space.

The Monthly Calendars are compiled from files of the "American Garden" of some years back, 


\section{KITCHEN-GARDEN PLANTING TABLE}

\section{A Guide to the Proper Times for Sowing of Various Seeds in Order to Obtain Continuous \\ SucCession of Crops}

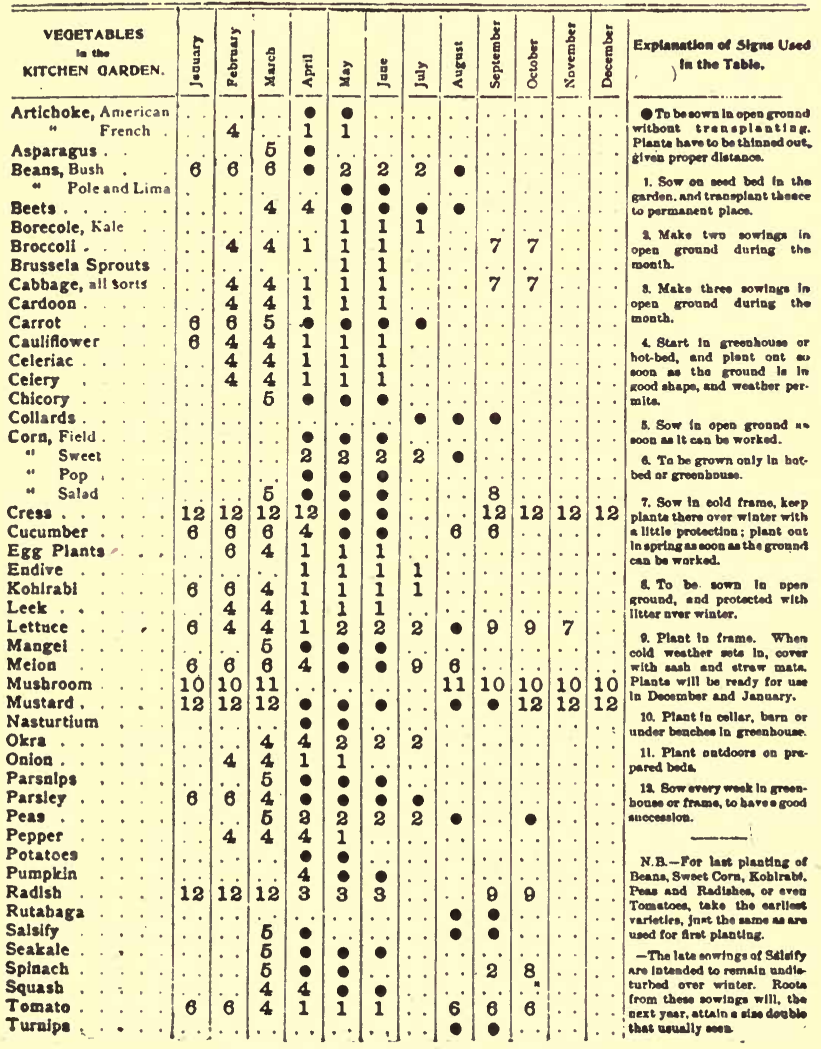




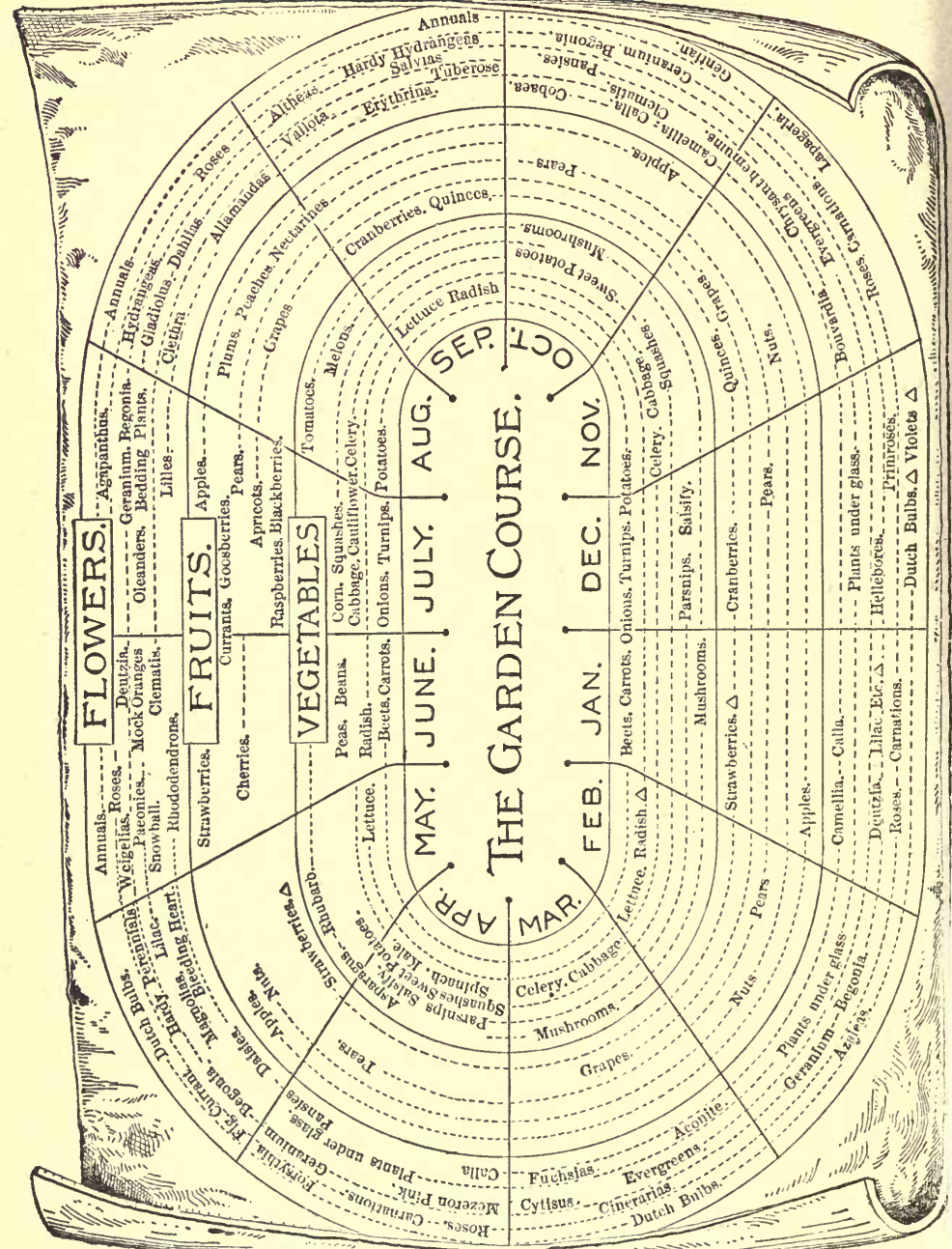

256. Bird's-eye view of the seasons in which the various garden products may be in their prime From "Popular Gardening." 
when the author had editorial charge of that magazine. The advice for the North was written by T. Greiner, LaSalle, N. Y., well known as a gardener and author. That for the South was made by H. W. Smith, Baton Rouge, Louisiana, for the first nine months, and it has been extended for this occasion to the months of October, November and December by F. H. Burnette, Horticulturist of the Louisiana Experiment Station.

\section{FOR THE NORTH}

JANUARY

Cabbage plants in frames need free airing whenever the temperature is above the freezing point, or so long as the soil of the bed is not frozen. Snow, in that case, should be removed soon after its fall. As long as the soil is frozen, the snow ean safely be left on for a number of days. Cabbage, eauliflower and lettuce seed should be sown at intervals to secure plants for extra-early sales or setting. A month later they will be ready to transfer to boxes, which should go to the coldframe and be given protection by mats or shutters.

Coldframes must be well ventilated on warm, sunny days; leave the sashes off as long as is possible without injury to the plants. Keep the soil in a friable condition, and llook carefully to any possible places where water ean stand and freeze. If the frames seem too cold, bank up around them with coarse manure.

Hotbeds.-Look up and repair the sashes. Save the horse-manure from day to day, rejecting dry litter, and piling up the droppings and urine-soaked bedding in thin layers to prevent violent heating.

Lettuce in frames treat as advised for cabbage plants.

Pruning should now be considered. Perhaps it is best to prune fruit-trees in March or April, but grapes and currants and gooseberries enn be pruned now. January and February are good months in which to prune peach 
trees. Thin out the peach trees well, taking care to remove all the dead wood. If you have much pruning to do in apple, pear or plum orchards, you will save time by utilizing the warm days now. Study well the different methods of pruning. Never let an itinerant pruner touch your trees until you are satisfied that he understands his business.

Tools ean now be inspected and repaired, and any new ones that are needed made or ordered.

\section{FEBRUARY}

Cabbage.-Sow seed of Jersey Wakefield in flats filled with light, loamy soil the last week of this month. Sow thinly, cover lightly, and place the boxes in a gentle hotbed or any warm, sunny situation. When the plants are strong, transplant them into flats $1 \frac{1}{2}$ inches apart each way. As growth begins, gradually expose them to the open air on all favorable occasions. Late in March remove them to a coldframe, and properly harden them off before setting them in the open ground.

Celery. - We urgently advise every one who has a garden, large or small, to make a trial of the new celery-culture. You need, first, good plants. Get some seed of White Plume or Golden Self-Blanching, and sow it thickly in flats filled with fine loam. Cover by sifting a thin layer of sand or fine soil over it, and firm well. Keep in a moderately warm place, watering as needed, until plants appear. If you have a number of flats, they may be placed on top of one another. At the first sign of plant-growth, bring the flats gradually to the light. When the plants are $1 \frac{1}{2}$ or 2 inches high, transplant them into other flats, setting them in rows $2 \frac{1}{2}$ inches apart, the plants half an inch apart in the rows. Then set the flats in a coldframe until the plants are large enough to plant out in the open ground.

Hotbeds for raising early plants should be made this month. Always break the manure up fine and tread it down well. Be sure to put enough in the center of beds, so that there will be no sagging. Fresh manure of hardworked and well-fed horses, free from dry litter, is best. An addition of leaves used for bedding will serve to produce a more moderate but more lasting heat. Sheepmanure may also be added to the horse-manure, should there be a seant supply of the latter on hand. 
Onions. - We urgently advise giving the new onionculture a trial. For seed, buy a packet or an ounce of Prizetaker, Spanish King, White Victoria, or some other large kind of globe omion. Sow the seed in flats, in a hotbed, or in a greenhouse late in the month, and transplant the onions to the open ground as soon as the latter is in working condition. Set the plants in rows one foot apart and three inches apart in the row. Seed will be scaree this season, that of white varieties especially so.

Plums.-Make a thorough inspection of all plum and cherry trees, wild and eultivated, for plum-knot. Cut and burn all the knots found.

Rhubarb.-Give the plants in the garden a heavy dressing of fine old compost. If you wish a few early stalks, place kegs or boxes over some of the plants, and heap over them some heating horse-manure.

\section{MARCH}

Beets. - A few seeds may be sown in the hotbed.

Cabbage, cauliflower and celery seeds may be sown for the early crop.

Eggplants.-Seeds should be sown. Take eare that the young plants are never stunted.

Grafting may be done in favorable weather. Cherries and plums must be grafted early. Use liquid graftingwax in cold weather.

Hotbeds may be made at any time, but do not grow impatient about the work, for there will be cold weather yet. Clean, fresh manure is necessary, and a layer two feet thick should be tramped hard. When once started and the seeds sown, do not let the beds get too hot. Give them air on fine days and give the seedlings plenty of water. Use two thermometers-one to test the atmosphere and the other the heat of the soil.

Lettuce should be sown in the hotbed for an early erop.

Onion seed for the new onion-culture may be sown at the close of the month.

Peas. - Sow now, if the ground can be worked.

Peppers may be sown late in the month.

Potatoes kept for seed must not be allowed to sprout. Keep them in a temperature near freezing point. Rub off the sprouts from potatoes kept for eating, and pick out all decayed specimens. 
Spinach.-Sow some seeds for an early crop.

Tomato seeds may be sown in the hotbeds.

\section{APRIL}

Artichokes.-Sow the seeds for next year's crop. A deep, rich, sandy loam is best. Fork in a dressing of wellrotted manure around the old plants.

Asparagus.-Spade in some good manure in the bed, and give the soil a thorough working before. the crowns start. Sow some seeds in the open ground for young plants for a new bed.

Beans.-Limas may be started on sods in a hotbed or a coldframe towards the last of the month.

Beets.-The ground should be prepared and the seed sown for beets for cattle as soon as the weather will permit. Put them in before planting corn. They will stand considerable cold weather, and should be planted early to get a start of the weeds.

Blackberries should be pruned, the brush drawn off, piled and burned. If it is necessary to stake them, try a wire trellis, the same as for grapes, putting on one wire two and a half feet high. The young plants should be dug before the buds start.

Cabbage seed may be sown in the open ground, in coldframes or in pans or boxes in the house. Early varieties should be started at once. Cabbages like a rich and heavy loam, with good drainage. Give them all the manure you can get.

Cauliflower seeds may be sown toward the last of the month. They should never have a check from the time the seed is sown until harvested.

Carrot.--Sow the seed of early sorts like Early Forcing as soon as the ground can be worked.

Celery. - Plan to grow celery by the new method. Plenty of manure and moisture are required to do this. Sow the seed in light, rich soil in the house, hotbed, coldframe or open ground. Transplant the plants once before setting them in the field.

Cress.-Sow early and every two or three weeks. Watereress should be sown in damp soil or in streams. The outer edges of a hotbed may also be utilized. Cress is a very profitable crop when rightly handled.

Cucumber seeds may be sown on sods in the hotbed.

Eggplant.-Sow in the hotbed, and transplant when two 
inches high to other beds or pots. They must have good care, for a check in their growth means all the difference between profit and loss.

Lettuce.-Sow the seeds in the hotbed and in the open ground as soon as it can be worked. Plants sown a month ago should be transplanted.

Leek. - Sow the seeds in the open ground in drills six inches apart and one inch deep, and when large enough thin to one inch in the row.

Muskmelon.-Plant some seeds in sods in the hotbed.

Parsnip.-Dig the roots before they grow and become soft and pithy. The seeds may be sown as soon as the ground is dry enough to work.

Parsley. - Soak the seeds in warm water for a few hours and sow in the open ground.

Peas.- - Sow the seeds as soon as the ground can be worked. They will stand considerable cold and transplanting also. Time may be gained by sowing some seeds in moist sand in a box in the cellar and transplanting when well sprouted. Plant deep in light, dry soil, cover an inch at first, and draw in the earth as the vines grow.

Potatoes.-Plant early on rich soil free from blight and scab. For a very early erop, the potatoes may be sprouted before planting.

Peppers.-Sow the seeds in the hotbed or in the boxes in the house.

Radish seeds may be sown in the open ground or in the hotbed and the crop harvested from there. The small, round rarieties are best for this purpose.

Strawberries.-Give a good, thorough cultivation between the rows and then remove the mulch from the plants, placing it in the rows, where it will help to keep the weeds down.

Salsify. - Sow the seeds as soon as the ground can be worked. Give the same care and cultivation as for carrots or parsnips.

Spinach seeds must be sown early, and then every two weeks for a succession. Thin out and use the plants before they send up flower-stalks.

Squash.-Hubbards and summer squashes may be started on sods in the hotbed.

Tomato.- Sow in the hotbed or in shallow boxes in the house. Try some of the yellow varieties; they are the finest flavored of any. 
Beans.-The bush sorts may be planted in the open ground, and Limas in pots or sods in a coldframe or spent hotbed. They require a löng season to mature, and should be started early.

Beets.-Sow for a succession. Transplant those started under glass.

Cabbages always do best on a freshly-turned sod, and should be set before the land has had time to dry after plowing. The secret of success in getting a large yield of cabbage is to start with rich land and put on all the manure obtainable. Clean out the hog yard for this purpose.

Cucumbers.- Sow in the open ground toward the last of the month. A few may be started as advised for Lima beans.

Lettuce.-Sow for a succession, and thin to four inches in the rows.

Melons.-Plant in the open ground toward the end of the month. It is useless to plant melons and other cucurbitaceous plants until settled weather has arrived.

Onions.-Finish planting and transplanting, and keep all weeds down, both in the seed-bed and the open field.

Peas.-Sow for a succession.

Squashes.-Plant as advised for melons and eucumbers. They require a rich, well-manured soil.

Strawberries.-Remove the blossoms from newly-set plants. Mulch with salt or marsh hay or clean straw or leaves those that are to bear. Mulching conserves moisture, keeps the berries clean, and prevent weeds from growing.

Sweet corn.-Plant early and late varieties, and by making two or three plantings of each, at intervals, a succession may be kept up all summer and fall. Sweet corn is delicious, and one can hardly have too much of it.

Tomatoes.-Set some early plants by the middle of the month or earlier, if the ground is warm and the season early and fair. They may be protected from the cold by covering with hay, straw, cloth or paper, or even with earth. The main crop should not be set until the 20th or 25th, or until all danger of frost is over. However, tomatoes will stand more chilly weather than is ordinarily supposed. 


\section{JUNE}

Asparagus.-Cease cutting and allow the shoots to grow. Keep the weeds down and the soil well stirred. An application of a quick commercial fertilizer or of liquid manure will be beneficial.

Beans.-Sow the wax sorts for succession. As soon as a crop is off pull out the vines and plant the ground to late cabbage, turnips or sweet corn.

Beets.-Transplant in rows one to three feet apart and six inches in the row. Cut off most of the top, water thoroughly, and they will soon start.

Cabbage and Cauliflower.- Set plants for the late crop. Rich, newly-turned sod and a heavy dressing of well-rotted manure go a long ways toward assuring a good crop.

Celery.- Set the main crop, and try the new method of setting the plants seven inches apart each way, if you have rich land and can irrigate, but not unless these conditions are present.

Cucumbers may yet be planted, if done early in the month.

Currants. - Spray with Paris green for the currant worm until the fruit sets. Hellebore is good, but it is difficult to get it of good strength.

Lettuce. - Sow for succession in a moist, cool, and partially shaded spot. The seed does not germinate well in hot weather.

Lima beans should be hoed frequently and started on the poles, if they are contrary.

Melons.-Cultivate often and watch for the bugs. A screen of closely woven wire or mosquito netting may be used to cover the vines, or tobaceo dust sifted on thickly.

Onions.-Keep free from weeds and stir the ground frequently, and especially after every rain.

Squashes.-Keep the ground well cultivated and look out for bugs. (See melons.) Layer the vines and cover the joints with fresh soil, to prevent death of the vines from the attacks of the borer.

Strawberries.-Plow up the old bed that has borne two crops, as it will usually not pay to keep it. Set the ground to late cabbage or some other crop. The young bed that has borne the first erop should have a thorough cultivation and the plow run close to the rows to narrow them to the required width. Pull up or hoe out all weeds and keep the ground elean the rest of the season. This applies with equal force to the newly-set bed. A bed ean be set late 
next month from young runners. Pinch off the end after the first joint, and allow it to root on a sod or in a small pot set level with the surface.

Tomatoes.-For an early crop train to a trellis, pinch off all side shoots, and allow all the strength to go to the main stalk. They may also be trained to poles, the same as Lima beans, and can be set closer if grown in this way. Spray with the Bordeaux mixture for the blight, keep the foliage thinned and the vines off the ground.

Turnips.-Sow for an early fall crop.

\section{JULY}

Beans.-Sow the wax sorts for a succession.

Beets.-Sow Early Egyptian or Eclipse for young beets next fall.

Blackberries.-Head back the young canes to three feet, and the laterals also when they get longer. They may be pinched with the thumb-nail and finger in a small patch, but this soon makes the fingers sore, and where there are many bushes to go over it is better to use a pair of shears or a sharp sickle.

Cabbage.-Set plants for the late crop.

Corn.-Plant sweet corn for succession and late use.

Cucumbers.-It is late to plant, but they may be put in for pickles if done before the Fourth. Cultivate those which are up, and keep an eye open for bugs.

Currants.-Cover a few bushes with muslin or burlap before the fruit ripens, and you can eat currants in $\mathrm{Au}$ gust. Use hellebore, rather than Paris green, for the last brood of currant worms, and apply it as soon as the worms appear. There is no danger in using it, even if the currants are ripe.

Lettuce seed does not germinate well in hot weather. Sow in a moist, shaded position for a succession.

Lima beans.-Hoe them frequently, and give assistance to get on the poles.

Melons.-Watch for bugs, and apply tobacco dust freely around the plants. Keep them well cultivated. A light application of bone meal will pay.

Peaches, pears and plums should be thinned to secure fine fruit and to help sustain the vigor of the tree. Ripening the seed is what draws on the tree's vitality, and if the number of seeds can be reduced one-half or two-thirds, part of the strength required to ripen 
them will go into perfecting the fruit and seeds left, and add greatly to the fine appearance, flavor and quality of the edible portion.

Radishes.-Sow the early kinds for a succession, and toward the end of the month the winter sorts may be put in.

Raspberries.-Pinch back the canes to two and onehalf feet, the same way as given for blackberries.

Squashes.-Keep the ground well stirred, and use tobaceo dust freely for bugs and beetles. Cover the joints with fresh soil, and apply the kerosene emulsion for the vine-borer.

\section{AUGUST}

Beets.-A last sowing of the early table sorts may be made for a succession.

Cabbage.-Harvest the early erop, and give good cultivation to the main erop. Keep down the bugs and worms.

Celery.-The latest crop may yet be set. Earlier set plants should be handled as they attain sufficient size. Common drain tiles are excellent for blanching if one has them, and must be put on when the plants are about half grown. Hoe frequently to keep the plants growing.

Onions.-Harvest as soon as the bulbs are well formed. Let them lie on the ground until cured, then draw to the barn floor or some other airy place and spread thinly. Market when you can get a good price, and the sooner the better.

Tomatoes may be hastened in coloring by being picked just as they begin to color and placed in single layers in a coldframe or hotbed, where they can be covered with sash.

\section{SEPTEMBER}

In many parts of the North it is not too late to sow rye, or peas, or corn, to afford winter protection for orchards. As a rule, very late fall plowing for orchards is not advisable. Now is a good time to trim up the fence-rows and to burn the brush piles, in order to destroy the breeding places of rabbits, insects and weeds. Cuttings of gooseberries and currants may be taken. Use only the wood of the current year's growth, making the cuttings about a foot long. Strip off the leaves, if they have not 
already fallen, tie the cuttings in large bundles, and bury them in a cold cellar, or in a sandy, well-drained knoll; or if the cutting-bed is well prepared and well drained, they may be planted immediately, the bed being well mulched upon the approach of winter. September and October are good months in which to set orchards, provided the ground is well prepared and well drained, and is not too much exposed to sweeping winds. Wet lands should never be set in the fall; and such lands, too, are not fit for orchards. Strawberries may still be set; also, bush fruits.

Seeds of various flowers may now be sown for winter bloom, if one has a conservatory or good window. Petunias, phloxes and many annuals make good window plants. Quicker results are secured, however, if border plants of petunias and some other things are dug up just before frost and placed in pots or boxes. Keep them cool and shaded for a couple of weeks, cut down the tops, and they will send up a vigorous and floriferous growth. Winter roses should now be in place in the beds or in pots.

There will be odd days when one can go to the woods and fields and collect roots of wild herbs and shrubs for planting in the yard or along the unused borders of the garden.

\section{OCTOBER}

Asparagus.-Old plantations should now be cleaned off, and the tops removed at once. This is a good time to apply manure to the beds. For young plantations, which may be started now as well as in spring, select a warm soil and sunny exposure, and give each plant plenty of room. We like to set them in rows five feet apart and at least two feet apart in the rows.

Cabbages.-The heads that will winter best are those just fully formed, not the over-ripe ones. For family use, bury an empty barrel in a well-drained spot, and fill it with good heads. Place a lot of dry leaves on top, and cover the barrel so that it will shed rain. Or, pile some cabbages in a corner of the barn floor and cover them with enough straw to prevent solid freezing.

Cabbage-Plants started from seed last month, prick out in coldframes, putting about 600 to the ordinary sash and setting them quite deep. 
Chicory.-Dig what is wanted for salad, and store it in sand in a dry cellar.

Endive.-Blanch by gathering up the leaves and tying them lightly at the tips.

General Garden Management.-The only planting that ean be done in open ground at this time is restricted to rhubarb, asparagus, and perhaps onion-sets. Begin to think about next year's planting, and to make arrangements for the manure that will be needed. Often you can purchase it now to good advantage, and haul it while the roads are yet good. Clean up and plow the ground when the crops are harvested.

Lettuce.-Plants to be wintered over should be set in frames like cabbage-plants.

Onions.-Plant sets of Extra Early Pearl, or some other hardy kind, in the same fashion as in early spring. They are likely to winter well, and will give an early crop of fine bunching onions. For the North, fall sowing of onion-seed cannot be recommended.

Parsley.-Lift some plants and set them in a coldframe four or five inches apart, or in a box filled with good soil, and place in a light cellar or under a shed.

Pears.-Pick the winter sorts just before there is danger from freezing. Put them in a cool, dark place, where they will neither mold nor shrivel. To hasten ripening, they can be brought into a warm room as wanted.

Rhubarb.- If plants are to $\mathrm{b} \theta$ set or replanted this fall, enrich the ground with a superabundance of fine old stable-manure, and give each plant a few feet of space each way. In order to have fresh pie-plant in winter, dig up some of the roots and plant them in good soil in a barrel placed in the cellar.

Siceet potatoes.-Dig them when ripe after the first frost. Cut off the vines, and turn the potatoes out with a potato-fork or plow. Handle them carefully to prevent bruising. Only sound, well-ripened roots are in proper condition to be wintered over.

\section{NOVEMBER}

Asparagus.-Manure before winter sets in.

Beets.-They keep best in pits. Some may be kept in the cellar for use during winter, but cover them with sand or sods to prevent shriveling. 
Blackberries.-Cut away the old wood and mulch the roots. Tender sorts should be laid down and lightly covered with soil at the tips.

Carrots.-Treats as advertised for beets.

Celery.-Dig up the stalks, leaving the roots on, and stand them close together in a narrow trench, tops just even with the ground-level. Gradually cover them with boards, earth and manure. Another way is to set them upright upon the floor of a damp cellar or root-house, keeping the roots moist and the tops dry. Celery cau stand some frost, but not exposure to less than $22^{\circ} \mathrm{Fahr}$. The stalks intended for use before Christmas may in most localities be left outdoors, to be used as wanted. Should cold weather set in early, they will need covering in some way.

Orchard Management.-Young trees should have a mound of earth raised around the stem as a support, and protection against mice, ete. Small and lately planted trees must have stakes set besides them, and be tied to the stakes with a broad band. Apple and pear trees may yet be planted. Trim superfluous or unhealthy wood out of the old orchards.

Spinach.-Cover the beds lightly with leaves or litter before winter sets in.

Strawberries.-Soon it will be time to mulch the beds. Provide marsh-hay, or other coarse litter, free from weed-seeds, and when the ground has frozen an inch or so, spread it all over the surface thinly and evenly.

\section{DECEMBER}

Cabbages.-Plants in coldframes should be aired freely and kept cool. Heads intended for winter and spring use, if not yet taken in or protected from severe freezing, must now be cared for. Do not cover them too deeply, nor store them in too warm a place.

Carrots.-Store them in cellars or pits. If in cellars, keep the roots covered with sand or sod, to prevent wilting.

General Garden Management.-Begin now to make your plans for next season's work. Carefully study up the matter of rotation, also that of feeding your crops in the most effective and economical manner. Repair frames, sashes and tools. Clear up the garden and premises. Underdrain where needed. Beds for early vegetables should be thrown 
up in high, narrow ridges, with deep furrows between. This will enable you to plant them several days or weeks earlier than otherwise.

Kale.-In very exposed or northern locations cover it lightly with coarse litter.

Onions.-For winter storage select only well-ripened, perfectly dry bulbs. Store them in a dry, airy place, not in the cellar. They may be spread out thinly on the floor, away from the walls, allowed to freeze solid, and then covered several feet deep with hay or straw.

Parsnips.-Take up some roots for winter use and store them in sand in the cellar.

Strawberry-beds should be given their winter covering of marsh-hay, etc., as soon as the ground is frozen solid.

\section{FOR THE SOUTH}

\section{JANUARY}

Annuals.-All kinds of hardy annuals and perennials, such as alyssum, snapdragon, foxglove, hollyhock, phlox, poppy, pansy, lobelia, candytuft, sweet pea, Chinese pink, sweet-william, larkspur, foliage cinerarias, centaurea, mignonette, and many others of the same class may be sown. Most of them should be sown thinly, and where they are intended to flower, as they transplant poorly in this latitude.

Cannas, caladiums, perennial phloxes, chrysanthemums and verbenas may be taken up, divided and re-planted.

Roses may be planted in quantities. Let the ground intended for them have a thorough dressing of manure. Oceasionally a plant ean be taken up and divided. The hybrid varieties may now be layered. This is done as follows: Select a shoot and bend it flat upon the ground; hold it in both hands, having a distance of about six inches between them. Keep the left hand firm, and with the right give the shoot a sharp twist. Now cover it with four inches of earth and tie the free end to an upright stake.

Asparagus beds should be liberally manured. New beds should now be made. Set the plants six inches deep. Sow seed now.

Beets and all hardy vegetables (carrots, parsnips, turnips, ruta-bagas, kohlrabi, spinach, lettuce, herbs, etc.,) may now be sown, planted or transplanted. 
Cabbage plants should be set out on heavily-manured ground. Sow seed of Early Summer for a later supply.

Fruits.-If possible, all planting and transplanting of fruit-trees and grape-vines should be finished this month. Pruning should be completed as soon as possible, and preparation made to protect the blossoms of tender fruits next month. Set out strawberry-plants, and during dry weather run the cultivator through all old beds that are at all weedy. It is a good plan, where practicable, to mulch the beds. Here, pine-straw can be had plentifully for the purpose. Examine peach trees for borers. Raspberries and blackberries should be pruned now if the work is not already done. Cuttings of Le Conte pears, Marianna plums, grape-vines and pomegranates should be put in at once if they have heretofore been forgotten. Root-grafting should be progressing rapidly; this is best time for this important work.

Onion seeds.-Sow at once, and plant sets as soon as possible.

Peas.-Sow early and late varieties. The late varieties succeed best if sown at this season.

Seasonable work. - This is a good month to obtain canes for staking peas, tomatoes and beans, hauling manure, making repairs and examining tools, etc. As the fall crop is harvested the land should be prepared for another crop. Tile-draining is now in order. Prepare frames to cover with canvas for use next month.

Sweet potatoes.-A few may be bedded in a frame from which to obtain "draws" for settting out about March 15.

Tomatoes, eggplants and peppers.- Sow now on a slight hotbed. When the plants come up all the air possible should be given during the day. They can be raised without heat, but at this season this plan is likely to be attempted only by the skillful.

\section{FEBRUARY}

Asters, cannas, dahlias, heliotropes, lobelias, petunias, pyrethrum, ricinus, salvias and verbenas are best sown in a coldframe where they can have some protection from heavy rain.

Cannas should be transplanted now.

Chrysanthemums must be planted in well-manured ground in a position where water can be readily supplied to them. 
Dahkias may be taken up and divided as soon as they begin growth.

Gladiolus and tuberose bulbs should he planted now. It is a good plan to extend the planting through March and April.

Pansies.-Plant them out in the beds where they are to flower.

Routine work.-Sodding should now proceed rapidly. If sods cannot be obtained the ground may be planted with Bermuda grass. Plant small pieces of the grass a foot apart and water them if the weather is dry, and they will grow rapidly. Hedges should be cleared up and put in good shape. All planting of trees and shrubs should be finished this month. All pruning of trees, etc., must be done early in the month. Young roses cannot be set too early in February. They thrive best when planted in fall.' Roll the drives and repair them where necessary. The lawn will now require constant care, and the mower should be used before the grass becomes $1 \frac{1}{2}$ inches high.

Bush-beans can be planted February 14. On alluvial land it is best to plant them on slight rises as a protection against the rains which sometimes oceur toward the end of the month. If frost should threaten just as the beans begin to peep out, cover them an inch deep with the plow or hand cultivator. Sow Early Mohawk first, and at the end of the month sow Early Valentine; a week later sow the wax varieties.

Cabbage.-Sow early varieties, such as Early Summer, Early Drumhead and Early Flat Dutch. Etampes, Extra Early Express and Winnigstadt sown for small heads in the order named have done very well with me. The earlier-sown plants should be transplanted as often as convenient. Should worms cause trouble, dust the plants with a mixture of one part of pyrethrum powder to six of fine dust.

Carrots, celery, beets, endive, kohl-rabi, onion-sets, parsley, parsnips, radishes and purple-top turnips must now be sown.

Corn.-Plant Extra Early Adams, Yellow Canada, Stowell Evergreen and White Flint toward the middle of the month. Sow again a week later, and again after another week. If the first two sowings fail, the last one will give the early crop.

Cucumbers.- Sow and protect with small boxes during cold days and nights, or sow in pots or on sods. Protect the seedlings with sashes or eanvas, and plant them out late. 
Lettuce.-Sow seeds and transplant the plants on hand. This crop requires a soil well supplied with plant-food.

Melons.-Plant seeds in the same manner as advised for cucumbers.

Okra.-Sow seeds on sods and set out the plants next month.

Peas. - Sow seeds of a number of varieties.

Peppers and eggplants, if not sown last month, should be sown now. Sow them under glazed sashes and keep close. When the plants appear give some air, and increase it according to the weather. If a large number of plants is required the sowing may be delayed until next month. Should flea-bugs trouble you, use plenty of pyrethrum powder.

Potatoes, Irish.-The main crop should be planted as early as possible. Standard varieties are Early Rose, Peerless and Burbank.

Potatoes, sweet, can now be bedded and protected with canvas, or a row or two of whole tubers may be planted for "draws" and vines.

Strawberries.-Run the cultivator through them at least once every three weeks; if they are to be mulched collect the necessary miterial. Strawberries planted in February seldom yield much of a crop.

Tomatoes in frames should be given all the air and light possible and plenty of room; if protected with canvas, don't allow the plants to erowd.

\section{MARCH}

Beans.-Sow all varieties for a fall crop. As soon as the plants appear the cultivator must be run through the crop, and kept going as often as necessary.

Corn.-Continue to plant; and we recommend harrowing the patch as soon as the young corn appears. It is generally planted in hills three or four feet apart, but better results will be obtained by planting in drills and leaving one stalk every twelve inches.

Cucumbers.-Sow in hills four feet apart, using a liberal quality of seed to each hill. When the plants come up thin them to about six in the hill. When the plants begin to get rough leaves pull out one or two more from each hill. Striped cucumber-beetles are sometimes very numer- 
ous, and in order to get a stand of plants it is necessay to go through the patch early every morning and sprinkle all the hills with air-slaked lime.

Eggplants. - Toward the end of the month the plants growing in frames can be transplanted to their fruiting quarters. Seed can be sown outside after March 15; sooner if a warm and sheltered spot is selected.

Lettuce.-Sow in drills, and when the plants are large enough thin to a foot apart. If transplanted at this season they often go to seed.

Okra.-A sowing can be made now, but the main planting had best be deferred until after March 15. Sow in drills three feet apart and thin the plants to eighteen inches apart in the drills.

Peas.-Early varieties may be sown; it is now too late to sow tall-growing kinds.

Peppers.-Treat as advised for eggplants.

Potatoes, Irish.-It is not too late to plant them, but the sooner they are planted the better. The erop planted in February should be harrowed as soon as the shoots begin to come up, and when the rows can be fairly seen the cultivator must be set to work to keep down weeds and grass.

Potatoes, sweet.-If slips or vines are at hand they may be planted late in the month for the earliest tubers. The whole potatoes may be planted on a ridge to yield vines for later planting.

Squashes.-Plant seed in hills six feet apart. The directions for planting melons can be followed. The same remarks apply to pumpkins and other vegetables of this kind.

Tomatoes.-About March 15 the frame plants can go to their fruiting quarters. It is necessary to use some judgment in this matter, as they may be killed or injured by an April frost. Seed may be sown in the open ground for plants for late fruiting. Set the plants four feet apart each way.

Strawberries. - The mulching of beds or rows should be no longer delayed, if clean and plentiful fruit is wanted.

\section{APRIL}

Alternantheras should go out now.

Annuals of all kinds can still be sown where they are to flower, as they transplant with difficulty at this seasor. 
Coleuses.-Plant out in the beds now. Cuttings root readily, simply requiring to be stuck in.

Beans of all kinds can be planted, Limas especially.

Beets.-Make another sowing of these.

Cabbage plants obtained from spring sowings should be set out as soon as fit. The ground requires to be very rich to carry this crop.

Cucumbers.-These ean be sown anywhere now.

Corn.-Make a sowing to yield roasting ears to come in after that sown last month.

Okra.-Sow in drills three or four feet apart.

Peas.-Making a sowing of early varieties for the last time.

Squash (bush) and pumpkin ean now be planted.

Tomatoes should be got out to their fruiting quarters as early in the month as possible. Let them be set at least four feet apart each way.

\section{MAY}

Beans.-Plant a few more bush and pole beans.

Celery may now be commenced with. The bed or box needs plenty of water, and should be shaded from sun.

Lettuce requires careful handling to encourage it to germinate. It is best sown in a box and kept shaded and moist.

Melons, cucumbers, squashes and pumpkins can be sown.

Radishes. - Sow the yellow and white summer varieties.

Remarks. - It is a constant struggle with weeds throughout this month, and the cultivator and plow are ever going. As the land becomes vacant sow corn or plant sweet potatoes-draws or vines. Sow some late Italian cauliflower. Let the orchard have constant and thorough cultivation, and remove all unnecessary growth from the trees as soon as they appear. Be always on the lookout for borers. Keep the strawberries as free of grass and coco, or knob-grass, as possible.

\section{JUNE}

Beans.-All kinds may now be sown.

Cauliflower.-Sow the Italian kinds.

Corn.-Make a planting at the beginning of the month and again at the end. 
Cucumbers.-Plant a few more hills. The plants at this season must be given plenty of water.

Endive. - Sow and attend to the tying up of the plants that are of sufficient size.

Melons.-Sow for a succession a few more water and muskmelons.

Okra can still be sown.

Radishes.-Sow the summer varieties now.

Squashes and pumpkins may yet be sown.

Sweet potato vines may now be set out in quantities.

Tomatoes.-About the middle of the month sow for the fall crop.

JULY

Beans.-Bush and pole beans ean be planted towards the end of the month.

Cabbage and cauliflower may now be sown, but the main sowing should be deferred until next month.

Carrots.-A sowing should be made.

Celery.-Sow and transplant what plants there may be on hand.

Cucumbers.-These can be sown now for pickling.

Endive.-Transplant and sow.

Grapes should be kept well tied to trellis and unnecessary growth removed, so that the wood may have the chance of becoming thoroughly ripened. If the cultivator and plow are not used judiciously a second growth will be started, which is not desirable.

Lettuce.-The seed requires to be sprouted before being sown, and if the sowing is done on a dry day the drills should be watered.

Radishes.-Sow the summer kinds.

Strawberries.-Keep the beds clear of weeds and grass.

Tomatoes.-Make a sowing early in the month, or what is much better, take cutting from plants still in bearing.

Turnips.-Sow a few after a shower towards the end of the month.

Remarks.-Much cannot be done this month, as the weather is hot and dry, but the opportunity should not be lost for killing weeds and preparing for the planting season, which is now rapidly drawing near. 


\section{AUGUST}

Artichokes.- Seed of the Green Globe can be sown now and large plants obtained by spring. The seed-bed requires to be shaded.

Bush beans, beets, pole beans, carrots, celery, endive, kohlrabi, lettuce, mustard, Black Spanish and Rose China radishes, parsley, turnips, ruta-bagas, and salad plants of all kinds may now be sown. The seed should be sown on small ridges, proportionate to the kind of plants, for level culture is not successful in the vegetable garden in this section.

Broccoli should be more cultivated, and is hardier than the cauliflower. Many cannot tell the difference between the two. Sow now.

Cabbages must be sown by the middle of the month. Make the ground very rich and shade the seed-bed, keeping it moist during the whole of the time.

Cauliflower should also be sown.

Potatoes, Irish, should be planted by the middle of the month, if possible. Plant only those that have sprouted, and instead of planting on top of the ridge set in the furrow and cover two inches deep; as the potatoes grow, work more soil down to them.

Potatoes, sweet.-Vines may still be set out, with prospects of harvesting a fair crop.

Salsify.-Sow now or early next month.

Shallots.-Plant them now.

Squash.-Bush kinds ean be planted now at any time.

Tomatoes.-If short of plants, eut off good-sized limbs from bearing plants and plant them deep. Keep them moist, and they will root in a few days. Do this just before it rains.

\section{SEPTEMBER}

Annuals of the hardy class may be sown this month; the following list will assist in making a selection: Calliopsis, candytuft, ealendulas, canterbury bells, columbine, cornflower, daisies, forget-me-nots, gaillardia, godetia, larkspur, Limnanthes Douglasii, mignonette, pansies, Phlox Drummondii, primroses, poppies of all kinds, Saponaria Calabrica, Silene pendula, sweet-williams and sweet peas.

Bulbs.-Study the catalogues and make out your wants, for it is nearing planting time. 
Lities.-If success is required of the St. Joseph's or Virgin lily ( $L$. candidum), it must be planted right away.

Perennials and biennials should be sown early this month. They have two good growing months ahead of them yet to make considerable progress. The seed-bed will require shade during the middle of the day until the young plants come up; frequent weedings will be required, as coco has not yet quit growing, and winter weeds are now putting in an appearance.

Remarks.-All plants used for salad purposes ean be sown this month. The ground between the rows of growing erops should be kept in a nice, friable condition. Vegetable seeds of all kinds should always be sown on slight ridges on all but very sandy soils. If the seed is sown on a level bed, as practiced at the North, the ground will become as hard as a turnpike road should a heavy rain occur; and should this shower come along before the plants are up, a crust a quarter of an inch deep will be formed, and the plants will never see daylight. Sown on a ridge they come all right, as the water gradually drains away, leaving the top of the ridge nice and soft.

\section{OCTOBER}

All spring flower seeds should be sown in boxes, or trays in the conservatory, and all spring bulbs should be planted. The hyacinth, narcissus, tulip and anemone, ranunculus and various lily bulbs, will bloom in good season planted at this time. The bedding plants should be carefully watched, so that any attack of aphis could be treated immediately. Sweet peas may be planted the first of this month, although they are commonly sown in September. A rich spot should be selected for them. This is the time to make the new lawn. The soil should be thoroughly stirred and well pulverized, mixing in a good dressing of commercial fertilizer, or if one prefers it, a mixture which may be made at home, consisting of cotton seed meal, acid phosphate and sulphate of potash, at the rate of 1,000 lbs., $300 \mathrm{lbs}$, and $100 \mathrm{lbs}$. respectively, per acre. A rich, well-rotted compost, as a top dressing, would also be highly beneficial. Roses pruned late in September or early this month will produce fine winter blooms.

In the garden this is a busy month; some of the winter vegetables are growing, and others should be sown. The 
bud artichokes should be separated and set fully three feet apart. Onions may still be sown in the early part of the month, and shallots should be divided and set. Some beans may be risked, and English peas sown for winter crop. A few cauliflowers may be tried and cucumbers planted in pots for the hotbeds next month. The following vegetables should be sown: Carrots, corn salad, chervil, Brussels sprouts, broccoli, beets, endive, kohl-rabi, kale, lettuce, leeks, mustard, parsley, parsnip, radish, roquette, spinach, Swiss chard, salsify. Some cabbage and a few cauliflowers should be added to the list.

Turnips should be sown for succession every two weeks until April or May. The celery should be kept growing and banking up commenced. This is an excellent time to plant the new strawberry bed. Make the bed rich with wellrotted manure and select good, healthy sets. The Michel's Early and Cloud are probably the most popular varieties for general planting, and should be set in alternating rows.

\section{NOVEMBER}

Flower seeds and bulbs may be planted this month of the same varieties as in October. Cuttings of all the herbaceous plants should 'be made and potted, for use in the house and for the borders next season. The coldframes should also be put in order. Some of the bulbs for winter forcing should be selected and potted. One of the best Louisiana gardeners recommends the following treatment: Select good, strong bulbs and plant them in rich, light soil, in five inch pots, covering them about half an inch. Water well and bury the pots six or eight inches deep in the ground, leaving them there about five weeks, when the bulbs will be found to be well rooted. From this time gradually expose to the light, and they will soon put forth blooms.

The same vegetables may be sown as for October, and the late cabbage seed planted. The Flat Dutch and Drumhead strains are prime favorites. New sowings of peas, turnips, mustard and radishes should be made, and the hotbeds prepared and set out to cucumbers. Too much care can not be taken that the manure should be in the best condition possible, so that a good supply of heat can be depended upon. The cucumbers planted last month will be ready now for setting in the hotbeds, and a winter crop forced. 
Orchard and vineyard planting.-This is the time to prepare land. That on which a late crop of cow-peas has grown is well suited for the purpose, and should be plowed deeply and well worked over. Towards the last of the month it should be cultivated again, in order to be ready for the trees next month.

\section{DECEMBER}

Lawns and yards need watching this month, and attention should be paid to the old leaves and fall rubbish, which makes the yard look untidy. A good place for the leaves is the compost heap. Hedges should be put in shape and the surface drains kept open. Shrubs and roses should be pruned for an early supply of flowers. The Camellia Japonicas are now in bloom, and care should be taken that the small branches are not torn off, instead of being cut properly. Many of these most beautiful of southern ornamental trees have been ruined by careless plucking of flowers.

Garden and orchard.-Many of the fall vegetables may be sown this month and others sown for a succession. Peas, spinach, roquette, radishes, lettuce, endive, and some Early York cabbage should also be sown. In the old spent hotbeds, tomatoes, peppers and eggplants may be started; there will not be enough heat to hurry them, and good, strong stocky plants will be secured if care is taken. Irish potatoes may be risked, should there be a favorable time for planting during the latter part of the month. Usually they are planted in January. The chances are about equal should they be planted late this month. Nuts of all kinds, both for budding and otherwise, should be planted. Some of the best Louisiana pecans are said to come true from seed, and may be sown where they are intended to grow. 



\section{INDEX}

\begin{tabular}{|c|c|}
\hline & \\
\hline conite, Winter ............272 & Bryonopsis \\
\hline Illiaceous plants ...........360 & Bulbs ...... \\
\hline lonsoa $\ldots \ldots \ldots \ldots \ldots \ldots$ & Burdock ......... \\
\hline maranthus ..............252 & Burnette, F. H., Calendars by . 38 \\
\hline mmoniacal copper carbonate .100 & Burpee, book by......... \\
\hline ndromedas ..............217 & Cabbage maggots....... \\
\hline nimals, injuries by ......... 103 & Cabbages .............. \\
\hline nise $\ldots \ldots \ldots \ldots \ldots \ldots$ & Calendars ............. \\
\hline tals..$\ldots \ldots \ldots \ldots \ldots$. & Calliopsis............ \\
\hline pple................... & Campanulas ............. \\
\hline e-scab ................312 & worm $\ldots \ldots \ldots \ldots \ldots$ \\
\hline pricot $\ldots \ldots \ldots \ldots \ldots \ldots \ldots \ldots \ldots \ldots \ldots$ & is $\ldots \ldots \ldots \ldots \ldots \ldots$. \\
\hline $\operatorname{tics} \ldots \ldots \ldots \ldots \ldots \ldots$ & $\mathbf{y} \ldots \ldots \ldots \ldots \ldots \ldots$ \\
\hline a............ & ermum .......... \\
\hline oke ............... & yedding.......... \\
\hline gus .................382 & $s \quad \ldots \ldots \ldots \ldots \ldots \ldots$ \\
\hline$\ldots \ldots \ldots \ldots \ldots \ldots \ldots \ldots \ldots 257$ & oil plant .............25 \\
\hline g grapes..............335 & $\ldots \ldots \ldots \ldots \ldots \ldots$ \\
\hline 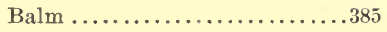 & $s \ldots \ldots \ldots \ldots \ldots$. \\
\hline $00 \ldots \ldots \ldots \ldots \ldots \ldots$ & wers $\ldots \ldots \ldots \ldots \ldots$. \\
\hline 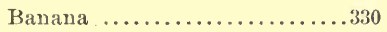 & ac $\ldots \ldots \ldots \ldots \ldots \ldots \ldots$ \\
\hline$\ldots \ldots \ldots \ldots \ldots \ldots \ldots \ldots 181$ & 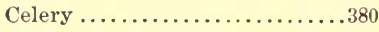 \\
\hline a.................... & for fruit $\ldots \ldots \ldots \ldots 366,30$ \\
\hline$\ldots \ldots \ldots \ldots \ldots \ldots \ldots \ldots$ & at $\ldots \ldots \ldots \ldots \ldots \ldots \ldots$ \\
\hline a garden ............352 & n.................... \\
\hline$\ldots \ldots \ldots \ldots \ldots \ldots \ldots \ldots 1$ & 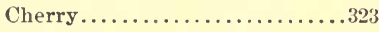 \\
\hline$\ldots \ldots \ldots \ldots \ldots 241,243$ & $\ldots \ldots \ldots \ldots \ldots \ldots \ldots \ldots$ \\
\hline$\ldots \ldots \ldots \ldots \ldots \ldots \ldots . \ldots 353$ & oxa.............. \\
\hline ixture........... 99 & Climbing plants.....213, 214, 23 \\
\hline$\ldots \ldots \ldots \ldots \ldots 142,217$ & 263,2 \\
\hline protecting.... & \\
\hline$\ldots 339$ & hemums . .......258, 2 \\
\hline $\operatorname{ar} \ldots \ldots \ldots \ldots$ & plants for ........... \\
\hline$\ldots 258$ & \\
\hline ceous plants .........364 & $\ldots \ldots \ldots \ldots \ldots \ldots \ldots \ldots, 38$ \\
\hline$\ldots \ldots \ldots \ldots$ & $\ldots \ldots \ldots \ldots \ldots \ldots 236,2$ \\
\hline Brussels Sprouts............369 & Coboea.................... \\
\hline
\end{tabular}


PAGE

Coldframes ................ 71

Collards .....................369

Columbine..................284

Conifers.............216, 225-234

Convallaria ...........272, 282

Convolvulus ................265

Copper carbonate ...........100

Coreopsis..................258

Coriander ....................385

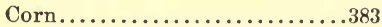

Corn Salad..................378

Costmary...................385

Covering plants ............60

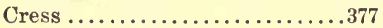

Crocus....................270

Curbs ...................183, 189

Cucumbers .................373

Cucurbitaceous plants .......373

Curculio .....................318

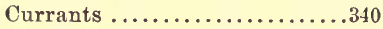

Curves......................186

Daffodil ...................271

Dahlia.....................275

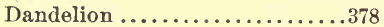

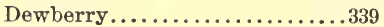

Dibbers................... 41

Dill........................ 385

Discloth Gourd................ 375

Diseases................. 88

Dolichos...................265

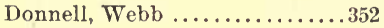

Draining................. 12

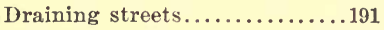

Drives .....................184

Dwarf fruits .................304

Eccremocarpus .............265

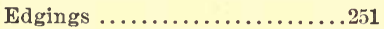

Eggplant ...................... 371

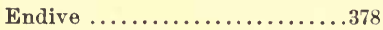

Enriching land...............114

Eranthis...................272

Erythroninm ..............282

Eschscholtzia.............259

Evergreens .........216, 225, 234

Falconer, book by............353

Falconer, qùoted..............144

Fences.....................183

Fennel.....................381

Fertilizers .................114

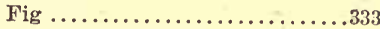

Filling about trees ............185

Flower-beds .........136, 142, 241

Flower-border ................ 142

Flower-garden ........136, 142, 144

Flowers............138, 144, 241

Forcing..............6 67

Forcing-box .............. 69

Forcing-hill..............67 67

Forcing-house ............ 83

Forsythias................213

Frames ................. 71

Fungi.................. 88

Fruit-plantation.............302

Fumigating.............. 97

Fundamentals of landscape gardening ................154

Gaillardia ................ 559

Galanthus ..................271

Gall on grape ................334

Galls .................. 91

Gilia......................259

Gladiolus ...................274

Godetia ..................259

Goff, quoted ............... 96

Gooseberries..................342

Gourd ...................... 375

Grading .............177, 200

Grafting-wax ............... 108

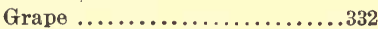

Grass for lawns ...........201

Grasses, hardy...............290

Greiner, T., calendars by .....389

Guards for trees..............103

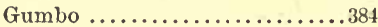

Gutter .....................196

Hand-box................6 69

Harrows................. 20

Heeling-in ............... 58 
PAGE
Hedges $\ldots \ldots \ldots \ldots \ldots \ldots \ldots \ldots \ldots .214$
Hellebore................. 99

Keeping fruit ................307

Herbaceous perennials. 238, 278, 291

Hicks, moving trees..........4 47

Hitehing posts ...............104

Hitching to a tree ............109

Hoes ..................... 24

Hop .....................265

Horehound ..................385

Horse, hitching .............. 109

Horse-radisl .................359

Hotbeds ................. 75

Humulus ..................265

Husk tomato ................371

Hyacinth .................270

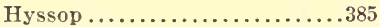

Insects $\ldots \ldots \ldots \ldots \ldots \ldots \ldots, 98,93$

Ipomøa .....................265

Jonquil ...................271

June-grass for lawn .........201

Kainit ......................118

Kale ............................. 369

Kalmias ....................217

Kerosene emulsion ........... 99

King, book by............ 7,116

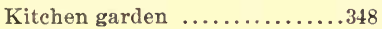

Labels ...................... 109

Lavender ................................

Land, enriching ..............114

- preparing the ........... 7

Lawn .................132, 139

- making ...................199

Laying down plants..........62 62

Leek........................361

Lettuce ...................... 376

Leguminons plants ..........361

Lilies ...................272

Lily-of-the-valley.........272, 282

Lima beans................. 363

Lodeman, book by ............100

London purple............. 98

Long, quoted ................217

Lovage ....................... 385
PAGE

Lombardy ................. 151

Luffa .................. 375,376

Lupton, quoted ...............367

Maggots in cabbage.......... 96

Maize....................254

Manures.....................114

Maps and plans.............. 195

Marigold...................261

Marjoram ....................385

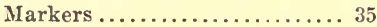

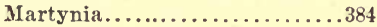

Mass-beds ..................251

Mathews, quoted .............142

Mats.................... 86

Maurandya..................265

Melons.....................374

Mice....................... 105

Michigan, list for ...........220

Mimulus..................261

Mint...................................

Moisture, saving........... 7

Morning-glory..............265

Mowing lawns... ............204

Moving trees................45

Mulehing ................ 59

Muskmelons.................374

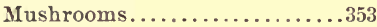

Mustard...................... 379

Nareissus................270

Nasturtium.............263, 266

Nectarine...................323

Nemophila ...............261

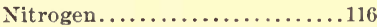

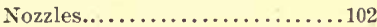

Okra.....................................

Old-fashioned garden..........144

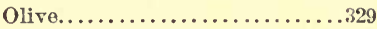

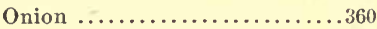

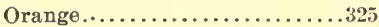

Pansy ........................261

Paris green............... 98

Parlsey.......................380

Parsnips......................357

Peach......................... 319 


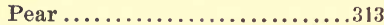

Peas...........................363

Pea, Sweet..................266

Pennyroyal....................385

Peppermint...................385

Peppers.....................372

Petunia.....................262

Phlox.......................262

Phosphoric acid...............116

Physalis .....................371

Picture in landscape ...........121

Pineapple.....................330

Plan of the place...............120

Plans and maps................195

Plant-food...................11

Planting ornamental grounds...211

Plowing......................18

Plum .........................

Polyanthus.................271

Poplar, Lombardy............151

Poplars................151, 212

Papaver......................262

Poppy......................262

Portulacea ...................251

Potash.......................116

Potato............................

Pot-herbs....................376

Preparing the land............ 7

Protecting plants.............. 58

Pruning...............53, 133, 306

Pumpkins....................375

Pumps .......................101

Quince...........................25

Rabbits.....................105

Radish.......................... 357

Raking lawns..............205

Raisins......................335

Raspberry.....................336

Records......................109

Reeds......................290

Rhododendrons..............217

Rhubarb......................380

Ribbon-beds.................2s1

Ricinus....................254

Roberts, book by .........7, 10, 116

Rollers.................... 33

Rolling lawns...............207

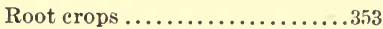

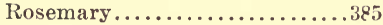

Roses .............148, 229, 294

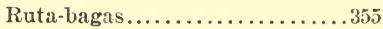

Sage ........................385

Salad plants.................376

Solanaceous plants ............369

Salsify......................357

Salvia .....................262

Savory......................385,

Seed, sowing................. 37

Scale insects................ 93

School grounds,..............198

Scilla.......................272

Shade, plants for..............210

Shearing plants............. 39

Shelter belts.................221

Shrubs for city lot.............168

- list of ...................226

Simonds, O. C................189

Small-fruits...................336

Smith, H. W., calendars by ....389

Snow-drop ..................271

Socrates, quoted............. 2

Sodding...................207

Sorrel .......................379

Sowing seed................. 37

Spearmint ....................385

Spinach.....................378

Sponge, vegetable.............376

Spraying................... 98

Spuds...................... 32

Squash.......................374

Stake label....................109

Storing fruits .............306-308

Strawberries..................343

Streets, suburban............189

Subsoiling.................. 16

Sub-tropical fruits..............325

Suburban streets...............189

Sunken fence................183 
Sweet corn....................... 383

Vegetable garden................348

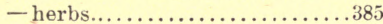

Vegetable sponge..............375

- pea .....................266

Verbena.....................263

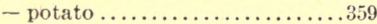

Vermin.......................105

Swiss Chard....................... 379

Sylvinit...........................

Taft, L. R., on fruits ..........305

Vines...................214, 235

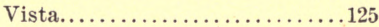

Tallies .....................110

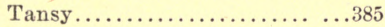

Tarryer, quoted............. 25

Terraces ...................179

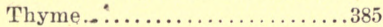

Walker, Ernest...............241

Walks....................... 184

Water lilies..................243

Watermelons................... 374

Waugh on vegetables ...............................

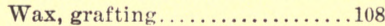

Time to plant.............. 55

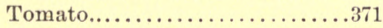

Torenia.......................252

Tracy's kitchen garden.......... 349

Transplanting.........38,44, 217

Trees, age to buy ...............305

- list of..................221

- moving ................... 45

Tricker, book by .............243

Trillium....................281

Trowels................. 32

Tropøolum ..............263, 266

Tropical effects...............252

Tuberose..................277

Tulip....................270

Turnip........................

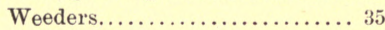

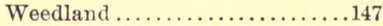

Weeping trees............151, 172

Wheel-hoes................. 22

Whitewashing .............6 64

Whitlavia..................252

Whitten, quoted............ 64

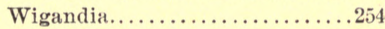

Willows.................... 153

Windbreaks.................221

Winter protection........... 58

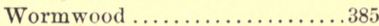

Yards................159 et seq.

Yellows .........................

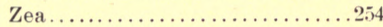

Zinnia....................263 



\section{The Best and Nervest Rural Books}

DOOKS ON LEADING TOPICS CONNECTED WITH AGRICULTURAL AND RURAL LIFE ARE HERE MENTIONED. EACH BOOK IS THE WORK OF A SPECIALIST, UNDER THE EDITORIAL SUPERVISION OF PROFESSOR L. H. BAILEY, OF THE CORNELL UNIVERSITY, OR BY PROFESSOR BAILEY HIMSELF, AND IS READABLE, CLEAR-CUT AND PRACTICAL. 


\section{THE RURAL SCIENCE SERIES}

Includes books which state the underlying principles of agriculture in plain language. They are suitable for consultation alike by the amateur or professional tiller of the soil, the scientist or the student, and are freely illustrated and finely made.

The following volumes are now ready:

THE SOIL. By F. H. KING, of the University of Wisconsin. 303 pp. 45 illustrations. 75 cents.

THE FERTILITY OF THE LAND. By I. P. ROBERTs, of Cornell University. Fifth edition. 421 pp. 45 illustrations. $\$ 1.25$.

THE SPRAYING OF PLANTS. By E. G. LODEMAN, late of Cornell University. $399 \mathrm{pp} .92$ illustrations. $\$ 1.00$.

MILK AND ITS PRODUCTS. By H. H. WING, of Cornell University. Third edition. $311 \mathrm{pp}$. 43 illustrations. $\$ 1.00$.

THE PRINCIPLES OF FRUIT-GROWING. By L. H. BAILEY. Fourth edition. $516 \mathrm{pp}$. 120 illustrations. $\$ 1.25$.

BUSH-FRUITS. By F. W. CARD, of Rhode Island College of Agriculture and Mechanic Arts. Second edition. $537 \mathrm{pp}$. 113 illustrations. \$1.50.

FERTILIZERS. By E. B. Voorhess, of New Jersey Experiment Station. Second edition. 332 pp. $\$ 1.00$.

THE PRINCIPLES OF AGRICULTURE. By L. H. BaIley. Third edition. 300 pp. 92 illustrations. $\$ 1.25$.

IRRIGATION AND DRAINAGE. By F. H. King, University of Wisconsin. 502 pp. 163 illustrations. $\$ 1.50$.

THE FARMSTEAD. By I. P. RoBERTS. 350 pp. 138 illustrations. $\$ 1.25$.

RURAL WEALTH AND WELFARE. By George T. Fairchild, Ex-Presi. dent of the Agricultural College of Kansas. 381 pp. 14 charts. $\$ 1.25$.

THE PRINCIPLES OF VEGETABLE-GARDENING. By L. H. BAIleY. 468 pp. 144 illustratious. $\$ 1.25$.

THE FEEDING OF ANIMALS. By W. H. JoRdAN, of New York State Experiment Station. 450 pp. $\$ 1.25$ net.

FARM POULTRY. By George C. Watson, of Pennsylvania State College. 341 pp. $\$ 1.25$ net.

New volumes will be added from time to time to the Rural Science Series. The following are in preparation:

PHYSIOLOGY OF PLANTS. By J. C. Arthur, Purdue University. BREEDING OF ANIMALS. By W. H. BREWER, of Yale University. PLANT PATHOLOGY. By B. T. Galloway and associates of U. S. Depart. ment of Agriculture.

CARE OF ANIMALS. By N. S. MAYo, of Connecticut Agricultural College. THE POME FRUITS (Apples, Pears, Quinces). By L. H. BAILEy. 


\section{THE GARDEN-CRAFT SERIES}

Comprises practical hand-books for the horticulturist, explaining and illustrating in detail the various important methods which experience has demonstrated to be the most satisfactory. They may be called manuals of practice, and though all are prepared by Professor BAILey, of Cornell University, they include the opinions and methods of successful specialists in many lines, thus combining the results of the observations and experiences of numerous students in this and other lands. They are written in the clear, strong, concise English and in the entertaining style which characterize the author. The volumes are compact, uniform in style, clearly printed, and illustrated as the subject demands. They are of convenient shape for the pocket, and are substantially bound in flexible green cloth.

THE HORTICULTURIST'S RULE-BOOK. By L. H. BATLE. Fourth edition. 312 pp. 75 cts.

THE NURSERY-BOOK. By L. H. BaIley. Fifth edition. 365 pp. 152 illustrations. $\$ 1.00$.

Plant-BREEDING. By L. H. Bailex. 293 pp. 20 illustrations. \$1.00.

THE FORCING-BOOK. By L. H. BAILEY. 266 pp. 88 illustrations, $\$ 1.00$.

GARDEN-MAKING. By L. H. BAlLEY. Fourth edition. 417 pp. 256 illustrations. $\$ 1.00$.

THE PRUNING-BOOK. By L. H. Barley. Third edition. 545 pp. 331 illustrations. $\$ 1.50$.

THE PRACTICAL GARDEN-BOOK. By C. E. Hunn and L. H. Batley. 250 pp. Hany marginal cuts. $\$ 1.00$. 


\section{THE EVOLUTION OF OUR NA- 1 TIVE FRUITS. By L. H. BaIley, Pro. fessor of Horticulture in the Cornell University.}

472 PACES - 126 ILLUSTRATIONS - \$2.00

In this entertaining volume, the origin and development of the fruits peculiar to North America are inquired into, and the personality of those horticultural pioneers whose almost forgotten labors have given us our most valuable fruits is touched upon. There has been careful research into the history of the various fruits, including inspection of the records of the great European botanists who have given attention to American economic botany. The conclusions reached, the information presented, and the suggestions as to future developments, cannot but be valuable to any thoughtful fruit-grower, while the terse style of the author is at its best in his treatment of the subject.

The Evolution of our Native Fruits discusses The Rise of the American Grape (North America a Natural Vineland, Attempts to Cultivate the European Grape, The Experiments of the Dufours, The Branch of Promise, John Adlum and the Catawba, Rise of Commercial Viticulture, Why Did the Early Vine Experiments Fail ? Synopsis of the American Grapes); The Strange History of the Mulberries (The Early Silk Industry, The "Multicaulis Craze,"); Evolu. tion of American Plums and Cherries (Native Plums in General, The Chickasaw, Hortulana, Marianna and Beach Plum Groups, Pacific Coast Plum, Various Other Types of Plums, Native Cherries, Dwarf Cherry Group); Native Apples (Indigenous Species, Amelioration has begun); Origin of American Raspberry-growing (Early American History, Present Types, Outlying Types); Evolution of Blackberry and Dewberry Culture (The High-bush Blackberry and Its Kin, The Dewberries, Botanical Names); Various Types of Berry-like Fruits (The Gooseberry, Native Currants, Juneberry, Buffalo Berry, Elderberry, High-bush Cranberry, Cranberry, Strawberry); Various Types of Tree Fruits (Persimmon, Custard-Apple Tribe, Thorn-Apples, Nut-Fruits); General Remarks on the Improvement of our Native Fruits (What Has Been Done, What Probably Should Be Done). 


\section{THE SURVIVAL OF THE UNLIKE: A Collection of Evolution Essays Suggested by the Study of Domestic Plants.' By L. H. BAILEY, Professor of Horticulture in the Cornell University.}

FOURTH EDITION - E 18 PAGES - 22 ILLUSTRATIONS - $\$ 2.00$

To those interested in the underlying philosophy of plant life, this volume, written in a most entertaining style, and fully illustrated, will prove welcome. It treats of the modification of plants under cultivation upon the evolution theory, and its attitude on this interesting subject is characterized by the author's well-known originality and independence of thought. Incidentally, there is stated much that will be valuable and suggestive to the working horticulturist, as well as to the man or woman impelled by a love of nature to horticultural pursuits. It may well be called, indeed, a philosophy of horticulture, in which all interested may find inspiration and instruction.

The Survival of the Unlike comprises thirty essays touching upon The General Fact and Philosophy of Evolution (The Plant Individual, Experimental Evolution, Coxey's Army and the Russian Thistle, Recent Progress, etc.); Expounding the Fact and Causes of Variation (The Supposed Correlations of Quality in Fruits, Natural History of Synonyms, Reflective Impressions, Relation of Seedbearing to Cultivation, Variation after Birth, Relation between American and Eastern Asian Fruits, Horticultural Geography, Problems of Climate and Plants, American Fruits, Acclimatization, Sex in Fruits, Novelties, Promising Varieties, etc.); and Tracing the Evolution of Particular Types of Plants (the Cultivated Strawberry, Battle of the Plums, Grapes, Progress of the Carnation. Petunia. The Garden 'Tomato, etc.). 


\section{CYCLOPEDIA OF}

\section{AMERICAN HORTICULLTURE}

COMPRISING DIRECTIONS FOR THE CULTIVATION OF HORTICULTURAL CROPS, AND ORIGINAL DESCRIPTIONS OF ALL THE SPECIES OF FRUITS, VEGETABLES, FLOWERS AND ORNAMENTAL PLANTS KNOWN TO BE IN THE MARKET IN THE UNITED STATES AND CANADA

\section{BY L. H. BAILEY}

ASSISTED BY MANY EXPERT CULTIVATORS AND BOTANISTS

In Four Quarto Volumes,

Illustrated with over Two Thousand Original Engravings

THHIS monumental work, the most comprehensive review of the vegetable world yet made by an American, is now in the press. Though distinctly an American work, not only plants indigenous to the North American continent are mentioned, but also all the species known to be in the horticultural trade in North America, of whatever origin. It is really a survey of the cultivated plants of the world.

The Editor, Professor L. H. Bailey, has been gathering material for this Cyclopedia for many years. He has enlisted the coöperation of many men of attainments, either in science or practice, and the Cyclopedia has the unique distinction of presenting for the first time, in a carefully arranged and perfectly accessible form, the best knowledge of the best specialists in America upon gardening, - fruit-growing, vegetable culture, forestry, and the 
like, as well as exact botanical information. It is all fresh, and not a rehash of old material. No precedent has been followed; the work is upon its own original plan.

Many scientific botanical authors of justly high repute decline to give attention to the important characters of cultivated plants, confining their work to the species in the original forms only. Professor Bailey takes the view that a subject of commercial importance, one which engages the attention and affects the livelihood of thousands of bright people, is decidedly worthy the investigation of the trained botanist. In the Cyclopedia of American Horticulture, therefore, very full accounts are given of the botanical features of all important commercial plants, as the apple, cabbage, rose, etc. At the same time, practical cultivators submit observations upon culture, marketing, and the like, and frequently two opinions are presented upon the same subject from different localities, so that the reader may have before him not only complete botanical information, but very fully the best practice in the most favorable localities for the perfection of any fruit or vegetable or economic plant.

\section{ILLUSTRATIONS}

The pictorial character of the work is likewise notable. There are nearly three thousand illustrations, and they are made expressly for this work, either from accurate photographs or from the specimens. These illustrations have been drawn by competent 
horticultural artists, in nearly every case under thy eye of the Editor, or with the supervision of some one of the sub-editors. No "trade" cuts are used.

In planning the illustrations, artistic effect has been kept in view, and while no drawing is used which does not show its subject with perfect scientific accuracy, the monotonous so-called "botanical" outlines, often made from lifeless herbarium specimens, are notably absent. The intention is to show the life of the plant, not merely its skeleton.

\section{CONTRIBUTORS, SYSTEM, ETC.}

As above mentioned, the contributors are men eminent as cultivators or as specialists in the various subjects. The important articles are signed, and it is expected that the complete work will include fully 5,000 signed contributions by horticulturists, cultivators and botanists.

The arrangement is alphabetical as to the genera, but systematic in the species. A very simple but complete plan of key-letters is used, and the whole arrangement is toward ease of reference as well as completeness of information. To each large genus there is a separate alphabetic index.

Important commercial subjects are treated usually under the best known name, whether it be the scientific or "common" designation. Thus, the apple is fully discussed as apple, rather than as Pyrus Malus, and the carnation comes into view in the third letter of the alphabet, not as Dianthus Caryophyllus. Carefully edited cross-references make it 
easy to find any desired subject, however, in the shortest time.

The plan of presenting the full details of culture of important plants, through the views of acknowledged practical experts upon the various subjects, assures the great value of the book to the man or woman who is obtaining a living from horticultural pursuits.

A special feature of the Cyclopedia of American Horticulture is its wealth of bibliographic reference. The world's horticultural literature has been thoroughly searched, and most carefully indexed, so that the student will find citations to nearly every available article or illustration upon any subject consulted.

\section{DETAILS OF PUBLICATION}

The Cyclopedia of American Horticulture is to be completed in four handsome quarto volumes, embracing about two thousand pages, with more than that number of original illustrations. It is carefully printed upon specially made paper of a permanent character. Vol. I (A to D, 509 pages, 743 illustrations, 9 plates), Vol. II ( $\mathrm{E}$ to $\mathrm{M}, 544$ pages, 710 illustrations, 10 plates), and Vol. III (N to $\mathrm{Q}, 432$ pages, 606 illustrations, 11 plates) are now ready, and the work will be completed in 1901 .

The work is sold only by subscription, and orders will be accepted for the full set only. Terms and further information may be had of the Publishers,

\section{THE MACMILLAN COMPANY}

No. 66 Fifth Avenue

NEW YORK 


\section{T ESSONS WITH PLANTS : Sugges- tions for Seeing and Interpreting Some of the Common Forms of Vegetation. By L. H. BAILEY, Professor of Horticulture in the Cornell University, with delineations from nature by W. S. HOLDSWORTH, of the Agricultural College of Michigan.}

\section{SECOND EDITION-49I PAGES-446 ILLUSTRATIONS-I2 MO- CLOTH-S1.10 NET}

There are two ways of looking at nature. The old way, which you have found so unsatisfactory, was to classify everything-to consider leaves, roots, and whole plants as formal herbarium specimens, forgetting that each had its own story of growth and development, struggle and success, to tell. Nothing stifles a natural love for plants more effectually than that old way.

The new way is to watch the life of every growing thing, to look upon each plant as a living ereature, whose life is a story as fascinating as the story of any favorite hero. "Lessons with Plants" is a book of stories, or rather, a book of plays, for we can see each chapter acted out if we take the trouble to look at the actors.

"I have spent some time in most delightful examination of it, and the longer I look, the better I like it. I find it not only full of interest, but eminently suggestive. I know of no book which begins to do so much to open the eyes of the student-whether pupil or teacher - to the wealth of meaning contained in simple plant forms. Above all else, it seems to be full of suggestions that help one to learn the language of plants, so they may talk to him."-DARWIN L. BARDWELL, Superintendent of Schools, Bing. hainton.

"It is an admirable book, and cannot fail both to awaken interest in the subject, and to serve as a helpful and reliable guide to young students of plant life. It will, I think, fill an important place in secondary schools, and comes at an opportune time, when helps of this kind are needed and eagerly sought."-Professor V. M. SPALDING, University of Michigan.

\section{FIRST LESSONS WITH PLANTS}

An Abridgement of the above. 117 pages-116 illustrations -40 cents net. 


\section{ROTANY: An Elementary Text for Schools. By L. H. BAILEY.}

\section{PAGES-500 ILLUSTRATIONS- 1.10 NET}

"This book is made for the pupil: 'Lessons With Plants' was made to supplement the work of the teacher." This is the opening sentence of the preface, showing that the book is a companion to "Lessons With Plants," which has now become a standard teacher's book. The present book is the handsomest elementary botanical text-book yet made. The illustrations illustrate. They are artistic. The old formal and unnatural Botany is being rapidly outgrown. The book disparages mere laboratory work of the old kind: the pupil is taught to see things as they grow and behave. The pupil who goes through this book will understand the meaning of the plants which he sees day by day. It is a revolt from the dry-as-dust teaching of botany. It cares little for science for science' sake, but its point of view is nature-study in its best sense. The book is divided into fonr parts, any or all of which may be used in the school: the plant itself; the plant in its environment; histology, or the minute structure of plants; the kinds of plants (with a key, and descriptions of 300 common species). The introduction contains advico to teachers. The book is brand new from start to finish.

"An exceedingly attractive text-book."-Educational Review.

"It is a school book of the modern methods."-The Dial.

"It would be hard to find a better manual for schools or for individual use."-The Outlook.

\section{THE MACMILLAN COMPANY}

No. 66 Fifth Avenue

NEW YORK 






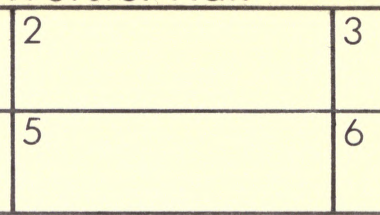

ALL BOOKS MAY BE RECALLED AFTER 7 DAYS Return books early if they are not being used

\section{DUE AS STAMPED BELOW}

FORM NO. DD 13,74m, 3/78 BERKELEY, CA 94720

UNIVERSITY OF CALIFORNIA, BERKELEY 
U.C. BERKELEY LIBRARIES

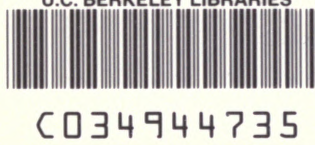


